\title{
PAISAJES PARA RECREAR INFANCIAS
}

Tesis presentada para obtener el título de Magister en Ciencias del Territorio Universidad Nacional de La Plata

Luciano Marcos Roussy

Directora: Dra. Patricia Redondo

Diciembre 2018 


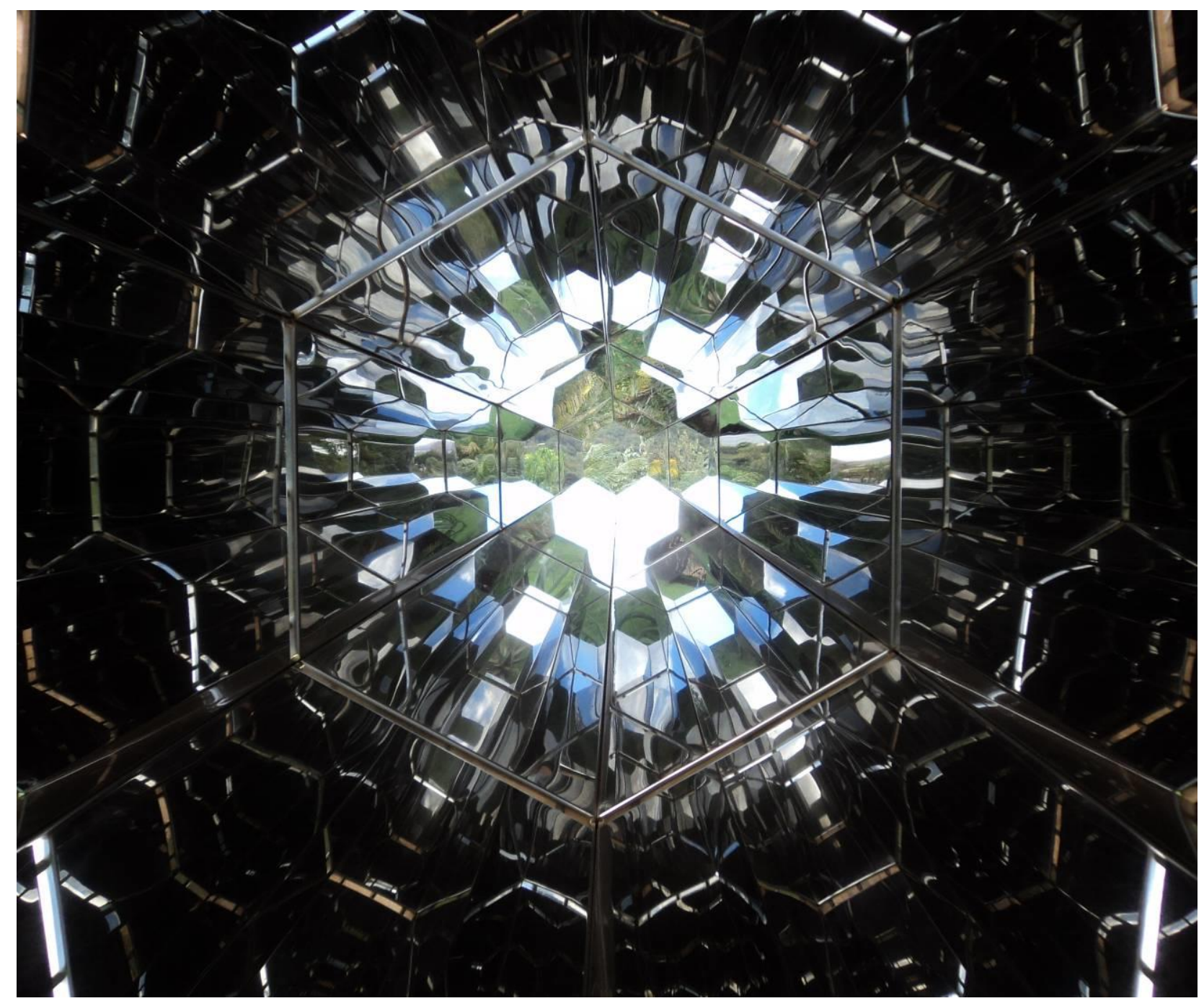

Caleidoscopio - Olafur Eliasson - INHOTIM Brasil.

"...the little kids have for Fisher-Price toys, they are not in concrete playgrounds, they are riding around the lawn. The pool is in the back. This is white america... "Los niños tienen juguetes de Fisher-Price $y$ no juegan sobre concreto. Juegan sobre césped. Tienen una piscina atrás. Esto es la EEUU blanca... ". (Livingston, 1991) 


\section{Agradecimientos}

Primero los institucionales: a la Facultad de Ciencias Agrarias y Forestales que financió este trabajo de investigación y nos permitió con total libertad desarrollar el tema. A la Universidad Nacional de La Plata que sigue apostando por una educación pública, gratuita, laica y de calidad. A sus estudiantes, que tarde o temprano van a continuar rompiendo cadenas y nos van a proponer nuevos cambios radicales, estaremos atentos para que esto suceda y poder acompañarles.

A Fredy por enseñarme lo que es la libertad. A Rubén, por siempre ser un apoyo fuerte para seguir y ayudarme a comprender la realidad. Al grupo: Pablo F., Carlitos, Pablo S., Pepe V. B. y la flaca Marina con los que aprendo todos los días lo que es el paisaje, el territorio, la amistad y el compañerismo.

A Patri que me guió en este camino, pero sobre todo porque supo construirme un sendero de preguntas y relaciones para pensar, para dar un pasito más.

A Manuel, por ser el compañero de mi vida con el que, de la mano, descubrí nuevas formas de ser.

A la Mirti que hizo la masa madre de lo que soy y al Edu que horneó este pan. A Mary, Susi y Juanse y también mis cuñadxs que me soportan como soy y con los que me peleo buscándome. A Delia y el Popo que siempre pero siempre están, con los que contamos para ser. A mis sobris: Abril, Gonza, Pedro y Fran que nos muestran nuevos caminos.

Finalmente a mi amigos y amigas, que me apoyan siempre en todo lo que hago. 


\section{RESUMEN}

La presente investigación estudia la conformación del paisaje en los ámbitos de juego de 13 plazas de la ciudad de La Plata en el año 2016. Para ello, se trabajó en base tres ideas del concepto de infancias recreadas (Bustelo, 2007): mayores grados de autonomía, una mirada sincrónica y diacrónica que las constituye y finalmente la diversidad de experiencias como clave del conocer. El objetivo del presente trabajo consiste en relacionarlas con categorías propias del paisajismo para poder así aportar a una infraestructura verde recreativa capaz de conformar paisajes para la recreación. Para ello, se caracterizaron los ámbitos de juego infantil a partir de su conformación espacial, los dispositivos lúdicos, la vegetación y las plantas viverizadas potenciales de ser usadas en los mismos.

Los resultados demostraron una homogéneidad en los ámbitos de juego en cuanto a su distribución, tipos de dispositivos lúdicos, sus formas, delimitaciones y la vegetación existente. El modelo que se reprodujo se correspondió con una concepción de infancia única, homogénea y repetible. Por otro lado, la falsa asociación entre control y seguridad redujo seriamente la autonomía en las infancias. Homogeneidad y vigilancia se manifestaron como dos exponentes de la idea de sociedad de control y heteronomía. Por el contrario, se observó la existencia de una alta diversidad de especies vegetales viverizadas en la región que tendrían la capacidad de complejizar y de establecer las condiciones para albergar infancias diversas y autónomas.

Algunas claves que se ponen en juego en la tesis tienen que ver con cuatro puntos: la necesidad de tener en cuenta el tiempo desde una mirada sincrónica y diacrónica, alejarnos de ámbitos normados y controladores para construir espacios de libertad y de cuidado, abrir a la imaginación a partir del juego libre y autónomo con la naturaleza, y finalmente planificar los lugares desde la diversidad de experiencias. Se concluyó que es necesario comenzar un camino de complejidad estructural de las masas vegetales con un claro sentido político: una Infraestructura Verde Recreativa que brinde mayor diversidad. Infancias en camino a la emancipación son capaces de crear y transformar, para ello la vegetación puede ser un aliado.

Palabras clave: ciudad, territorio, verde urbano, infraestructura verde recreativa, niñez. 


\section{ABSTRACT: Landscapes to recreate childhoods}

This research studies landscape conformation in the playgrounds of 13 plazas of the city of La Plata in 2016. Three ideas on the concept of recreated childhoods (Bustelo, 2007): lie at the base of our work: greater degrees of autonomy, a synchronic and diachronic look that constitutes them, and finally the diversity of experiences as a key to knowledge. The objective of this work is to relate them to categories of landscaping in order to contribute to a green recreational infrastructure capable of shaping landscapes for recreation. To this end, the play spaces were characterized according to their spatial conformation, play devices, vegetation and nursery plants that could be included in them.

The results showed the playing areas were homogeneous in terms of distribution, types of play devices, their shapes, boundaries and existing vegetation. The reproduced pattern corresponded to a unique, homogeneous and repeatable conception of childhood. At the same time, the false association between control and security substantially reduced autonomy of children. Homogeneity and vigilance appeared as two exponents of the idea of a society of control and heteronomy. On the other hand, a great diversity of nursery plant species were observed in the region, which could enhance the spaces and ensure the conditions for diverse and autonomous childhoods.

Some key points the thesis raises have to do with four factors: to consider time from a synchronic and diachronic stance, to move away from normalized and controlling environments in order to construct spaces of freedom and care, to inspire imagination with free and autonomous play with nature, and finally to plan spaces based on diversity of experiences. It was concluded that it is necessary to pave the wayfor structurally complex plant masses guided by a clear political objective: a Recreational Green Infrastructure that offers greater diversity. Childhoods on the way to emancipation are capable of creating and transforming. For that purpose, vegetation can be an ally.

Key words: city, territory, urban green, recreative green infrastructure, childhood 


\section{ÍNDICE DE CONTENIDOS}

Agradecimientos 3

RESUMEN 4

ABSTRACT 5

1. CAPÍTULO 1

1.1. Introducción 10

1.2. Definición del problema 12

1.3. MARCO TEÓRICO 18

1.3.1. De la recreación de infancias y el paisaje 18

1.3.2. Categorías de análisis en las infancias 26

1.3.2.1. Autonomía para la recreación 26

1.3.2.2. Sincronía y diacronía en las infancias 29

1.3.2.3. Diversidad de experiencias en la niñez 30

1.3.2.4. Hacia infancias emancipadas 32

1.3.3. Categorías de análisis para el paisaje 35

1.3.3.1. Vegetación urbana 35

1.3.3.2. Sincronía y diacronía vegetal 37

1.3.3.3. Tipología Vegetal 41

1.3.3.4. Hacia una Infraestructura Verde Recreativa 44

1.4. ANTECEDENTES 48

1.4.1. Clasificación de las plantas $\quad 48$

1.4.2. Situación de las plazas platenses $\quad 48$

1.4.3. Referencia de parques infantiles $\quad 50$

1.4.4. Aportes desde el arte 56

1.4.5. Estudio de la normativa existente relativa a los espacios de juegos 57

2. CAPÍTULO 2

2.1.OBJETIVOS 61

2.1.1. Objetivo general 61

2.1.2. Objetivos específicos 61

2.2. HIPÓTESIS 61

2.3. METODOLOGÍA UTILIZADA PARA LA TOMA DE DATOS 64

2.3.1. Relevamiento de elementos construidos 64

2.3.2. Inventario de la vegetación existente 66

2.3.3. Análisis de las especies presentes en viveros comerciales 69 


\section{CAPÍTULO 3}

3.1.RESULTADOS Y CONCLUSIONES

3.1.1.Caracterización de los ámbitos de juego 75

3.1.2. Diagnóstico de la vegetación existente 83

3.1.3. Categorización de las especies presentes en viveros comerciales $\quad 97$

3.1.4. Desarrollo de nuevas variables tipológicas 101

3.2. SÍNTESIS DE RESULTADOS 137

\section{CAPÍTULO 4}

4.1. DISCUSIÓN 139

4.1.1. Heteronomía y la autonomía en las infancias paisajísticas 139

4.1.2. Sincronía y Diacronía en las vegetación con las infancias 146

4.1.3. Sobre la Diversidad de experiencias con las plantas 150

4.1.4. Paisajes para la recreación 154

4.2.BIBLIOGRAFÍA 155

4.3. EPÍLOGO 160 


\section{ÍNDICE DE FIGURAS}

Figura 1: Calesita. Plaza Moreno. Ciudad de La Plata. Ocho niñxs jugando 15

Figura 2: Rivera pública del Río de La Plata. Punta Lara, Ensenada. Gonzi cosechando flores para su mamá 16

Figura 3: Plaza 19 de Noviembre con el inventario de vegetación y de solados $\quad 49$

Figura 4: Bosque en El Jardín de los Niños en la Montaña Encantada 5

Figura 5: Bosque de Álamos y lomadas. Bosque de Papel $\quad 52$

Figura 6: El Anfiteatro y el fuego $\quad 53$

Figura 7: El "bosque encantado". Metáfora sobre el bosque construido a partir de palos de madera vertical 54

Figura 8: "Casita del árbol". Casa de juegos ubicada sobre un árbol muerto con las ramas mutiladas 55

Figura 9: Tejidos lúdicos. Toshiko Horiuchi Mac Adam $\quad 56$

Figura 10: Planilla de relevamiento $\quad 69$

Figura 11: Esquema de siluetas en base a la arquitectura de la planta $\quad 71$

Figura 12: Ámbito de juego en Plaza España $\quad 75$

Figura 13: Plaza Italia y Plaza Olazábal $\quad 76$

Figura 14: Plaza Belgrano $\quad 77$

$\begin{array}{lr}\text { Figura 15: Plaza Moreno } & 78\end{array}$

$\begin{array}{lr}\text { Figura 16: Plaza Azcuénaga } & 78\end{array}$

$\begin{array}{lr}\text { Figura 17: Plaza Belgrano } & 78\end{array}$

$\begin{array}{lr}\text { Figura 18: Solado que absorbe impactos } & 79\end{array}$

Figura 19: Plaza Irigoyen $\quad 81$

Figura 20: Plaza Italia $\quad 82$

Figura 21: Porcentaje de especies arbóreas $\quad 83$

Figura 22: Edad de las especies arbóreas $\quad 86$

Figura 23: Estado fitosanitario de las especies arbóreas $\quad 88$

Figura 24: Plaza Azcuénaga: Cupressus arizonica var Green glauca $\quad 89$

Figura 25: Plaza Belgrano: presencia de dos ejemplares de Morus nigra $\quad 90$

Figura 26: Plaza Italia: Ejemplar de Enterolobium contortisiliquum $r$

Figura 27: Plaza Moreno: presencia de Cedrus deodara $\quad 92$

Figura 28: Porcentaje de especies arbustivas $\quad 93$

Figura 29: Edad de las especies arbustivas $\quad 95$

Figura 30: Estado fitosanitario de las especies arbustivas $\quad 95$

Figura 31: Plaza Italia: Se puede observar la presencia de arbustivas, Nerium oleander 96

Figura 32: Distribución de magnitudes de las especies vegetales 98

Figura 33: Distribución del hábito vegetativo en viveros comerciales 99

Figura 34: Distribución de texturas $r$

Figura 35: Distribución de siluetas $\quad 101$

Figura 36: Especies de Agave sp. resguardadas mediante cerco perimetral 102

$\begin{array}{lr}\text { Figura 37: Árbol inclinado utilizado para trepar } & 104\end{array}$

Figura 38: Niñas dialogando en la copa de un Ombú Phytolacca dioica $\quad 106$

$\begin{array}{lr}\text { Figura 39: Pradera de Taraxacum officinale Diente de León } & 108\end{array}$

Figura 40: Pradera de Allium sp. Manto de la virgen $\quad 108$

Figura 41: Floración del Jacarandá mimosifolia Jacarandá y de Cotynus coggyria Flor de humo 111

Figura 42: Producción de especies comestibles con sugerencia de recetas de cocina 112

Figura 43: Huerta infantil. Parque temático Tecnópolis $r$

Figura 44: Espacio existente dentro de una Acacia bayleyana $\quad 116$

Figura 45: Se puede observar una Magnolia liliflora siendo utilizada como refugio y para trepar 117

Figura 46: Este conjunto de Retamas se convirtieron en un refugio natural luego de nevadas 117

Figura 47: A origem da obra de arte $\quad 119$

Figura 48: Piñas de Pinus sp. dispuestas en cuenco $r$

Figura 49: Ceiba insignis Palo Borracho $r$

Figura 50: Platanus x acerifolia Plátano $r$

Figura 51: Washingtonia robusta Washintonia $\quad 123$

Figura 52: Ámbito de juegos libre para niñxs con sombra media $\quad 125$

Figura 53: Ámbito pautado de juegos para niñxs $r$

Figura 54: Agrupamiento de Liquidambar styraciflua Liquidambar $\quad 127$

Figura 55: Ejemplar aislado de Diospyrus kaki Caqui $\quad 127$

Figura 56: Alineación de Platanus acerifolia Plátano $r$

Figura 57: Macizo de Fraxinus pennsylvanica Fresno americano $\quad 130$

Figura 58: Macizo de Populus alba var. bolleana. Álamo plateado piramidal o Álamo boleana 132 
Figura 59: Macizo de Populus nigra var itálica. Álamo piramidal

Figura 60: Bosque de tambores

Figura 61: Niñxs tocando diferentes texturas de plantas

134

Figura 62: Ficus elastica Gomero

136

Figura 63: Pinus halepensis caido sobre hamacas

145

Figura 64: Juegos de vanguardia y Jardín Didáctico de Especies Nativas

152

Figura 65: Muestra: "Dar vuelta una montaña"

161 


\section{CAPÍTULO 1}

\subsection{INTRODUCCIÓN}

El proceso de una investigación permite formarnos en una manera de mirar el mundo despojada de prejuicios, abierta al descubrimiento y a un estar atentos a las señales que se van despertando en el devenir de la misma.

Este trabajo de investigación se inició a partir de una inquietud personal sobre preguntas respecto a la infancia y la naturaleza. Sin embargo, rápidamente se fue convirtiendo en un problema de estudio, una mirada social que incluía a otrxs. Aquí, ansiamos encontrarnos entre las personas, así como también con un otrx naturaleza, con un otrx vida que conjugue nuevas (o reconfigure antiguas) formas de convivencia bajo valores universales de amor, solidaridad, respeto, cuidado, reconocimiento. No desde una mirada naif del tema o peor aún individualista. Ansiamos poder aportar a políticas de Estado y gestión del espacio público que cultive miradas más inclusivas en la conformación de comunidades más diversas.

Esta tesis habla principalmente a los adultos y se plantea como un primer comienzo para abrirnos a Ixs niñxs, escucharlos, ponerla en juego, refutarla, reconfigurarla y reformularla a partir de la mirada infantil. Deseamos que sirva como insumo para poner en diálogo y no como verdad revelada o transferida desde el mundo adulto.

Si bien nosotros ya no jugamos como cuando éramos chicos, sí disfrutamos de la vida, nos divertimos, nos alegramos y angustiamos, nos comprometemos, descubrimos nuevos caminos, nos asustamos, trabajamos, compartimos, elegimos, habilitamos, creamos, deconstruimos para empezar de nuevo, amamos, nos solidarizamos, luchamos. A este juego los convocamos, a bailar un poco, a dejarse llevar al ritmo de la música, a abrirse a experiencias inexploradas para así, algún día, comenzar a escuchar. 


\section{ENGARCE}

La mano que lleva a un niño de la mano, lleva una llave enciende el fuego al tacto, un sueño y una noche que niega la hondonada, una en la otra se aprende a caminar, a respirar.

Y va enlazada a un ramo.

La mano que ha plantado una mano en la suya siente hundirse un aliento en el agua del día, da confianza de manos abrazadas, como el lugar donde se abre lo por decir, lo por llegar. Y el que conduce es conducido.

La mano que lleva a un niño de la mano da un cuenco un viento en ese cuenco y un viaje en ese viento donde estallan banderas de colores y bestias fabulosas comparten un camino que comienza en un sitio de manos abrazadas.

La mano que lleva un niño de la mano fue a la cita en un lugar de robustas memorias donde la mano que traga saliva era recuperada de la soledad.

Una en la otra.

La mano que lleva a un niño de la mano no retrocede nunca.

Jorge Boccanera 


\subsection{DEFINICIÓN DEL PROBLEMA}

El paisaje es un concepto polisémico y por lo tanto tiene múltiples acepciones. En esta tesis se toma la definición de la Convención Europea del Paisaje del año 2000, donde se definió que "El Paisaje es cualquier parte del territorio tal como lo percibe la población, cuyo carácter sea el resultado de la acción y la interrelación de factores naturales y/o humanos". En este sencillo enunciado se conjugan tres ideas centrales: territorio, población e interrelación. Esta tesis busca establecer puentes conceptuales entre el paisaje y las infancias, a partir del estudio de los ámbitos de juego en las plazas y parques públicos de la ciudad de La Plata. La mirada específica de la vegetación desde y para la niñez, permitirá iniciar caminos de análisis del paisaje con una finalidad: en nuestro caso recrear ${ }^{1}$ infancias. Para ello, se analizarán los elementos construidos de los ámbitos de niñxs ${ }^{2}$ en las plazas del casco fundacional de la ciudad de La Plata.

En nuestro caso, en la idea de paisaje, la componente de la población se refiere a Ixs niñxs. En este sentido, recrear infancias es un concepto definido por Bustelo (2007) donde juega con dos situaciones: volver a crear y recreo (juego). Bustelo (2007) diagnostica que, en nuestro momento histórico, la niñez no se encuentra definida claramente como sujeto colectivo. Esta idea, es puesta en debate por algunos autores que incluso tienen como tesis la desaparición de la infancia como categoría social (Corea y Lewcowicz, 1999). En este contexto, Bustelo (2007) expresa la necesidad de volver a construirla. Así, recrear significa volver a fundar infancias. Sin embargo, en este camino, Bustelo (2007) sugiere que no debe ser desde la mirada del mayor que "muestra" un camino hacia la adultez, sino todo lo contrario, es necesario crear las condiciones para que esas infancias se auto conformen de manera disruptiva con respecto al universo constituido. De esta manera, se adquiere una nueva función, que refiere a conformar las condiciones para que Ixs niñxs puedan desarrollarse libremente en un mundo que cambia aceleradamente.

\footnotetext{
${ }^{1}$ Recrear y recreación se escriben en cursiva en referencia al concepto definido por Bustelo (2007).

${ }^{2}$ Se utilizará la letra equis $(x)$ cuando se haga referencia a niñxs con el objetivo de no realizar distinción de género.
} 
También, estas nuevas infancias, deben ser concebidas como categoría social colectiva e histórica sujeta de derechos, ya no desde la concepción individual de niñx. Esta mirada, lleva a pensar que tenemos que observar las múltiples infancias y sus interrelaciones en clave colectiva. Ahora bien, ¿cómo se vuelve a crear infancias? Bustelo (2007) brinda doce tesis sobre el recreo de la infancia. Nosotros tomaremos como referencia las siguientes que se sintetizan en las expresiones a continuación:

- "La infancia es autonomía que se afirma contra la heteronomía disciplinaria y controladora" (Bustelo, 2007, p.185). La categoría de autonomía como base para la construcción de infancias recreadas.

-. "La infancia se define como una temporalidad diacrónica, como ruptura y quiebre" (Bustelo, 2007, p.185). Las categorías de diacronía y sincronía hablan sobre qué debe continuar, pero principalmente de que todo tiene que cambiar constantemente.

-. "El recreo de la infancia es la metodología de lo nuevo como descubrimiento y, por lo tanto, una dimensión del conocer" (Bustelo, 2007, p.186). La categoría de lo nuevo como base para la recreación.

-. "La infancia es una categoría emancipatoria" (Bustelo, 2007, p.185). Debemos pensar la infancia en categoría disruptiva del mundo adulto de manera de contenerla y albergarla.

De esta manera, las infancias recreadas serían autónomas, diacrónicas y ávidas por conocer, entre otras, que aportan a un camino de emancipación. Entonces: ¿es posible pensar una infraestructura verde recreativa que contenga estas categorías de manera tal de que permita conformar paisajes para la recreación?

Se busca abordar el problema del paisaje como motor en la recreación de infancias. Se indaga la mirada sobre la vegetación para establecer una infraestructura verde recreativa capaz de realizar un aporte a volver a crear infancias en clave emancipadora. Encontrar una manera de cultivar paisajes para la recreación. 
Actualmente no existen estudios específicos que permitan analizar el paisaje y la vegetación desde la recreación de infancias. Es interés del trabajo de investigación poder arribar a una idea de paisaje e infraestructura verde recreativa desde y para las infancias.

Para ello, se abordó como caso de estudio el casco fundacional de la ciudad de La Plata que posee un diseño urbanístico particular, ampliamente estudiado, que se basa, desde lo morfológico, en una concepción higienista. La trama urbana regular se estructura en base a un eje fundacional (Avenidas 51 y 53), con espacios verdes públicos distribuidos de manera homogénea cada seis cuadras aproximadamente. De esta manera, el sistema verde se conforma con una red de parques y plazas de distintos tipos y jerarquías, un arbolado urbano de alineación en veredas y boulevares ${ }^{3}$, ramblas verdes conectoras y un parque urbano denominado Paseo del Bosque. La consolidación de la vegetación estructurante (árboles y arbustos grandes) se corresponde con plantaciones realizadas a principios del siglo XX. Contienen un diseño formal basado en la prolongación de calles y avenidas en el interior del espacio verde, así como la consolidación de su perímetro con árboles. Estas características le otorgan cierta uniformidad en términos de vegetación: coetáneos ${ }^{4} \mathrm{y}$ distribuidos en un soporte geomorfológico similar (Benassi, 2013). Sin embargo, según Benassi (2013), el antroposistema vegetal se encuentra en estado maduro y sobre maduro, en claro retroceso y degradación. La afluencia de nuevos e intensivos usos sobre los espacios verdes públicos afectó el normal desarrollo de la vegetación, que, según Benassi (2013), necesita un re-diseño bajo nuevos paradigmas. En este punto, creemos ${ }^{5}$ que la nueva planificación debería dar cuenta del tema que interesa abordar en este trabajo de investigación: paisajes para la recreación de infancias.

\footnotetext{
3 Se define como arbolado estructurante a los elementos vegetales, principalmente de primera, segunda y tercera magnitud, que conforman una matriz arbórea capaz de brindar los servicios sociales y ambientales requeridos en la ciudad. 4 Un mismo rango etáreo.

${ }^{5}$ Al utilizar primera persona del plural nos referimos al autor de la tesis y su dirección.
} 
Se considera espacios verdes públicos del casco de la ciudad de La Plata a todos los parques y plazas delimitados por la avenida circunvalación. Sin embargo, esta tesis abordará sólo $13^{6}$ plazas fundacionales, por ser las únicas de las que se tiene datos de su vegetación estructurante?

En este sentido, se distinguen dos escenarios o ámbitos principales de juego en la ciudad de La Plata: los pautados y los no pautados o azarosos. Los primeros, son los delimitados por la existencia de dispositivos lúdicos (tobogán, hamacas, sube y baja, escaleras, pasamanos, calesita), lo que comúnmente denominamos "juegos de la plaza". En dichos espacios, el juego presenta una pauta o forma de comportamiento: en la calesita se da vueltas (ver Figura 1), en el pasamanos se trepa, en el tobogán se desliza, entre otros. El dispositivo lúdico constituye el escenario principal, esta tesis estudia su conformación. Se trabajará como central el estudio de la vegetación del ámbito y el rol que cumple.

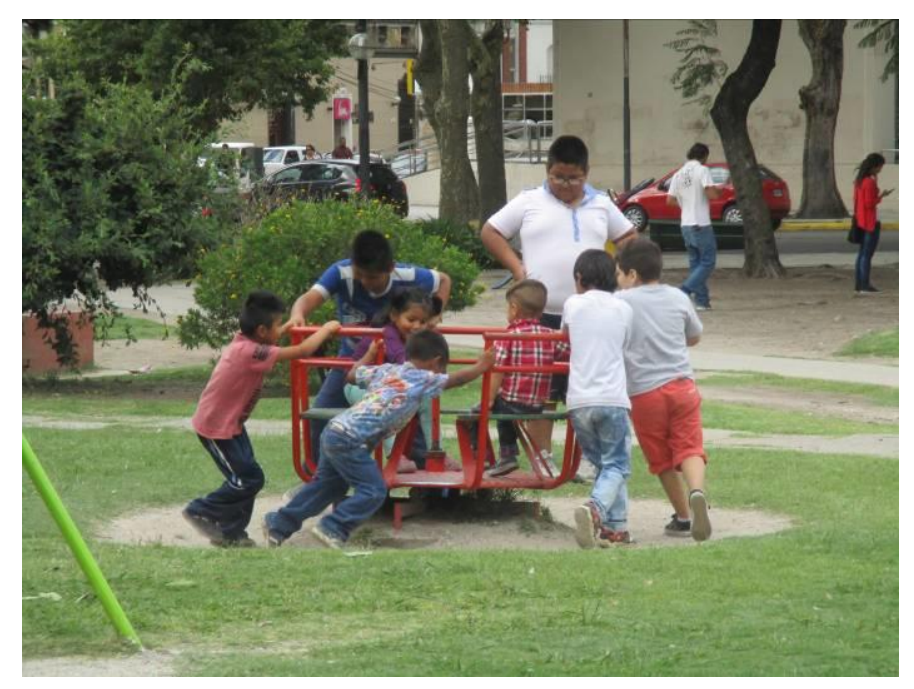

Figura 1: Calesita. Plaza Moreno. Ciudad de La Plata. Ocho niñxs jugando. Este dispositivo se encontraba en Estado Sin Función (categoría que detallaremos más adelante), sin manubrios y con ruleman en pésimo estado. Año: 2016.

En el caso de los segundos, los ámbitos no pautados o azarosos, se refieren al juego que se desarrolla fuera de los determinados por los dispositivos lúdicos. En este sentido, el autor realizó un

\footnotetext{
619 de Noviembre (Av. 25 y Av. 44); Azcuénaga (Av. 19 y Av. 44); Belgrano (Av. 13 y calle 39); España (Av.7 y Av. 66); Yrigoyen (Av. 19 y Av. 60); Italia (Av. 7 y Av. 44); Moreno (Av. 13 y Av. 51); Olazábal (Av. 7 y Av. 38); Paso (Av. 13 y Av. 44); Rosas (Av. 13 y Av. 60); Perón (Av. 25 y Av. 60); Rocha (Av. 7 y Av. 60); San Martín (Av. 7 y Av. 51).

${ }^{7}$ Si bien existen datos del Parque Saavedra, no fueron tomados en cuenta por no ser comparable por magnitud y diseño con el resto de las plazas.
} 
relevamiento preliminar ${ }^{8}$ donde detectó que el juego de niñxs en los parques y plazas de la ciudad ocurre no sólo en los ámbitos pautados sino que existen, también, otros espacios que admiten actividad lúdica pero menos determinada espacialmente. Aparecen zonas en las plazas con troncos para trepar, vegetación para explorar o flores para cortar (Figura 2), o simplemente césped para poder correr. Si bien el trabajo de campo se centrará en el estudio de los ámbitos de juego pautados, se intentará identificar situaciones lúdicas fuera de los mismos donde la vegetación tenga un rol fundamental.

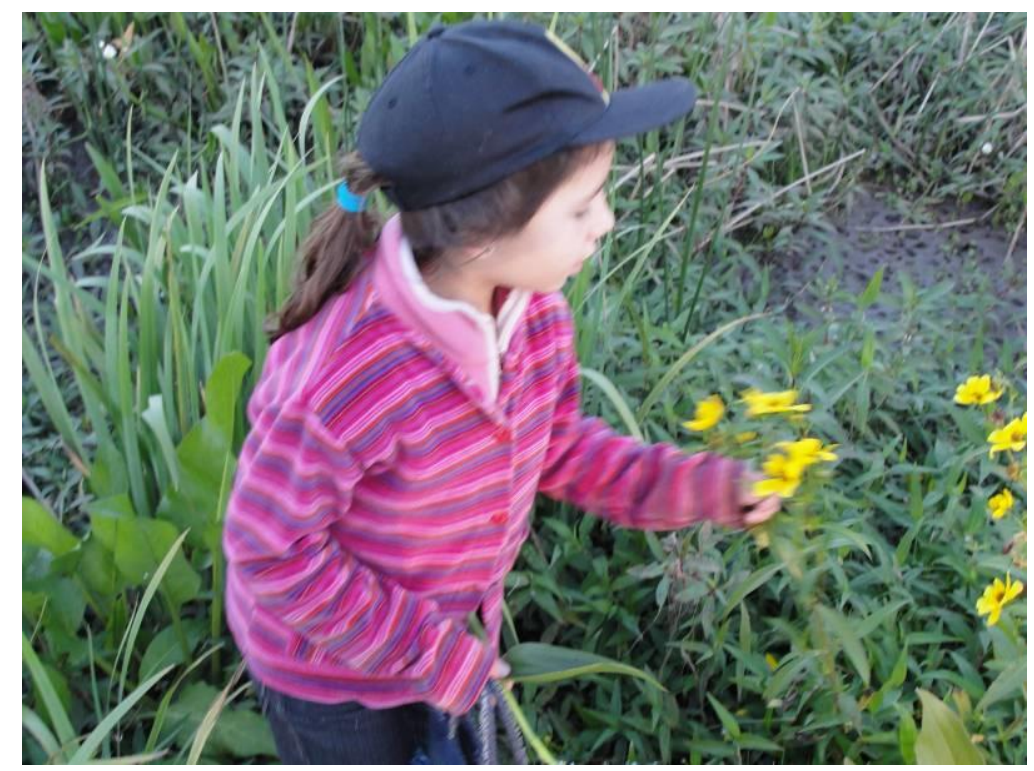

Figura 2: Rivera pública del Río de La Plata. Punta Lara, Ensenada, Buenos Aires. Gonzi cosechando flores para su mamá. Año 2015.

En el relevamiento preliminar realizado y en la bibliografía existente, se observó que los espacios verdes públicos de la ciudad tienen, en todos los casos, sectores destinados al juego infantil, con la instalación de dispositivos lúdicos específicos que las distintas gestiones municipales renuevan, mantienen o complementan a los existentes (Domínguez, 2013). Sin embargo, no existen informes técnicos por parte del Estado Municipal sobre la situación actual de dichos espacios, su estado y conservación, su nivel de uso y apropiación.

\footnotetext{
${ }^{8}$ El relevamiento consistió en una recorrida por todas las plazas de la ciudad donde se registró la existencia o no de ámbitos de juegos para niños, tanto pautados como no pautados, y características generales de los mismos. A partir de dichos datos se diseñó la investigación a realizar.
} 
Para poder desarrollar el trabajo de investigación, se definieron dos unidades de análisis, una referida a la identificación y caracterización de los ámbitos de juego, y otra al estudio de la vegetación e IVR. Para conocer cómo se encuentran conformados los ámbitos de juegos en 13 plazas del casco fundacional de la ciudad de La Plata9 en el año 2016, se estudiaron los tipos de solados, vegetación estructurante, dispositivos o elementos lúdicos que poseen de manera tal de poder caracterizarlos. Así, se buscará dar respuesta a la pregunta: ¿Cómo se encuentran conformados los ámbitos de juego en el espacio verde público en el 2016 en el casco fundacional de la ciudad de La Plata? ¿Qué rol cumple la vegetación en la conformación de dichos paisajes?

De manera paralela, el estudio de la vegetación e IVR, se realizó a partir del análisis de la producción existente en los principales viveros de cultivo comerciales y de una aproximación en el jardín botánico de Universidad Nacional de La Plata (UNLP). El objetivo fue indagar la vegetación factible de ser utilizada en ámbitos infantiles de manera tal de aportar a la categorización de la IVR en función de las infancias y así dar respuesta a: ¿Qué vegetación podría ser incorporada para complejizar los ámbitos de juego? ¿Es posible conformar una infraestructura verde recreativa que abone paisajes para recrear infancias?

Entonces, la unidad de análisis para estudiar la vegetación en los ámbitos de juego fueron las plazas de la ciudad de La Plata. A su vez, la unidad de análisis para el estudio de la vegetación factible de ser utilizada, fueron los catálogos de viveros comerciales y la vegetación existente en el jardín botánico UNLP.

\footnotetext{
9 Existe un inventario de vegetación del año 2010 realizado por la Facultad de Ciencias Agrarias y Forestales de la Universidad Nacional de La Plata en convenio con la Municipalidad de La Plata. Dicho inventario relevó las existencias arbóreas y arbustivas de 13 plazas de la ciudad y un parque urbano (Parque Saavedra). Estos datos fueron compartidos por la dirección del convenio (Director Alfredo. H. Benassi) y sirvieron como insumo base para la elaboración de la presente tesis. A partir de allí, se realizó la actualización inventarial de los sectores con ámbitos de juegos de las 13 plazas.
} 


\subsection{MARCO TEÓRICO}

\subsubsection{DE LA RECREACIÓN DE INFANCIAS Y EL PAISAJE}

La infancia como concepto y como categoría social surge durante los siglos XVII y XVIII junto a la idea de la modernidad (Bustelo, 2012a). Previo a la era Moderna el niño era propiedad del padre, era considerado un pequeño adulto que entraba rápidamente a la sociedad como un mayor. La infancia era un tiempo avergonzante, que no era necesario grabar en la memoria, un estado que había que soportar para llegar a la única edad valorada: la del adulto maduro. De esta manera, el vínculo parento-filial era más distante que en la Modernidad, no existía la escuela tal cual la concebimos hoy y el niñx aprendía conviviendo con adultos (Moreno, 2003). Es a partir de Comenius (1666, en Narodowski, 1994) que se trata de construir un instrumento (la escuela moderna) capaz de "enseñar todo a todos", lo que suele resumirse bajo el título de ideal pansófico (Narodowski, 1994). Comenius introduce en la educación algunos principios que hoy nos son muy conocidos: incorpora a todas las edades, los dos sexos y todas las clases sociales, creación de establecimientos educativos dispersos por todo el territorio (universalización), normativizar la enseñanza y un nuevo contrato padre-hijomaestro, entre otros (Narodowski, 1994). Es aquí, donde comienza a formarse la idea de infancia.

El concepto de infancia, también aparece asociado a una nueva idea de familia, construida, en parte, a partir del movimiento romántico. El grupo familiar se constituye en un proyecto de vida del cual Ixs niñxs forman parte. De esta manera, aparece un ámbito donde son contenidos, separados de la sociedad, encerrados: el hogar (Bustelo, 2012a). Así, los niñxs modernos, son inocentes, sin maldad, ni pecado, ni sexualidad. Son seres frágiles, indefensos que deben ser protegidos por los adultos de los mismos adultos. Por este motivo, se lo cuida, se lo instruye, se lo educa (Moreno, 2003, 2014; Rousseau, 1967 y Comenius, 1966 en Narodoswski, 1994). Narodowski (1994) analiza a Jacques Rousseau, en Émile ou de l'enfance (1967), como el autor que configura la idea del niño educable, su educabilidad, como contenedor de una condición natural a ser formado. Se constituye así 
definitivamente la infancia como nuevo fenómeno objeto de estudio, campo de significados, potencial aplicable, desarrollo social y ámbito de acción educativa (Narodowski, 1994).

A partir de la aparición de la infancia como categoría social moderna, surgen dos corrientes o teorías sobre la misma, una más biologicista o psicobiologista, la teoría piagetiana, y otra teoría basada en una perspectiva cultural de las infancias desde la sociología de la infancia. (Bustelo, 2012a). No es interés de esta tesis el desarrollo de cada teoría, pero sí marcar que el fuerte arraigo de la primera forjó ciertos supuestos sobre la infancia que buscamos discutir en este trabajo de investigación. El principal es que Ixs niñxs al nacer siguen un camino lineal de adquisición de conocimiento pasando por ciertas etapas de desarrollo hasta llegar a la madurez del adulto con un nivel de conocimiento y complejidad máximos. Esta idea supone que Ixs niñxs son seres simples, dependientes, maleables, vulnerables, que se encuentran en estado natural, incompletos, irracionales, inmaduros, incapaces, menores. Por el contrario, los adultos, somos seres complejos, autónomos, independientes, con fuerza, que nos encontramos en estado cultural, completos, racionales, maduros, capaces, formados, mayores. El planteo es de una infancia transitoria, formativa hacia a la adultez. Por el contrario, Bustelo $\left(2007,2012^{a}, 2012^{b}\right)$ entiende que los primeros años de vida se constituyen en un momento de creatividad, originalidad y asociatividad ligados al atributo de la libertad. En este sentido, Ixs niñxs son poseedores de la patria trascendental del hombre libre, el sujeto de la libertad capaz de transformar la realidad. De esta manera, se toma a la infancia como un estado virtuoso capaz de albergar altos grados de complejidad. Este pensamiento tiene una relación entre los adultos y las nuevas generaciones que se replica en la cultura como construcción colectiva de la que Ixs niñxs forman parte. (Bustelo, 2012a)

En este sentido, Eduardo Bustelo (2007), establece como tesis central de su análisis la necesidad de definir la infancia como una categoría social, de manera tal de colocarla en el juego de las relaciones sociales que se constituyen históricamente con los adultos. Esta idea, es eje de la visión del trabajo de investigación desarrollado aquí, donde se comparte con Bustelo la idea de niñx social 
como una singularidad que se crea con los adultos pero que simultáneamente construye "otra" adultez, recreando, según Bustelo (2007), otra infancia como categoría social esencialmente emancipadora. La idea de recrear ${ }^{10}$ infancias conforma el ¿para qué? de esta tesis que pretende relacionar y analizar los elementos vegetales del paisaje bajo categorías específicas de las infancias en los ámbitos para niñxs ${ }^{11}$ en los espacios verdes públicos de la ciudad, con el objetivo de aportar a una nueva mirada del paisaje.

Como se desarrolló anteriormente, el paisaje es un concepto polisémico por lo tanto tiene múltiples acepciones. Compartimos la definición de la Convención Europea del Paisaje del año 2000 que expresa que "El Paisaje es cualquier parte del territorio tal como lo percibe la población, cuyo carácter sea el resultado de la acción y la interrelación de factores naturales y/o humanos". En esta sencilla definición hay tres ideas centrales: territorio, población e interrelación. El paisaje no es definido por especialistas sino que es una mirada cultural sobre un territorio determinado. En términos de Moreno (2003): "es la cultura lo que nos diferencia de cualquier otra especie viviente" (p.27). Lxs niñxs son seres culturales y, por lo tanto, siempre tienen algo para decir al respecto así como también tienen la capacidad de intervenir en el paisaje de manera novedosa. Este ejercicio que se renueva con cada nacimiento se encuentra ligado a lo que Hanna Arendt (2003) denomina lo nuevo como condición de la acción humana, como constitutivo de humanidad y que nosotros agregamos: de la cultura.

De manera concurrente con la Convención Europea del Paisaje (2000), Ernesto Belli (2010) expresó que "el paisaje es una explicación" (p.14). Sintéticamente, lo que nos quiere decir el autor es que no existe paisaje sin cultura, sin una acción humana que convierta y otorgue de contenido a una parte del territorio. Si se puede explicar, interpretamos que existe una construcción de un campo simbólico en un espacio determinado. Los significados otorgados muestran una manera de habitarlo, que nos transforma pero que también nosotros como sociedad lo cambiamos en un juego dialéctico constante. Un territorio que podemos explicar, entonces constituye paisaje.

\footnotetext{
10 Recrear y recreación se escriben en cursiva en referencia al concepto definido por Bustelo (2007).

11 Se utiliza la "x" para referirse a todos los géneros existentes en las infancias.
} 
Sin embargo, en las clases magistrales del profesor E. Belli12, realizaba un ejercicio muy simple para poner en discusión qué es paisaje. Nos hacía cerrar los ojos a toda la audiencia y pensar en una imagen cualquiera. Posteriormente pedía que lo describamos y el resultado era que todos evocábamos espacios abiertos, idílicos, con presencia de naturaleza principalmente. Finalmente, para abrir la discusión, el profesor expresaba que para él no existía un paisaje industrial, de la ciudad, o uno sin naturaleza. En este sentido, hasta mediados y finales del siglo XX, el paisaje era determinado por los técnicos paisajistas, profesionales o entidades de gobierno y estaba asociado a una vivencia con la naturaleza, profundamente modificada, en parques pintorescos o zonas muy específicas, bajo una visión tecnocrática del territorio. Hoy, pensamos al paisaje como un hecho cultural y que como tal se encuentra en el debate público (Donadieu, 2006). En ese sentido, si bien una parte del pensamiento del profesor actuaba desde la tradición paisajista, también, quizá sin saberlo, fue una persona de estos tiempos al expresar: "El paisaje es una explicación". Es allí, donde incluyó ambientes que desde la concepción tradicional no serían paisaje y que en la contemporaneidad pueden constituirse en verdaderos hitos simbólicos de una sociedad, en imágenes y sensaciones que nos forman y que posiblemente, protejamos, cambiemos, renovemos, pongamos en valor o simplemente descartemos.

A su vez, en una visión más pragmática, Kongjian Yu (2017) define "landscape is an art of survival", el paisaje como el arte de la supervivencia. Es de destacar esta mirada porque toma al paisaje como parte de un territorio a transformar simplemente para poder sobrevivir. El nuevo siglo nos trajo una sociedad principalmente urbana y ya nadie discute que ese será su destino. Las megalópolis son sinónimo de oportunidades, pero también de problemáticas complejas cada vez más graves a las que no puede darse respuesta fácilmente: la marginalidad extrema y fragmentación urbana, adaptación al cambio climático, ambientes altamente degradados, entre otros. K. Yu es un paisajista contemporáneo chino que viene a mostrar y decir que el paisajismo puede aportar a soluciones urbanas inclusivas, de restauración ambiental y paisajísticamente novedosas. Contrariamente, el

\footnotetext{
12 Dictadas en el año 2011, y de la cual fui alumno, en la Especialidad en Planeamiento Paisajista y Ambiente de la Facultad de Ciencias Agrarias y Forestales de la Universidad Nacional de La Plata.
} 
neoliberalismo, como corriente de pensamiento, no fue ajena al paisajismo y lo ubicó en un lugar de banalidad y simplicidad extremas poniendo en riesgo el sentido mismo de la disciplina. Originariamente, el paisajismo moderno, surgió como ordenador urbano y fue de la mano de grandes urbanistas que se transformaron las principales ciudades hasta principios del siglo XX. El fundador de esta corriente fue el paisajista Edouarde André quien bajo las directivas de Adolph Alphand transformó los espacios verdes con la reforma urbana de París de mediados del siglo XIX. E. André escribió el tratado "L'art des jardins" (1879) que se constituyó en uno de los mojones iniciales del paisajismo moderno. K. Yu viene a realizar un puente temporal, desde los siglos XIX y XX hacia el nuevo milenio, retomando la tradición paisajista con intervenciones de gran escala y complejidad demostrando que el paisajismo puede contribuir a solucionar parte de las problemáticas existentes en las ciudades.

Finalmente, en el mismo sentido, James Corner (2014), aborda el paisaje desde un concepto que denomina landscape imagination y lo define de la siguiente manera: "there is nothing about natural about landscape: even though landscape invokes nature and engages natural processes over time, it is first a cultural construct, a product of the imagination" (p.7). Es interesante destacar que tanto la escuela norteamericana, la europea y la vanguardia asiática confluyen en una misma idea ligada al paisaje como constructo cultural. En los tres casos, conforman una disciplina que busca dar respuesta a las problemáticas de la ciudad.

Si bien la discusión sobre qué es paisaje no se encuentra saldada creemos que la definición de la Convención Europea del Paisaje, junto con las reflexiones respecto a la experiencia de ciertos autores, nos permiten tener un acercamiento más acabado sobre el tema. Esta tesis busca estudiar la conformación del paisaje desde una mirada de las infancias en las plazas públicas. En este sentido, el elemento central que se estudiará como parte de la componente territorial del paisaje será lo construido y específicamente la vegetación como una infraestructura verde recreativa (IVR).

En nuestro caso, en la idea de paisaje, la componente de la población se refiere a las infancias. En este sentido, la idea de recrear infancias es un concepto definido por Bustelo (2007) donde a partir 
de la palabra recrear juega con dos situaciones: volver a crear y recreo (juego). Bustelo (2007) parte de un diagnóstico de que las infancias en nuestro momento histórico no se encuentran definidas claramente como sujeto social. Esta idea, es puesta en debate incluso por algunos autores que tienen la tesis de desaparición de la infancia como categoría social (Corea y Lewcowicz, 1999). En este contexto, Bustelo (2007) conceptualiza la necesidad de volver a construirla. Este recrear significa un volver a edificar como sociedad infancias. Sin embargo, en este volver a crear, Bustelo (2007) plantea que no debe ser desde la mirada del mayor que "muestra" un camino hacia la adultez, sino todo lo contrario, en nuestras sociedades es necesario crear las condiciones para que esas infancias se auto conformen de manera disruptiva con respecto al mundo adulto. De esta manera, el adulto adquiere una nueva función, que refiere a conformar las condiciones para que Ixs niñxs puedan desarrollarse libremente en un mundo que cambia de forma acelerada.

En este sentido, Larrosa y Pérez de Lara (1997) refieren que la infancia es lo otro: lo que está siempre más allá de cualquier intento de captura. Pensar la infancia como algo otro es, justamente, pensar esa inquietud, ese cuestionamiento y ese vacío. De lo que se trata aquí entonces, es de devolver a la infancia su presencia enigmática y de encontrar la medida de nuestra responsabilidad en la respuesta ante la exigencia que ese enigma lleva consigo. Como una manera de responder, de abrirse a la interpelación de una llamada (desde la infancia) y aceptar dicha responsabilidad. En este caso, el responder a la llamada de Larrosa y Pérez de Lara (1997) se liga a la idea de Bustelo (2007) respecto a la nueva función del mundo adulto, la de crear las condiciones justamente para albergar ese enigma.

Bustelo (2007), a su vez, escribe que "las infancias pueden ser concebidas como categoría social" (p.139). En consecuencia, no hay que verlas desde la concepción individual de niñx sujeto de derechos sino que hay que pensarlas como categoría social e histórica, como colectivo sujeto de derechos y no como individuo. Esta idea nos lleva a pensar que tenemos que ver las múltiples infancias y sus interrelaciones en clave colectiva y no individual. Ahora bien, ¿cómo se vuelven a crear 
infancias? Una clave que brinda el autor es a través del recreo. En este sentido, desarrolla doce tesis sobre el recreo de la infancia. Nosotros tomaremos como referencia las siguientes que se sintetizan en las expresiones a continuación:

- "La infancia es autonomía que se afirma contra la heteronomía disciplinaria y controladora" (Bustelo, 2007, p.185). La categoría de autonomía como base para la construcción de infancias recreadas.

-. "La infancia se define como una temporalidad diacrónica, como ruptura y quiebre" (Bustelo, 2007, p.185). Las categorías de diacronía y sincronía hablan sobre qué debe continuar, pero principalmente de que todo tiene que cambiar constantemente.

-. "El recreo de la infancia es la metodología de lo nuevo como descubrimiento y, por lo tanto, una dimensión del conocer" (Bustelo, 2007, p.186). La categoría de lo nuevo como base para la recreación.

-. "La infancia es una categoría emancipatoria" (Bustelo, 2007, p.185). Debemos pensar la infancia en categoría disruptiva del mundo adulto de manera de contenerla y albergarla.

La tercera categoría, definida como la dimensión del conocer, la denominamos como diversidad. Así, la diversidad, y por lo tanto la dimensión del conocer, en este trabajo de investigación, es entendida como la posibilidad de vivir múltiples experiencias en diferentes ámbitos. La idea de que puedo saber, conocer, a partir de que tengo qué explorar, qué descubrir, qué ensayar, nos sitúa en el lugar de habilitadores de posibles vivencias. La concepción de diversidad de ámbitos que faculten múltiples experiencias, tanto individuales como colectivas, de niñxs, es motivo de indagación de este trabajo de investigación. Sin embargo, esta idea de inclusión de las múltiples identidades infantiles, no desconoce que existe en nuestras sociedades una dimensión socio-económica que limita severamente la manifestación de dichas identidades e incluso la posibilidad de vivir la infancia tal como la concebimos. Si bien, este análisis escapa a los estudios de esta tesis, entendemos que no se resolverá la inclusión de niñxs solamente brindando diversidad de ámbitos. En este sentido, pareciera 
necesario abordar condiciones estructurales de las infancias relacionadas al hogar, el alimento y la salud que permita habitar la infancia a grandes sectores de la sociedad que hoy no lo pueden realizar de manera plena.

A modo de síntesis, y retomando los enunciados de la tesis de Bustelo, pensaremos a las infancias recreadas como autónomas, diacrónicas, diversas y emancipadoras. Entonces: ¿es posible pensar la infraestructura verde recreativa con referencia a estas categorías de manera tal de que nos permitan conformar paisajes para la recreación? 


\subsubsection{CATEGORÍAS DE ANÁLISIS EN LAS INFANCIAS}

\subsubsection{Autonomía para la recreación}

Bustelo (2007) plantea que "hemos pasado de una sociedad disciplinaria a una sociedad de control y que ésta pasa por la interiorización de un dispositivo disciplinario que cumple el rol normatizante de las prácticas cotidianas" (p.60). Esta manera de manifestación del poder como característica biopolítica implica múltiples aristas. En principio es comprender que el capitalismo infantil (Bustelo, 2007) define a Ixs niñxs como consumidores y no como ciudadanos. Niñxs son modelados para incorporarse rápidamente al consumo. Su subjetividad se va configurando induciendo directa 0 indirectamente al consumo. Pertenecer es consumir y la escala de valores común en la infancia pasaría por el consumo. Carli (2009) plantea, entre otras, la figura del niño de la calle y el niño consumidor, estableciendo diferencias en cuanto a las infancias existentes. Sin embargo, esas diferencias no se constituyen en la escala de valores y deseos imaginados, ambas figuras se constituyen en el consumo, las primeras como horizonte imaginado y las segundas como poseedores de esa materialidad.

Entonces, el consumo aparece como hecho cultural (Carli, 2009). Un hecho cultural sería según García Canclini (1993) "el conjunto de procesos de apropiación y uso de productos en los que el valor simbólico prevalece sobre los valores de uso y de cambio o donde al menos estos últimos se configuran subordinados a la dimensión simbólica" (p.34). Es en ese campo simbólico en el que buscamos constituirnos en esta tesis para la recreación de infancias, buscando caminos contrahegemónicos donde el espacio público pueda ser pensado como parte constituyente de nuevas infancias que no tengan solamente como hecho cultural el consumo. La construcción del paisaje, según la definición aquí utilizada, es un hecho cultural en sí mismo y por lo tanto el análisis y trabajo de sus componentes pueden constituir un camino contrahegemónico.

Volviendo a la sociedad de control, Carli (2009) plantea las figuras del niño víctima y el niño peligroso como representaciones sociales utilizadas en los medios de comunicación para generar 
polémica en lo referido al miedo social o, por el contrario, para promover conductas de compasión social. Ambas de manera sensacionalista y borrando la polisemia personal y los matices de cada historia individual, desdibujando la responsabilidad del adulto. El niño peligroso es un menor que incurre en delitos y debe ser juzgado (baja de la edad de imputabilidad) y el niño víctima es un ser al que debe protegerse. Esta idea se podría asociar a dos características, por un lado la exclusión del espacio público de infancias peligrosas y, por el otro lado, la sobreprotección de infancias víctimas. Este mecanismo se constituye en una de las aristas de la sociedad de control planteada por Bustelo (2009). Esta idea podría tener su correlato en el espacio público en los ámbitos para niñxs. ¿Es posible detectar en la vegetación la idea de sobreprotección y de exclusión como mecanismo que aporta a una sociedad de control?.

Los ámbitos en el espacio público, como se desarrollará más adelante, constituyen un dispositivo biopolítico que norma conductas. La conformación espacial de dichos lugares puede ser analizada en base a dos categorías de la sociedad de control normativizante: la sobreprotección y la exclusión. En nuestro caso estudiaremos qué sucede con las experiencias de Ixs niñxs en el espacio público, cuáles se encuentran habilitadas y de qué manera y cuáles se encuentran omitidas o negadas. También, se piensa cómo la idea de la sobreprotección se encuentra permeada por el discurso de la seguridad-inseguridad de manera tal de profundizar el dispositivo que Foucault (1975) desarrolló como panóptico, permeando en las conductas y experiencias que puede desarrollar la niñez. Se busca indagar sobre la falsa idea de que cuánto más seguros (vigilados), más cuidados, más protegidos, están Ixs niñxs. De esta manera, la sobreprotección o exceso de cuidado se podría ligar al discurso de la seguridad como una forma de control y no como una idea cargada de buenas intenciones sobre el cuidado de la niñez.

A su vez, la idea de sociedad de control y heteronomía se contrapone a la de autonomía en las infancias. Mientras que la primera busca normar conductas, establecer caminos correctos o válidos, descontextualizar las problemáticas, excluir individuos, reforzar la mirada del adulto sobre Ixs niñxs y 
encasillar la imaginación, la segunda, busca transgredir y crear nuevas normas, constituirse en las diferencias, buscar caminos de convivencia y crear nuevas formas sociales. La autonomía es el proceso por el cual las infancias desarrollan progresivamente su conciencia, su subjetividad, y se diferencia de la generación adulta y lo que ello representa (Bustelo, 2009). La autonomía es la capacidad de una persona de referenciarse ella misma y tomar decisiones sin hacer referencia a otro (Bustelo, 2012ª). La autonomía ligada a la libertad no debe confundirse con la desaparición del adulto como ser responsable del cuidado y de la definición de los límites y condiciones de dicho espacio. En este sentido, Carli (2011), en el análisis de la obra de Aberastury, señala que libertad y autoridad ha sido una antinomia clásica en la historia de la pedagogía, desde el extremo de la familia autoritaria de principios de siglo XX a las familias permisivas de los 60', pareciera que es necesario una presencia del mundo adulto con funciones bien definidas que no sólo cuiden el ámbito de la niñez sino que también sepan delimitar el ámbito en el que se desarrolla. Entonces, cuando pensamos la autonomía no la expresamos desde un deseo autonomista para las infancias sino desde la generación de espacios físico-temporales cuidados y determinados por los adultos donde se habiliten prácticas, creaciones y vivencias propias de las infancias, seguramente desconocidas u olvidadas para los adultos.

En contraposición, la heteronomía está conformada por los valores socialmente hegemónicos en una sociedad y las instituciones que los representan, las que intentan oponerse sobre niños y niñas (Bustelo, 2007).

Sociedad de control y heterenomía, como contracara a la autonomía conforman categorías que se consideran en la investigación realizada para responder a la pregunta: ¿Cómo se traducen estas ideas en la vegetación en los ámbitos para niñxs? ¿Cómo podemos pensar ámbitos para niñxs en clave autónoma que genere las condiciones para la recreación de infancias? 


\subsubsection{Sincronía y diacronía en las infancias}

En las infancias, la sincronía representa la estabilidad asociada al pasado y la tradición en donde el tiempo se hace una continuidad/discontinuidad y su esencia la repetición (Bustelo, 2007). De otro lado, la diacronía representa la ruptura, el ritmo, el movimiento y la apertura hacia lo nuevo en donde el tiempo es por esencia discreto. Sincronía y diacronía son instancias correlativas que se suponen mutuamente (Bustelo, 2007).

Si pensamos la sincronía y la diacronía como un esquema constituido por una línea con puntos determinados, la sincronía sería la línea continua y la diacronía se movería de punto en punto, mediante saltos. La sincronía podría estar ligada a ese mecanismo basal que constituye nuestra identidad histórica y la diacronía podría estar ligada a lo nuevo, lo disruptivo, lo diferente que funda nuevas formas. Niñx no es sinónimo de una transición histórica, donde toma la historia que le trasmiten y la continúa, sino que hay un corte, es diferente, es autónomo, hay ruptura, hay otredad, hay diacronía (Bustelo, 2012a).

En este sentido, Bustelo (2007, p.144) reflexiona que:

...el significante crucial de la infancia es la diacronía. La infancia se identifica con ruptura ... y se desarrolla como categoría social en un tiempo como proceso discontinuo. Es la acumulación del comienzo, de otro comienzo que convoca al tiempo de la emancipación.

Estos saltos diacrónicos, seguramente produzcan un destilado que alimenta un mecanismo basal y que se podría constituir en una nueva sincronía. Sin embargo, no deben pensarse como procesos lineales y acumulativos, la diacronía puede producir disrupciones que remitan a formas anteriores 0 , por lo menos, a relaciones sincrónicas de otros momentos, por lo tanto la diacronía es ese ir y venir dialéctico en las historias de las infancias.

Creemos que es posible observar en el espacio público la manifestación de saltos diacrónicos y la presencia de estigios sincrónicos a partir del análisis de los usos que se dan del mismo. Es posible observar dispositivos lúdicos que ya no despiertan interés o que no tienen una frecuencia elevada de 
uso, lo que podría dar cuenta de cambios en las infancias que alojan. Por el contrario, la aparición de nuevas prácticas en los espacios verdes hacen emerger nuevos formas de habitarlo. Por ejemplo, la aparición del skateboarding, bmx y roller es un emergente en las generaciones actuales, lo que llevó a planificar la existencia de parques de skate a partir de los cuales se tejen nuevas relaciones sociales. Pensamos que la identificación de los cambios en las frecuencias de uso, la detección de nuevos emergentes, es una manera de dialogar con las infancias sobre cuáles son sus necesidades y así conceptualizar y potenciar cambios que tengan una lectura diacrónica y/o sincrónica.

Entonces, ¿puede pensarse el espacio para niñxs en clave sincrónica y diacrónica? ¿Cómo puede pensarse la infraestructura verde recreativa de manera sincrónica y diacrónica en términos de infancias para la conformación de paisajes recreados?

\subsubsection{Diversidad de experiencias en la niñez}

Como se mencionó anteriormente, Bustelo (2007), sitúa a las infancias recreadas en la dimensión del conocer. Esta idea, la ligamos a una categoría que denominamos diversidad de experiencias. En contraposición a ella, se encuentra la homogeneidad, que piensa a la infancia como única y estática, sin conocimientos y débil y con igualdad de derechos. Carli (2009), en sus figuras de Ixs niñxs, ya plantea una diferenciación al respecto. El contraste de clases sociales no permite el acceso igualitario a educación de calidad ni de salud, así como tampoco de hábitat para todas las infancias, lo que se traduce en dificultad en el acceso a derechos. Si lo pensamos en términos del derecho a la ciudad, la situación es similar, si bien Ixs niñxs provenientes de familias con menores recursos son los que más circulan en el espacio público y quizás los que mayor uso le den, no siempre se realiza en términos de derecho al ocio, la recreación y la socialización, sino que también ocurre ligado al trabajo. En este sentido, Rausky et al. (2016), realizaron una investigación pormenorizada de Ixs niñxs y adolescentes en situación de calle en la ciudad de La Plata. Allí, se relevaron al menos 14 formas de trabajo en el espacio público, predominando en niñxs la venta de flores y plantas, estampitas, curitas y el limosneo. Si bien no es eje central de esta tesis abordar las diferencias de 
clases sociales y por lo tanto la dificultad en el acceso a ciertos derechos, sí es necesario acercarse a comprender la complejidad de un colectivo por definición heterogéneo en múltiples dimensiones.

Las infancias también son diversas de manera transversal a las clases sociales. En este sentido, la Convención sobre los Derechos del Niño (Año 1989) y la Ley de Protección Integral de los derechos de niños, niñas y adolescentes (Ley 26.061, Año 2005), establecen derechos universales. Sin embargo, el Estado tiene que brindar las condiciones para que puedan ser ejercidos por cualquier niñx habitante de Argentina. En este punto, se juegan, entre otros, las personalidades 0 identidades de cada niñx. Pareciera que los espacios de juegos para niñxs en las plazas son pensados sólo en términos motrices y para un tipo de niñx activo varón de clase media. Es aquí también donde el Estado no garantiza las condiciones para que se puedan ejercer los derechos enunciados. Cada vez son más diversas las identidades, con niñxs que desean leer, usar videojuegos, jugar a la pelota, trepar, dialogar, inventar, correr, sacarse fotos, pensar, descubrir, leer, estar, etc. Esta heterogeneidad de experiencias forma parte de la riqueza en las infancias y conforma la categoría de diversidad de este estudio. Como expresa Benjamin en la cita que trascribe Carli (2011, p.28), "sólo puede llegar a ser parte integrante de la memoria involuntaria aquello que no ha sido vivido expresa y conscientemente, en suma aquello que no ha sido una 'experiencia vivida' " (p. 28). En este sentido, buscamos crear ámbitos que tengan disponibles diversidad de experiencias para poder abonar esa memoria involuntaria, ligada a los sentidos y especialmente al olor como, en palabras de Benjamin (en Carli, 2011), refugio inaccesible de la memoria involuntaria.

A su vez, según Kohan (2014, Kohan y Kennedy, 2015), existen dos dimensiones del tiempo: un momento chrónos y uno aión. Estas categorías de tiempo pueden ser pensadas en la niñez. En este sentido, mientras que el primero se encuentra ligado al momento escolar tradicional, lineal y sucesivo, el segundo designa la intensidad del tiempo de la vida, una duración, un destino, algo así como una temporalidad no numerable, ni consecutiva ni sucesiva. Es en el tiempo aión que el trabajo de investigación busca, a través de la diversidad de experiencias abrir a futuras intervenciones. Poder 
establecer un marco conceptual para la generación de ámbitos de juegos potentes en este otro tiempo, sutiles en la vivencia pero profundamente intensos en la experiencia vivida.

En este sentido, las preguntas que guían la investigación se refieren a: ¿Son los ámbitos de juego habilitadores de múltiples experiencias en la Ciudad de La Plata? ¿Es posible conformar ámbitos para la recreación que admitan mayor diversidad de vivencias? ¿Cómo la vegetación puede construir una Infraestructura Verde Recreativa capaz de aportar diversidad de usos que intensifiquen el tiempo aión en la niñez?

\subsubsection{Hacia infancias emancipadas}

Bustelo (2007) expresa que: "La infancia significa comienzo, pero principalmente otro comienzo. En este sentido podemos afirmar que infancia equivale a principio" (p.140). Si la infancia es una categoría generativa podemos pensar que tiene un comienzo constante o que también se constituyen en el cambio permanente. Si tomamos el cambio constante como categoría formadora de la infancia podríamos preguntarnos: ¿cómo se conforma el espacio para niñxs en referencia a este cambio constante? ¿Cómo se encuentra concebida la vegetación en los espacios para niñxs con referencia al trasmutar permanente?

Si la transformación forma parte intrínseca de las infancias, su interpretación difícilmente pueda darse desde el mundo adulto. Entonces, es necesario pensar esas infancias como forjadoras de su propio destino. En este sentido, Tonucci (1996) señala como un posible instrumento los Consejos de niñxs en lo que denomina la "Ciudad de los Niños". Los Consejos, en este sentido, se proponen como espacios habilitados para la escucha y el estímulo emergente de propuestas y sugerencias en pos de lograr una ciudad amigable con las infancias. La participación en las infancias se encuentra enmarcada en la construcción de ciudadanía, niñxs ciudadanxs capaces de interpretar y expresar sus propias necesidades, así como también que puedan contribuir a la construcción de la ciudad (Goldstein, 2017). Esta idea se asocia a la de infancias con mayores grados de autonomía, con capacidad de pensar y 
decidir, de elegir su propio destino en un contexto contenido y cuidado determinado por los adultos. Quizás así, Ixs niñxs, puedan formar parte en procesos participativos de diseño de sus propios ámbitos de juegos.

En este sentido, Bustelo (2007) marca que en la historia de las ideas ha habido siempre una dualidad entre libertad y necesidad. Libertad como apertura sin ataduras y necesidad como opresión de la materialidad que no habilita la dignidad del existir. Así, la liberación es como una conquista de opciones y una apertura al "sin límites". La emancipación, en cambio, es un concepto referido más a la opresión que se deriva de la materialidad e implica salir de la dominación y de las necesidades asociadas a esta. La emancipación se mueve en el eje de la igualdad y en el de una libertad que es secundaria con respecto al eje igualitario. En este sentido, Rancière (2003; en Vermeren et al, 2003) coincide y la denomina en términos de igualdad, no de iluminación y la llama emancipación intelectual. En este punto, existe una diferencia respecto a otros autores ya que Rancière interpreta a Jacocot (en Vermeren et al, 2003) como una emancipación en una relación individual y la contrapone a una emancipación social ligada más al pensamiento de pedagogos latinoamericanos como Paulo Freire. En este sentido, Bustelo (2007) habla de que la libertad presupone un "ser en el mundo" y que por lo tanto no se puede pensar a la infancia fuera de la teoría del cambio social (Bustelo, 2007). Esta concepción de las infancias es profundamente inclusiva de la diversidad y plantea desafíos en cuanto a cómo constituirnos, en nuestro caso en el espacio público, para poder dar lugar finalmente a esa emancipación social. Boaventura de Sousa Santos (2010) señala un camino en ese sentido en lo que denomina una epistemología del Sur para dar lugar a nuevos caminos de encuentro y transformación social.

En nuestro caso, las ideas de infancias autónomas, cambiantes y diversas se contraponen con las de heteronomía y sociedad de control, con lo estático y lo homogéneo. Las infancias recreadas se plantean en esta tesis como un camino hacia la emancipación social, hacia un cambio social 
construido por Ixs propixs niñxs, a partir de ámbitos cuidados que puedan ser habitados por niñxs libres.

Entonces, la estrategia que seguimos en este trabajo de investigación como horizonte es la emancipación social. Para ello, se aspira a tender un puente conceptual entre los estudios de las infancias y los del paisajismo que nos permita pensar y diseñar la vegetación en ámbitos para la niñez donde tenga lugar la autonomía, la diacronía-sincronía y la diversidad de experiencias. 


\subsubsection{CATEGORÍAS DE ANÁLISIS PARA EL PAISAJE}

\subsubsection{Vegetación Urbana}

De manera precisa, Benassi (2013), define a la vegetación urbana como "toda aquella vegetación implantada o espontánea entre y/o sobre la fase urbanizada, integrando el paisaje y acompañando al proyecto urbano y la planificación territorial. La vegetación urbana integra las plantas nativas y exóticas, naturalizadas y espontáneas, alóctonas y autóctonas" (p.23). Según Benassi (2013, 2015), podemos pensarla en términos de una Infraestructura Verde Urbana lo que llevó a desarrollar un modelo de gestión de la vegetación (Benassi, 2015). Como podrá observarse, allí se encuentra incluida tanto las especies vegetales cultivadas en parques y plazas así como también toda la vegetación espontánea que se encuentra entre y sobre la fase inerte construida. Es un manto verde que constituye una de las capas vivas de la ciudad, que respira y produce biomasa, que retiene contaminantes y filtra el aire, que brinda servicios ambientales y sociales para hacer más amigable la ciudad. Aquí se encuentra lo que Peter del Tredici (2014, en Reed y Lister, 2014) denomina The Flora of the Future (la Flora del Futuro) refiriéndose a todas las plantas que crecen espontáneamente en la ciudad sin ningún tipo de aporte externo (riego, corte, poda, etc.) y la señala como parte de un nuevo paradigma estético y social para las comunidades actuales y futuras.

Esta definición, nos permite tener una mirada superadora sobre la vegetación en la ciudad ya que nos permite operar con la misma en términos de infraestructura e ingeniería. Ya no hablamos como algunos autores denominaban el binomio naturaleza y artificio (Ábalos, 2010), o como desde la ecología de paisajes de ecosistemas naturales. Estas dos miradas plantean una serie de preguntas difíciles de responder. Para poder tener capacidad de gestión, en el primer caso, la definición de qué es naturaleza y qué artificio nos lleva a un punto sin salida. Podríamos pensar que un ecosistema en una plaza es naturaleza y que lo artificial se refiere a lo construido. Sin embargo, aquí nos preguntaríamos: ¿es posible que las plantas en un espacio público crezcan en un ambiente donde haya sido modificado todo el componente suelo-clima? ¿es posible tener servicios sociales y 
ambientales, a partir de la vegetación, sin construir sustratos, cultivar las especies, instalar riego, etc. ? En este punto, el límite entre artificio y naturaleza se hace difuso. En el artefacto urbano pareciera no existir elementos que no sean construidos a partir o desde la intervención humana.

En el segundo caso, el manejo de la vegetación a partir de la visión desde la ecología de paisajes, se introducen nuevos problemas teóricos. En este sentido, no es la ciudad y sus habitantes el eje a partir del cual se interviene en la vegetación, sino que, según esta teoría, la misma sucede de manera inversa con centralidad en el ecosistema. Así, las variables referidas a los servicios sociales quedan relegadas 0 , en el mejor de los casos, igualadas a categorías propias de los ecosistemas con bajos niveles de antropización y donde las necesidades de la ciudadanía no son tan urgentes.

Es la nueva mirada sobre la vegetación, como una infraestructura verde urbana, ligada al cultivo de las especies, la que nos permite operar sobre la misma con eje en el hábitat humano. Aquí, John Dixon Hunt (2000) Ilama tercera naturaleza a la vegetación cultivada en espacios altamente antropizados con una gran carga simbólica, los paisajes altamente diseñados que conectan ideas, experiencias y que nos llevan a la reflexión. También Donadieu (2006) se expresa en el mismo sentido. La primera naturaleza serían los ecosistemas nativos, la segunda naturaleza la creada por la agricultura y la tercera ligada más a los paisajes culturales. Este último grupo es el que se encuentra ligado de manera más estrecha a la concepción de Hannah Arendt (2003) cuando denomina a la acción humana en tanto condición de la humanización, una vegetación que forma parte de la humanidad como producto de la intervención y definición por parte del humano.

La mirada del trabajo de investigación refiere a la vegetación urbana anclada desde los paisajes culturales. Forma parte de la Infraestructura Verde Urbana en la que se encuentra la Infraestructura Verde Recreativa.

La mirada cultural de los paisajes es lo que permite pensar y planificar la vegetación desde y para la niñez, conformar ecosistemas donde la centralidad esté colocada en la recreación de infancias. De esta manera, la vegetación urbana, como infraestructura verde recreativa, puede ser habilitadora 
de las tres categorías para las infancias habilitando ámbitos con mayores grados de autonomía, una visión sincrónica y diacrónica y con infinidad de experiencias por vivir.

\subsubsection{Sincronía y diacronía vegetal}

Según Benassi (2013), la sincronía en el modelo de infraestructura verde urbana (IVI) se refiere a la planificación de la vegetación en función los usos que se dan de manera simultánea en un territorio dado. En otro sentido, la diacronía se refiere a cómo ese manto vegetal se desarrolla a lo largo del tiempo, cuáles son las trayectorias ecosistémicas y cómo se planifica el manejo de la vegetación en función del tiempo (Benassi, 2013).

Como se mencionó, la sincronía es de usos y a partir de allí cómo se conforma el manto vegetal en un momento dado. La idea de sincronía de usos establece un mosaico muy diverso de posibilidades para la vegetación en un momento histórico dado. En este sentido, la diversidad de vegetación estará determinada por las funciones o usos que contiene. Pero también, estará condicionada por una lectura diacrónica de la misma que se desarrolla en el punto siguiente. Esta doble lectura de la vegetación, sincrónica y diacrónica, se cruza con la lectura de las infancias en clave sincrónica y diacrónica. Si bien tienen significados diferentes, es posible establecer puentes entre ambas ideas.

Bustelo (2007) define la sincronía como la continuidad/discontinuidad en el tiempo y la diacronía como los cambios/saltos en dicho tiempo. Benassi (2013) define la diacronía como los cambios en el tiempo y la sincronía como un mosaico territorial de usos en un momento determinado. Pareciera que la idea de los saltos diacrónicos en las infancias se encuentran ligados al análisis sincrónico de la vegetación, y que la sincronía en las infancias a una mirada diacrónica de la vegetación.

A su vez, la sincronía vegetal como mosaico territorial de usos pareciera establecer un puente con la idea de diversidad de experiencias en las infancias. En este sentido, cuanta mayor variabilidad en los ámbitos de juego, existirá una mayor diversidad de usos y por lo tanto un mosaico vegetal más 
complejo que los admita. Aquí nos preguntamos: ¿existen en la ciudad de La Plata diversidad de experiencias para las infancias? ¿Existe una planificación sincrónica de usos para la vegetación en la niñez en la ciudad de La Plata? ¿Es la sincronía vegetal una clave para pensar la diversidad de experiencias en las infancias?

Ahora bien, si cambian los usos, es necesario pensar que debiera existir un cambio en la vegetación que los contiene. Los saltos diacrónicos en las infancias, como se desarrolló anteriormente, tienen múltiples expresiones ya que traen una nueva forma de ver el mundo, de habitarlo. Los cambios pueden ser proyectivos (nuevos) o retrospectivos (vuelta a formas pasadas). La necesidad de detectar estos cambios en clave de nuevos usos o desaparición de algunos, nos sitúa en una situación de rediseño de los ámbitos de juego de manera tal de que puedan albergar las generaciones venideras. En este sentido, la sincronía vegetal, no sólo se asociaría a la diversidad de experiencias, sino también, a la capacidad de re-adecuar, mediante el re-diseño, las comunidades vegetales existentes en un momento dado. Así, el concepto de diacronía en las infancias se encontraría asociado al de sincronía vegetal. ¿Es posible pensar la sincronía vegetal como un modo de lectura del territorio en clave de diacronía en las infancias?

Si se relevase regularmente los usos infantiles existentes en el espacio público de una ciudad y se manifestase que el juego ya no es el mismo, quizás sea un síntoma de que hayan ocurrido cambios diacrónicos en las infancias que no se hayan detectado y por lo tanto habilitado. Detectados los cambios, se planificaría nuevamente la vegetación que los contenga, tendiendo un puente entre sincronía vegetal y diacronía en las infancias.

En otro sentido, la diacronía vegetal se refiere a las trayectorias de los ecosistemas urbanos (antroposistemas) en el tiempo. Para ello debemos acercarnos a comprender qué es un ecosistema y cómo funcionan. En este sentido, los sistemas ecológicos tienen cuatro propiedades: interacciones complejas que conforman un sistema (systems properties), cualidad histórica (historical quality), enclave espacial (spatial interlocking) y estructuras de su límites no lineales (nonlinear structural 
properties). En el primer caso se refiere a que los ecosistemas son caracterizados no sólo por sus partes sino principalmente por la interacción entre dichas partes. Segundo, los sistemas se encuentran inmersos en el tiempo y su historia previa en parte los define. En tercer lugar, los ecosistemas complejos tienen significativas interacciones espaciales, los ecosistemas son afectados por eventos que tienen su correlato espacial, este correlato espacial determina que los ecosistemas no sean homogéneos y se manifiesten en el territorio como un mosaico con características físicas y biológicas determinadas. Finalmente, los ecosistemas tienen límites que no son lineales, tampoco necesariamente continuos ni claramente definidos (Holling and Goldberg, 1971 en Reed y Lister 2014).

El comportamiento del flujo de los sistemas proviene de dichas propiedades. En conjunto, producen resiliencia y estabilidad. Estos conceptos se refieren a que los ecosistemas existen en un ambiente de altísima variabilidad. La teoría tradicional planteaba que los ecosistemas tenían momentos sucesionales de mayor complejidad hasta un punto donde se llegaba a una comunidad clímax, donde la producción de biomasa y de diversidad de especies era la máxima. Ahora bien, actualmente se plantea que dicho clímax en realidad se encuentra en constante movimiento y cambio. Raramente, en un determinado momento los sistemas se mantienen estables. De esta manera, el concepto de estabilidad se resignifica como un dominio de estabilidad en el cual los ecosistemas se mueven sin perder sus propiedades ecosistémicas. Este dominio de estabilidad es lo que se denomina resiliencia, como la capacidad de los sistemas de absorber las consecuencias del cambio sin perder sus propiedades. Este dominio de estabilidad tiene límites y cuanto más se acerca el sistema a dichos límites más débil es. (Holling and Goldberg, 1971 en Reed \& Lister, 2014). Esta visión de estabilidad y resiliencia se encuentra simplificada ya que los límites tampoco son estáticos en un ecosistema, sino que dicho dominio de estabilidad también cambia.

Ahora bien, ¿qué sucede en las áreas urbanas? Lo primero que nos tendríamos que preguntar es si existen ecosistemas. Si definimos a un ecosistema bajo las cuatro propiedades nombradas al comienzo podríamos decir que sí. En primer lugar, los sistemas verdes existentes en las ciudades se 
conforman de partes que interactúan, no sólo con el sustrato-suelo, clima, aire y agua que circula sino también con las personas y el resto de las infraestructuras de la urbe. En segundo lugar, las ciudades y los sistemas verdes en las ciudades tienen una historia y ese pasado, en parte, los define. Tercero, la ciudad no es homogénea y tiene características espaciales que son heterogéneas y que interactúan entre sí, un mosaico urbano, o un sistema verde urbano. Este sistema verde urbano interactúa no sólo con su medio físico sino también con procesos sociales. Finalmente, tienen límites no lineales que cambian según el tamaño de la ciudad, esos límites pueden ser difusos y discontinuos. De esta manera, también tienen un dominio de estabilidad que define la resiliencia de dicho sistema y que lo define en un cambio permanente. Dichos cambios pueden afectar el dominio de estabilidad y hacer un sistema más débil o no, e incluso, hacer que un sistema colapse y se convierta en otro cuando no es capaz de absorber dichos cambios, ya sea porque es poco resiliente o el cambio llevó al sistema fue ra del dominio de estabilidad.

Entonces, un sistema verde recreativo urbano tiene características ecosistémicas, donde las partes y sus interacciones conforman una de sus propiedades, al igual que su historia, su disposición espacial y sus límites. Las interacciones no sólo se refieren al complejo suelo-planta-clima sino principalmente a cómo dicho complejo se conjuga con procesos sociales demandantes de usos. Esta ecuación debe ser tal que conforme sistemas que admitan el cambio constante y que dichos cambios permitan tomar decisiones que mantengan, o aumenten, la capacidad de un sistema de absorberlos sin colapsar, o sea la conformación de ecosistemas resilientes o robustos.

La idea de diacronía vegetal (Benassi, 2013) toma los sistemas verdes de las ciudades como ecosistemas antropogénicos en constante cambio. La diacronía como el paso del tiempo de dichos antroposistemas y los cambios que se dan principalmente en la vegetación nos da una idea de rehacer y deshacer constante, de no-equilibrio, no-estabilidad y por lo tanto la necesidad del re-diseño permanente con el paso del tiempo. También, esta idea del re-diseño contempla una ponderación de las pre-existencias y la constitución de pre-existencias futuras. Este análisis histórico de cualquier 
proyecto es lo que permite establecer un puente con la idea de sincronía en las infancias (continuidad según Bustelo, 2007), esa línea continua que constituye el conector o la memoria histórica del lugar con el hoy y el mañana. Las infancias del presente se constituyen con las infancias del pasado y del futuro a partir de elementos que podrían ser vegetales. No como un deber ser desde el pasado o desde el futuro sino como un comprender el aquí y ahora para definir ese soy social colectivo.

La pregunta que nos hacemos en el trabajo de investigación entonces es: ¿es la ecología del no-equilibrio, y la diacronía vegetal, una manera para pensar la infraestructura verde recreativa para las infancias en clave sincrónica? La sincronía en las infancias se refiera a lo que permanece, continúa y que en su discontinuidad, en términos arendtianos, constituye y alberga lo nuevo como condición de la acción humana. En nuestro caso, la diacronía vegetal refiere al cambio, al salto, del ecosistema en el tiempo. ¿Se puede pensar la diacronía vegetal como parte de una estrategia sincrónica para las infancias?

\subsubsection{Tipología Vegetal}

La vegetación en las ciudades puede ser manejada mediante el concepto de tipología vegetal (Benassi, 1994). Benassi (1994) expresa que la tipología vegetal es: "la suma de atributos específicos que tienen la capacidad de expresar y satisfacer la intencionalidad y argumento de un proyecto de paisaje" (p.4). Esta idea permitió a los paisajistas hacer operable el universo de plantas de manera más práctica en función de un proyecto de paisaje y además abrió la posibilidad del diálogo interdisciplinario sobre los elementos vegetales sin necesidad de ser un especialista en la materia. La clasificación taxonómica de las plantas, iniciada por Linneo (1762), permitió desarrollar un conocimiento pormenorizado de la flora. Sin embargo, dicho ordenamiento no categoriza las plantas en función de un proyecto de paisaje, sino, principalmente, en base a características morfológicas que determinan un orden filogenético de las especies, de manera tal de agruparlas en géneros, familias, orden. La tipología vegetal se complementa a esta clasificación y produce un reordenamiento práctico de las mismas a fin de hacerlas operables para el proyecto paisajístico. 
A partir de allí, la tipología vegetal definió atributos primarios, secundarios y terciarios. Los primarios referidos a la magnitud de las plantas (altura y ancho de copa adultos), el hábito vegetativo (permanencia o no de follaje a través de las distintas estaciones del año) y la silueta (arquitectura de la planta en base a modelos teóricos). Los secundarios señalados como color (por follaje, floración, fructificación) y textura/densidad (tamaño, cantidad y disposición de hojas y ramas). Finalmente, los terciarios, se describen la singularidad de las especies, tales como floración, fructificación, corteza, aromas, otros (toxicidad, espinas). Esta última categoría es la menos desarrollada en los libros de paisaje y que, en conjunto con los secundarios, definen la sutileza o calidad de un proyecto de paisaje. Es objetivo de este trabajo de investigación averiguar la existencia de nuevos atributos paisajísticos que se encuentren en función de infancias recreadas.

Los nuevos atributos vegetales se refieren a una manera intencionada de mirar la vegetación desde la óptica de la niñez. Así, podemos pensar a las plantas como elementos capaces de multiplicar las experiencias vividas en las infancias en un espacio determinado. También, como generadoras de ámbitos que permitan el diálogo entre y con Ixs niñxs, que habiliten lo nuevo. A su vez, pueden funcionar como puentes conectores entre el pasado, presente y el futuro, permitiendo rescatar la memoria del lugar en clave de proyección. En este sentido, Jelin (2001), marca a la memoria como un "proceso subjetivo, anclado en experiencias y en marcas simbólicas y materiales" (p.27) y la reconoce como objeto de disputas. Lo que implica un rol activo productor de sentido de esa memoria por parte de los participantes, de manera tal de generar sentido al pasado. Si bien este es un tema complejo de abordar, tal cual lo menciona Jelin (2001), pensamos a las infancias como creadoras de resignificaciones de la memoria. Pensar en ámbitos donde sea posible que tenga lugar, en términos de debate público, la memoria desde y para la niñez nos parece interesante como aporte inclusivo a la discusión colectiva. Brindar la posibilidad de que las plantas formen parte de la memoria colectiva e individual abre múltiples dimensiones a un ámbito de juego. 
En otro sentido, características tales como la caída de las hojas en el otoño, las flores para cortar y percibir, el arbusto que auspicia de casita, el cantero que se replanta anualmente, las plantas que pinchan y las que son comestibles, las plantas "venenosas", son algunas de las categorías que nos interesa explorar cuando hablamos de diversidad de experiencias y nuevos atributos tipológicos. Sólo una pequeña cantidad de especies permiten esas experiencias y es objetivo de esta tesis acercarnos a conocer cuáles son, qué vivencias nuevas surgen en esta búsqueda y si se expresan hoy en las plazas platenses.

Los nuevos atributos serían de orden secundario o terciario específicos para un proyecto para las infancias, ya que los primarios son universales para cualquier propuesta de paisaje. Si un proyecto de paisaje, cualquiera sea, tiene mal resuelto la categoría de los principales (magnitud, hábito vegetativo, silueta específica), difícilmente se pueda cumplir el objetivo por el que se lo convoca. Con lo cual, para dar lugar a las particularidades o sutilezas que eleven la calidad del mismo se tienen que tener definidos de manera exitosa los atributos primarios. Una vez determinada la estructura general del sitio, se trabajará en base a los detalles, en nuestro caso una mirada de vegetación en función de las infancias.

La posibilidad de clasificar las plantas a partir de una mirada desde las infancias permitirá pensar proyectos que contengan una mayor diversidad de experiencias. En este sentido, una de las claves para pensar la multiplicidad de vivencias en un ámbito determinado es la categorización de los elementos vegetales. Si se clasifica la vegetación desde la niñez y a partir de allí se puede constituir en una herramienta proyectual, será posible configurar ámbitos más diversos que formen parte de una Infraestructura Verde Recreativa.

Las preguntas que buscamos responder entonces son: ¿es la tipología vegetal una herramienta proyectual para la conformación de ámbitos de juegos para las infancias? ¿Cómo pueden clasificarse las plantas de manera tal de aportar a la conformación de infraestructura verde recreativa para las infancias? 


\subsubsection{Hacia una infraestructura Verde Recreativa}

Como se señaló anteriormente, buscamos comprender el problema del paisaje como motor en la recreación de infancias. En este sentido, el trabajo de investigación, cultiva la mirada de la vegetación para conformar una infraestructura verde recreativa. Según Calmels (2013), el vínculo entre naturaleza y niñez se encuentra alejado actualmente en la ciudad. Calmels (2013) plantea que: "el juego del niño de ciudad está alejado de cinco condiciones ... una de ellas era jugar en y con la naturaleza" (p.41). Anteriormente se establecía un acceso directo, de cercanía y contacto con diversos animales e insectos que habitaban la vegetación de jardines, fondos, baldíos y terrenos sin nombre, incluso arroyos y zanjas (Calmels, 2013). En la actualidad, son los espacios públicos los únicos capaces de regenerar ese vínculo perdido.

Aquí estudiamos el paisaje y específicamente el componente de vegetación como infraestructura verde recreativa para la generación de ámbitos para niñxs dentro de los espacios verdes públicos de la ciudad de La Plata. Para ello, se considera necesario precisar algunos conceptos. En este sentido, se comparte la idea de Fernando Carrión (2010) de que el espacio público es un ámbito o escenario de la conflictividad social que puede tener distintas funciones según los pesos y contrapesos sociales y políticos. Se estudia el espacio público como ámbito contenedor de la conflictividad social (Carrión, 2010) o para la integración social. En palabras de Jordi Borja (2000, p9):

El espacio público es el de la representación, en el que la sociedad se hace visible. La historia de la ciudad es la de su espacio público. Las relaciones entre los habitantes y entre el poder y la ciudadanía se materializan, se expresan en la conformación de las calles, las plazas, los parques, los lugares de encuentro ciudadano, en los monumentos. Es un espacio físico, simbólico y político.

Buscamos realizar un aporte en ese sentido. Las plazas y parques son una parte del espacio público de una ciudad y se encuentran formados por "un conjunto de ámbitos y canales que los conectan" (R. Opel, comunicación personal, 12 de Septiembre de 2016). Augé (1995, p.45) cita a Certeau (1990), indicando que el espacio es un "lugar practicado", un "cruce de elementos en movimiento". A partir de allí, Augé (1995) plantea que el lugar es un conjunto de elementos que 
coexisten en un cierto orden, podríamos simplificarlo como lo que se encuentra planificado y construido. El espacio es la animación de estos lugares por el desplazamiento de un elemento móvil. Teniendo en cuenta estas definiciones entonces un espacio verde es un conjunto de lugares (construido) que conforman ámbitos y canales que admiten ciertas funciones.

El trabajo de investigación, toma como dimensión principal de los espacios verdes públicos a los lugares y, por lo tanto, nos referiremos a todo lo construido que los constituye (solados, dispositivos lúdicos, equipamientos, vegetación implantada). En este sentido, estaremos señalando principalmente a la dimensión construida del mismo. Según el Código de Ordenamiento Territorial y Uso del suelo de la municipalidad de La Plata, es el Estado municipal el principal gestor del espacio público. De manera análoga, el Estado provincial posee el Decreto/Ley 8912 de Ordenamiento Territorial y Uso del Suelo. Sin embargo, en ninguna de las normativas existe una reglamentación específica de los ámbitos de juego para niñxs.

Por otro lado, definimos a los ámbitos para niñxs como los lugares donde la actividad principal que se podría desarrollar es la actividad lúdica o zonas de estar de niñxs. Cuando existe un lugar delimitado donde se podría desarrollar de manera satisfactoria una actividad decimos que nos encontramos en un ámbito, que, según las definiciones aquí mencionadas, es considerado también un espacio. 
En este sentido, una docente entrevistada en el marco de una investigación doctoral ${ }^{13}$ (p. 194) expresó:

Si uno genera en los suyos, si a mí me gusta ir a la plaza, y, bueno, yo genero que ellos vayan a la plaza (aclaración: refiriéndose a alumnos de la escuela), porque a mí me parece buenísimo el espacio verde y que se trepen, que se trepen con otros. ¿Por qué? Porque genera otros vínculos, otras relaciones, genera comunicarse. Y porque son chicos, lo necesitan. No porque estamos en una educación especial; lo necesitan porque son chicos.

Es interesante el testimonio porque vincula lo que teóricamente se viene desarrollando. Aquí, el espacio verde público (la plaza), es vivido como un ámbito compartido donde se generan vínculos, relaciones, comunicación. En términos de Carrión (2010), conflictividad social o encuentro e integración social. En términos de Augé (1995), la existencia de un espacio.

La formación del tesista (paisajista), constituye una mirada particular para la conformación de dichos ámbitos, donde se busca indagar sobre la vegetación como parte integrante de las infancias en los espacios verdes de la ciudad, qué rol cumple y cómo podría integrarse a la idea de recrear infancias para poder conformar una Infraestructura Verde Recreativa.

En este sentido, las plantas constituyen un universo inexplorado por gran parte de la sociedad. Si bien todos convivimos con ellas, en muy pocos casos comprendemos la infinidad de procesos ecofisiológicos que suceden en un vegetal que permiten la vida, no sólo de él mismo, sino de nosotros como humanidad. La ciudad como artefacto urbano sólo posee una infraestructura viva: la vegetación. Esta capa verde es la que permite hacerla habitable a partir de un conjunto de procesos de captación de carbono, producción de oxígeno, reducción de contaminantes, entre otros, muy bien desarrollados en el campo de la Arboricultura Urbana, Paisaje y Paisajismo y Arquitectura Paisajística (Dowhal, 2016).

${ }^{13}$ REDONDO, Patricia (2016) La escuela con los pies en el aire: Hacer escuela, entre la desigualdad y la emancipación. La Plata, Argentina: Universidad Nacional de La Plata, Facultad de Humanidades y Ciencias de la Educación. Disponible en: http://www.memoria.fahce.unlp.edu.ar/tesis/te.1279/te.1279.pdf 
La infraestructura verde, en el mejor de los casos, sólo nos detenemos a mirarla, contemplarla. Esta visión, a veces romántica, de la naturaleza conforma una mirada cultural de la misma. Este ser naturaleza como ser cultural aporta complejidad a la temática y puede ser abordada mediante múltiples dimensiones. En nuestro caso, ese ser naturaleza cultural, que denominamos paisaje, tiene por objetivo estudiarlo desde una mirada de las infancias.

El trabajo de investigación, toma como marco teórico de de gestión territorial mayor a la Infraestructura Verde Urbana. A partir de allí estudia la vegetación urbana para las infancias con el objetivo de poder constituir una Infraestructura Verde Recreativa (IVR) y por lo tanto un modelo de comprensión y gestión de la misma. La vegetación se convierte en una Infraestructura Verde Recreativa cuando existe un proyecto de infancias que la sustenta, cuando hay un manejo de la misma con un sentido determinado. 


\subsection{ANTECEDENTES}

\subsubsection{Clasificación de las plantas.}

Carlos Linneo (1707-1778) fundó en 1753 con su publicación Species plantarum una forma de clasificar las plantas, basada en su evolución y la herencia y promulgó el sistema binario de clasificación de las especies vigente en la actualidad. La taxonomía de plantas se basa en caracteres botánicos, donde a partir de singularidades morfológicas, principalmente, se establecen géneros y familias de especies. Sin embargo, para el paisajismo la taxonomía botánica tradicional, no fue suficiente para poder resolver el proyecto. En este sentido, el paisajismo moderno desarrolló el concepto de tipología vegetal. La tipología vegetal se define como: "la suma de atributos específicos que tienen la capacidad de expresar y satisfacer la intencionalidad y argumento de un proyecto de paisaje" (Benassi, 1994). Esta clasificación de las especies permitió a los paisajistas hacer operables los elementos vegetales bajo categorías específicas del paisajismo y también estableció un lenguaje que puede ser compartido en la interdisciplina concurrente en un proyecto de paisaje. Sin embargo, no se encuentra desarrollada la categoría de atributos terciaros que permitirían hacer operables los elementos vegetales desde la visión específica de la creación de ámbitos de juego para las infancias. El trabajo de investigación toma el concepto de tipología vegetal y se funda en el estudio de una nueva manera de ver los atributos tipológicos, principalmente terciarios, bajo la mirada de las infancias.

\section{Situación de las plazas platenses.}

La tesis doctoral de Domínguez (2013) aborda la valoración del patrimonio cultural de las plazas platenses. Allí, existe un aporte fundamental para la comprensión de cada plaza en su dimensión histórica y patrimonial. En dicho estudio se comprende la dimensión urbana, arquitectónica y patrimonial de los espacios verdes de la ciudad de La Plata. Sin embargo, se excluyen explícitamente del análisis los juegos infantiles de las plazas, asegurando que se encontraron presentes en todos los espacios verdes de la ciudad. Esta investigación, estableció como antecedente la existencia de 
ámbitos para las infancias en todos los espacios verdes de la ciudad, sin definirlas ni tomarlas como eje de análisis.

En otro sentido, Benassi (2013) aborda en su tesis doctoral el análisis de la vegetación como infraestructura verde urbana de todos los parques y plazas de la ciudad de La Plata, excluyendo el paseo del Bosque y los parques Vucetich, Castelli y Alberti. En dicho análisis se pueden encontrar las proporciones de solados permeables e impermeables, los porcentajes de cobertura arbórea y de perenne-caduco, el inventario total de árboles y arbustos de las plazas y parque Saavedra, su estado fitosanitario y las especies faltantes según diseño original (Figura 3). Esta información constituye la base fundamental para el estudio de la vegetación en los ámbitos de juegos. A partir de una actualización inventarial se pudo contar rápidamente con datos sobre la vegetación de todos los espacios verdes. En este sentido, se cuenta con autorización del autor (Benassi, 2013) para la actualización de los datos disponibles y su utilización en el trabajo de campo.

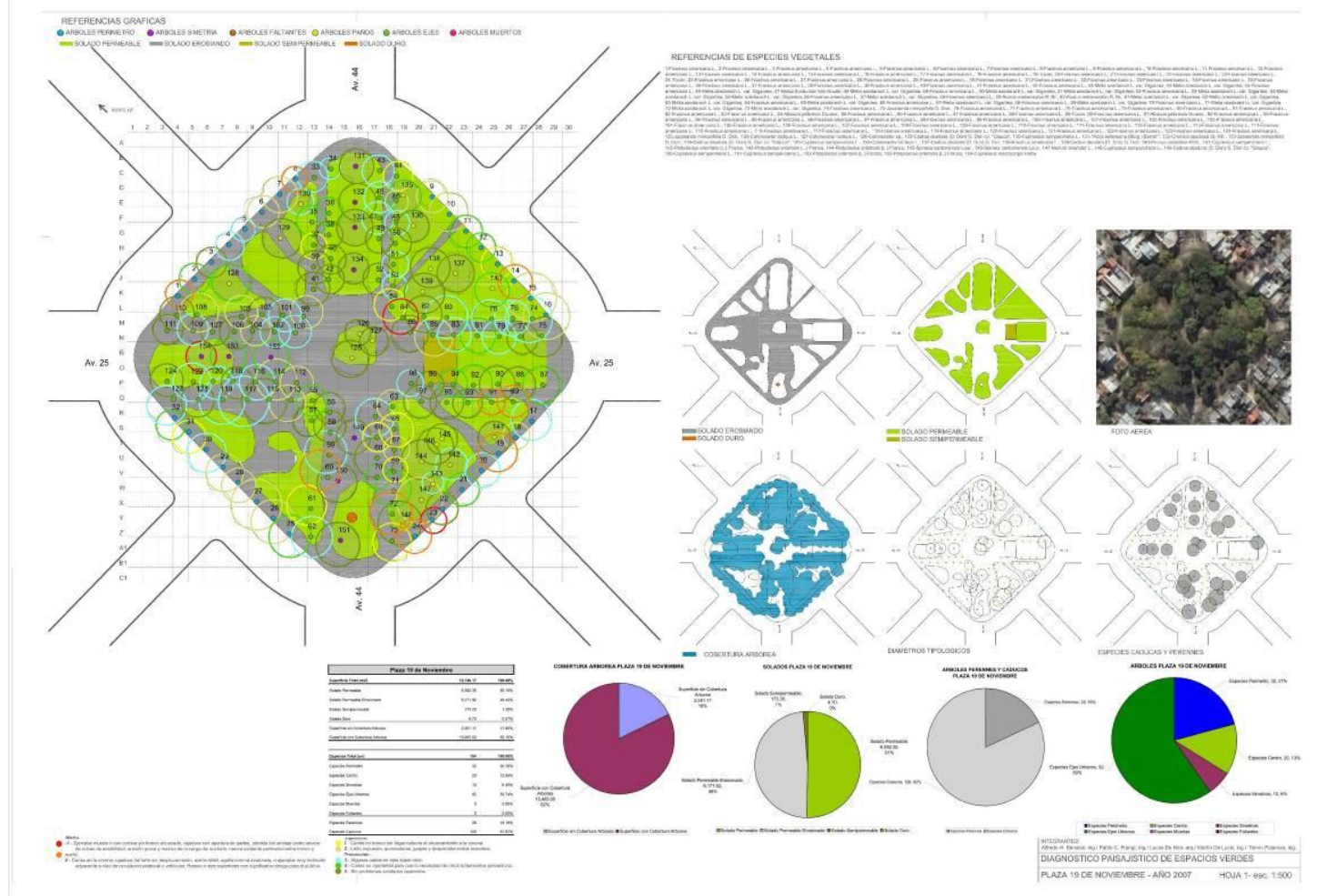

Figura 3: Plaza 19 de Noviembre con el inventario de vegetación y de solados. Ciudad de La Plata. Año 2010. Tesis doctoral Benassi, 2013. 


\subsubsection{Referencia de parques infantiles}

En la provincia de Santa Fe, en Rosario y ciudad de Santa Fe, existen dos experiencias destinadas específicamente a las infancias: el Tríptico de la Infancia y el Tríptico de la Imaginación ${ }^{14}$. En los trípticos se aborda, principalmente, la dimensión poética en la infancia, con un dispositivo de gestión estatal efectivo y exitoso. En estos casos, la vegetación toma mayor importancia, determinando los ámbitos e incluso los contenidos (como en la Granja del Tríptico de la Infancia o la montaña mágica en el Jardín de los Niños, ver Figura 4). La referencia de estos parques sirve para el tema de tesis para el estudio de los ámbitos con dispositivos lúdicos en clave poética y también como clave para la construcción de un camino hacia una política emancipadora.

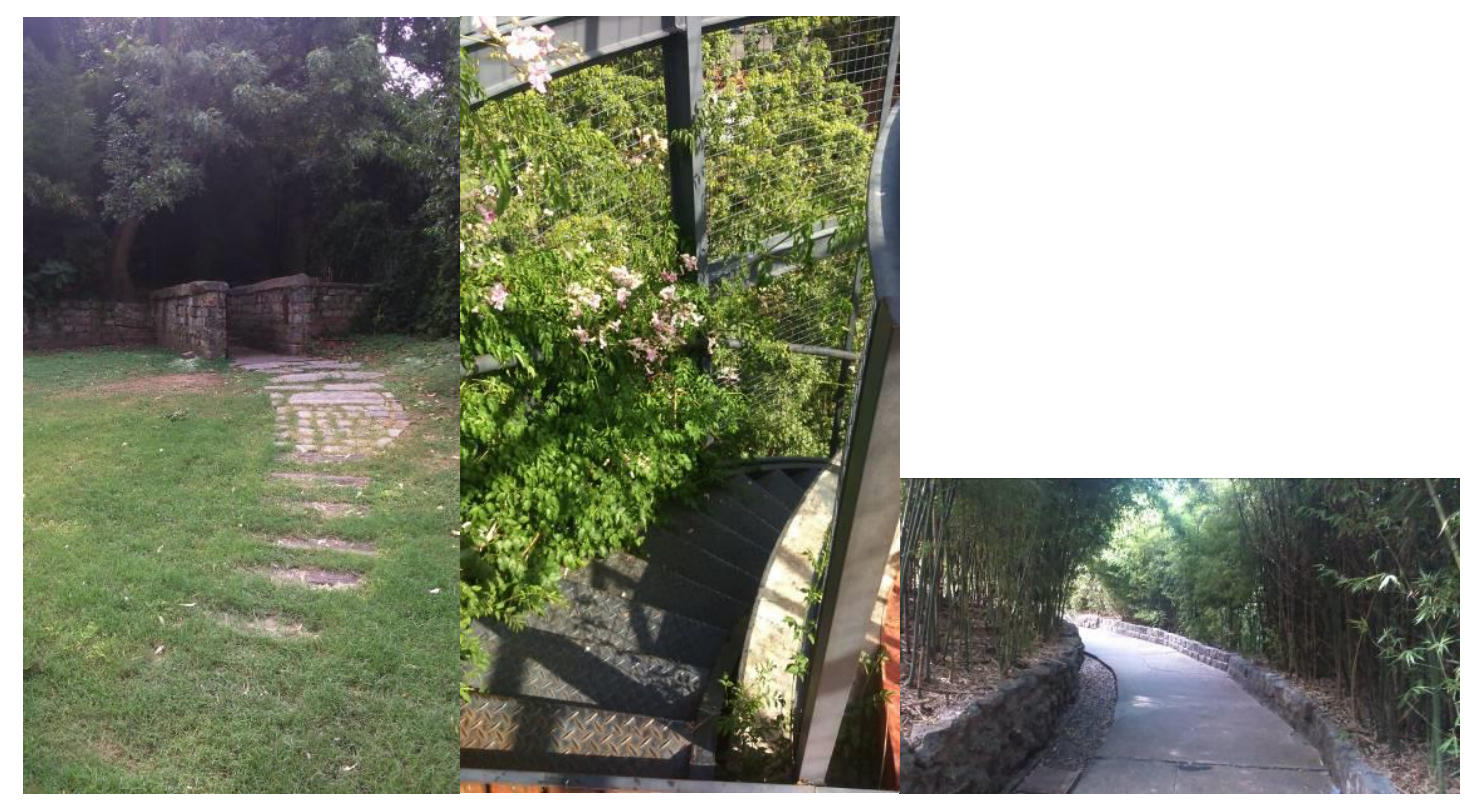

Figura 4: Bosque en El Jardín de los Niños en la Montaña Encantada. Ciudad de Rosario, Santa Fe. Año 2015.

Se realizó una visita al Tríptico de la Infancia y se pudo constatar las múltiples dimensiones que se abordan desde la conformación del espacio. En este sentido, se observó que el mayor desarrollo respecto de la vegetación se dio en la Granja. Allí, niños y niñas pueden vivenciar la producción de alimentos a partir de un trabajo educativo en la huerta, así como también habitar bosques con

\footnotetext{
${ }^{14}$ Ambas propuestas fueron desarrolladas por la Secretaría de Cultura y Educación de la ciudad de Rosario y por el Ministerio de Innovación y Cultura de la provincia de Santa Fe, respectivamente, durante la gestión de María de los Ángeles González quien junto a sus equipos de trabajo desarrollaron la propuesta innovadora.
} 
memoria, lomadas para jugar y un jardín de mariposas (ver Figura 5 y 6 ). En la página oficial del sitio se presenta al paisaje del lugar como:

Un espacio para descubrir árboles que son casas, lomas, puentes y un laberinto cerca del estanque, escuchar el agua y la danza del cuerpo. Entre los álamos el viento baila en remolinos, el viejo bosque habla el idioma de las estaciones, un tiempo redondo que cruje en las hojas y pinta las flores.

Poesía y vegetación conforman un mismo idioma denominado Paisaje. Esta idea se comparte en el trabajo de investigación al definir el paisaje como un concepto netamente cultural. Aquí, en la Granja de la Infancia en Rosario, comienza a aparecer un paisaje para la niñez que habilita y habita experiencias múltiples relacionadas a la naturaleza.

Es interesante rescatar el desarrollo de la provincia de Santa Fe porque es una política de un Estado. Esto nos permite reflexionar que es posible un pensamiento nacional respecto al tema y habilita perspectivas latinoamericanas desde lo vivido y experimentado en condiciones reales que nos permitan elaborar conceptualizaciones teóricas propias. Quizás, el desafío principal del trabajo de investigación, sea aportar lineamientos teóricos que potencien futuros desarrollos.
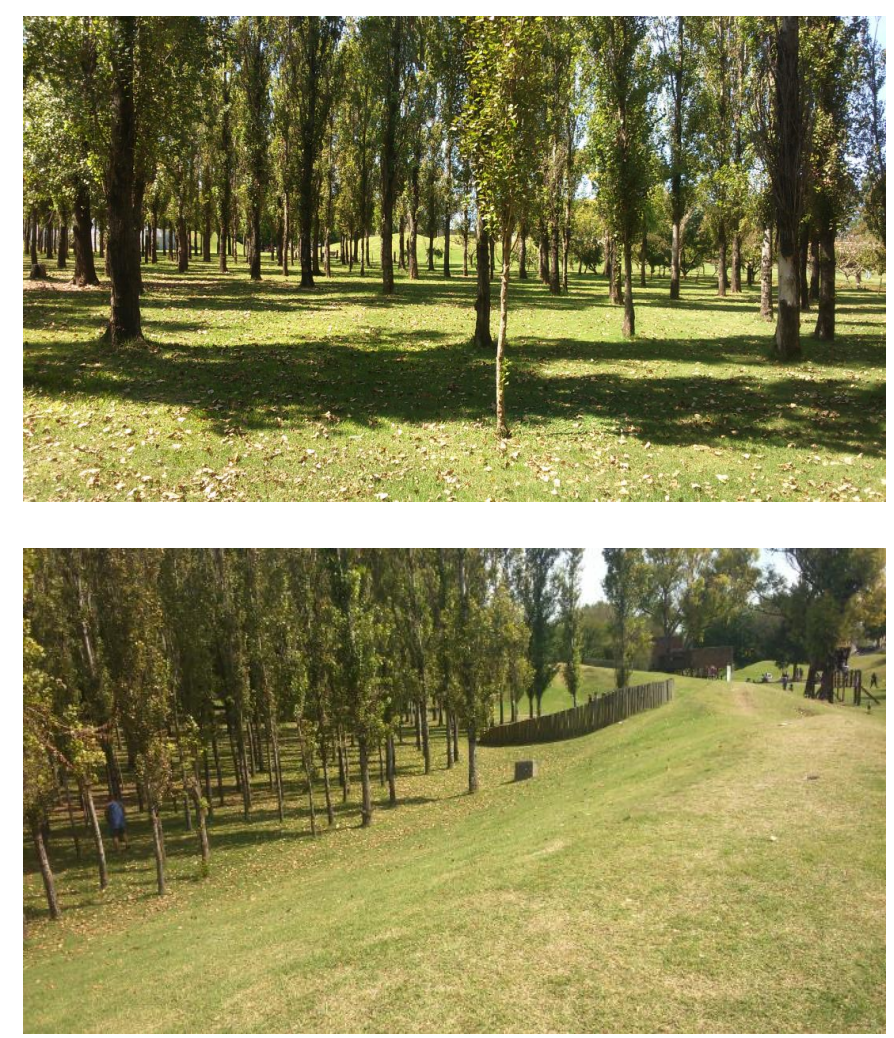

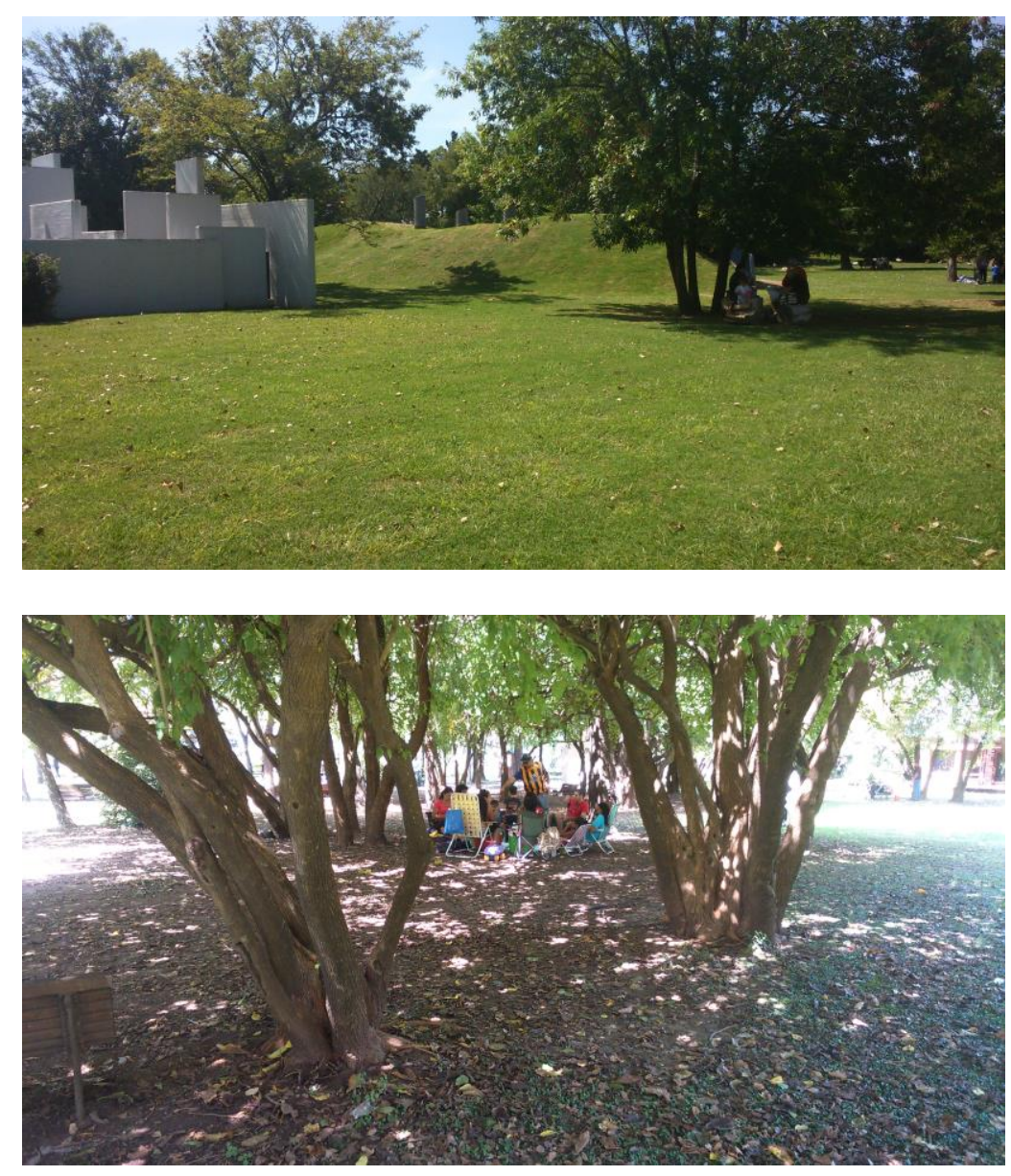

Figura 5: Bosque de Álamos y lomadas. Bosque de Papel. Ciudad de Rosario, Santa Fe. Año 2015 

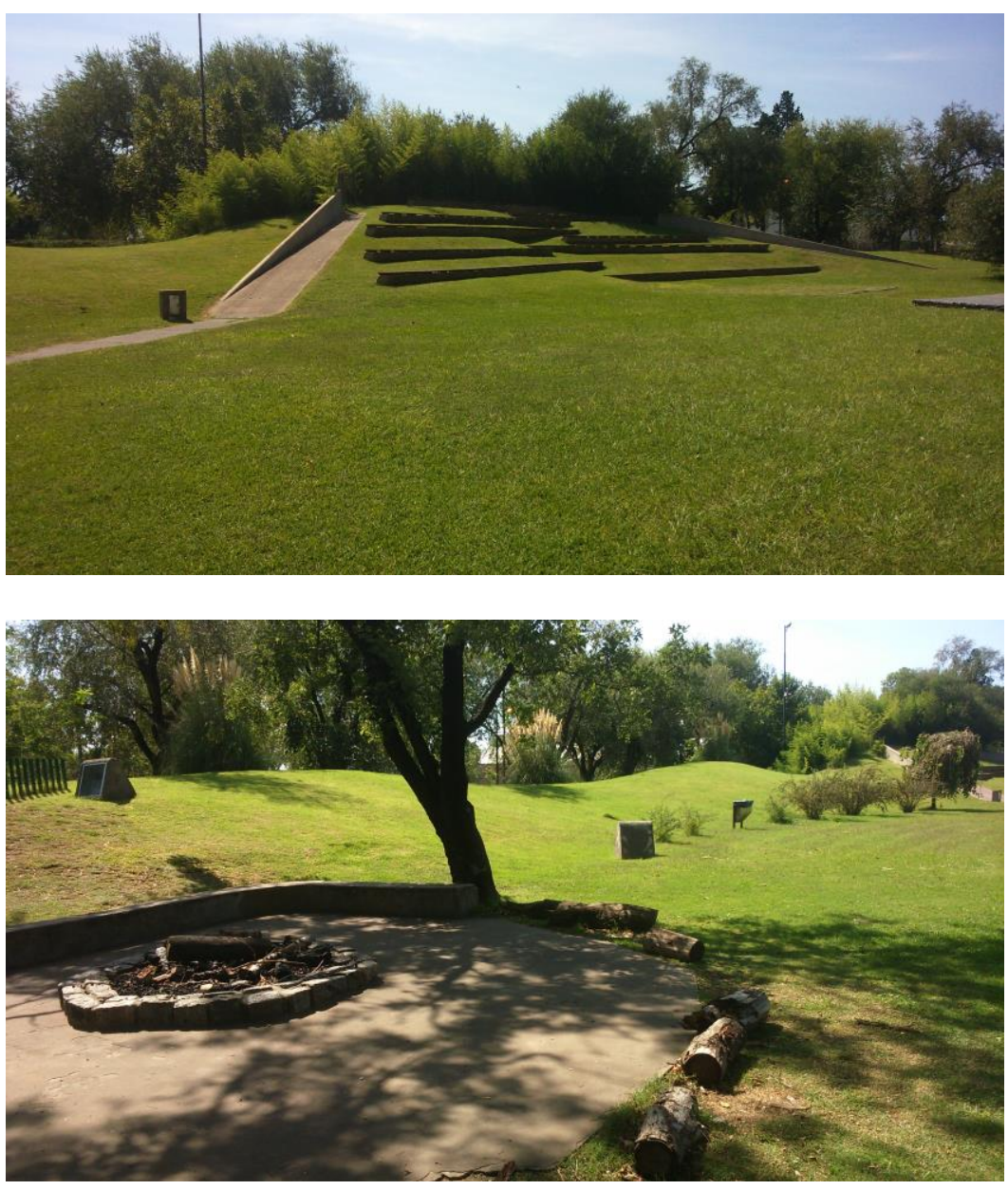

Figura 6: El Anfiteatro y el fuego. Ciudad de Rosario, Santa Fe. Año 2015.

Finalmente, en la publicación "Nuevos Parques Infantiles" (2012) se sintetiza una recopilación de las principales intervenciones en el mundo en zonas de juegos en las últimas dos décadas. Se encuentran recopilados 84 espacios de juegos y parques. Es interesante destacar las referencias 0 trabajos con la naturaleza en los mismos. En siete espacios se hace referencia al Bosque como bosque encantado (ver Figura 7), de niebla, de maderas, de palos. Sin embargo, en ningún caso de los 84 descriptos aparece el bosque como categoría de diseño o como conformador del espacio, las referencias al bosque son metafóricas a partir de diseños con materiales que no son vegetación. 

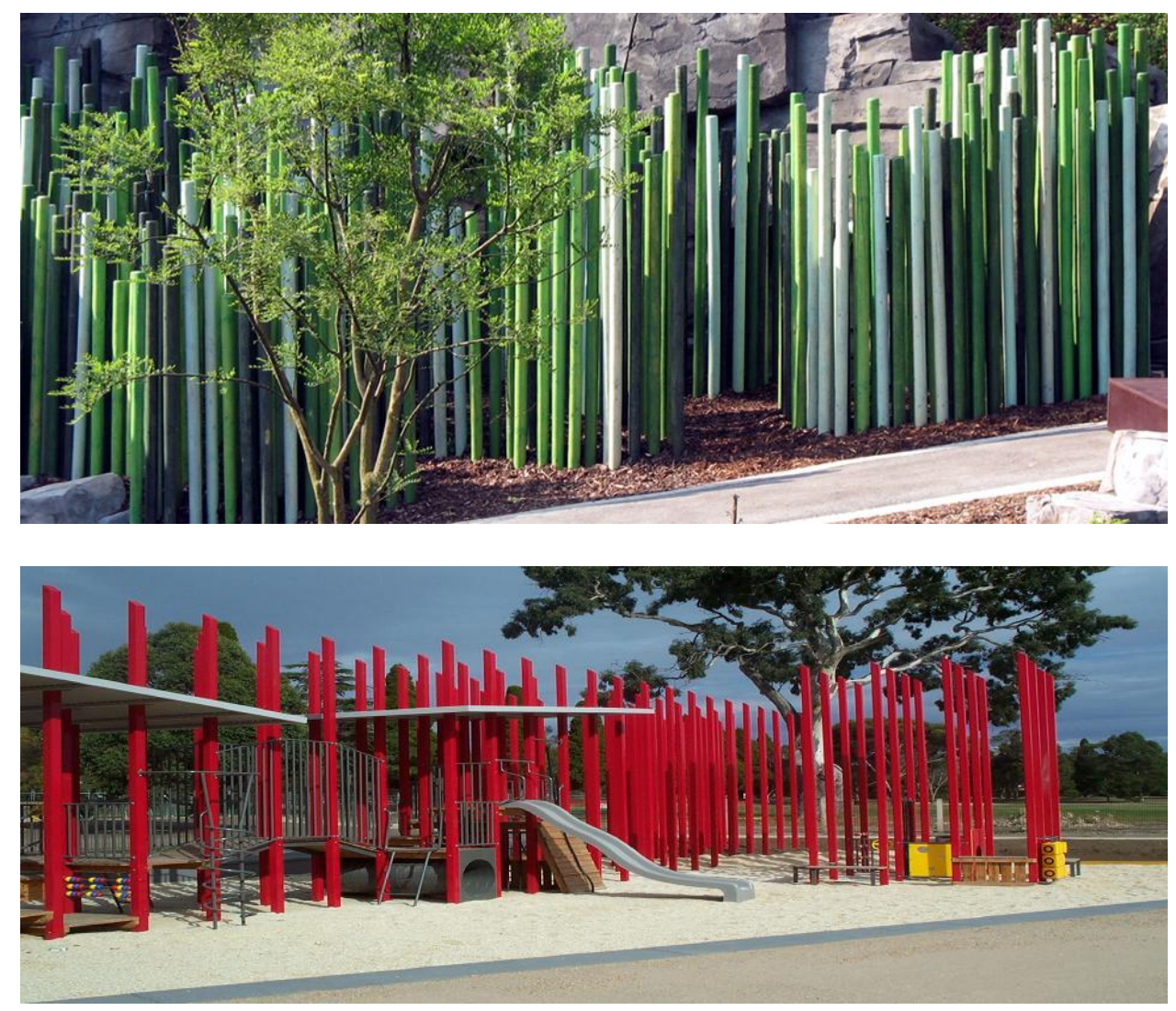

Figura 7: El "bosque encantado". Metáfora sobre el bosque construido a partir de palos de madera vertical. Imagen superior: Zoo Wuppertal, Wuppertal, Alemania, http://www.rehwaldt.de. Imagen inferior: Springthorpe, Inglaterra. http://www.pga.net.au

Existen 10 ejemplos en los que se realiza un trabajo con la vegetación, tomando la naturaleza como una aventura o como parte intrínseca del diseño, brindando sombra con árboles en los ámbitos. Aparece en un caso la "Casita del árbol" pero lamentablemente ubicada sobre un ejemplar muerto con sus ramas mutiladas (ver Figura 8). Finalmente en ocho parques aparece la referencia metafórica a elementos de la naturaleza (gran duna sin arena, hojas de árboles hechas de metal, etc.). Es de destacar que la publicación que posee las referencias mundiales de plazas o parques con juegos infantiles fueron pensados en un $90 \%$ sin tener en cuenta a la naturaleza como elemento estructurante y formador del ámbito de juego, ubicada, principalmente, en un lugar marginal en los diseños, ligado a la formalidad en la conformación del lugar y no como un elemento de diseño del ámbito lúdico. Incluso en algunos ejemplos se denomina a la vegetación como especies "decorativas" no invasoras y fáciles 
de mantener. También aparece en algún caso la necesidad de que los dispositivos lúdicos funcionen para mantener la actividad infantil aislada del entorno natural sensible como algo positivo y buscado.

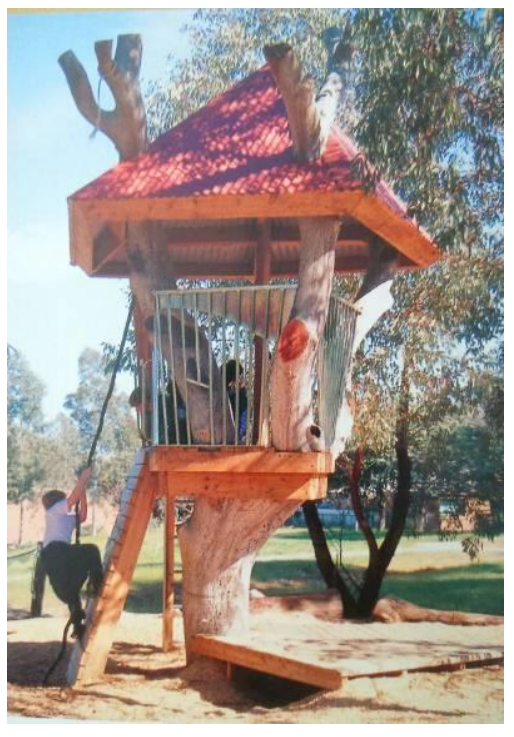

Figura 8: "Casita del árbol". Casa de juegos ubicada sobre un árbol muerto con las ramas mutiladas. Tea Tree Guly, Australia. Brotto (2012)

También existe una gran valoración de otros elementos naturales como las arenas, las rocas y el agua conformando verdaderos dispositivos lúdicos con una magnífica experiencia sensorial y una gran interacción entre el elemento y lxs niñxs. En el libro sólo se presenta un caso de parque latinoamericano en Perú conformado a partir de elementos reciclados (Basurama, 2010).

Para culminar, es de destacar el trabajo realizado por Toshiko Horiuchi Mac Adam (ver Figura 9) quien retoma una antigua técnica de telar oriental para construir verdaderos dispositivos lúdicos para todas las edades. Esta referencia se liga con lo planteado por Redondo (2016) cuando analiza los contextos institucionales de trabajo en la escuela. Allí se plantea la existencia de una urdimbre institucional, un tejido que contiene propuestas pedagógicas innovadoras y exitosas, haciendo referencia a los telares del Norte Argentino. Esta idea del tejido que contiene, envuelve pero no asfixia, protege pero no encierra, pareciera ser universal. Quizá si pensamos los ámbitos para las infancias esta idea sea una manera de abordarlos. 

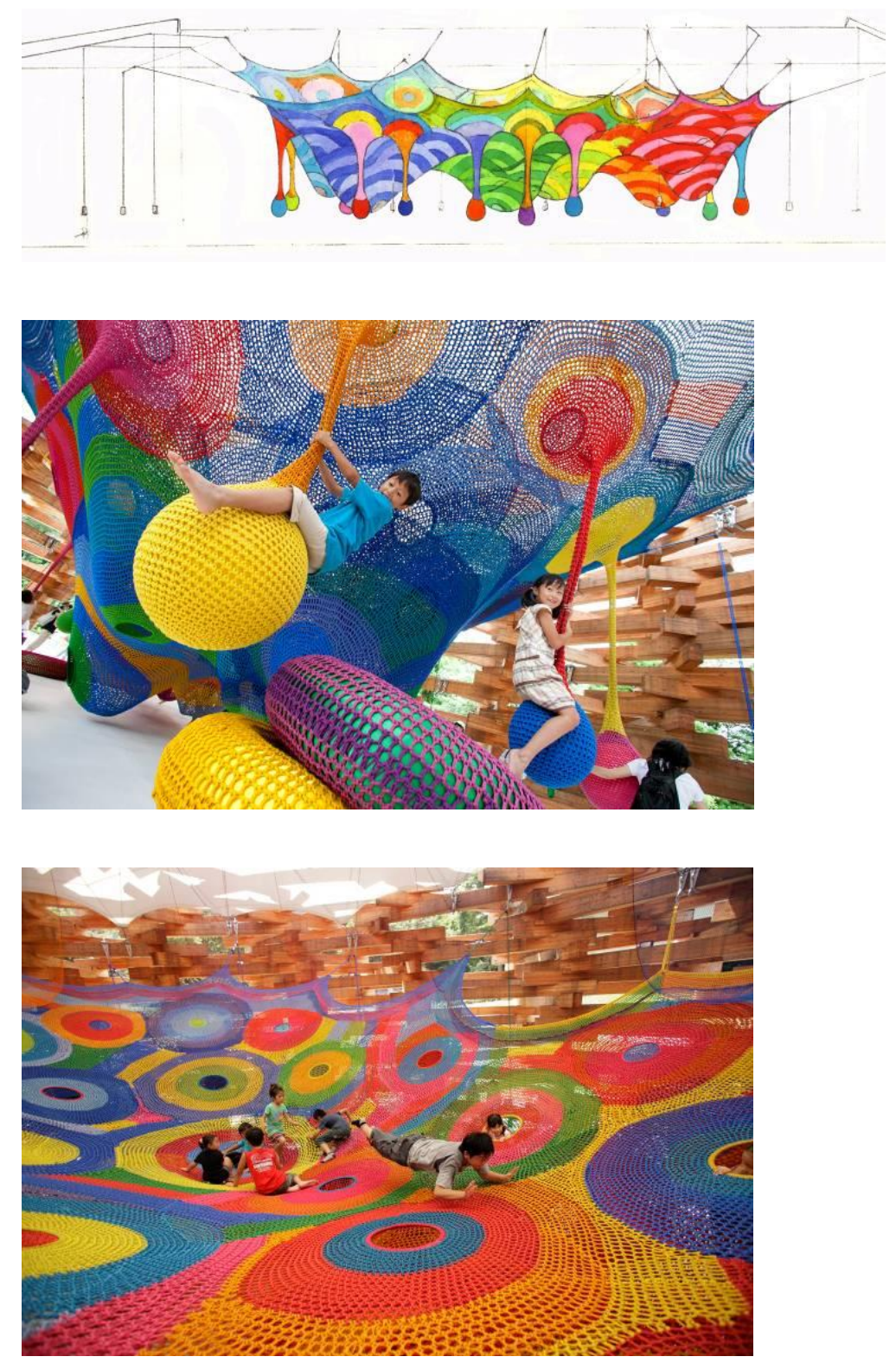

Figura 9: Tejidos lúdicos. Toshiko Horiuchi Mac Adam. Fuente imagen superior:

https://www.volviendoanuncajamas.wordpress.com . Fuente imágenes inferiores: http://www.archdaily.com.

\subsubsection{Aportes desde el arte.}

La película animada estadounidense Inside Out (denominada Intensa-Mente en Hispanoamérica) (Rivera, Docter y Del Carmen, 2015), forma parte del estado de la cuestión porque sintetiza en un esquema visual la hipótesis de cómo los sentimientos básicos en un niño (TristezaAlegría) se van complejizando en una maquinaria cada vez más contradictoria y refundante de las personalidades. En esta tesis compartimos la idea planteada en la película de que existe en las 
infancias un motor fundamental en la formación de los humanos ligado a las emociones y sentimientos (en la película planteados como Alegría, Tristeza, Temor o Miedo, Ira o Furia, Asco o Desagrado).El trabajo de investigación busca recrear infancias que se constituyen, entre otras cosas, en la diversidad de experiencias. Este ejercicio, tiene que ver con la dimensión social y colectiva de las infancias pero también con la dimensión individual, la conformación de las personalidades. Inside-out sintetiza de manera metafórica la dimensión individual sobre la conformación de las personalidades. Ahora bien, esta consideración no excluye el análisis sobre la película como dispositivo biopolítico hegemónico que busca crear un tipo de infancias determinadas que no comulgan con la idea de recrear. Sin embargo, el hecho artístico posee una dimensión creativa destacable que el autor valora para la comprensión de la subjetividad individual de las infancias.

\subsubsection{Estudio de la normativa existente relativa a los espacios de juegos.}

Respecto a la normativa específica para ámbitos de juegos, se relevó el Manual de Seguridad en Patios de Juegos de la Ciudad de Buenos Aires; la Normativa del Instituto Argentino de Racionalización de Materiales (IRAM) N:3655 Juegos Infantiles de Instalación Permanente al Aire Libre; la Normativa Europea del Comité Europeo de Normalización: UNE 1176:2008 Equipamiento de las Áreas de Juegos y Superficies y 1177:2008 Revestimientos de las superficies de las áreas de juego absorbedores de impactos. Determinación de altura caída crítica; y la Normativa Española UNE 147103:2001: Planificación y gestión de las áreas y parques de juego al aire libre.

En este sentido, la Normativa Española UNE 147103:2001: Planificación y gestión de las áreas y parques de juego al aire libre homologada con la Normativa Europea, se distingue entre espacio de juego (ámbito no pautado) y ámbito de juego. Además distingue una tercera categoría: área cercana a la naturaleza que la define como una superficie con una gran parte de elementos naturales para el juego y la aventura, como por ejemplo, jardines y especies arbóreas, en lo posible con capacidad de autoregeneración, piedras y superficies naturales. 
También la norma define la accesibilidad según la edad de Ixs niñxs para que puedan acceder por sus propios medios: 1000 m mayor a 12 años, 400 m de 6 a 12 años y 200 m menores de 6 años.

Además plantea como generalidades que los ámbitos de juegos son: "Para fomentar desarrollo corporal, mental y lúdico de niños y jóvenes deben existir diseño variados y esto puede lograrse entre otros con vegetación". Es interesante que en la normativa se encuentra presente constantemente el elemento vegetación y la naturaleza en general. Así, en el punto de estímulo de los sentidos y del movimiento aparece el empleo de elementos relacionados con la naturaleza como arena, tierra, corteza, madera, grava así como también plantas (con sus distintas formas y cambios de la floración, coloración, etc.), se estimulan los sentidos para la percepción del mundo exterior - olfato, gusto, tacto, oído y vista -

La norma plantea que las zonas de juego para niños pequeños deben ser controlables visualmente. Sin embargo, no especifica desde dónde y hacia dónde.

En lo referido a la creación de espacios se refiere a que la diversidad en la distribución del espacio a través de árboles, matas, arbustos, y hierbas, posibilitan diversas actividades de juego y hace que los niños se sientan protegidos. En este sentido, aconseja la plantación de árboles de hoja caduca, con el fin de contar con zonas soleadas en invierno y umbría en verano.

La norma también plantea superficies por escala de municipio o residencia. Y luego determina los distintos juegos: Juegos con arena y barro, Juegos con agua, Aparatos para parques de juego, Juegos de pelota, Propuestas especiales, Zonas para la integración, Áreas para el fomento de la vida en la naturaleza: en áreas cercanas a la naturaleza se ha de prestar especial atención al diseño y el tipo de especies vegetales empleadas, respetando el entorno. En el caso de áreas de gran superficie de uso intensivo se ha de fomentar especialmente la variedad de especies, las posibilidades de diseño así como la capacidad de regeneración forestal. También fija el cultivo de plantas como actividad en las áreas de juego asistidos (por ejemplo por un tutor). 
Existe un apartado específico para la vegetación: Césped. Plantación y vegetación espontánea: se deben escoger especies variadas, adecuadas para el entorno y resistentes. Arbustos y árboles con frutos comestibles pueden ampliar el valor del juego y la experiencia natural. Las plantaciones deben cumplir con la función de protección contra el clima, es decir del viento, los rayos solares y la lluvia. Si el tamaño de las superficies lo permite, las áreas pueden abandonarse también a la sucesión natural. Finalmente, plantas con riesgo: por ingestión principalmente de frutos.

Finalmente, las áreas de juego deben estar delimitadas para separarlas de calles, aparcamientos, vías de tren, aguas profundas, pendientes y otros peligros similares. No deben poder ingresar animales a las áreas de juego.

También se plantea una señalización de las áreas de juego y que los niños de 0-3 años deben estar acompañados por adultos todo el tiempo.

Las áreas pueden estar delimitadas o no. Áreas delimitadas: áreas de juego que se encuentran limitadas físicamente mediante un cerramiento que no puede ser traspasado fácilmente, obligando a que la entrada o salida de las mismas se realice a través del acceso o accesos previstos. Áreas no delimitadas: Áreas de juego que no se encuentran limitadas físicamente mediante un cerramiento o si éste existe, no presenta un impedimento para acceder 0 abandonas las mismas desde distintos puntos.

Por otro lado, la norma UNE 1176 y 1177: 2008: Equipamiento de las áreas de juego y superficies la primera. La segunda: Revestimientos de las superficies de las áreas de juego absorbedores de impactos. Determinación de altura caída crítica, respectivamente. En estas normas, se plantea la necesidad de asumir riesgos como característica esencial del juego en todos los entornos en los que Ixs niñxs pasan un tiempo jugando. El juego pretende ofrecer a Ixs niñxs la posibilidad de encontrar unos riesgos aceptables como parte de un entorno de aprendizaje estimulante, desafiante y controlado. El juego debería dirigir a la gestión del equilibrio entre la necesidad de ofrecer conflictos y 
la necesidad de mantener a los niños a salvo de daños serios. En el juego, puede que la exposición a cierto grado de riesgo sea ventajosa, porque satisface una necesidad humana básica y proporciona al niño la posibilidad de aprender sobre los riesgos y sus consecuencias en un entorno controlado. Los niños necesitan aprender a enfrentarse al riesgo y esto puede provocar golpes, magulladuras e incluso a veces la rotura de una extremidad. El propósito de la norma es, primero y principalmente, evitar accidentes que produzcan incapacitación u otras consecuencias fatales, y en segundo lugar, reducir las consecuencias graves derivadas de los posibles contratiempos que inevitablemente se producirán por el afán de los niños de aumentar su nivel de competencia, ya sea social, intelectual o físicamente.

Para finalizar, el Manual de Seguridad para Patios de Juego de la Ciudad Autónoma de Buenos Aires y la norma IRAM N³655 se refieren principalmente a la construcción y disposición de los dispositivos lúdicos (tobogán, hamacas, calesita, etc.) de manera tal de poder reducir los riesgos graves por la instalación de juegos en espacios públicos y privados. Sin embargo, realiza un aporte muy acotado respecto a la conformación de los ámbitos de juegos. En ninguna de las dos se tiene en cuenta la vegetación.

Este escenario determina dos situaciones, por un lado la inexistencia de la vegetación como elemento de diseño constitutivo de un ámbito de juego. Y por otro lado, quizá más importante, la ausencia de normas básicas de manejo de las plantas, específicas para ámbitos de juegos infantiles, en términos de una gestión del riesgo en función del cuidado de Ixs niñxs. La categoría vegetación en los ámbitos infantiles queda relegada al manejo general de la misma que se pueda hacer en un Municipio o una provincia, desconociendo la importancia y especificidad del tema. 


\section{CAPÍTULO 2}

\subsection{OBJETIVOS}

\subsubsection{Objetivo general:}

- Indagar y descubrir las relaciones entre la infraestructura verde recreativa y las infancias para la conformación de paisajes recreados.

\subsubsection{Objetivos específicos:}

- Diagnosticar la disposición y el estado de los ámbitos de juego en los espacios verdes públicos de la ciudad de La Plata para comprender la infraestructura verde recreativa en el 2016 y su relación con las infancias.

- Relevar la vegetación, disponible en viveros comerciales de la región, que contribuya a la conformación de una infraestructura verde recreativa en función de la recreación de infancias.

- Desarrollar atributos tipológicos de la vegetación que permitan hacer operable la infraestructura verde recreativa para la recreación de infancias.

\subsection{HIPÓTESIS}

Se plantea una hipótesis general que se somete a indagación a partir del análisis de las hipótesis específicas:

Es posible establecer una relación entre las categorías de infancias y la infraestructura verde recreativa en los ámbitos de juego para niñxs. Esta relación se manifiesta de la siguiente manera:

Existe una concepción de infancias controladas y heterónomas que se expresa de manera normativizante en los espacios verdes analizados. Los ámbitos de juegos se construyeron de manera homogénea, con ausencia de complejidad de estratos vegetales, visuales plenas que admiten el control desde la adultez por sobre el cuidado de la niñez y con una distribución regular en todo el territorio estudiado. 
La homogeneidad se expresa en una misma batería de dispositivos lúdicos que aceptan un solo tipo de juego activo, motriz. Se visualiza también en la bajísima diversidad de especies vegetales, principalmente arbóreas y arbustivas, en un estado fitosanitario deteriorado. Por último, la distribución regular de los ámbitos de juego en todo el territorio no da cuenta de las particularidades y necesidades barriales en las que se encuentra inserto cada uno.

El estado y disposición de los solados, equipamientos y de las especies vegetales, determina una mirada de control sobre la niñez que limita los desarrollos autónomos de la misma. La idea de cuidado de la niñez, y por lo tanto el desarrollo de la misma en ambientes seguros, se encuentra ausente, reforzando la mirada controladora sobre la misma.

A su vez, la ausencia de un información respecto a las especies vegetales existentes, así como también de los antroposistemas naturales, en los ámbitos de juegos para niñxs constituye una forma de eliminación del conocer-se que atenta contra la conformación de espacios autónomos para las infancias. La vegetación existente no se encuentra asociada a ningún dispositivo educativo que pueda dar cuenta del patrimonio vegetal y los procesos ecológicos que se desarrollan en el mismo.

Por otro lado, la vegetación no posee una planificación en términos sincrónicos (complementación de usos y diversidad de los mismos) ni tampoco diacrónico. La misma se encuentra madura o sobre-madura demostrando una ausencia de dicha visión. El único camino diacrónico existente es el de la degradación por envejecimiento de la vegetación. Sin embargo, la presencia de elementos vegetales añosos permitiría establecer relaciones sincrónicas en términos de infancias, como continuidad o legado de las generaciones pasadas. Estos elementos vegetales podrían funcionar como conectores en el tiempo de las distintas generaciones de infancias, como testigos de lo que sucedió, sucede y sucederá. En otro sentido, la ausencia de complejidad de estratos vegetales, permite pensar en la necesidad de un re-diseño de los ámbitos de juegos, a partir de proyectos particularizados, que admitan los cambios diacrónicos, en términos de nuevos usos, que tuvieron y 
tienen las infancias. De esta manera, un análisis sincrónico de la vegetación con los usos actuales y futuros incorporaría una visión diacrónica para las infancias.

Finalmente, existe un universo de especies disponibles en viveros comerciales que es significativamente mayor al plantado actualmente y que son capaces de abastecer proyectos paisajísticos particularizados para infancias recreadas. La existencia de nuevos atributos terciarios permite hacer operable el universo vegetal disponible en función de las infancias.

Una mayor complejidad de especies y estratos vegetales es la clave para desarrollar una mayor diversidad de experiencias en las infancias. En este sentido, la posibilidad de establecer una nueva relación con la naturaleza en la que se pueda cosechar flores, trepar, disfrutar de los colores y la caída de las hojas, habilitar refugios para que circule el secreto, el diálogo y la intimidad en las infancias, donde exista el bosque, el descubrir y el peligro, entre otros, constituye una mirada particular sobre el universo vegetal. Esta mirada tiene que ver con la clasificación de las plantas a partir de los atributos terciarios.

Los atributos terciarios permiten clasificar en: los árboles que escenifican el otoño y producen un colchón de hojas, las plantas que tienen frutos y flores que se pueden cosechar, las que pueden ser comestibles, los árboles y arbustos que producen la sensación de bosque (mayor humedad y oscuridad), las plantas que producen por su arquitectura natural un refugio para niñxs, los árboles que admiten trepado, los que tienen una longevidad tal que traspasa generaciones completas, las plantas tóxicas y con espinas, las no recomendables por riesgo de caída y magnitud, entre otras. La hipótesis que se desarrolla refiere a que estos atributos son los que admiten la diversidad de experiencias a partir de la habilitación de ámbitos para nuevas vivencias. 


\subsection{METODOLOGÍA UTILIZADA PARA LA TOMA DE DATOS}

\subsubsection{Relevamiento de elementos construidos}

Durante el invierno y primavera del 2016, se relevaron los ámbitos de juegos de trece plazas ${ }^{15}$ de la Ciudad de La Plata. En este sentido se determinaron las siguientes variables:

Delimitación: se relevó se los ámbitos se encontraron delimitados o no y cómo se encuentra conformado dicho límite. Los límites pueden ser construidos: una reja, una pared o determinados por un tipo de solado o una implantación específica del dispositivo lúdico.

Tipos de pisos en la zona de juegos, se definieron:

- Permeable: césped.

- Semi-permeable: grava, piedras, conchilla, arena, tierra erosionada.

- Impermeable: solado, concreto.

Porcentaje de erosión: para ello se realizó una estimación visual como porcentaje de la totalidad del sector. Se consideró erosión cuando se observó desplazamiento de material (tierra, conchilla, etc.), suelo desnudo y compactado, surcos de drenaje no planificados que desplazan material de suelo. Se relevaron tres situaciones de erosión:

- 10-30 \%: se observan sectores con suelo desnudo, disfuncionalidades puntuales que con una breve intervención pueden revertirse. Se observa erosión principalmente por exceso de uso del ámbito.

- 30-50 \%: se observan áreas de suelo desnudo o desplazado, compactación en las proporciones entre 30 y $50 \%$ de la superficie total. Se afecta la funcionalidad del espacio en cuanto a circulación. Existen problemas estructurales de drenaje que requieren una intervención integral.

- Mayor a $50 \%$ : la zona se encuentra estructuralmente erosionada, con problemas serios de drenaje, desplazamiento de material, exceso de uso. Su estado se encuentra disfuncional en cuanto a circulaciones y uso. Se observa sobre sombreado que favorece la erosión, pendientes inadecuadas.

\footnotetext{
1519 de Noviembre (Av. 25 y Av. 44); Azcuénaga (Av. 19 y Av. 44); Belgrano (Av. 13 y calle 39); España (Av.7 y Av. 66); Yrigoyen (Av. 19 y Av. 60); Italia (Av. 7 y Av. 44); Moreno (Av. 13 y Av. 51); Olazábal (Av. 7 y Av. 38); Paso (Av. 13 y Av. 44); Rosas (Av. 13 y Av. 60); Perón (Av. 25 y Av. 60); Rocha (Av. 7 y Av. 60); San Martín (Av. 7 y Av.51).
} 
Los problemas plantean la necesidad de una re-ubicación y re-diseño del ámbito para poder evitar los problemas de erosión, o por el contrario una intervención estructural en el solado.

Se determinó la antigüedad de los dispositivos y en este sentido se establecieron dos categorías: - Nueva generación (NG): Juegos generalmente integrados, de plástico y caño, incluidos en el espacio público durante las últimas dos gestiones municipales.

- Antigua generación (AG): Juegos conformados principalmente por hamacas, sube y baja, pasamanos, calesita, tobogán. Se encuentran cada juego separado, generalmente no integrado. Los materiales utilizados son caño, madera y cadenas. Son los juegos instalados con una antigüedad mayor a 10 años.

También se determinó el tipo de dispositivo lúdico. Se establecieron las categorías de:

- Hamaca $(\mathrm{H})$.

- Sube y baja (SB).

- Pasamanos (P).

- Calesita (C).

- Escalera (E).

- Tobogán (T).

- Integrados (I): son los juegos que tienen como finalidad realizar dos o más actividades en un mismo dispositivo.

- Para personas con capacidades especiales (PD): son dispositivos lúdicos diseñados para que puedan ser utilizados de manera indistinta por personas con capacidades especiales.

- Otro (0): todas las situaciones no incluidas en las categorías anteriores.

Se relevaron el número de hamacas y sube y baja por dispositivo.

Se relevó el estado de conservación de los mismos:

- Muy Bueno (MB): se encuentran en perfecto estado de mantenimiento (pintura, estado de los materiales) y son perfectamente funcionales. No necesita intervención en el mediano plazo. 
- Bueno (B): su estado de mantenimiento es regular (problemas con la pintura y materiales gastados), sin embargo no se afecta la funcionalidad del mismo. Necesita intervención de mantenimiento en el mediano plazo.

- Deteriorado (D): su estado de mantenimiento es deficiente y puede afectar la integridad física de los niños y niñas que lo utilizan. Se encuentra afectada su funcionalidad de manera parcial. Necesita intervención inmediata.

- Sin función (SF): ausencia de mantenimiento que puede afectar la integridad física de los usuarios (óxido, presencia de púas o caños rotos, etc). Son dispositivos sin la funcionalidad lúdica por la que fueron colocados. Necesidad de reemplazo o arreglo integral.

Finalmente, se relevaron los materiales utilizados en los dispositivos lúdicos. En este sentido, se clasificaron como madera $(\mathrm{M})$, metal $(\mathrm{H}$, hierro o acero), plástico $(\mathrm{P})$, otro $(\mathrm{O})$ : todos los no contenidos en los anteriores.

\subsubsection{Inventario de la vegetación existente}

Con respecto a la vegetación, se realizó una actualización inventarial, durante la primavera de 2016, de los datos relevados por la cátedra de Planeamiento y Diseño del Paisaje de la facultad de Ciencias Agrarias y Forestales de la Universidad Nacional de La Plata. Mediante sucesivos convenios con la Municipalidad de La Plata, se completó el inventario de la vegetación de 13 plazas durante los años 2004, 2005, 2006 y 2007. A partir de dicha información, en la temporada primavera-verano del 2016 y 2017, se actualizó el inventario utilizando una planilla (ver Figura 10) con la que se determinó en cada ejemplar:

Especie botánica: se determinó la especie botánica de cada ejemplar.

Magnitud: Se refiere al tamaño adulto del ejemplar según especie, sin podas ni competencia con otros ejemplares. Se determinaron 6 magnitudes:

- 1ra Magnitud: más de $15 \mathrm{~m}$ de altura. Árboles

- 2da Magnitud: entre 10-15 m de altura. Árboles 
- 3era Magnitud: entre 6-10 m de altura. Árboles

- 4ta Magnitud: entre 3-5 m de altura. Arbustos

- 5ta Magnitud: entre 1-3 m de altura. Arbustos

- 6ta Magnitud: menos de $1 \mathrm{~m}$ de altura. Herbáceas y Arbustos.

Hábito Vegetativo: se determinaron tres variables: Follaje caduco, semipersistente y perenne.

Disposición espacial de la vegetación: se relevaron dos variables:

- Dentro del espacio lúdico: se consideró a la vegetación dentro del ámbito de juego cuando se encontró en relación directa dispuesta entre los dispositivos lúdicos.

- Perimetral al espacio lúdico: se relevó toda la vegetación existente de manera perimetral al ámbito de juego. Se tomó como vegetación perimetral a toda aquella que por caída de ejemplares podría afectar al ámbito de juego.

Referido a la edad de los mismos: Expresión del ejemplar con referencia a la magnitud tipológica habitual y esperable en la región, considerada en forma independiente de la edad para detectar los defectos debidos a causas como tipo de suelos, opresión de otros ejemplares, mutilaciones, podas o accidentes.

Se establecen cinco valores posibles:

- 1: Ejemplar de reciente implantación o con riesgo de muerte.

- 2: Ejemplar consolidado y juvenil.

- 3: Ejemplar adulto. Según la especie del $25-50 \%$ de su expresión.

- 4: Ejemplar maduro. Según la especie del $50-100 \%$ de su expresión.

- 5: Ejemplar remarcable por notable longevidad y extraordinaria expresión.

Para el estado fitosanitario se separaron árboles y arbustos por su diferenciar riesgo en caso de muerte o caída. Para los árboles se utilizó la escala publicada por Benassi (2007). En ella se determinan 7 estados: 
- -1: Ejemplar muerto o corona y/o tronco ahuecado, rajadura del tronco con apertura de partes, pérdida de anclaje (corte severo de raíces de estabilidad, erosión grave y masiva de la carga del sustrato, ranura evidente perimetral entre tronco y suelo por pérdida de estabilidad).

- 0: Caries en la corona. rajadura del leño sin desplazamiento, estión débil, agalla corona avanzada o ejemplar muy inclinado si es adyacente a vías de circulación peatonal o vehicular. Ramas o ejes superiores con significativo riesgo para el público.

- 1: Caries en tronco sin llegar al ahuecamiento de la corona, leño expuesto mayor al $40 \%$ perimetralmente.

- 2: Leño expuesto menor al 40\%, quemaduras, golpes y desprendimientos recientes. Alto número de caries en ejes superiores en evolución acelerada.

- 3: Algunas caries en ejes superiores.

- 4: Lesiones y daños menores o caries no aparentes pero con la necesidad de tratamientos preventivos específicos.

- 5: Sin problemas sanitarios aparentes.

Para el estado fitosanitario de los arbustos se determinaron cuatro estados:

- Muy bueno (MB): Estado fitosanitario muy bueno, sin presencia de podas, con la forma estereodéndrica según la especie, crecimiento excelente en función de la edad del ejemplar. No se observan plagas ni enfermedades.

- Bueno (B): Estado fitosanitario bueno, con presencia de podas leves o topiarias innecesarias que no afectan la vida del ejemplar y que sin intervenciones recupera su forma estereodéndrica original según especie. No se observan plagas ni enfermedades.

- Regular (R): Estado fitosanitario regular, con mutilaciones del ejemplar que afecta de manera irreversible su forma estereodéndrica original. Presencia de plagas y enfermedades. Necesidad de intervenciones sucesivas para su recuperación o reemplazo del mismo. 
- Malo (M): Estado fitosanitario malo, con presencia de mutilaciones que afectaron la vida del ejemplar, ramas principales muertas, ejemplares deformados, ejemplares muertos. Presencia de plagas y enfermedades. Ejemplares a extraer. Estado fitosanitario irreversible.

\begin{tabular}{|c|c|c|c|c|c|c|c|c|c|}
\hline \multicolumn{3}{|c|}{ Fecha relevamiento: } & \multicolumn{2}{|l|}{ Hora: } & \multicolumn{5}{|c|}{ Relevador: } \\
\hline Plaza & Nro & Delimitación & Tipo de pisos & Erosión (\%) & Tipo & Antigüedad & Estado de cons & Materiales & Observaciones \\
\hline & & & $\mathrm{P}$ & $0-30$ & \multirow{3}{*}{ H } & NG & $\mathrm{MB}$ & $M$ & \\
\hline & & & $S P$ & $30-50$ & & & $B$ & $\mathrm{H}$ & \\
\hline & & & & & & AG & $\frac{R}{M}$ & $\frac{p}{O}$ & \\
\hline & & & & & \multirow{3}{*}{ SB } & NG & $\mathrm{MB}$ & $M$ & \\
\hline & & & & & & & B & $\mathrm{H}$ & \\
\hline & & & & & & AG & $\frac{R}{M}$ & $\frac{p}{0}$ & \\
\hline & & & & & \multirow{3}{*}{$P$} & NG & $\mathrm{MB}$ & $M$ & \\
\hline & & & & & & & $\frac{10}{B}$ & $\mathrm{H}$ & \\
\hline & & & & & & AG & $\frac{R}{M}$ & $\frac{p}{0}$ & \\
\hline & & & & & \multirow{3}{*}{ c } & & $M B$ & & \\
\hline & & & & & & NG & $B$ & $\mathrm{H}$ & \\
\hline & & & & & & AG & $R$ & $\mathrm{P}$ & \\
\hline & & & & & \multirow{3}{*}{$\mathrm{E}$} & $N G$ & $\mathrm{MB}$ & $M$ & \\
\hline & & & & & & NG & $B$ & $\mathrm{H}$ & \\
\hline & & & & & & AG & $\frac{R}{M}$ & $P$ & \\
\hline & & & & & \multirow{3}{*}{ T } & NG & $\mathrm{MB}$ & $M$ & \\
\hline & & & & & & & $\frac{B}{8}$ & & \\
\hline & & & & & & AG & $\frac{K}{M}$ & $\frac{0}{0}$ & \\
\hline & & & & & \multirow{3}{*}{1} & NG & MB & $M$ & \\
\hline & & & & & & & & & \\
\hline & & & & & & AG & $\frac{R}{M}$ & $\frac{\mathrm{p}}{\mathrm{O}}$ & \\
\hline & & & & & \multirow{3}{*}{ PD } & NG & $M B$ & $M$ & \\
\hline & & & & & & & & & \\
\hline & & & & & & AG & $\frac{R}{M}$ & $\frac{\mathrm{p}}{\mathrm{O}}$ & \\
\hline & & & & & \multirow{3}{*}{ o } & NG & $M B$ & $M$ & \\
\hline & & & & & & & $\frac{B}{B}$ & $\frac{H}{P}$ & \\
\hline & & & & & & AG & $\frac{k}{M}$ & 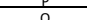 & \\
\hline
\end{tabular}

Figura 10: Planilla de relevamiento.

\subsubsection{Análisis de las especies presentes en viveros comerciales}

Para el relevamiento de la vegetación existente en viveros comerciales se tomó como referencia el productor más grande de la zona ${ }^{16}$ que posee una amplia disponibilidad de especies en cantidad y calidad situándose como uno de los líderes en el país. Además, su ubicación en la localidad de La Plata como asegura la adaptabilidad de las especies al lugar.

Se excluyeron de este análisis las especies Cactáceas, las anuales y bulbosas, y las plantas que comercialmente se encuentran categorizadas como "de interior". El objetivo fue conformar un universo menor para que fuera abordable.

Para ello, se trabajó en base al catálogo comercial de plantas, las que fueron clasificadas según atributos tipológicos formales (Benassi, 1994, 2013) y atributos tipológicos especiales:

${ }^{16}$ Vivero Ferrari Hnos. S.A. 
Respecto a los atributos tipológicos formales se computó la Magnitud, Hábito Vegetativo, Silueta, Textura, Singularidad y Variedades:

Magnitud: se consideró la magnitud al tamaño definitivo de la especie en la región, libre de competencia y en plena disponibilidad de nutrientes. Se determinaron 6 magnitudes:

- 1ra Magnitud: más de 15 m de altura. Árboles

- 2da Magnitud: entre 10-15 m de altura. Árboles

- 3era Magnitud: entre 6-10 m de altura. Árboles

- 4ta Magnitud: entre 3-5 m de altura. Arbustos

- 5ta Magnitud: entre 1-3 m de altura. Arbustos

- 6ta Magnitud: menos de $1 \mathrm{~m}$ de altura. Herbáceas y Arbustos.

Hábito Vegetativo: se refiere al comportamiento del follaje según los cambios estacionales.

- Follaje Deciduo o Caduco: pierde las hojas durante el otoño.

- Follaje Persistente o Perenne: follaje durante todo el año.

- Follaje semi-persistente: pierde las hojas al inicio de la primavera.

Silueta: se refiere a la arquitectura o forma de la especie en tamaño adulto sin competencia ni podas, sólo especies arbóreas. Se tomaron como referencia las siguientes formas: Elipsoidal, Columnar, Circular, Esferoidal, Cónica, Triangular, Péndula, Aparasolada, Irregular, Especiales y Palmeras (ver Figura 11). El resto de las plantas se catalogó como arbustos, arbusto/arbolito, herbáceas, gramíneas, rastrero y enredaderas como categorías separadas. 

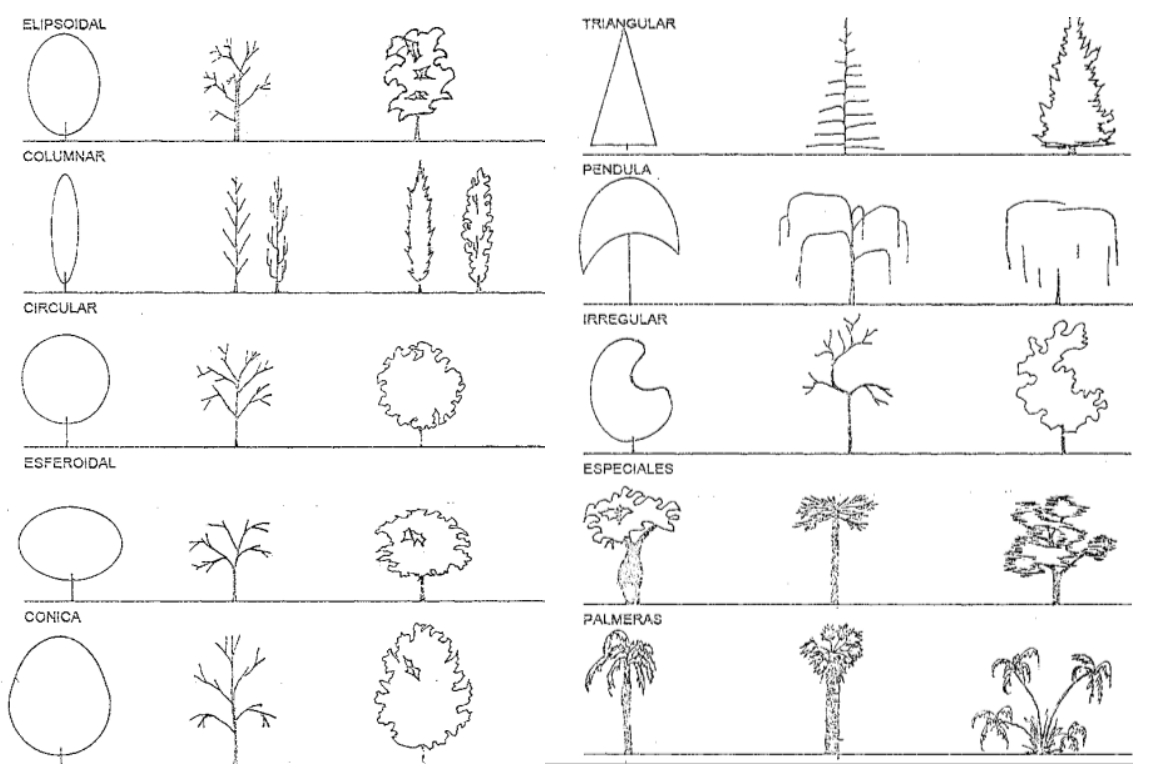

Figura 11: Esquema de siluetas en base a la arquitectura de la planta. Extraído de Benassi, 2013.

Textura: se refiere al tamaño, tipo y cantidad de hojas así como a la cantidad, flexibilidad y disposición de las ramas de las especies. Se tomaron tres tipos de texturas: fina, media y gruesa.

Singularidad: se refiere a la descripción del atributo que otorga la principal singularidad de la especie. Se puede referir a floraciones, fructificaciones, coloración de follaje otoñal, color de cortezas, etc.

Se computaron en la categoría variedad los cultivares de las especies. Se excluyeron de este casillero los cultivares que tienen amplia adaptabilidad y difusión y que pueden ser utilizados a los fines de esta tesis, los que figuran como una especie diferente. Algunas especies injertadas de amplia difusión, como Acacia bayleyana, se computó como una especie diferente, al igual que Ligustrum lucidum var aureomarginata.

Respecto a los atributos tipológicos especiales se computaron las siguientes categorías: Precautorio, Trepable, Flores podables, Color, Comestible, Laberíntica, Refugio, Frutos y semillas, Semillas volubles, Monumentalidad, Sombra, Color otoñal, Colchón de hojas, Bosque.

Se consideraron atributos precautorios a las especies que poseen espinas, toxicidad, hojas cortantes, que pinchan por hoja o aguijones, que poseen alérgenos relevantes o que irrita la piel. Estas 
especies podrían llegar a ser usadas en un ámbito lúdico para las infancias pero bajo la supervisión de adultos. Es un grupo interesante de especies para ser utilizadas en términos educativos y para aprender sobre los riesgos a los que tenemos que estar alertas.

Trepable: se consideró una especie trepable a aquella especie que en tamaño adulto pueden admitir el trepado de niñxs sin perder su estructura ni comprometer su supervivencia, con ramificación baja y con altura abordable por adultos.

Flores podables: se refiere a las especies de las que se puede cosechar sus flores de manera manual sin comprometer su supervivencia.

Color: se consideró la coloración singular respecto al verde dominante de las especies en la región. El color computado puede ser por follaje (perenne o en primavera-verano para las caducas), floración o fructificación.

Comestible: se computaron las especies que pueden ser consumidas como alimento, tanto sus frutos como su follaje.

Laberíntica: en esta categoría se ubicaron las especies aptas para la realización de laberintos sin podas excesivas y con altura menor a un árbol de 3ra Magnitud.

Refugio: se registró la vegetación con una arquitectura o forma específica que genera un vacío interior al cual se puede acceder y permanecer. Este vacío interior se encuentra rodeado de ramas y follaje por lo que no permite su contacto visual directo con el exterior. Se registraron aquí las enredaderas que con soporte pueden constituir refugios.

Frutos y semillas: se listaron las especies que poseen abundante fructificación que puede ser cosechada pero que no es comestible ni tóxica.

Semillas volubles: se refiere a las especies que producen una semillazón voluble, las especies que producen sámaras, disámaras o trisámaras, o que por las características morfológicas de las semillas pueden ser trasladadas por el viento con facilidad. 
Monumentalidad: se refiere a las especies arbóreas que por su tamaño y forma pueden constituirse en hitos de grandiosidad y espectacularidad. Se registraron aquí sólo los árboles que tienen mínimo riesgo de caída de ramas, de excelente anclaje, buena cicatrización ante daños y que no pueden constituir un peligro ante posibles caídas si se realizó el manejo fitosanitario adecuado.

Sombra: aquí se registraron los árboles que pueden conformar un ámbito de sombra, sin riesgos de caída ni excesiva magnitud. Se priorizaron los ejemplares de 3ra magnitud y en menor medida de 2da magnitud. Se conformaron tres categorías: sombras plenas o frescas, medias y laxas o calientes. El primer caso se referenció como los análogos a la sombra de un Tilo (Tilia x moltkei), sombra plena, densa y fresca. En el último caso se tomó como referencia la Acacia de Constantinopla (Albizia julibrissin), sombra laxa y caliente.

Color otoñal: referido a la presencia de coloración de follaje por caída de las hojas en otoño. Pueden ser atropurpúreas, anaranjados, amarillos, marrones. La importancia de esta categoría es que se computaron solamente las especies que marcan o muestran el otoño. No todas las especies caducas tienen una caída de hojas que hace evidente la llegada del otoño.

Colchón de hojas: se computaron las especies que tienen la capacidad durante el otoño de formar una capa de hojas que permanece en el piso y cubre el manto cespitoso o el solado. Estas especies reflejarían el otoño en la superficie del suelo. Se refirió particularmente especies arbóreas.

Bosque: se computaron las especies que pueden conformar el imaginario de un bosque. Para ello tuvieron que reunir las siguientes características: posibilidad de ser plantadas de manera densa, que conformen un dosel y que permitan conformar un atmósfera sombría y de mayor humedad que el exterior.

Tacto: las texturas. Se realizó una indagación sobre posibles especies vegetales que puedan ser utilizadas para la conformación de dispositivos lúdicos que fomenten el tacto como sentido sensible a ser explorado. 
Árboles longevos: se realizó un relevamiento sobre los árboles que tienen comprobada longevidad (más de 150 años). 


\section{CAPÍTULO 3}

\subsection{RESULTADOS Y CONCLUSIONES}

\subsubsection{Caracterización de los ámbitos de juegos}

En el trabajo de campo realizado, se observó que en un total de 13 plazas existieron 27 ámbitos de juego pautado para niñxs, lo que dio como resultado un promedio de 2,1 ámbitos por plaza con un desvío estándar de 0,8 (ver Figura 12). Esto confirma lo planteado por Domínguez (2013) que identificó ámbitos de juegos para niñxs en todos los espacios verdes. Así como también, mostró una distribución territorial homogénea que no dio cuenta de las particularidades de cada barrio. Como se verá más adelante, sólo hay diferencias en el tamaño y/o cantidad de dispositivos lúdicos pero el ámbito se forma de la misma manera en todas las plazas.

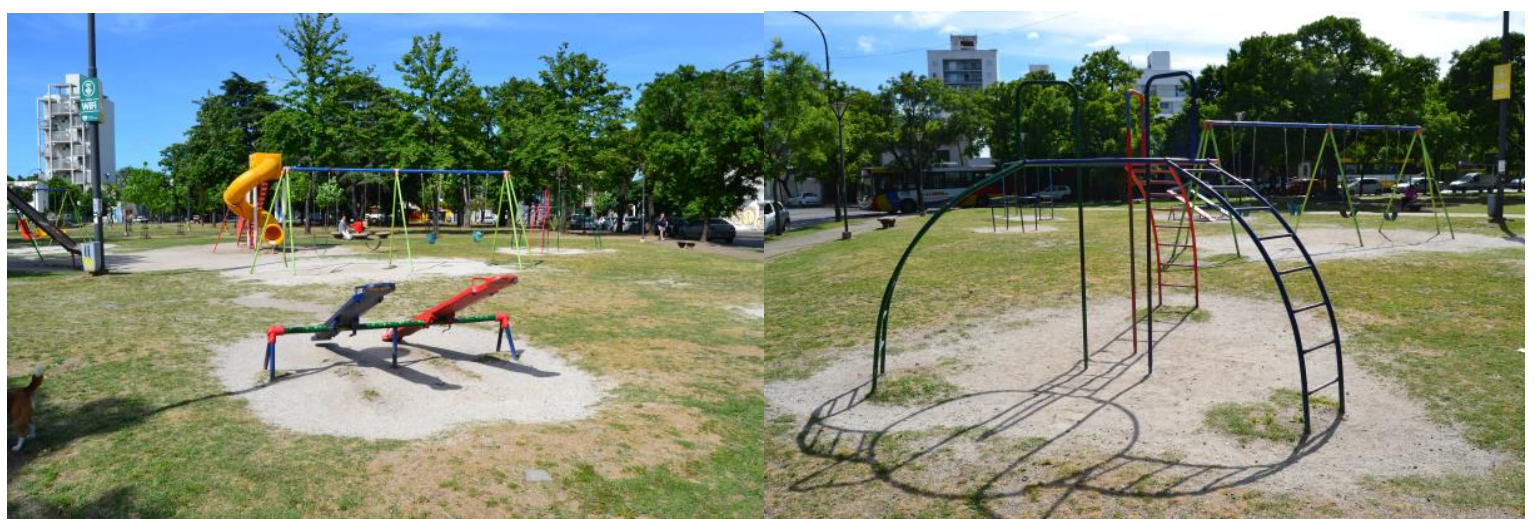

Figura 12: Ámbito de juego en Plaza España. Ciudad de La Plata. Año 2018.

También, se observó que el $63 \%$ de los ámbitos pautados no tuvieron ningún tipo de delimitación física de sus bordes. En el 37\% restante lo más frecuente fue la existencia de límites muy precarios. La situación se materializó con la presencia de pequeños muros perimetrales de mampostería o simplemente un reborde que contuvo la conchilla del suelo semi-permeable del ámbito de juego (ver Figura 13). Por el contrario, los juegos tipo Calesita, se encontraron rodeados de alambrado olímpico (en algunos casos con alambrado de púa) el que para poder traspasarlo fue necesario abonar un pase (ver Figura 14). 

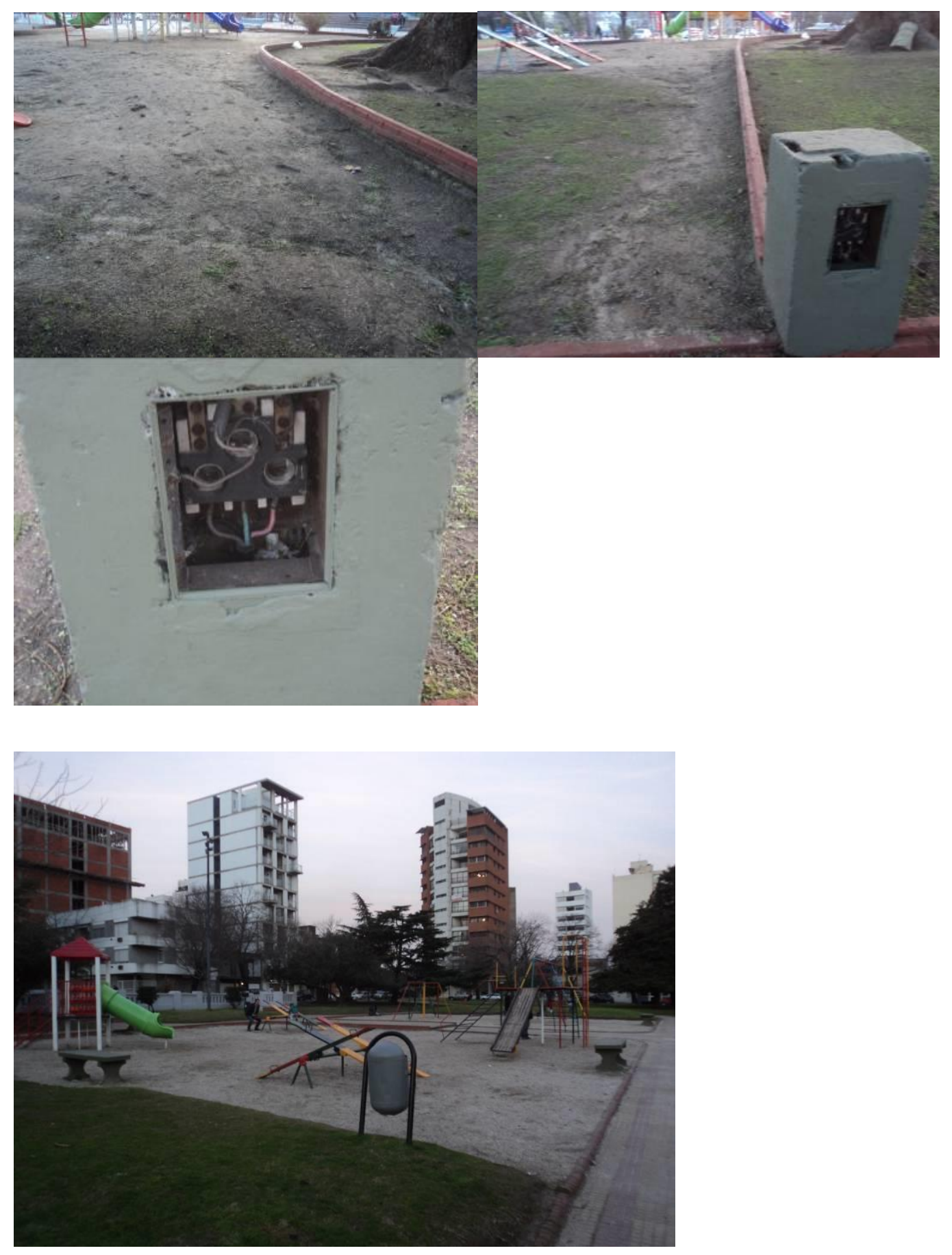

Figura 13: Imágenes superiores: Plaza Italia, se puede observar la delimitación del ámbito por una leve pared de mampostería. Se observa también presencia de elementos peligrosos para el desarrollo del juego de manera segura. Imagen inferior: Plaza Olazábal: ámbito con solado semi permeable tipo conchilla sin presencia de erosión. Ciudad de La Plata. Año: 2016. 


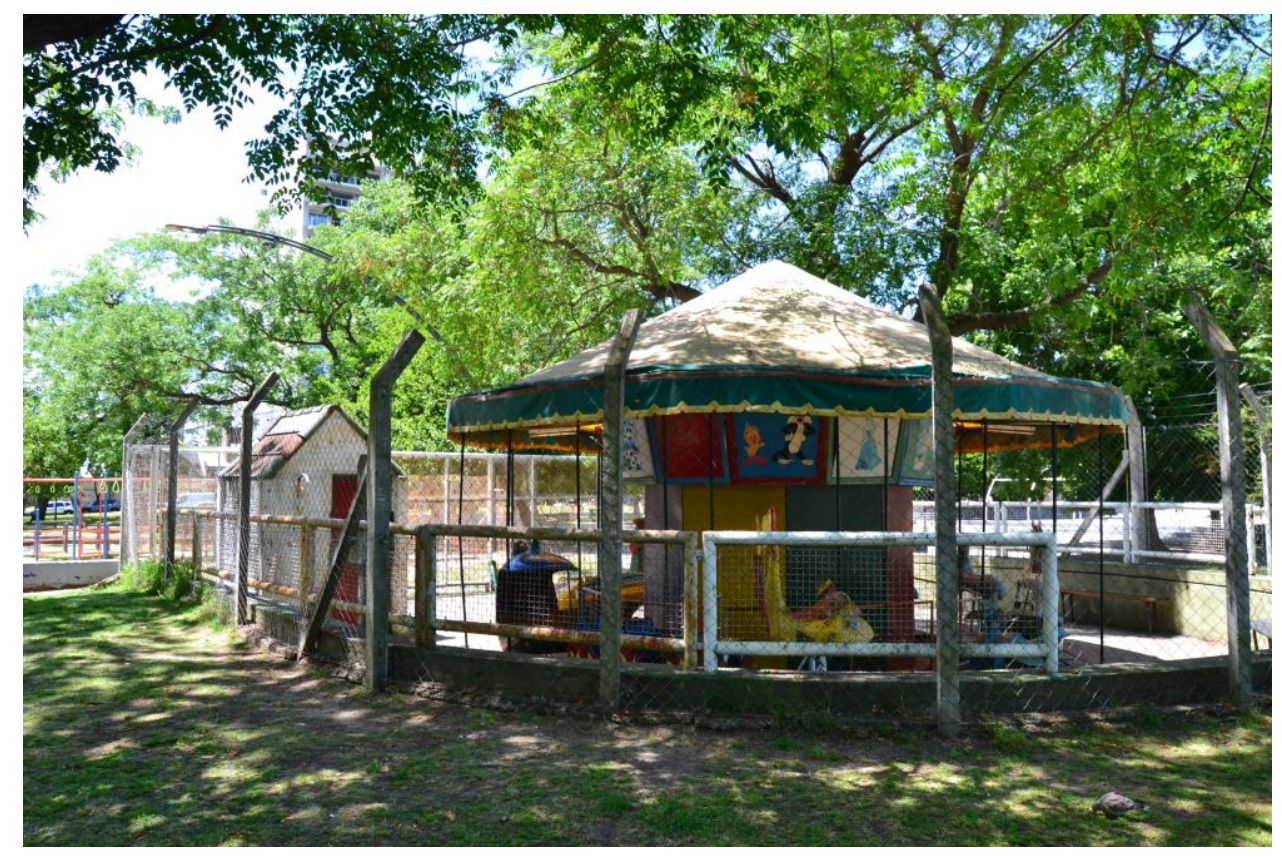

Figura 14: Plaza Belgrano. Juego tipo Calesita con enrejado perimetral. Ciudad de La Plata. Año: 2018.

En lo referido a pisos, el $74 \%$ presentó suelo semi-permeable del tipo conchilla y un $15 \%$ tuvo suelo permeable del tipo césped y tierra. Sólo el $4 \%$ se materializó completamente con suelo impermeable (baldosas y hormigón) y fue principalmente en los ámbitos de juego tipo Calesita. Se observó un $7 \%$ de ámbitos con piso impermeable y semi-permeable, constituido por una vereda perimetral. Es de destacar que la conformación de dichos ámbitos presentó disfuncionalidades por presencia de un 19\% con erosión mayor al 50\% (ver Figura 15). En estos casos, se dificultó gravemente el desarrollo del juego en períodos prolongados de tiempo por anegamientos temporales. A su vez, existió una mayor compactación que impidió el drenaje. El 41 \% presentó una erosión del 3050\% que también limitó seriamente su normal funcionamiento (ver Figura 16 y 17). Tan sólo el 40\% de los ámbitos presentaron superficies con erosión entre 0 y 30\%. En síntesis, si bien la mayoría tuvo pisos permeables o semipermeables, no se garantizó la funcionalidad del ámbito ya que se observaron altísimos niveles de erosión y desgaste. 


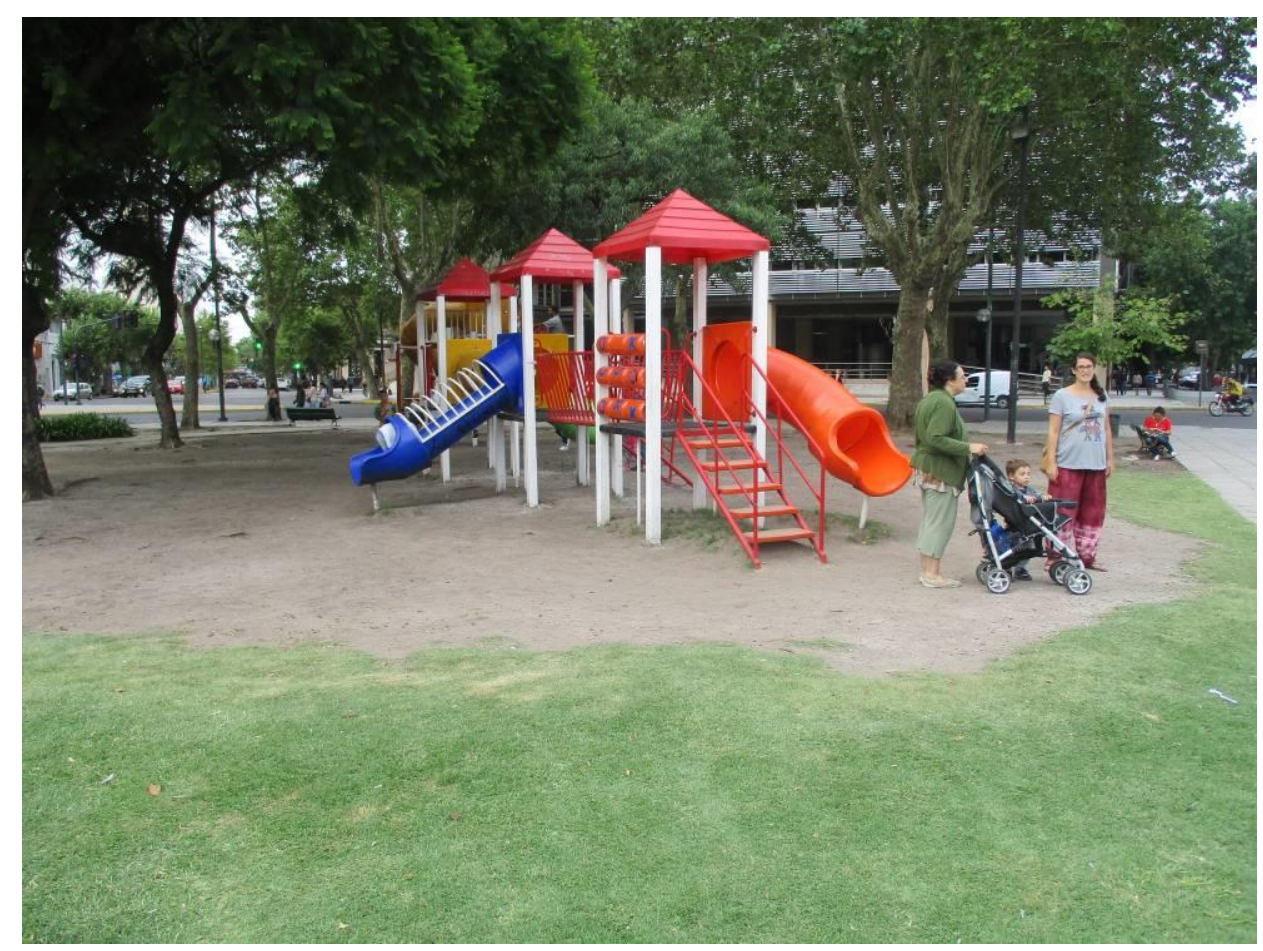

Figura 15: Plaza Moreno: Piso erosionado completamente. Ciudad de La Plata. Año: 2016.

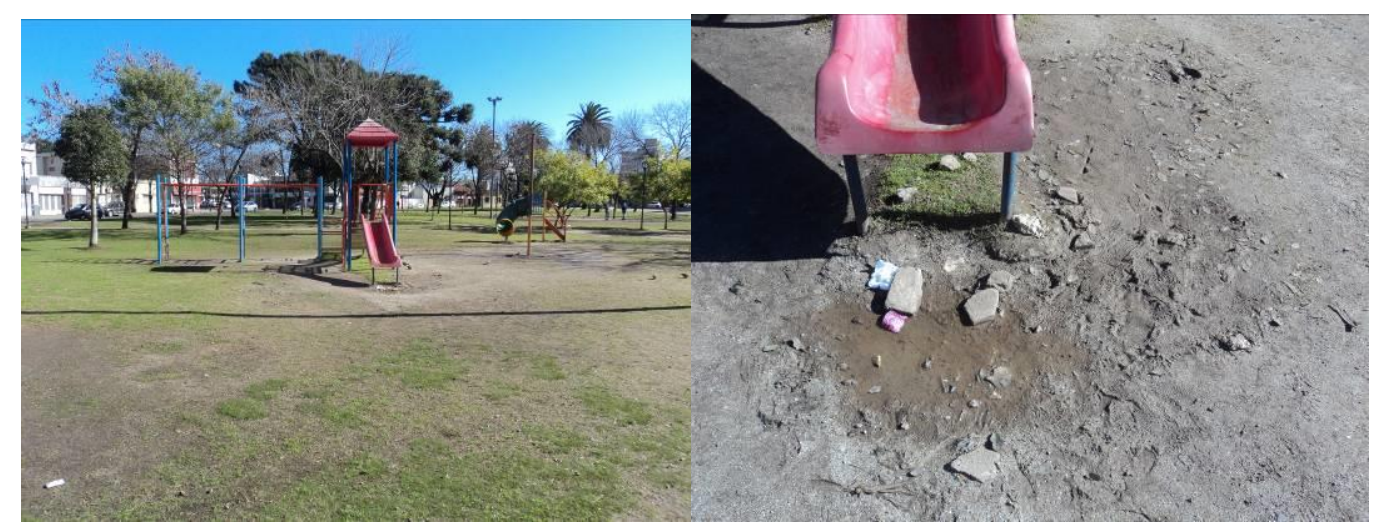

Figura 16: Plaza Azcuénaga. Erosión entre el 30-50\%. Ciudad de La Plata. Año 2016.

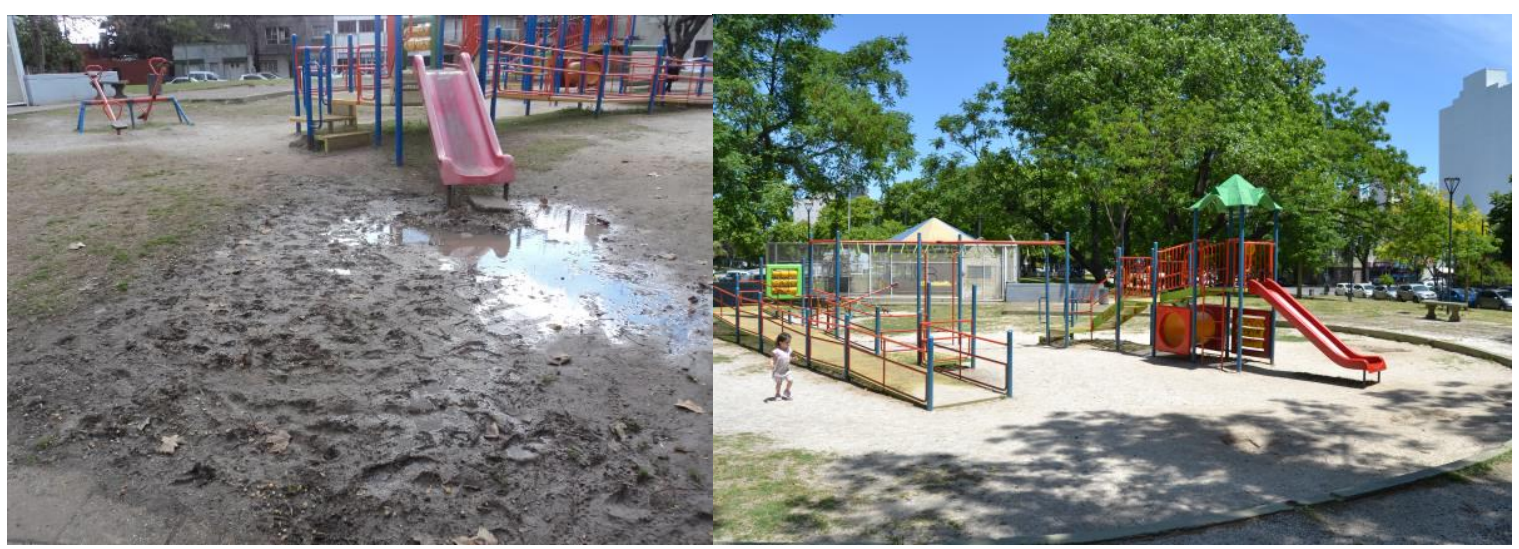

Figura 17: Plaza Belgrano. Erosión mayor al 50\%. Ciudad de La Plata. Año 2016 y 2018. 
En función de los datos relevados, podemos pensar que el piso de los ámbitos de juego determinó estructuralmente su funcionalidad y, por lo tanto, el cuidado de Ixs niñxs que se desarrollaron en él. La existencia de compactación con problemas de drenaje y permeabilidad, así como el excesivo uso, no permitieron establecer una carpeta cespitosa homogénea. En el caso de los solados semipermeables (conchillas), la situación fue similar, observándose una falta de reposición de material, ausencia de drenaje planificado y un diseño de contención de solados ineficiente, lo que aceleró los procesos de lavado de la misma en lluvias torrenciales. En uno y otro caso el resultado fue una superficie con barros, acumulación de agua y la presencia de un suelo compactado con características similares a la de una piedra. Esta condición aumenta el número de accidentes ante caídas, así como también los riesgos por lastimaduras graves ya que no existe una superficie que absorba impactos. En este sentido, existen numerosos ejemplos de solados que absorben impactos, ya sean orgánicos como inertes (ver Figura 18).

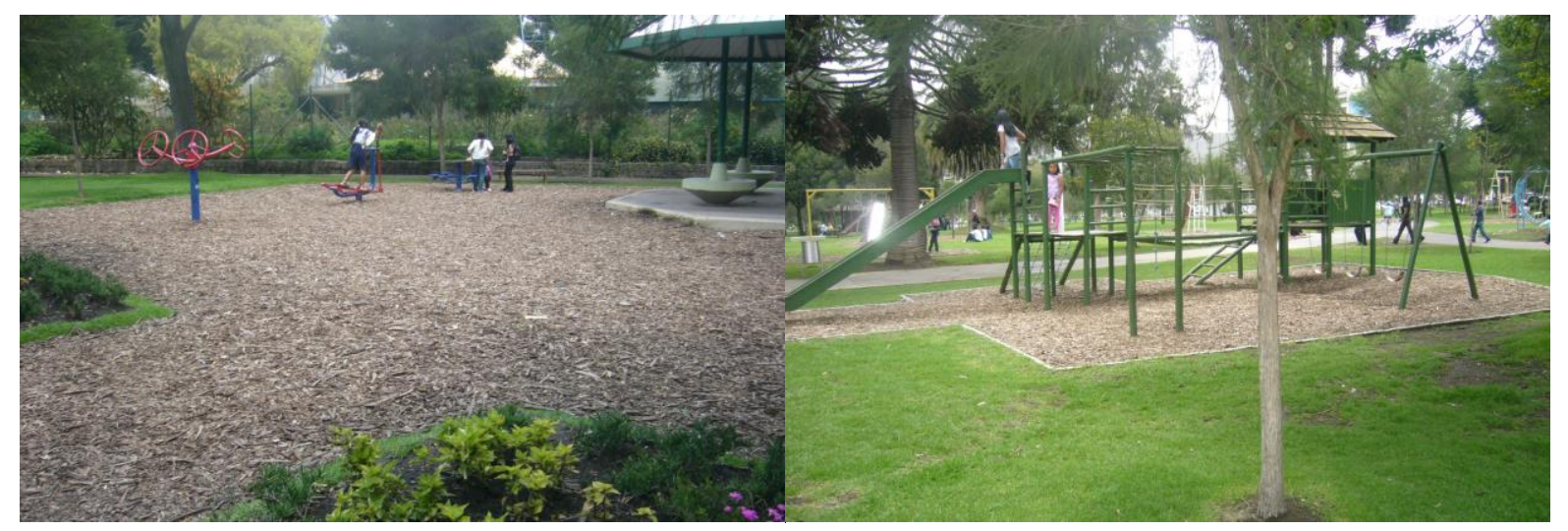

Figura 18: Solado que absorbe impactos y proveniente del chipeado de podas, solado absorbente y orgánico, delimitado por contención perimetral. Quito, Ecuador. Año: 2013.

Una de las hipótesis de esta tesis es la existencia de una sociedad de control hacia las infancias que prescribe sus conductas de manera homogénea, limitando los desarrollos autónomos. Si pensamos la situación descripta en los solados de los ámbitos de juegos se expresan dos situaciones: por un lado la inexistencia de un cuidado mínimo para evitar accidentes en un ámbito lúdico. Y, por el otro, y derivado del anterior, la necesidad imperiosa de un cuidado constante y cercano por parte del adulto responsable, controlando el juego y diciendo esto se hace y esto no porque existe un peligro 
real. La ausencia de ámbitos donde las infancias se encuentren cuidadas limita seriamente los grados de autonomía para el juego.

Respecto a la conformación de los dispositivos lúdicos existentes se observaron dos categorías: los de antigua generación conformados por caños, maderas, cadenas y con las normas básicas de seguridad y los de nueva generación que repiten los esquemas de los de antigua generación pero con nuevos materiales y mayores normas de seguridad. En ambos casos, el ámbito se formó con hamacas, sube y baja, tobogán, pasamanos y calesita. Este esquema básico se complejizó mediante la repetición (Hamacas múltiples y sube y baja múltiples) y con el agregado de algún dispositivo lúdico integrado. El dispositivo lúdico integrado se refirió a construcciones que tuvieron esquemas para trepar, tobogán, puentes, ta te ti y/o escaleras en un sólo elemento o dispositivo. Por último, se agregaron juegos que integraron a personas con capacidades diferentes, así como dispositivos lúdicos especiales tipo escalera, tubo, trepador.

Se observó que los ámbitos estuvieron conformados en promedio por 1,3 hamacas, 1 sube y baja, 0,8 toboganes, 0,4 calesitas, 0,4 integrados, 0,2 pasamanos, 0,1 escaleras, 0,3 con capacidades diferentes, 0,7 otros. Si lo trasladamos a un promedio por plazas llegamos al resultado siguiente: 2,8 hamacas, 2 sube y baja, 1,8 toboganes, 0,9 calesitas, 0,9 integrados, 0,5 pasamanos, 0,2 escaleras, 0,5 con capacidades diferentes, 1,4 otros.

Es interesante observar en términos absolutos las distribuciones de dispositivos lúdicos: se observaron 3 hamacas individuales, 11 hamacas para dos personas, 4 hamacas para tres y 18 hamacas para 4 personas, sumando un total de 109 hamacas. Se relevaron 26 sube y baja (estos pueden ser de uno o dos, excepcionalmente 3), 23 toboganes, 12 calesitas, 12 juegos integrados (estos siempre tuvieron tobogán y escaleras), 6 pasamanos, 3 escaleras, 7 para niñxs con capacidades diferentes y 18 otros (en su mayoría ta te ti, volantes y tubos horizontales pasantes). 
Respecto a la antigüedad de los dispositivos lúdicos, se observó un 52 \% de nueva generación y un $43 \%$ de antigua generación. En el primer caso fueron dispositivos instalados en los últimos 10 años y en el segundo caso anteriores. Ambos se encontraron compuestos por hierro, pero se diferenciaron en que los de antigua generación utilizaron madera mientras que los nuevos la reemplazaron por plástico.

Por último, lo más relevante fue el estado de conservación de los mismos. En este sentido, se observó que el $62 \%$ se encontraron en estado Bueno, se encontraron funcionales y sin riesgo para Ixs niñxs. Tan sólo el 15\% se encontró en estado Muy Bueno, lo que describió que no sólo se encontraron funcionales sino que además se encontraron pintados y en perfecto estado de conservación y mantenimiento. Por el contrario, se observó un $23 \%$ de los juegos en la categoría Regular y Malo (ver Figura 19 y 20), por lo que no pudieron cumplir la función para la que fueron colocados y más aún, representaron un riesgo a la integridad física de lxs niñxs.

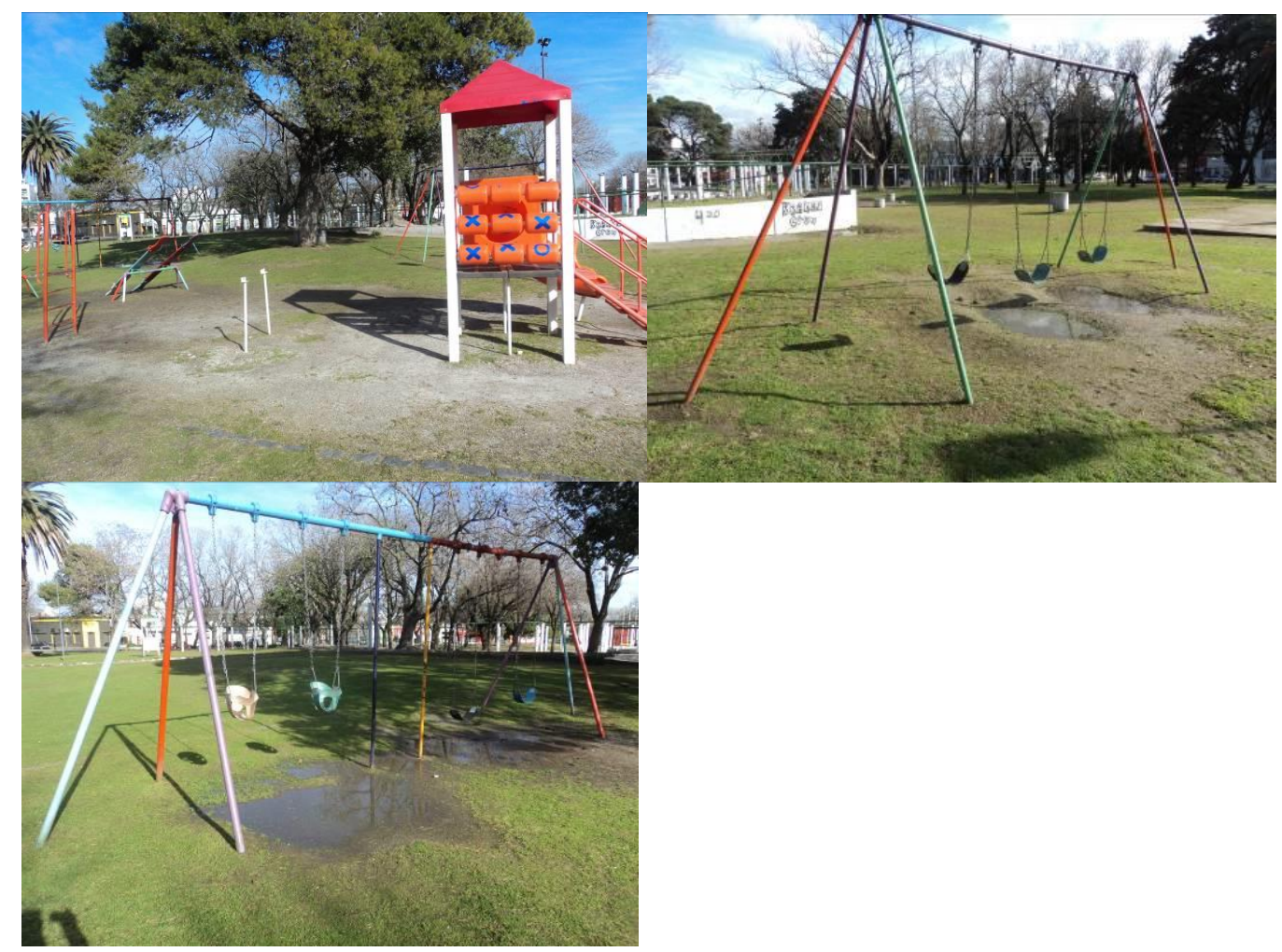

Figura 19: Plaza Irigoyen: se puede observar a la izquierda un dispositivo lúdico integrado en estado Malo por ausencia de puente, barandas y tobogán. 


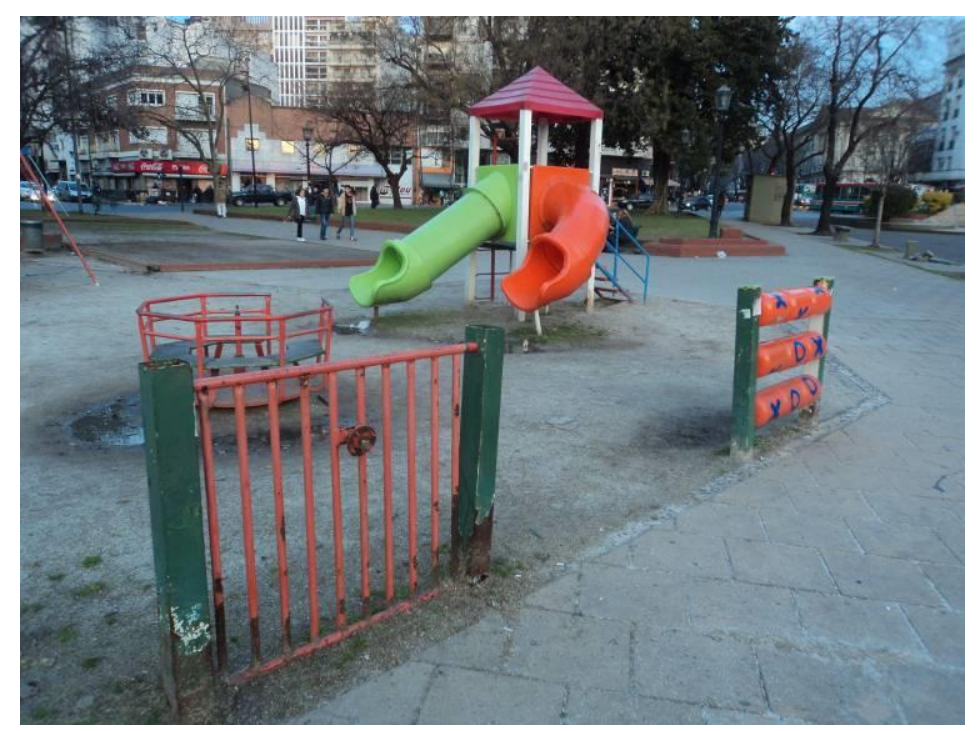

Figura 20: Plaza Italia: se pueden observar dispositivos lúdicos categoría Otro (volante) y Calesita en estado Malo, por ausencia de funcionalidad y presencia de óxido. A su vez, se observa erosión en todo el ámbito con presencia de encharcamientos que dificultan su uso.

Tal como se analizó en las hipótesis, se corroboró homogeneidad en la conformación de los dispositivos lúdicos, en base a una concepción de una infancia unitaria a la que se le ofreció un tipo de juego principalmente motriz, activo, que se repitió de plaza en plaza sin variaciones sustanciales. Esto se corroboró con la distribución y los tipos de juegos relevados donde la principal actividad planteada fue trepar, saltar, deslizarse, etc. La ausencia de diversidad de experiencias nos situó de manera muy lejana a la idea de recreación de las infancias.

La presencia de juegos en estado deteriorado, disfuncionales, algunos peligrosos por ausencia de defensas (barandas), determinó una mirada sobre las infancias que no contempló el resguardo de las mismas. Tomamos la idea de cuidado de las infancias como una protección mínima que evite accidentes graves y que minimice los riesgos por lastimaduras evitables. El cuidado se asocia en esta tesis a la concepción de seguridad, ambos como la capacidad de poder llevar adelante una actividad sin estar expuesto a riesgos evitables. Más adelante se desarrollará la discusión sobre seguridad ligado a la idea de vigilancia o ligado a la idea de cuidado. En nuestro caso, ámbitos cuidados se constituyen en ámbitos seguros. Los ámbitos de juegos en la ciudad de La Plata, tanto en los solados 
como en los dispositivos lúdicos que contienen, no constituyeron lugares cuidados ( por lo tanto tampoco seguros) para el desarrollo de las infancias. En estas circunstancias, difícilmente la mirada adulta sobre Ixs niñxs les permita jugar de manera libre, explorando y encontrando su propios límites dados por sus capacidades y por lo que les plantea el contexto, en definitiva que les permitan crear momentos con mayor independencia donde puedan constituirse. Esta situación claramente inhabilita el desarrollo del juego autónomo descripto para el desarrollo de infancias recreadas.

\subsubsection{Diagnóstico de la vegetación existente}

Se registró un total de 41 especies arbóreas. Sin embargo, sólo 12 especies representaron el 76 $\%$ del arbolado. Las más frecuentes fueron Fresno (Fraxinus pennsylvanica), Tilo (Tilia $x$ moltkei), Ciprés (Cupressus sempervirens), Tipa (Tipuana tipu), Cedro (Cedrus deodara), Fénix (Phoenix canariensis), Plátano (Platanus x acerifolia), Palo Borracho (Chorisia speciosa), Juniperus (Juniperus sp.), Jacarandá (Jacaranda mimosifolia), Paraíso (Melia azedarach) y Ciprés piramidal (Cupressus sempervirens var. stricta). Sólo el Fresno junto al Tilo, Ciprés y Tipa representaron el $50 \%$ del arbolado existente, destacándose el Fresno con el 30\% (ver Figura 21).

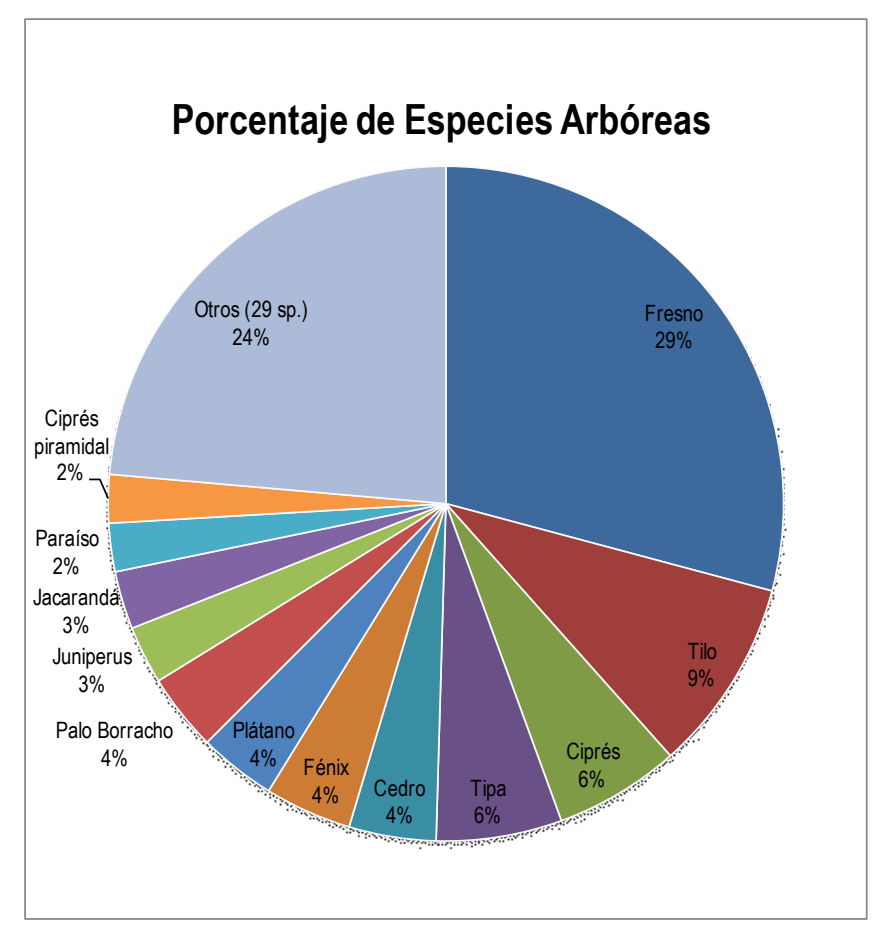

Figura 21: Porcentaje de especies arbóreas. Ámbitos de juego. Ciudad de La Plata. Año 2016. 
Retomando la hipótesis planteada respecto a la homogeneidad de los ámbitos de juegos, esto tuvo su correlato en la bajísima diversidad de especies arbóreas encontradas. La existencia de doseles arbóreos determinados, en su mayoría, por un reducido número de especies, estableció una estructura en términos de morfología del paisaje (estructura de llenos, coberturas arbóreas) muy similar entre los distintos ámbitos. La principal diferencia entre los mismos se dio por mayor o menor presencia de árboles, pero no por las características de los mismos ya que los atributos tipológicos principales fueron similares.

En este sentido, como se verá más adelante, los árboles tuvieron magnitudes inalcanzables por Ixs niñxs ya que las podas realizadas establecieron un inicio de copa a gran altura (mayor a tres metros), lo que limita su incorporación como elemento lúdico. Además, la poda de ramas bajas, no permitió tener contacto directo con la mayoría de las hojas. La baja diversidad específica disminuyó la complejidad del plafón vegetal superior con una mayor homogeneidad de copas, de siluetas (arquitectura de la planta), de situaciones fenológicas y ecológicas típicas de un bosque coetáneo mono específico. El bajo número de especies, al menos acota el disfrutar de diferentes floraciones, fructificaciones, aromas que podrían habilitar mayores vivencias en las infancias con la vegetación.

Por otro lado, al analizar la ubicación de dichas especies, se registró que el 85\% se encontraron fuera del ámbito de juego, de manera perimetral, mientras que sólo el 15\% lo hizo dentro. La ubicación de los árboles, principalmente en los bordes, limitó las posibilidades de interacción con los mismos, la naturaleza no estuvo dentro de los ámbitos al alcance de la mano sino que hubo que ir a buscarla, estuvo fuera. En muy pocos casos, la ubicación perimetral, contuvo al ámbito de juego, otorgándole entidad y definición. El análisis marcó que la posibilidad de vivir experiencias con los árboles se vio seriamente limitada.

El $66 \%$ se correspondió con especies de segunda magnitud, el $23 \%$ especies de primera magnitud y tan sólo el $11 \%$ con especies de tercera magnitud. La estructuración de las coberturas principales con especies de primera y segunda magnitud demostró una clara ausencia de planificación 
respecto a la temática. En este sentido, retomando la idea de infancias cuidadas en ámbitos seguros, las especies más frecuentes fueron las de primera y segunda magnitud y en su mayoría no fueron recomendadas para ámbitos lúdicos. El tamaño de las mismas las constituyó en factores de riesgo por caída de ramas y ejemplares. La vegetación, de esta manera, comenzó a ser un elemento del que hubo que cuidarse y no una oportunidad para el juego. A su vez, las especies de primera y segunda magnitud, en muy pocos casos pueden ser abordadas por niños ya que es muy dificultoso el trepado, y en caso de que suceda hay riesgos muy altos por caídas en altura. De esta manera, encontramos restringidas seriamente las experiencias que se pudieron vivir con las especies arbóreas, se redujo la diversidad de las mismas en pos de reforzar la homogeneidad, la idea de que se juega de una sola manera.

En otro sentido, el $59 \%$ de las especies arbóreas fueron caducas y el $30 \%$ y $11 \%$ perennes y semipersistentes respectivamente. Esta proporción, reflejó lo analizado por Benassi (2013) donde refirió una relación de $60 \%$ caduco y $40 \%$ perenne para todas las plazas de la ciudad. Vale aclarar que las especies semi-persistentes se computan como perennes por poseer hojas en invierno. Esta situación reforzó la hipótesis de que no existió un diseño paisajístico particularizado para los ámbitos de juegos, sino que éstos se insertaron en una matriz general proveniente de la tradición paisajística fundacional del siglo XIX. En este sentido, el punto siguiente referido a la edad de las especies arbóreas, lo corroboró.

En el punto de la edad de las especies arbóreas, el $59 \%$ se encontró en estado maduro y el 36\% en edad adulta. En conjunto conformaron el 95\% de la estructura arbórea. Se observó un bajísimo nivel de reposiciones, correspondiente al $4 \%$ a ejemplares de 1-2 años de implantado y el $7 \%$ a ejemplares juveniles consolidados (ver Figura 22). 


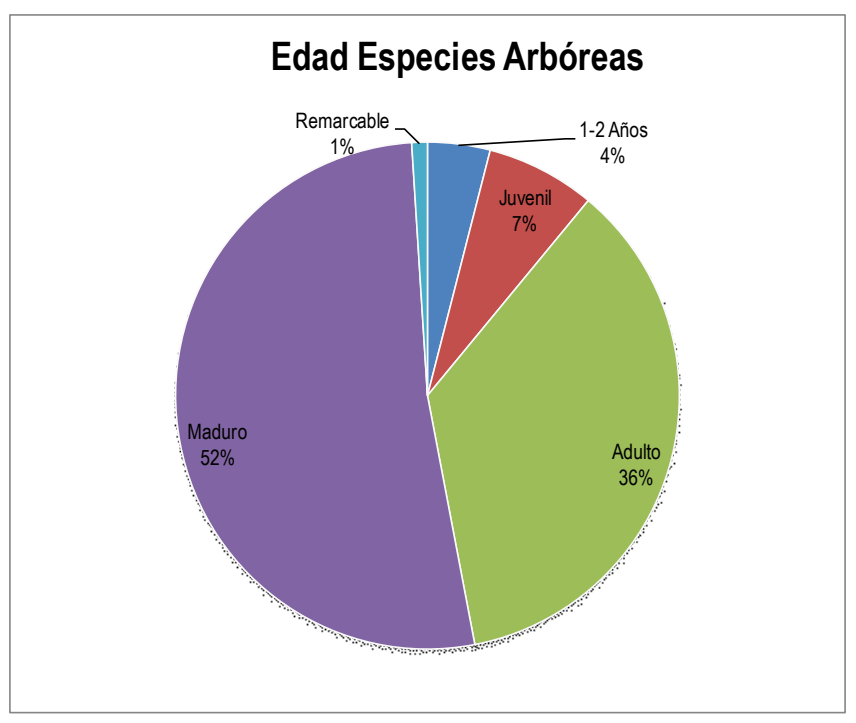

Figura 22: Edad de las especies arbóreas. Ámbitos de juego. Ciudad de La Plata. Año 2016.

La situación respecto a la edad de las especies arbóreas abrió un panorama de discusión y análisis en términos diacrónicos y sincrónicos, tanto para la vegetación como para las infancias. Como podemos observar, no existió una visión diacrónica de la infraestructura verde recreativa ya que ésta supone la existencia de un continuo de edades de especies arbóreas que permitan el desarrollo de ecosistemas de reposición constante. La idea de ecología del no-equilibrio, en nuestro caso, genera estructuras arbóreas discetáneas, de manera tal de establecer ecosistemas más resilientes. Particularmente, se observó una ausencia casi total de reposiciones. En contraposición, la presencia fue de árboles principalmente maduros y sobremaduros, que pusieron en riesgo la estabilidad futura del sistema. La pérdida de ejemplares adultos por muerte natural, con ausencia de reposiciones que la prevean, establecería baches temporales de coberturas larguísimos (puede llegar hasta 30 años) donde el sistema entraría en una fase de altísimo riesgo. Esta falta de visión diacrónica de la vegetación puede llevar a colapsar los ecosistemas que sostienen hoy el paisaje de las plazas platenses.

A su vez, la homogeneidad de coberturas y la baja diversidad de especies determinaron una ausencia también de una visión sincrónica de la vegetación en términos de usos. La existencia o no de cobertura en un ámbito determinado no estuvo dado por los usos que se presentaron y dispusieron allí, 
sino principalmente por el diseño original del siglo XIX de las plazas platenses. La lógica fue la incorporación de usos a una estructura o matriz de vegetación existente, sin realizar ninguna adecuación o re-diseño que dé cuenta de la nueva actividad. En nuestro caso, fueron las infancias las que no se tuvieron en cuenta para la planificación de la cobertura arbórea.

Sin embargo, si pensamos las coberturas arbóreas en las categorías de sincronía y diacronía para las infancias, la situación fue diferente. Como se expresó en el marco teórico, sincronía es lo que continúa (y la discontinuidad como parte de dicho esquema) y diacronía es el cambio, el punto de quiebre. En este sentido, tuvimos la ventaja de poseer una estructura arbórea que nació con los orígenes mismos de la ciudad, con ejemplares que fueron testigos de infancias pasadas, presentes y que lo serán de infancias futuras. Esta situación fue vista como una oportunidad para revalorizar, poner en contexto y dotar de contenido a una estructura arbórea que necesita reemplazo pero que necesita principalmente cuidados especiales para poder subsistir. Hay allí una posibilidad de establecer un camino sincrónico para las infancias, en términos de continuidades históricas, donde el árbol actúe como un testigo. Estos árboles, tuvieron marcas en su vida de los distintos usos que cada sociedad proyectó en ese espacio que vivió. Marcas pasadas, actuales y futuras. En este sentido, es una oportunidad para re-pensar en términos diacrónicos, cuáles son las marcas que las infancias hoy quieren dejar en esos espacios y también cuál es la memoria del lugar. En términos de Jelin (2001), poder establecer procesos subjetivos, anclados en experiencias y marcas simbólicas y materiales, donde se ejerza y debata la memoria. La ausencia de proyecto paisajístico particularizado fue un vacío que permitió pensar las infancias de manera diacrónica, albergando nuevos usos, con espacios para la memoria individual y colectiva, donde se habiliten actividades futuras desconocidas. Este reflexionar los ámbitos de manera diacrónica se cruzó más adelante con repensar la vegetación en términos de sincronía territorial de usos de hoy y del porvenir.

Finalmente, respecto al estado fitosanitario de las especies arbóreas, se observó que el $75 \%$ registró los niveles 3, 4 y 5. Esto evidenció que el 75\% no representó, para la comunidad, peligro 
potencial por caída de ramas y ejemplares, siempre en condiciones climáticas normales y previsibles. Sin embargo, el $14 \%$ tuvo estado fitosanitario - 1 y 0 , lo que conformó un riesgo inmediato por posible caída de árboles completos. Finalmente, el $11 \%$ se correspondió con los niveles 1 y 2 , referidos a ejemplares en estados de alerta y precaución que necesitan un seguimiento y cuidado especial (ver Figura 23).

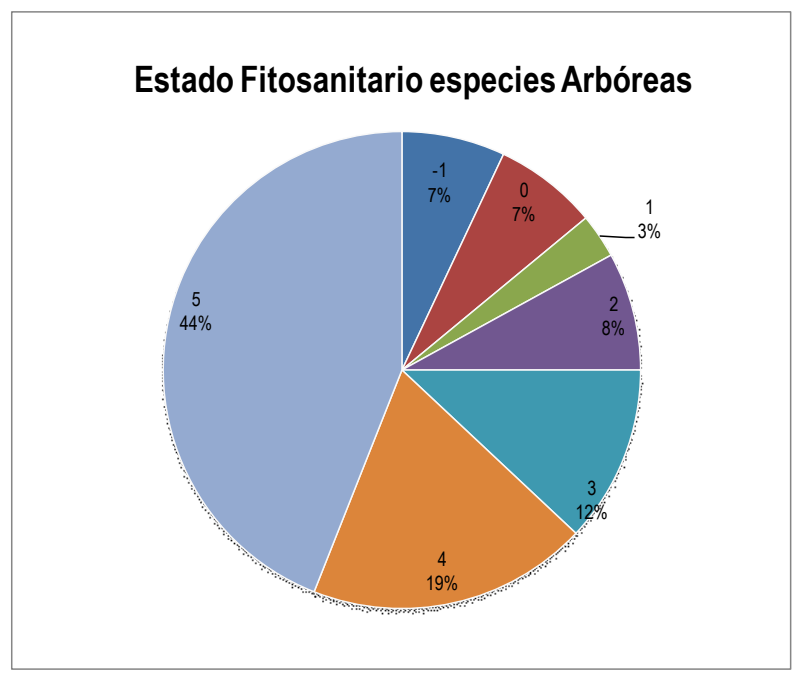

Figura 23: Estado fitosanitario de las especies arbóreas. Ámbitos de juego. Ciudad de La Plata. Año 2016.

El estado fitosanitario de los árboles fue alarmante y comulgó con lo planteado anteriormente para solados y dispositivos lúdicos respecto a la seguridad y cuidado de la niñez en los ámbitos de juego. La idea que tratamos de desarrollar en esta tesis refiere a que el estado actual de los ámbitos de juegos no contempla el cuidado de las infancias y por lo tanto no se encuentran seguras en el espacio público. La idea de cuidado y seguridad son conceptos que nosotros asociamos y entendemos que en cuanto no se encuentren presentes en el espacio público, difícilmente podamos lograr el desarrollo de infancias autónomas. La vegetación arbórea se constituyó en un factor de riesgo, por caída de ramas y ejemplares, alarmante. La existencia de ejemplares muertos, elementos vivos pero con serios problemas de estabilidad y ramas principales secas, ahuecamientos en las bases y la existencia de ejemplares de gran magnitud por sobre los ámbitos de juego, confirmó la inexistencia de una preocupación respecto al cuidado y seguridad en la niñez (ver Figuras 24, 25, 26 y 27). Esta 
ausencia, junto a las otras marcadas anteriormente, determinó que los dispositivos de cuidado por parte de los adultos acompañantes sean muy marcados, no permitiendo habilitar el juego libre y autónomo. Estas situaciones, entre las ya marcadas, fueron las que atentaron contra la conformación de infancias más libres, convirtiendo la mirada de cuidado del adulto en una visión más vigilante y controladora. El binomio cuidado-seguridad es una discusión que se profundiza en las conclusiones.

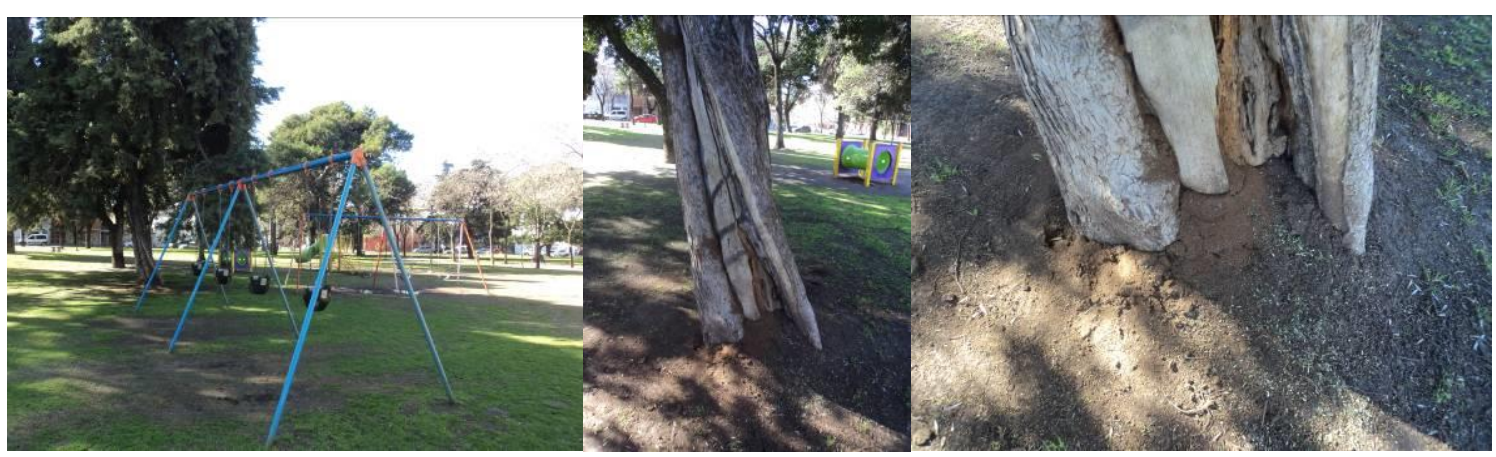

Figura 24: Plaza Azcuénaga: Cupressus arizonica var Green glauca. Dentro de ámbito de juegos, segunda magnitud perenne. Estado fitosanitario: -1 .
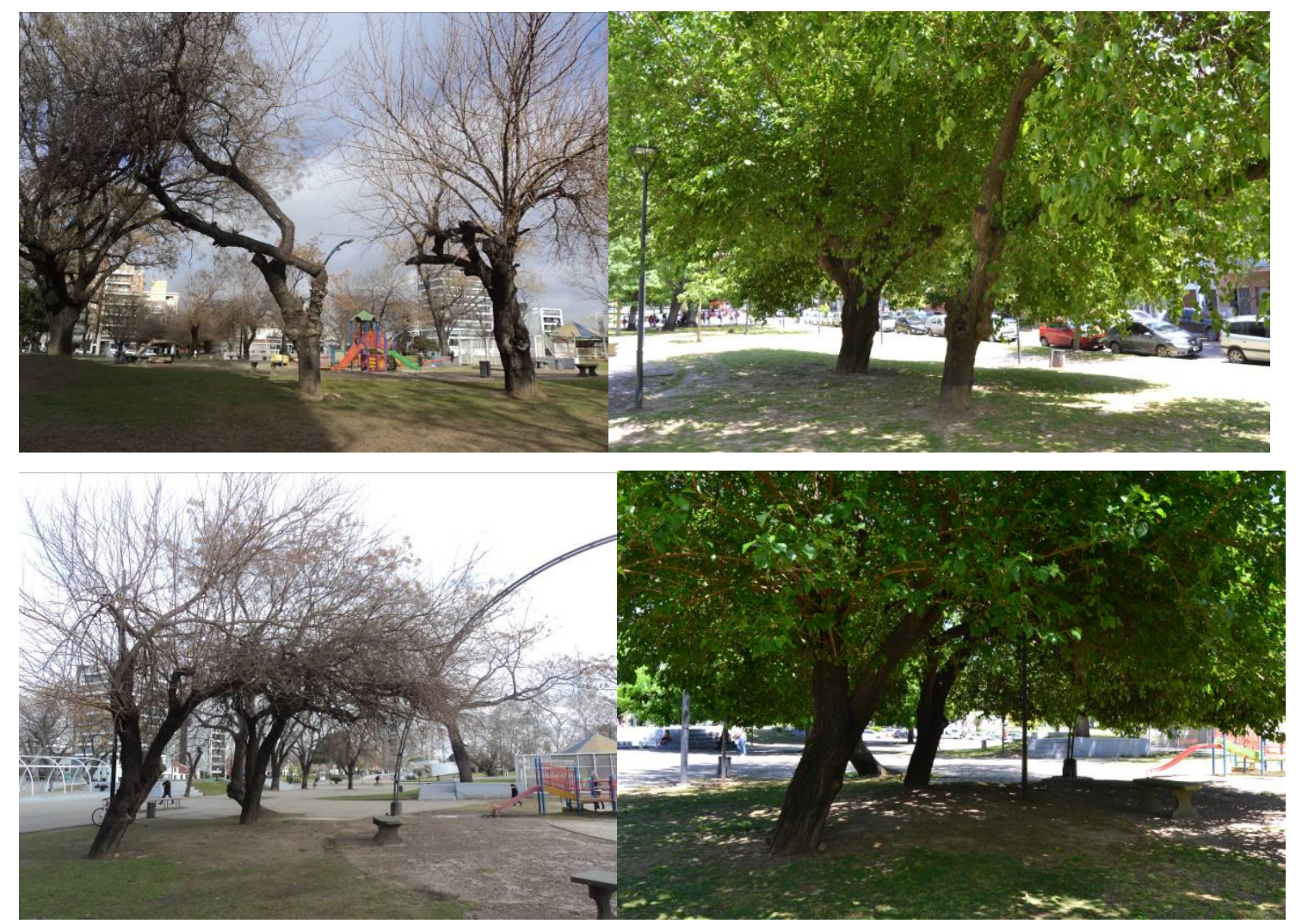

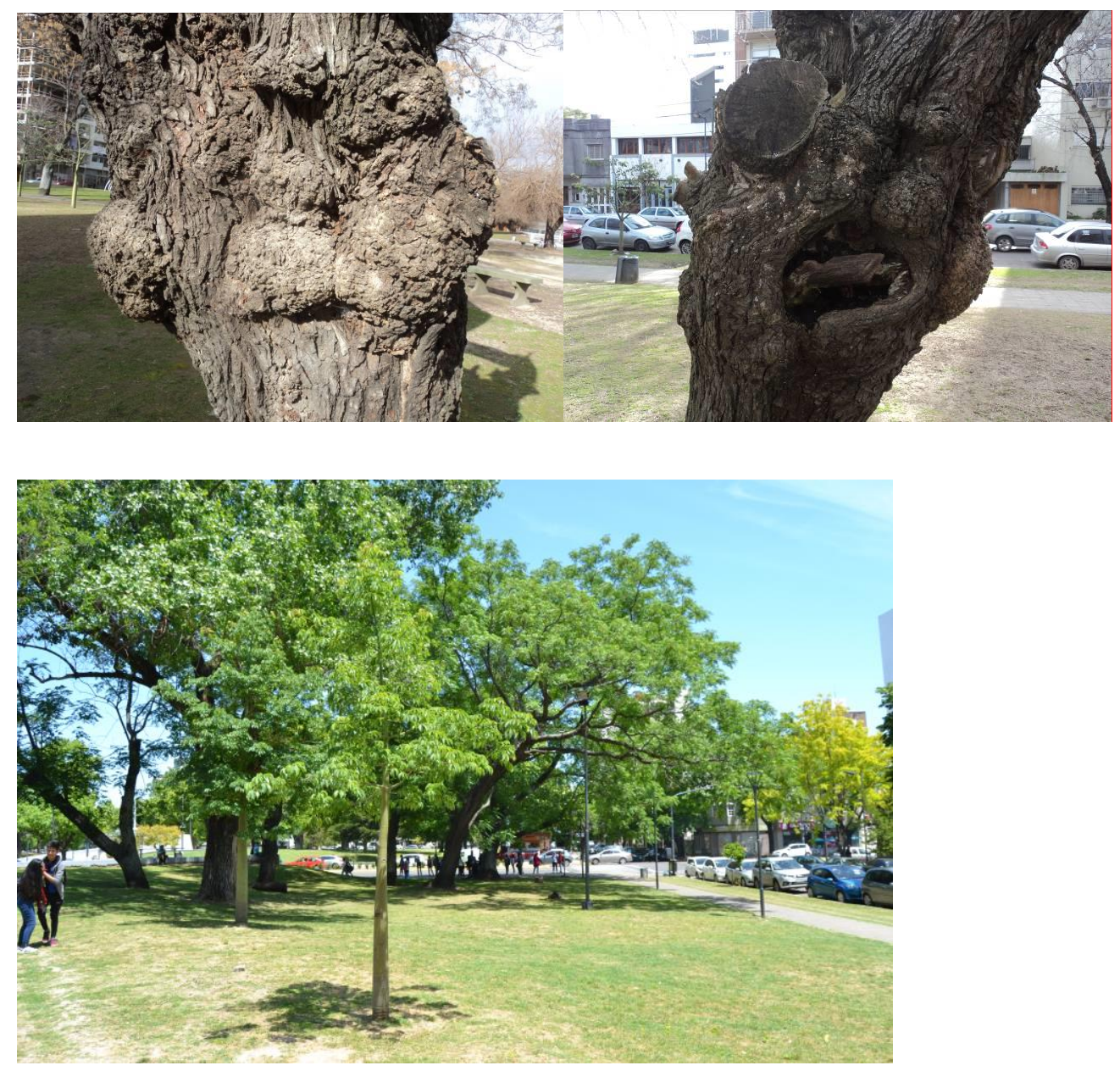

Figura 25: Plaza Belgrano: Primeras seis imágenes: presencia de dos ejemplares de Morus nigra perimetrales al ámbito de juego en estado fitosanitario -1. Última imagen: Reposición de Chorisia sp. en estado juvenil sin riesgo de muerte. Años 2016 y 2018. 

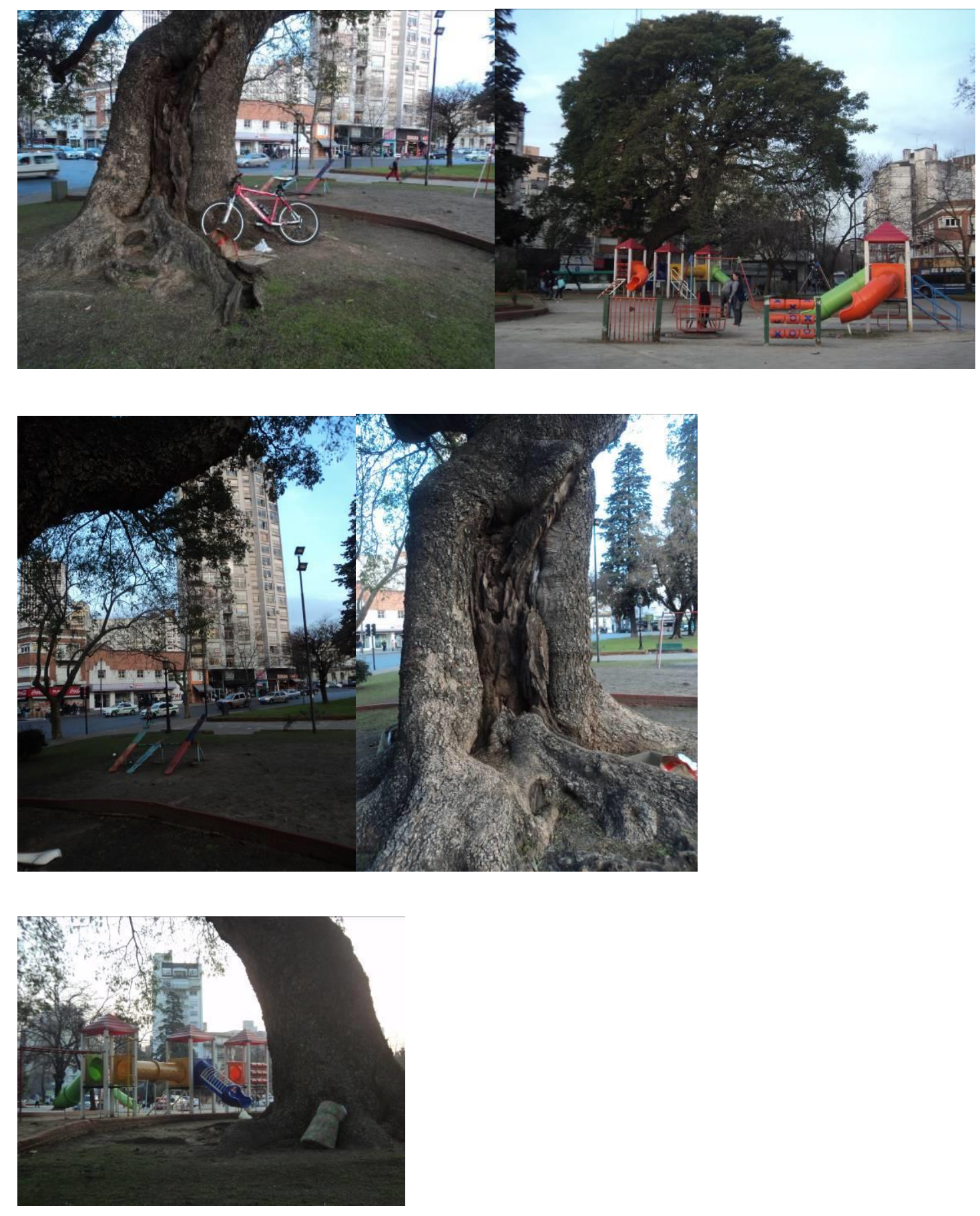

Figura 26: Plaza Italia: Ejemplar de Enterolobium contortisiliquum de primera magnitud de extraordinaria expresión

(Categoría Edad 5) pero con problemas fitosanitarios en la base (EF: 0), desestructurado y con riesgo de caída hacia el sector de juegos. 

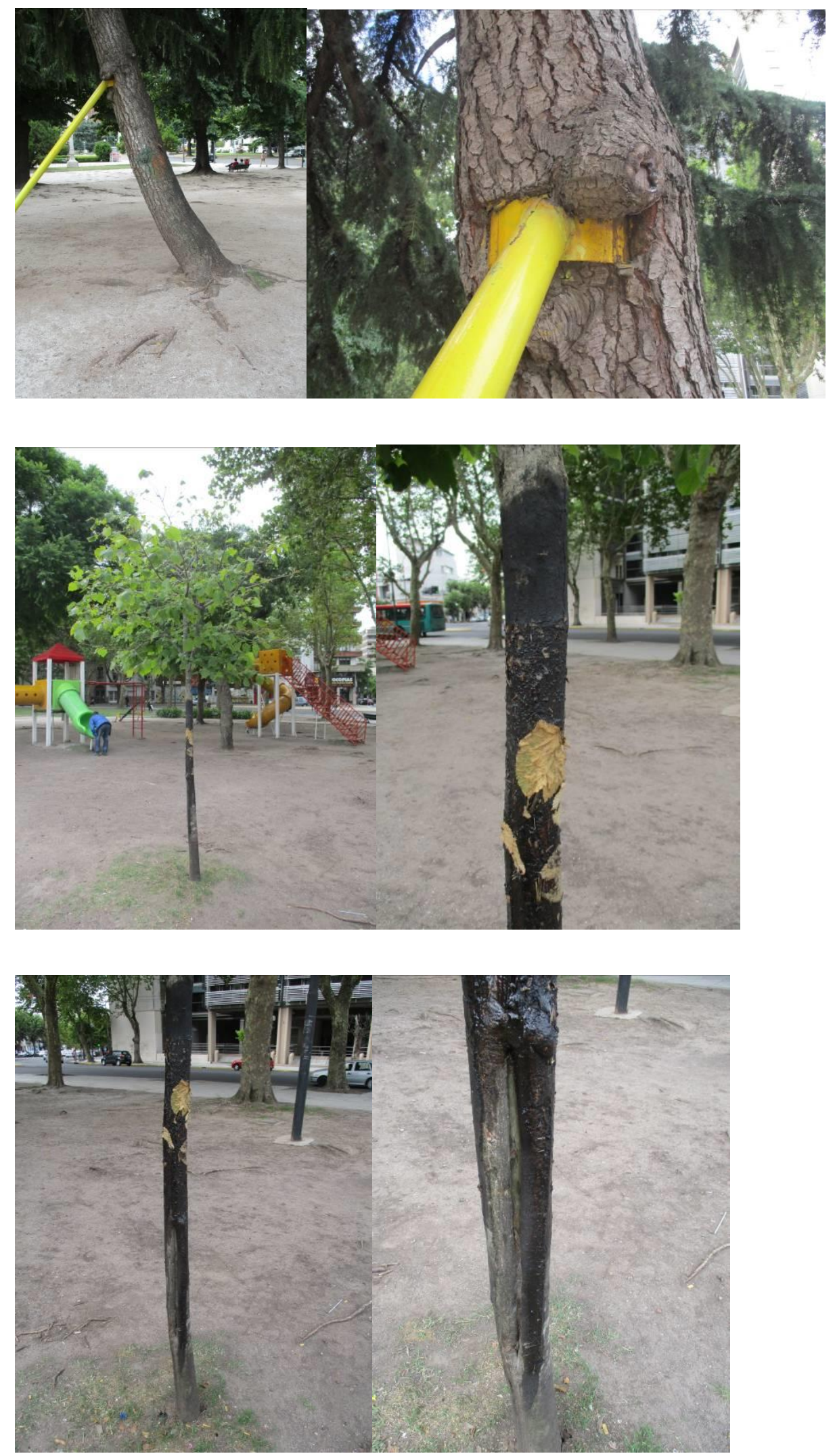

Figura 27: Plaza Moreno: presencia de Cedrus deodara con inclinación pero con tratamiento de sostén que ocasiona daños al leño. Reposición de Tilia moltkei con tratamiento antihormigas que daña la corteza y viabilidad del ejemplar de manera irreversible. 
Algo similar ocurrió con las especies arbustivas, con presencia de plantas tóxicas. En este sentido, en el trabajo de campo, se registró un total de 15 especies arbustivas y herbáceas. Sólo 8 especies representaron el $81 \%$ del total. Las más frecuentes fueron Laurel de jardín (Nerium oleander), Formio (Formiun tenax), Viburno (viburnum odoratissimun), Euriops (Euryops pectinatus), Rosa de Siria (Hibiscus syriacus), Evonimo (Evonymus sp.), Laurentino (Viburnum tinus) y Eleagnus (Eleagnus pungens variegado). Sólo 5 especies representaron el 65\% del total (ver Figura 28).

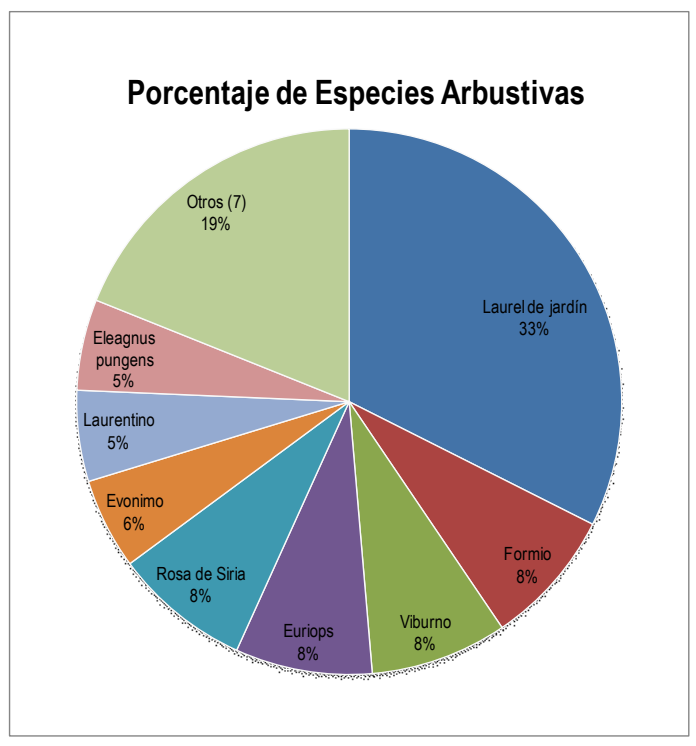

Figura 28: Porcentaje de especies arbustivas. Ámbitos de juego. Ciudad de La Plata. Año 2016.

Nuevamente la situación se repitió al igual que con las especies arbóreas. Sin embargo, la situación fue aún peor, no sólo por la mínima diversidad específica encontrada, sino porque este universo vegetal (arbustivas), posee en comparación con las especies arbóreas, una complejidad muchísimo mayor en cantidad de especies disponibles. Las especies arbustivas y herbáceas son las capaces de generar múltiples estratos vegetales, así como también las que tenemos al alcance de la mano, de la vista y del olfato principalmente. En este sentido, estas plantas son la clave para establecer otro tipo de relación con la naturaleza, que explore un nuevo campo de experiencias en la niñez. Como se desarrolló en las hipótesis, la baja variedad y cantidad de especies vegetales limitó seriamente las posibilidades de habilitar diversidad de experiencias para las infancias. 
Si analizamos la ubicación de dichas especies, se registró que el $63 \%$ se encontraron fuera del ámbito de juego, de manera perimetral, mientras que el $37 \%$ se encontró dentro. El $65 \%$ se correspondió con especies de cuarta magnitud, el 25\% especies de quinta magnitud y tan sólo el 10\% con especies de sexta magnitud. Las especies de quinta magnitud se encontraron con la práctica de topiaria o poda excesiva con pérdida de la forma original de la especie. Como puede observarse, se repitió el esquema existente con las especies arbóreas donde la mayor parte se encontró delimitando o acompañando de manera perimetral el ámbito de juego. Nuevamente, la naturaleza hubo que ir a buscarla y no formó parte integral del dispositivo lúdico.

El $93 \%$ de las especies arbustivas y herbáceas fueron perennes mientras que el $7 \%$ fueron caducas. Esto se explicó porque la gran mayoría de las especies arbustivas se encontraron bajo coberturas y, en este sentido, las especies que tuvieron mejor comportamiento en dichas condiciones ambientales fueron las perennes. Generalmente, las especies arbustivas perennes soportan mejor la baja disponibilidad de luz, lo que les permite vivir y desarrollarse bajo coberturas.

En el trabajo de campo, también se observó que el $62 \%$ de las especies arbustivas y herbáceas se encontró en estado adulto, mientras que el $33 \%$ en edad madura (ver Figura 29). En conjunto conformaron el $95 \%$ de la estructura de este estrato vegetal. Se registró nulo nivel de reposiciones recientes y se evidenció tan sólo un 5\% de plantas juveniles. La inexistencia de reposiciones, así como también la baja cantidad de especies juveniles, reforzó la idea de que no existieron proyectos paisajísticos particularizados para los ámbitos de juegos. Esto marcó una ausencia de lectura sobre las infancias actuales, cuáles fueron sus necesidades y hacia dónde van, en definitiva que den cuenta de los cambios diacrónicos vividos y por vivir. 


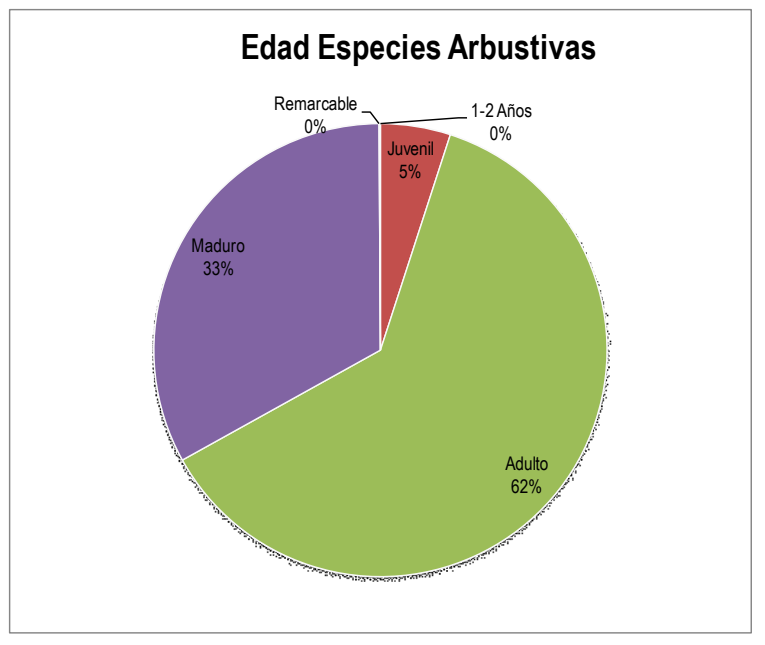

Figura 29: Edad de las especies arbustivas. Ámbitos de juego. Ciudad de La Plata. Año 2016.

Finalmente, respecto al estado fitosanitario de los arbustos y herbáceas se observó que el 65\% se encontró en la categoría de Regular y Malo, determinando que deberían ser reemplazados por su estado de deterioro. Sólo el 3\% se observó en estado fitosanitario Muy Bueno. El 32\% presentó estado fitosanitario Bueno, sin embargo, la gran mayoría de los ejemplares poseía topiado y pérdida de forma específica (ver Figura 30 y 31). Esta última situación, no hizo más que reforzar y agudizar lo planteado anteriormente ya que determinó la casi ausencia total presente y futura de un pobre estrato que se encuentra camino a la senectud.

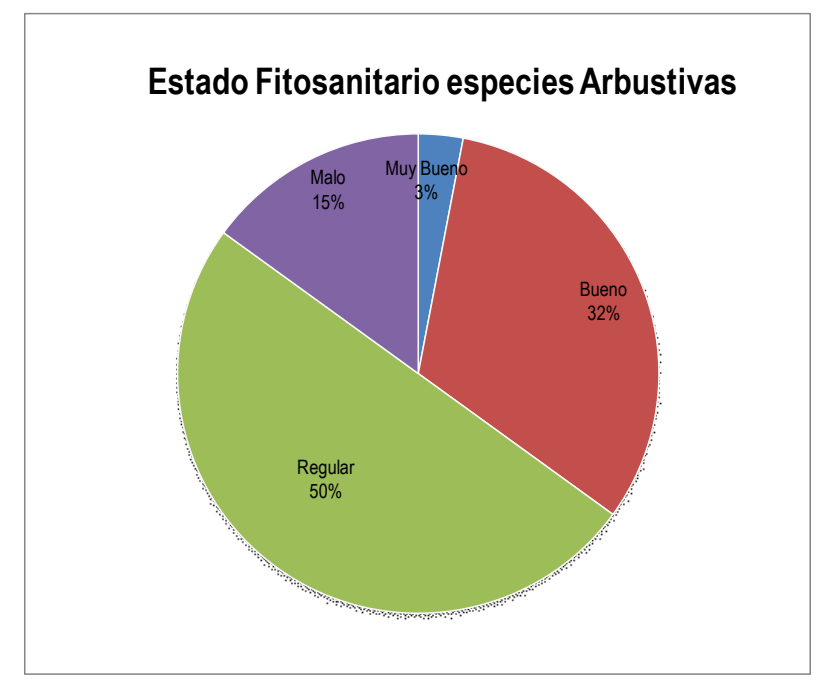

Figura 30: Estado fitosanitario de las especies arbustivas. Ámbitos de juego. Ciudad de La Plata. Año 2016. 


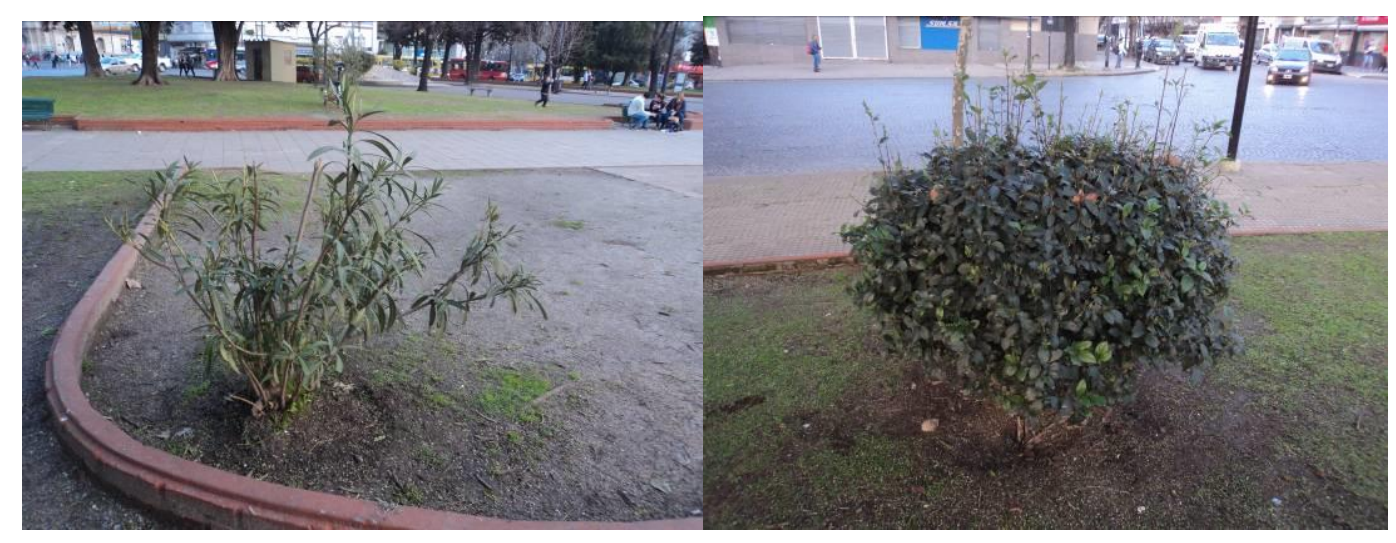

Figura 31: Plaza Italia: Se puede observar la presencia de arbustivas, Nerium oleander estado fitosanitario regular y Viburnum tinus en estado fitosanitario bueno pero topiado. 


\subsubsection{Categorización de las especies presentes en viveros comerciales}

\section{Diversidad botánica: Análisis de atributos tipológicos principales.}

Las especies relevadas, en el vivero comercial principal de la ciudad de La Plata, sumaron 354.

Las 354 especies son las que podrían ser utilizadas en distintos dispositivos lúdicos bajo algún diseño específico. Se computaron en esta lista sólo las especies de primera y segunda magnitud que por su anclaje radicular, su sanidad y su tipo de crecimiento se constituyen en especies muy estables que con los cuidados habituales de la arboricultura urbana no constituyen riesgo a las personas ni a los bienes. Por ejemplo, se eliminaron de esta lista Tipuana tipu, Enterolobium contortisiliquum, los Robles, los Eucalyptus, Araucarias. Se incluyeron algunos Pinos y Cipreses que tuvieron algún aporte recreativo. En este sentido, se incluyó el Pino piñonero por el fruto que puede ser utilizado para el juego.

Se eliminaron las especies excesivamente tóxicas como el Ilex aquifolium, Nerium oleander, Melia azedarach, Nandina domestica, Rhus succedanea; que podrían constituirse en elementos peligrosos para la niñez.

También se eliminó del listado Salix babylonica por gran magnitud, estructura de madera blanda. Por este motivo se eliminaron también los Álamos.

De las 354 especies, el 63\% se correspondió con especies de 6ta, 5ta y 4ta magnitud, especies sin riesgo por caída de ramas, de alto valor paisajístico y que aportan gran diversidad botánica a los ámbitos de juegos. Las menores proporciones se encontraron en las especies arbóreas, siendo las más frecuentes 3ra (24 \%) y 2da magnitud (12\%). Tan sólo el 1\% se correspondió con especies de 1ra magnitud (ver Figura 32).

En contraposición a lo existente en las plazas descripto anteriormente, aquí podemos observar un universo de posibilidades para explorar, con especies que priorizan el cuidado de la niñez para la conformación de espacios seguros. En este sentido, la eliminación de especies de gran magnitud, de 
maderas blandas y/o altamente tóxicas permitió tener un conjunto de especies capaces de abastecer otro programa de usos del espacio de manera cuidada y segura. Un programa que contenga otra relación con la naturaleza y que favorezca las relaciones vinculares entre niñxs, y entre niñxs y adultos, en clave de disfrute y goce pero también de reflexión, sorpresa, descubrimiento. Este precepto básico es el primer escalón a desarrollar en un camino hacia infancias autónomas, libres.

Por otro lado, la existencia de 354 especies plausibles de ser utilizadas, permite pensarnos en una diversidad de experiencias muchísimo mayor a la existente hoy en día. La capacidad de explorar se multiplica junto con las posibilidades de descubrir. Con este agrupamiento mínimo de especies relevadas, es viable pensar nuevas prácticas en el espacio público para la niñez, se puede comenzar a jugar con la naturaleza de manera diversa y autónoma. Esta situación se complejiza cuando analizamos el resto de los atributos tipológicos de las plantas relevadas, desarrollando una curva exponencial de experiencias por la combinatoria de los mismos.

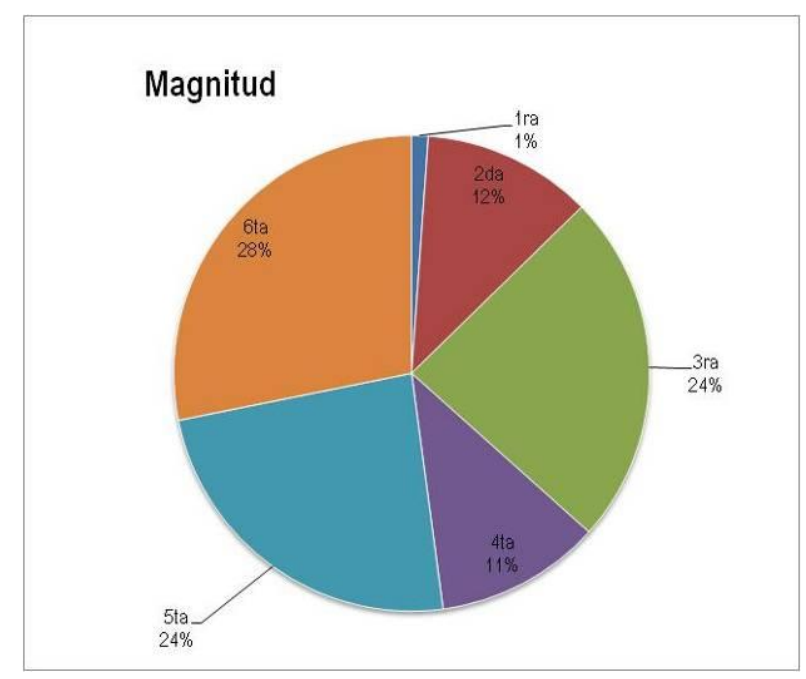

Figura 32: Distribución de magnitudes de las especies vegetales presentes en los viveros comerciales. Ciudad de La Plata. Año 2016.

Respecto al hábito vegetativo, se observó que el 63\% se correspondió con especies perennes y el $32 \%$ con especies caducas. Se registró como semipersistentes el 5\% (ver Figura 33). El gran porcentaje de perennes fue aportado por las especies arbustivas y herbáceas. Esta situación fue 
altamente positiva, ya que la existencia de coberturas arbóreas determinó casi en su totalidad el uso de especies perennes bajo las mismas. La posibilidad de contar con especies arbustivas y herbáceas perennes para proyectos particularizados para las infancias bajo estructuras arbóreas es un dato relevante.

A su vez, en el análisis de los árboles, se diferenciaron luego los tipos de sombra que proyectan. De esta manera, se observaron sombras laxas o calientes a sombras densas o frías, según el hábito vegetativo, silueta, densidad y textura.

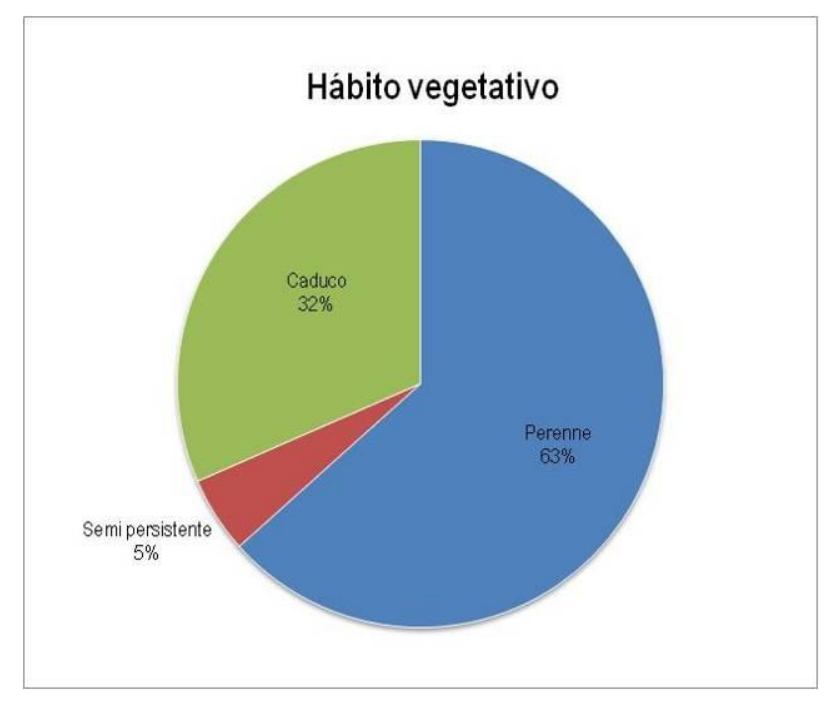

Figura 33: Distribución del hábito vegetativo en las especies vegetales presentes en los viveros comerciales. Ciudad de La Plata. Año 2016.

Respecto a la textura de las especies se observó que la mayor frecuencia fue de especies de textura media con 59\%, le siguieron las especies de textura fina (32\%) y tan sólo el $9 \%$ se correspondió con especies de textura gruesa (ver Figura 34). Como desarrollamos anteriormente, la textura es un atributo principalmente visual que se utilizó desde los orígenes del paisajismo. Es una característica formal de composición y diseño. Es de relevancia ya que nos permite establecer contrastes visuales, continuidades, determinación de ámbitos. Más adelante, se desarrollará también la textura en las plantas desde una perspectiva asociada al tacto, diferente al concepto original. Esta mirada más sutil es una categoría de atributo terciario para las infancias. 


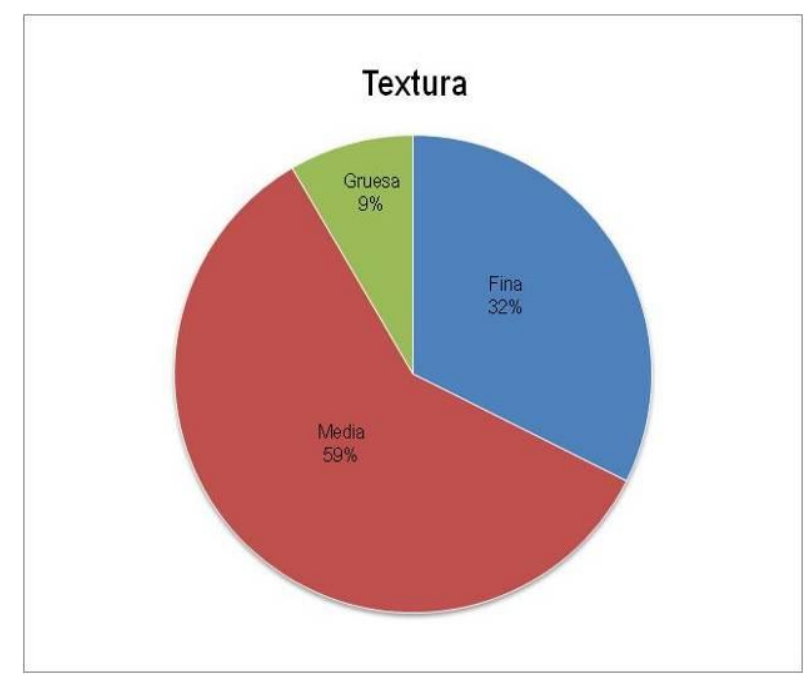

Figura 34: Distribución de texturas en las especies vegetales presentes en los viveros comerciales. Ciudad de La Plata. Año 2016.

Finalmente, el $40 \%$ se correspondió con árboles, donde la silueta predominante fueron la esferoidal y la elipsoidal (23\% en total). Finalmente se relevaron las formas cónica, triangular, circular, especial, irregular, péndula, aparasolada y columnar, todas ellas con menos del $4 \%$ cada una. La arquitectura de los árboles es el último atributo tipológico formal principal que otorga, junto con magnitud, textura y hábito vegetativo, la capacidad de definir ámbitos. Es posible observar las siluetas mediante un ejercicio de abstracción que nos permita observar la forma. Esta variabilidad puede determinar distintas experiencias a ser vividas. De esta manera, copas triangulares se pueden trepar desde la base por niñxs de cualquier edad, mientras que copas elipsoidales, esferoidales, circulares y cónicas sólo por jóvenes. Las siluetas columnares pueden funcionar como barreras, o como elementos que buscan marcar la verticalidad. También, este tipo de especies admiten una mayor densidad de plantación sin entrar en competencia, lo que permite crear la atmósfera de bosque con gran cantidad de presencia de troncos.

En otro sentido, el mayor porcentaje de las especies se correspondió con la tipología Arbusto y Arbusto/Arbolito (30\%) que junto a las herbáceas conformaron el $46 \%$ del total. A este grupo se sumaron la tipología de enredaderas (7\%) y gramíneas (4\%). La forma rastrero conformó el $2 \%$ del total (ver Figura 35). 
Finalmente, las palmeras representaron tan sólo el $2 \%$.

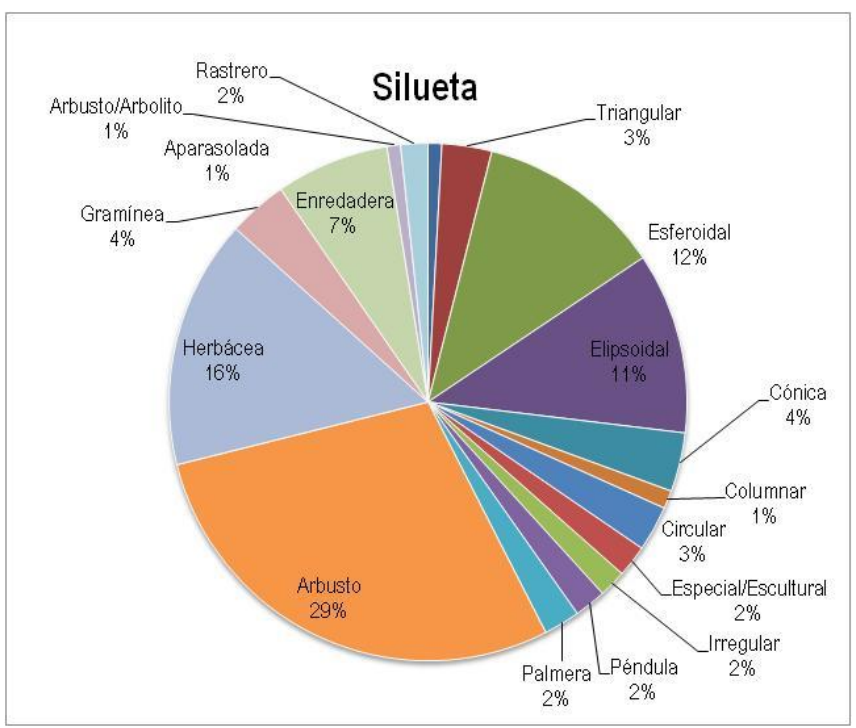

Figura 35: Distribución de siluetas de las especies vegetales presentes en los viveros comerciales. Ciudad de La Plata. Año 2016.

\subsubsection{Desarrollo de nuevas variables tipológicas}

\section{Especies precautorias}

En este grupo de especies se ubicaron las que poseen algún tipo de toxicidad (ya sea en hojas, corteza, fruto, flor o látex), las especies alergénicas, con espinas, aguijones u hojas con punta. Se eliminaron las que son excesivamente tóxicas o las que producen severas irritaciones, así como las que pueden constituir lastimaduras severas.

Se registró un total de 55 especies con algún tipo de toxicidad, alérgeno o elementos que puedan lastimar. Se encontraron 30 especies que poseen espinas o algún tipo de elemento punzante, 15 especies con toxicidad baja, 5 con algún grado de toxicidad y alérgenos leve, 2 con alérgenos muy leves, 1 especie muy tóxica, 1 muy tóxica y alérgena y 1 que reúne las tres características: frutos tóxicos, alérgena y punzante.

El universo presente en esta categoría no constituyó un grupo de especies a eliminar en la construcción de los ámbitos de juegos para niñxs. Pero es necesario tener claridad respecto a su uso y 
función y los peligros que esto conllevaría. La particularidad de este grupo de especies, en caso de ser usadas, es que debieran contener mecanismos de protección que impidan su ingesta o que las personas se vean lastimadas por la espinas o con afecciones alérgicas. Estos mecanismos de defensa pueden ser múltiples. De esta manera, se pueden constituir canteros que impidan la accesibilidad a este tipo de plantas (ver Figura 36) o simplemente se puede advertir mediante información en el lugar sobre las características que la planta posee. En este sentido, el trabajo en dispositivos lúdicos educativos que informen y prevengan sobre las sustancias y compuestos que poseen las plantas como mecanismo de defensa ante la depredación (que, en muchos casos, también pueden ser usadas para prevenir y curar enfermedades humanas y animales) es una manera de conocer y de activar un posible mundo de interés para las infancias.

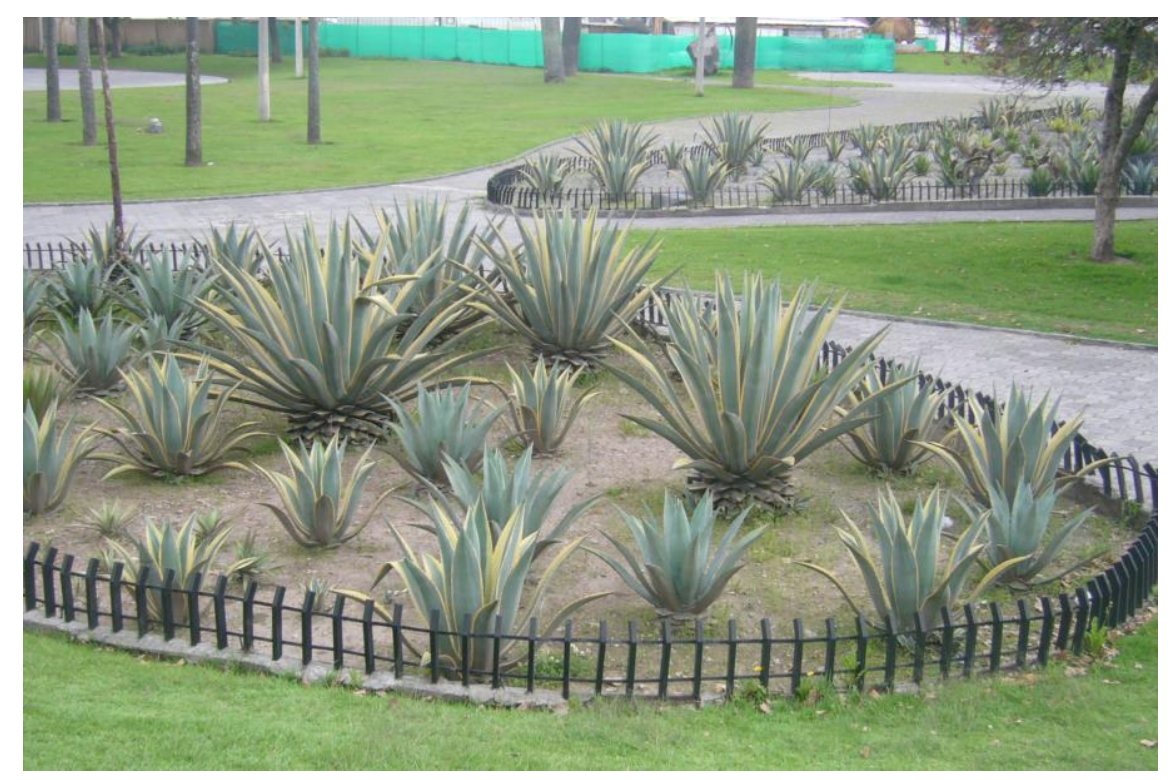

Figura 36: Especies de Agave sp. resguardadas mediante cerco perimetral. Quito, Ecuador. Año 2013.

La conformación de "jardines químicos o farmacéuticos o medicinales" así como también los "jardines venenosos" y los "jardines impenetrables", pueden ser dispositivos que nos permitan profundizar y expandir el conocimiento sobre las plantas. Es usual, en el espacio público, la prohibición o eliminación de grupos de plantas que representarían un riesgo potencial para cierto grupo social, ya sea porque tienen espinas o porque tienen algún grado de toxicidad. Esto genera mitos sobre ciertas 
especies fundados principalmente en el desconocimiento. El autor considera que el mecanismo de eliminación para prevenir no sería el más conveniente ya que en vez de profundizar sobre el conocimiento, y a partir de allí, comprender los posibles riesgos, se priva directamente de esta posibilidad. En este sentido, se cree que la solución no es la eliminación de todas las plantas con espinas de los espacios públicos, sino presentándolas de manera tal de que se pueda aprender a partir de ellas en una nueva forma de convivencia pacífica. Retomando lo planteado por Zaffaroni (2015), una nueva ética ambiental pone en debate una nueva relación con la naturaleza, no las eliminamos para nuestra mejor existencia sino que la comprendemos y buscamos la mejor manera de convivir.

Una propuesta que genere condiciones para la realización de experiencias que alojen la recreación de las infancias, busca conformar ámbitos diversos donde la autonomía del individuo tenga mayor relevancia, en un marco definido por los adultos. Si ese es el objetivo, el uso de las especies catalogadas como precautorias puede ser visto como una oportunidad para conocer y trabajar un discurso sobre la diversidad ambiental y establecer otras maneras de relación con la naturaleza. Lo primero que decimos haciendo presentes estas especies es darles entidad, existencia como elementos de la naturaleza que determina una vivencia particular. La presencia de este tipo de vegetación en los dispositivos lúdicos para niñxs es la excusa perfecta para abrir el abanico de conocimientos sobre las plantas, así como también poder advertir sobre los peligros que habitan en la naturaleza para la vida humana.

Se pueden experimentar o presentar distintos tipos de plantas con diferentes espinas, las mismas se pueden observar con lupa o con algún dispositivo. También se pueden presentar plantas con diversos principios tóxicos y desarrollar sus propiedades, aislar sus principios activos, aprender de química.

Finalmente, la existencia de estas especies ligadas a un discurso del conocer-se aporta en términos de la diversidad de experiencias vividas en un ámbito. En este sentido, las plantas 
precautorias, aportan en conocer el peligro, experimentarlo y saber que la naturaleza no es una entelequia, tampoco es idílica ni inabordable, sino real, diversa y compleja. La advertencia y conocimiento de este mundo vegetal permite a Ixs niñxs tener la capacidad de decidir de manera autónoma qué realizar ante circunstancias similares. Son dispositivos que aportan a la autonomía en las infancias.

\section{Especies Trepables}

Se registraron 47 especies, principalmente arbóreas, que tienen la capacidad de ser trepadas 0 escaladas con distintos grados de dificultad (ver Figura 37 y 38). En este sentido, se registraron plantas que pueden ser abordadas desde el piso por poseer ramificación basal. Éstas pueden ser abordadas por niñxs de menor edad y también pueden ser asistidos por adultos una vez arriba de ellas. Aquí, se encontraron las especies arbustivas grandes de 4ta magnitud como Blepharocalyx tweediei Anacahuita o la Thuja sp.

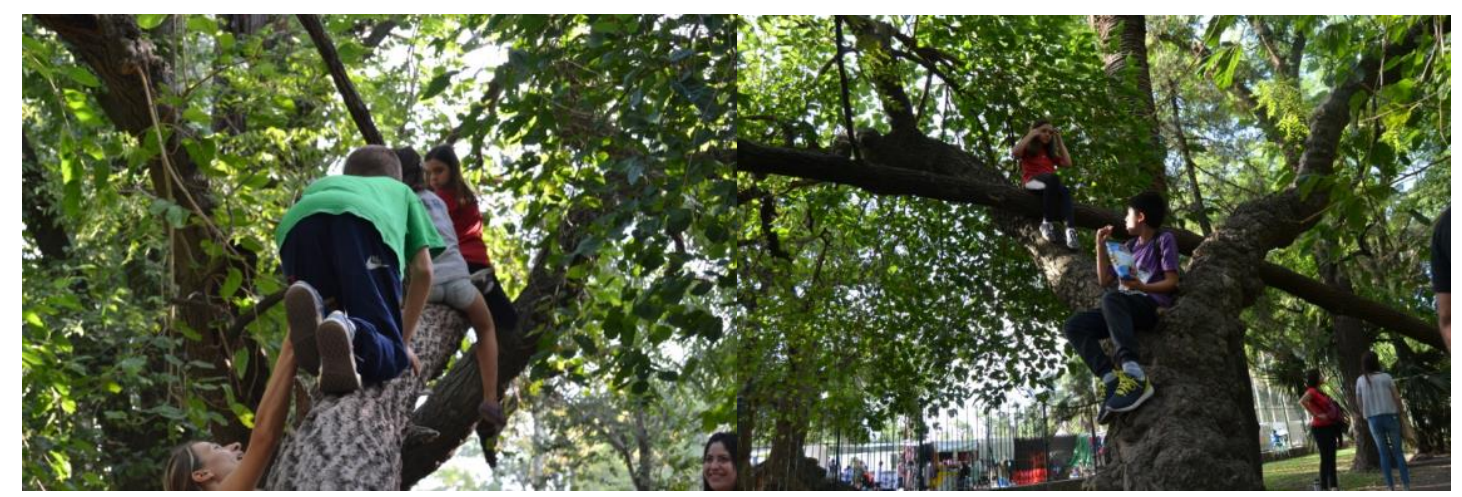

Figura 37: Árbol inclinado utilizado para trepar. Parque Saavedra. Ciudad de La Plata. Año 2018.

Un segundo grupo estuvo conformado por las especies arbóreas de 3ra magnitud, que pueden ser trepadas por niñxs de mediana edad, con o sin asistencia de adultos, conforman un nivel superior de dificultad, con mayor altura pero al alcance fácilmente por un adulto desde la base. Un ejemplo de esto son Erythrina crista-galli Ceibo o la Acacia dealbata Aromo Australiano.

Finalmente, encontramos un tercer grupo de especies conformado por árboles de 2 da y 1 ra magnitud, con mayor complejidad, al que se puede acceder a mayor altura, tanto niñxs como adultos. 
La arquitectura de las ramas tipo escalera y/o su crecimiento excesivamente horizontal permite crear estructuras de trepado natural disminuyendo los riesgos graves por caídas de gran altura. Esta disminución del riesgo se daría por dos circunstancias: interceptación de otras ramas ante un tropiezo o dificultoso acceso a sectores de caída libre.

Un ejemplo de esto es el Cupressus sempervirens Ciprés, la arquitectura de esta especie y el crecimiento horizontal de sus ramas, permite crear una escalera interior mediante la cual se puede trepar fácilmente. Este acceso desde el interior a grandes alturas conforma un ámbito que dificulta la caída libre. En caso de producirse, existe una gran cantidad de ramas horizontales que permiten aminorarla y a su vez ofrece múltiples posibilidades para volver a estabilizarse y reconstruir el equilibrio. Es muy difícil también en esta estructura quedar por fuera de la copa en un sector de vacío pleno.

Otra estructura fácilmente trepable, pero de manera horizontal, la conforman el Ficus elástica Gomero o el Cinamomun glanduliferum Falso alcanforero. Estas especies tienen un crecimiento de copas horizontal excesivo, de esta manera quedan a muy baja altura ramas de gran calibre que pueden ser abordadas por muchos niñxs a la vez. A su vez, desde estas ramas y desde la base surgen raíces que auspician de toboganes y lianas naturales de las que se pueden deslizar, colgar y trepar sin riesgo de ruptura.

En una sola categoría de plantas identificamos tres tipos de experiencias posibles de ser vividas. La posibilidad de descubrir hasta dónde uno puede llegar, de qué manera, cuáles son los escollos que encuentra, tener una visión desde arriba, ayudarse con amigos y amigas para lograrlo, habilitar el diálogo entre pares dentro del árbol en un ámbito íntimo, sentir la rugosidad de las cortezas, las hojas en la cara, son algunas de las posibilidades que pueden ocurrir en una experiencia de este tipo. Actualmente, se relevaron dispositivos lúdicos tipo escalera en los ámbitos de juegos. Si bien la actividad es la misma, trepar, las dimensiones que le ocurren a Ixs niñxs en una escalera metálica en 
comparación con un elemento vegetal son abismales. Pareciera que en los árboles son infinitas las situaciones vividas por cada unx de Ixs niños, donde un poco escapan a la mirada del adulto.

En este punto, existe un puente entre vegetación como habilitadora de diversidad de experiencias en la niñez y cómo se desarrollan en un campo de mayor autonomía para las infancias. La existencia del diálogo entre pares arriba de un árbol, o simplemente mirar lo que los adultos no pueden ver desde abajo, son propias de Ixs niñxs y cada unx de ellxs lo transforma en lo que cree y desea (ver Figura 38).

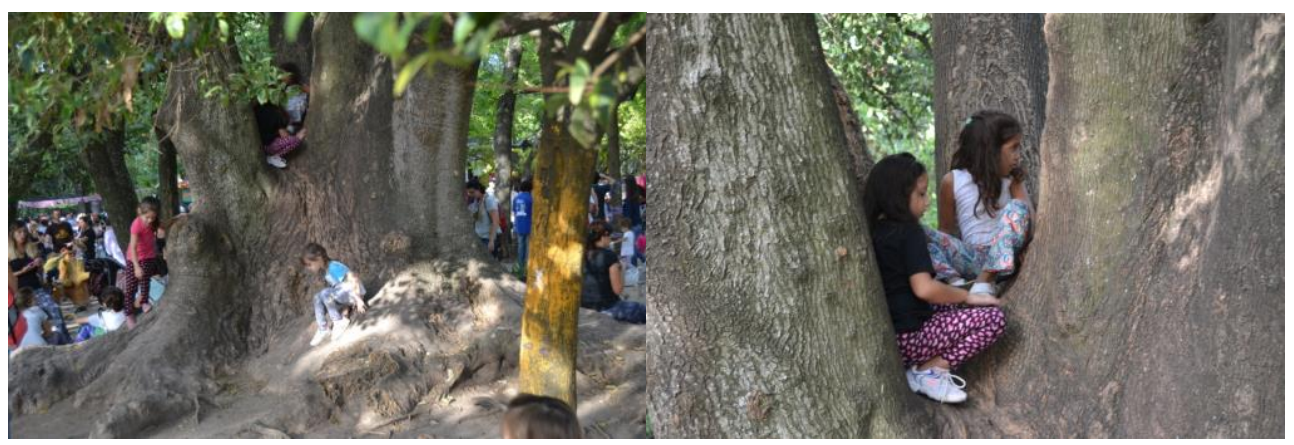

Figura 38: Niñas dialogando en la copa de un Ombú Phytolacca dioica. Parque Saavedra. Ciudad de La Plata. Año 2018.

\section{Especies con flores podables}

En esta categoría se encontraron 161 especies que en mayor o menor media poseen una floración que puede ser cosechada. Cuanto más masiva o prolongada es la floración, más oportunidades tiene de ser extraída. En muchos casos, Ixs niñxs cosechan flores para regalar a sus acompañantes adultos, como manera de retribuir o demostrar su afecto hacia ellos.

Las diferentes especies poseen diferentes tipos de floración. De esta manera encontramos floraciones masivas pero efímeras, como la de la Spiraea cantoniensis Coronita de novia, que admiten una cosecha importante de sus flores sin afectar el normal desarrollo de la planta. Tampoco por esta actividad se priva al resto de los asistentes de la contemplación de un floración, ya que aunque se cosechen flores es muy difícil que no queden en la planta. 
También en el grupo de especies con flores podables encontramos las floraciones prolongadas pero que no son masivas y no producen una espectacularidad tal como las anteriores especies. Estas plantas tienen una floración abundante que permite su cosecha por largos períodos sin afectar el crecimiento. Un ejemplo de esto es Abelia grandiflora Abelia que posee floración blanca prolongada o el Euriops pectinatus Euriops que tiene una floración amarilla prolongada y abundante sin ser masiva.

Por el contrario, otras especies tienen una floración muy limitada en cantidad pero extraordinaria en cuanto a su complejidad y belleza. Este tipo de plantas no fueron incluidas en el grupo de especies con flores podables, ya que se priorizó la posibilidad de que sean de disfrute colectivo más que individual. Un ejemplo de este tipo de plantas son las especies bulbosas, sólo producen por bulbo una vara al año de flores que puede tener una flor individual o un racimo, ejemplo Lilium sp. En este grupo se encuentran también los Agapanthus Flor de navidad, que sólo emiten una vara con flores por planta una vez al año. Entonces, sólo fueron incluidas en flores podables las especies que admiten el disfrute colectivo y el individual si se realizare cosecha de sus flores.

La categoría, especies con flores podables, abre hacia Ixs niñxs un mundo de vivencias que aportan a la idea de diversidad de experiencias desarrollada en puntos anteriores, así como también a la capacidad de realizar actividades de manera autónoma. De esta manera, la cosecha de flores puede ser en soledad o en grupo, donde cada unx elije qué flor cosechar y cuántas. En la colecta misma de flores se habilitan posibilidades: poder realizar un regalo a quien Ixs acompaña o a quién quedó en la casa, seleccionar y combinar colores para la realización de un racimo, tocar y oler las plantas (que generalmente emiten cada especie un aroma particular al ser cortadas), percibir la diferencia de tamaños, el polen y los insectos polinizadores, o simplemente deshojar una flor. Estas actividades no necesitan la supervisión directa de un adulto, sino que la pueden desarrollar de manera libre y espontánea. En los parques, es corriente observar niñxs cosechando flores del césped, la flor de Taraxacum officinale Diente de León, Allium triquetrum Lágrima de la virgen o de Oxalis sp. Vinagrillo (ver Figura 39 y 40). Existe aquí una posibilidad no explorada profundamente en esta tesis pero que 
deseamos dejar planteado, que consiste en la conformación de praderas florales que puedan ser transitadas por niñxs y que se encuentren al alcance de la mano, con el objetivo de fomentar una relación más estrecha con la naturaleza y donde se pueda cosechar flores, semillas y hasta plántulas.

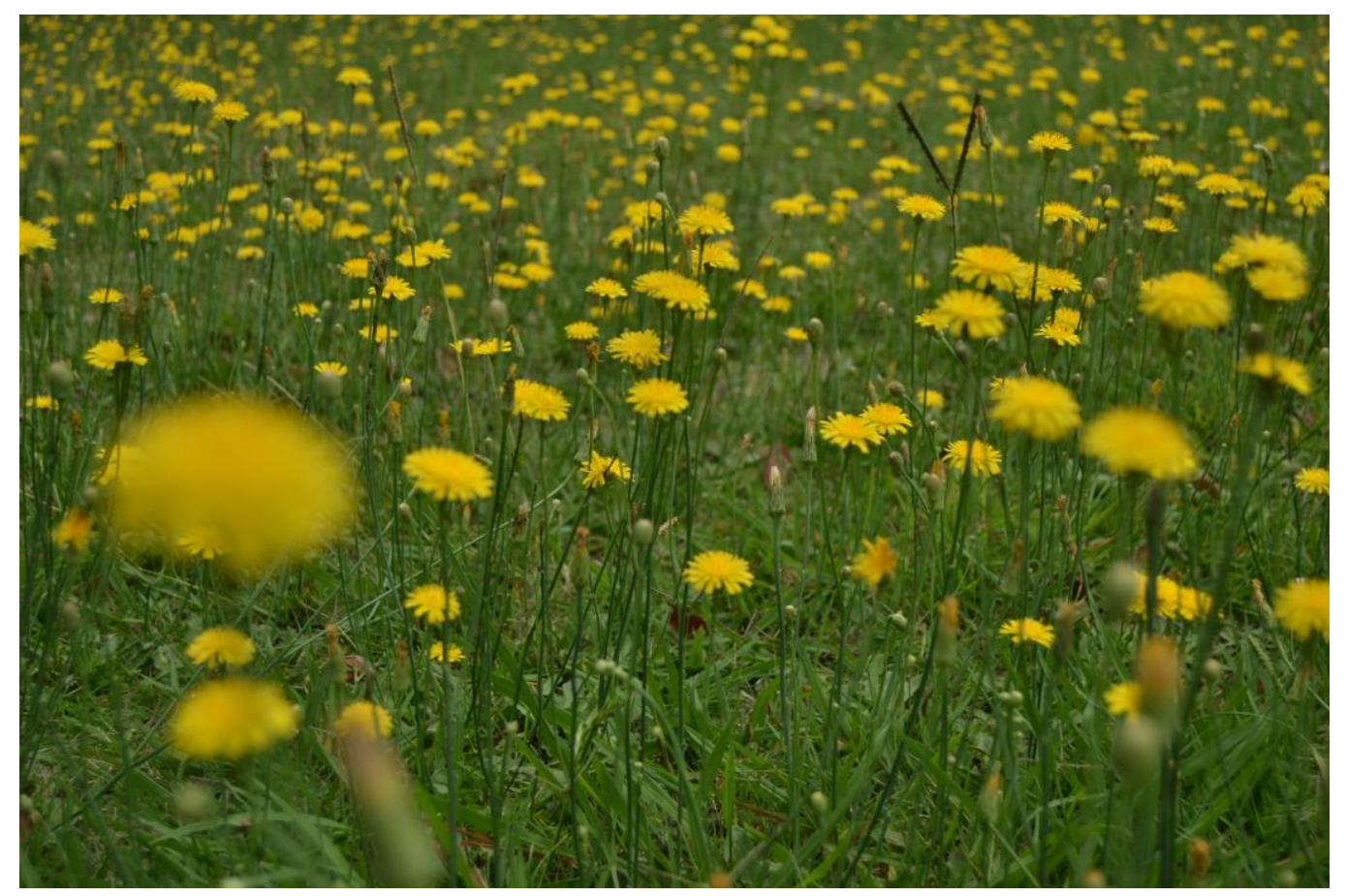

Figura 39: Pradera de Taraxacum officinale Diente de León. Es una especie interesante porque desarrolla en sectores con poca disponibilidad de luz bajo las coberturas arbóreas. Facultad de Ciencias Agrarias y Forestales. Ciudad de La Plata. Año 2018.

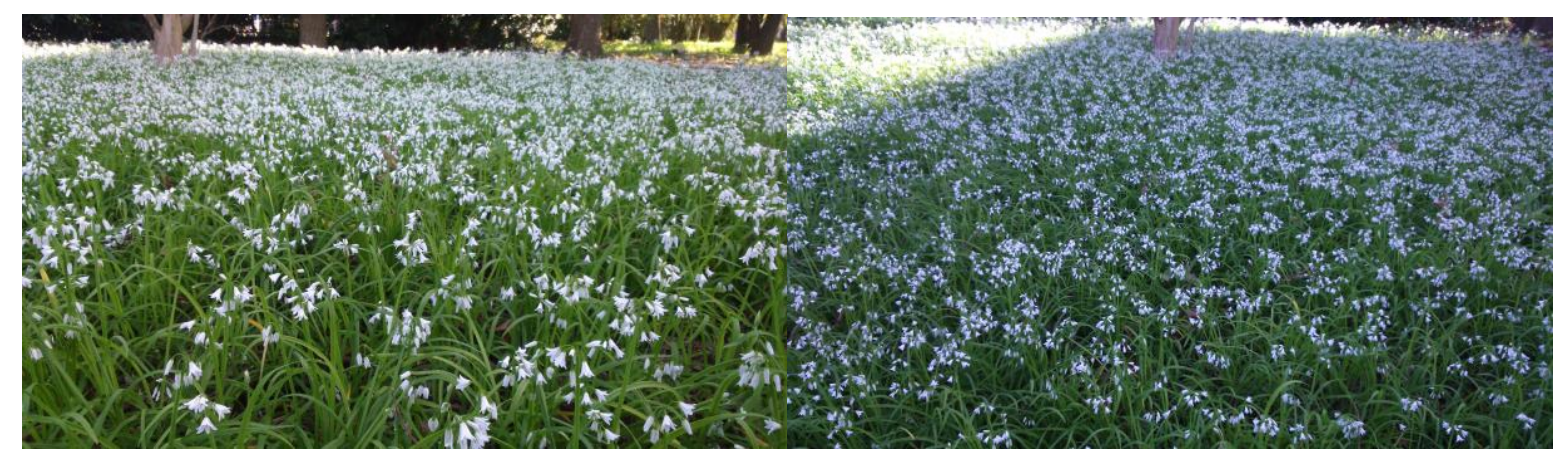

Figura 40: Pradera de Allium sp. Manto de la virgen. Desarrolla de manera espontánea bajo coberturas arbóreas. Facultad de Ciencias Agrarias y Forestales. Ciudad de La Plata. Año 2017.

En otro sentido, si a la acción de podar flores la acompañamos de un dispositivo educativo la experiencia es diferente: se puede aprender sobre la reproducción de las plantas, sobre cómo 
cosecharlas sin lastimar a la planta, cómo conservarlas, la existencia del polen y los insectos polinizadores, entre otros. Este tipo de dispositivos son los que aportan a la dimensión del conocer y del conocer-se conformando espacios autónomos para las infancias, donde a a partir del saber Ixs niñxs pueden elegir qué hacer, qué les gusta y qué no, cómo actuar.

\section{Especies contrastantes por color}

El color es una categoría que tiene gran interés en la niñez, a partir de allí aprendemos las gamas cromáticas, las singularidades, las preferencias, las asociaciones. El color en el paisaje es un atractor visual ineludible tanto para niñxs como adultos. En el trabajo de investigación se desarrolló la categoría color como la singularidad sobre una matriz verde que auspicia de fondo. Sin embargo, en paisaje el color no está dado solamente sobre una matriz verde. De esta manera, por ejemplo en una playa donde la matriz es arena amarilla el color de contraste en este caso es el verde. Por el contrario, en matrices policromáticas, el color pasa a ser la uniformidad o la secuencia. Así, también nos podemos preguntar cuál es el color de contraste en un paisaje de un sector de acopio de contenedores. En la categoría color pareciera que englobamos todo lo que produce una singularidad o contraste respecto a las matrices o estructuras de proyecto, a veces el color es textura y otras es densidad de plantación o flores u hojas. Para hacer abordable este universo, se unificó la matriz como si fuera verde y los contrastes que se producen allí ya sea por follaje (follajes glaucos, disciplinados), floración y/o fructificación.

En este grupo se encontraron 182 especies que tienen singularidad por floración. Estas especies tuvieron una floración de color que contrastó con el verde general. Un ejemplo es el Jacaranda mimosifolia Jacarandá o el Tecoma stans Lapachillo que poseen una floración violeta y amarilla respectivamente (ver Figura 41).

Se encontraron 19 especies que tiene singularidad de color por fructificación. Un ejemplo es el Schinus molle Aguaribay que posee las drupas globosas de color rojo violáceo. 
Hubo especies que compartieron singularidad por floración y fructificación. En este sentido, Heteropteris angustifolia Heteropteis, es ejemplo de ello con su trisámara roja y su floración amarilla.

Finalmente, se encontraron 63 especies que poseen singularidad por color del follaje. Los colores de follaje fueron glaucos (grises), atropurpúreas (bordeaux), disciplinados o variegados (amarillo y verde en la misma hoja), alba (blanco y verde en la misma hoja), áureos (tonalidades amarillas) y follaje discolor (generalmente verde en el haz y plateado en el envés de la misma hoja). E Senecio cineraria Senecio se caracterizó por su follaje glauco, el Prunus cerasiffera var atropurpúrea Prunus pisardi por su follaje atropurpúrea, el Phormium tenax Formio por sus variedades disciplinadas y púrpuras, la Feijoa sellowiana Falso guayabo por su follaje discolor verde brillante en el haz y glauco opaco en el envés.

El grupo de especies desarrollado en este punto, nos permite complejizar los diseños paisajísticos en base a contrastes o pasajes por color de follaje, fructificación o floración, así como también resaltar algún atributo paisajístico determinado. En las infancias, la variedad de colores resulta fundamental porque aporta a la diversidad de experiencias y también a la autonomía en la niñez en términos de elección. En diseños con escalas policromáticas se puede elegir qué deleita más, qué se prefiere observar, dónde se quiere estar. Se permite cosechar hojas o flores de distintos colores. También se puede generar ambientes más tranquilos con coloraciones suaves cálidas 0 más excitantes con múltiples tonalidades fuertes.

En otro sentido, si se lo asocia a un dispositivo educativo, a partir de diseños con múltiples tonalidades, se pueden enseñar los colores en las distintas edades. A su vez, a edades mayores, es posible comprender la causa de que las plantas posean dichas coloraciones, cómo los forman, así como también las funcionalidades que tienen en la naturaleza. Esta forma de saber aporta a la autonomía en las infancias ya que le permite ver más allá y cuestionarse lo que ve. 


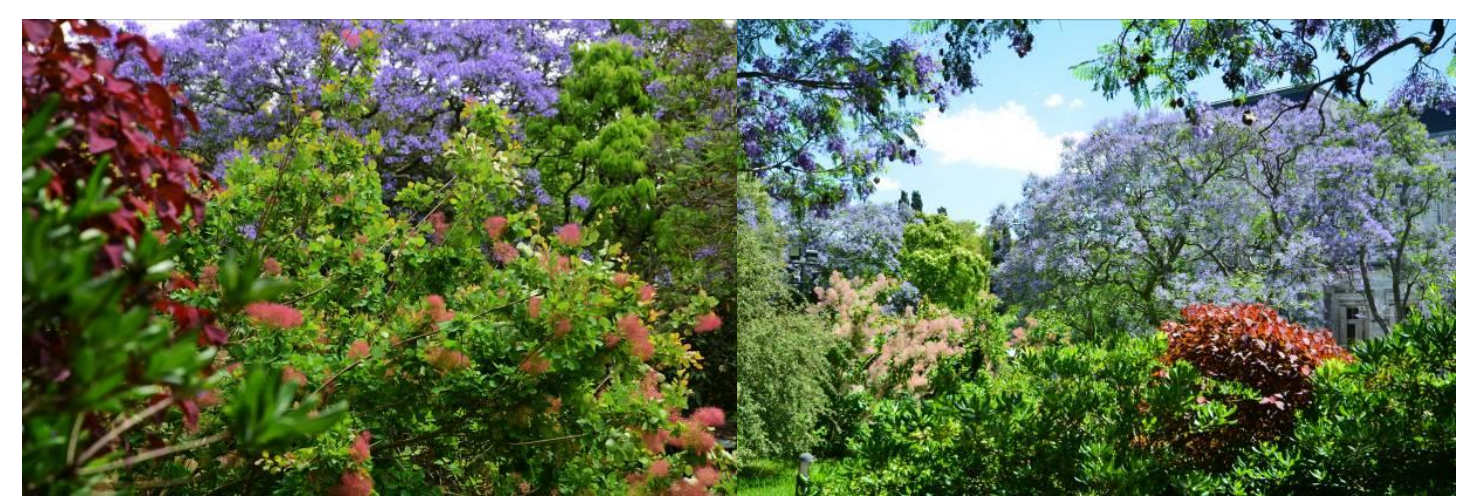

Figura 41: Se puede observar el color por floración del Jacarandá mimosifolia Jacarandá y de Cotynus coggyria Flor de humo. También se observa el contraste generado por el color atropurpúrea del follaje de Euphorbia cotinifolia Euforbia (Categorizada como tóxica). Jardín de la Memoria, Facultad de Ciencias Agrarias y Forestales, UNLP. Autor: Jorge Nedela.

\section{Especies comestibles}

En esta categoría se encontraron 41 especies que podrían ser utilizadas como comestibles, tanto en el uso de sus hojas y/o flores para las especies aromáticas como del fruto en las especies frutales. En el primer caso, se tomó como ejemplo el Rosmarinus officinalis Romero que se puede cosechar para su uso como especie aromática. En el segundo caso, el Diospyrus kaki Caqui que se puede cosechar su fruto como comestible.

En este grupo se encontraron especies con abundante fructificación que puede ser colectadas múltiples veces como Morus alba Mora y especies que tienen una fructificación más acotada como Pyrus comunis Peral.

El uso de especies comestibles en ámbitos para niñxs permite crear ese puente entre la producción y el consumo. En la ciudad se produce una separación entre producción y consumo que en muchos casos lleva a un desconocimiento sobre el origen de los productos.

La producción de alimentos como actividad y el conocimiento sobre la misma son posibilidades que deben estar presentes en las nuevas generaciones urbanas de niñxs. El grupo de especies relevadas en esta categoría, son plausibles para el proceso de germinación, crecimiento, desarrollo: floración y fructificación, cosecha de semillas, hojas o frutos. 
Esta categoría permite también trabajar recetas de cocina con las especies existentes, una manera de conectar la producción con el alimento. Un ejemplo de esta experiencia se desarrolló en el Jardín Botánico de la ciudad de Quito en el Jardín para niñxs, mediante recorridos pautados (ver Figura 42).

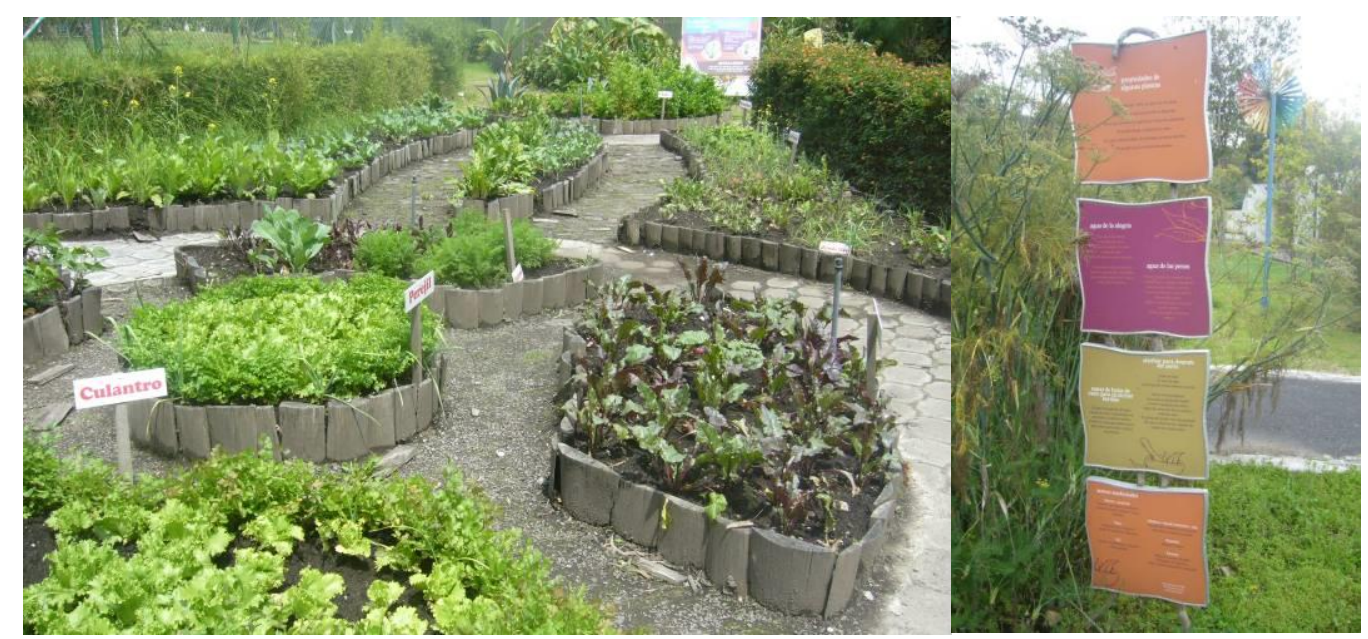

Figura 42: Producción de especies comestibles con sugerencia de recetas de cocina, una manera de aportar a la autonomía de las infancias desde la capacidad de preparar alimento. Jardín Botánico, Ciudad de Quito, Ecuador. Año: 2013.

Las especies aquí trabajadas aportan también a la diversidad de experiencias y a la autonomía en las infancias recreadas. Como se describió anteriormente, es necesario asociarlas a un discurso educativo de manera tal de potenciar una relación con las plantas, la producción y la alimentación. El alimento fundó y constituye las civilizaciones, la cultura. Compartir nuestros sabores, conocer desde dónde vienen, sitúa a Ixs niñxs en un momento y lugar histórico y los proyecta en un sentir qué les gusta, qué no, qué quieren prolongar, qué se puede continuar produciendo y qué no. En este sentido, los movimientos campesinos del mundo, desarrollaron la idea de soberanía alimentaria ${ }^{17}$ y la precisaron como la capacidad de cada pueblo para definir sus propias políticas agrarias y alimentarias de acuerdo a objetivos de desarrollo sostenible y seguridad alimentaria. Esta idea que sitúa a las

${ }^{17}$ Especialmente los ligados a la Vía Campesina, quienes con motivo de la Cumbre Mundial de la Alimentación de la Organización para la Alimentación y la Agricultura (FAO) del año 1996, desarrollaron el concepto de soberanía alimentaria. Gran cantidad de movimientos campesinos latinoamericanos tomaron esta idea como bandera de lucha de los pueblos. Tal es el caso del Movimiento Nacional Campesino e Indígena (MNCl) de Argentina. La idea de soberanía alimentaria se contrapone a la de revolución verde que fue presentada al mundo como la solución del hambre de la humanidad. 
personas como protagonistas en la producción de alimentos, pero también en el abastecimiento y comercialización como parte de una cultura colaborativa, solidaria y respetuosa, es quizá una llave para trabar con las infancias.

En este sentido, las huertas urbanas (ver Figura 43), los prados frutales o simplemente aprender de especies que podemos tener cotidianamente en los diseños de nuestros parques es una tarea que, ligada a la idea de soberanía y seguridad alimentaria, puede abonar a la diversidad de experiencias y la autonomía de elección como manera para desarrollar la dimensión del conocernos. Comprendernos dentro de ese ser colectivo social del que habla Bustelo (2007) que tiene que sobrevivir hoy y en el futuro.

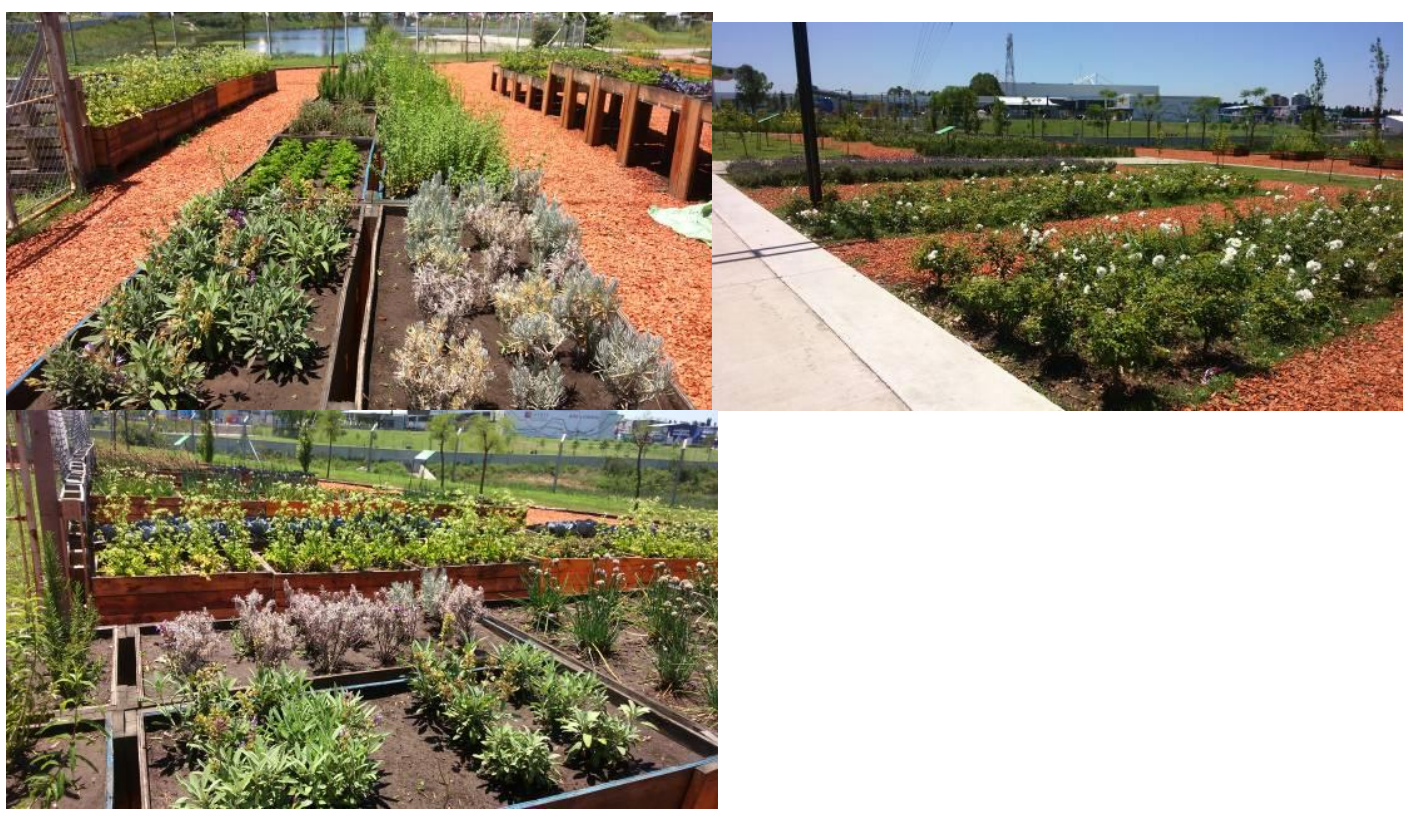

Figura 43: Huerta infantil. Parque temático Tecnópolis. Villa Martelli, Buenos Aires. Año 2015.

\section{Especies para laberintos}

Se registraron un total de 48 especies que pueden ser utilizadas para la construcción de laberintos o circuitos que se encuentren delimitados por especies herbáceas o arbustivas. Se observó que existieron dos grupos de plantas, las de 6ta magnitud que permiten ver por sobre la pared del laberinto, y las de 5ta magnitud que no permiten ver por sobre la pared del laberinto. En el primer caso se puede tener mayor control visual por parte de los adultos de Ixs niñxs que intervienen en la 
experiencia. En el segundo caso, sólo se los puede ver desde un nivel superior que exceda las paredes del laberinto.

El primer grupo de plantas permite la utilización del laberinto por niñxs de edades muy tempranas ya que pueden desarrollar una experiencia laberíntica donde Ixs niñxs no pueden ver a través de las paredes pero pueden ser observados por los adultos. Un ejemplo de este grupo de plantas es el Dietes bicolor Dietes, el Equisetum hyemale Equisetum o los Penisetum sp.

El segundo grupo de especies, puede ser utilizado por niñxs de mayor edad ya que las plantas poseen más altura. Este tipo de elementos vegetales pueden ser vivaces (aparecen sólo en verano) 0 perennes. En el primer caso, la Canna indica Achira o el Hedychium coronarium Caña de ámbar, son especies muy adecuadas para la conformación de macizos que pueden convertirse en laberintos distintos todos los años según el corte que se realice de la misma. Por el contrario, las especies perennes conforman un mismo laberinto todo el año, entre las que se encuentran Phylostachis sp. Caña, Hedychium garderianum Garderianum, Alpinia speciosa Alpinia o Cyperus alternifolium Papiro. Estas especies tienen la particularidad de que no sólo permiten definir las paredes de un laberinto sino que también permiten crear túneles naturales por la unión de sus partes aéreas.

La experiencia del laberinto también aporta a un universo de experiencias inexplorado. La intriga, el descubrir, la tristeza o felicidad de la soledad, la ayuda colectiva, el perderse, la superación, el comenzar y llegar, la trampa, el miedo a no salir, el escucharse, son algunas de las vivencias que se pueden dar en un laberinto que aportan a la diversidad desarrollada en esta tesis.

Pero también se desarrollan otras dimensiones que habilitan la autonomía en las infancias. El no ser visto por los adultos permite que el secreto, el diálogo entre pares, el beso, las caricias, las miradas cómplices, el odio y la bronca, entre otros, tengan un lugar, existan sin represiones 0 condicionamientos morales. 
En este sentido, Bauman (2013, p.36) define al secreto como:

Un secreto, como las demás posesiones personales, es por definición esa parte del conocimiento que se impide y prohíbe compartir con los demás y/o que se controla celosamente. Es lo que delimita la privacidad o como lo llama: el territorio de la soberanía exclusiva, dentro del cual cada uno tiene el poder total de decir quién y qué soy.

Habilitar espacios donde pueda conformarse el secreto y quizá ser compartido entre pares es una posibilidad que se cree no debe despreciarse.

\section{Especies para refugio}

Existe un grupo de plantas que tienen la posibilidad de crear refugios naturales donde Ixs niñxs pueden desarrollar actividades de manera resguardada y jugar a lo que la imaginación les convoque.

Este tipo de plantas les permite entrar debajo de su copa ya que, por su forma, genera un vacío interior con las ramas que llegan hasta el suelo. Depende la especie, son refugios más umbríos y cerrados o más laxos y visibles. En ambos casos la idea es la de brindar un lugar seguro para el juego libre sin la mirada directa o plena de los adultos, crear un espacio íntimo de la niñez que sugiera cierta autonomía.

Estos ámbitos de refugio deben ser perfectamente conservados en términos de limpieza y de resguardo de extraños. Los ámbitos de refugio es conveniente que no sean plenamente ciegos de manera tal de que se pueda acceder desde el exterior en diferentes puntos, tanto para niñxs como para adultos. Para ello puede ser necesaria alguna escamonda de entresaca de ramas que genere entradas o bordes laxos y no plenos.

Se registraron un total de 71 especies capaces de generar refugios naturales. En este grupo de plantas se incluyeron las enredaderas que son capaces, mediante la construcción de una estructura, conformar este tipo de ámbitos. Se computaron 19 enredaderas, tales como Wisteria sinensis Glicina o 
Thunbergia grandiflora Bignonia azul que mediante una estructura pueden cubrirla y conformar un ámbito interior.

En el grupo de la especies que tienen una arquitectura que crea ámbitos interiores se registró el Jazminum meznyi Jazmín amarillo o la Acacia bayleyana Bayleyana (ver Figura 44). En el primer caso se conforma una estructura interior con alta densidad de ramas perimetral por lo que necesita un corte de las mismas para poder conformar un refugio más amplio y con acceso de luz. En el segundo caso se forma un ámbito interior de mayor tamaño y de bordes más laxos. Lo mismo sucede con la Magnolia liliflora Magnolia lila (ver Figura 45).

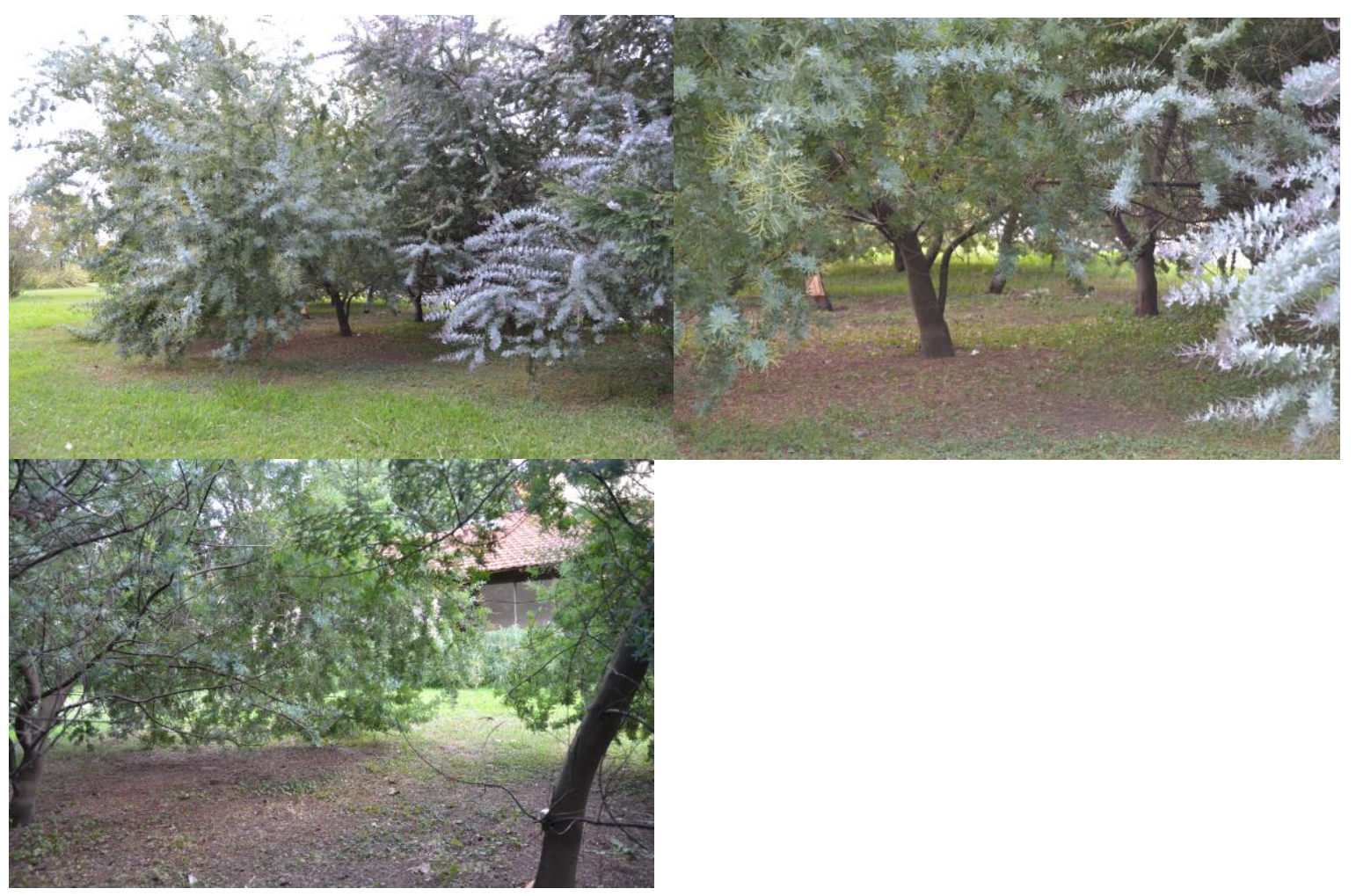

Figura 44: Se puede observar el espacio existente dentro de una Acacia bayleyana. Polo Industrial Ezeiza. Ezeiza, Buenos Aires. Año 2017. 


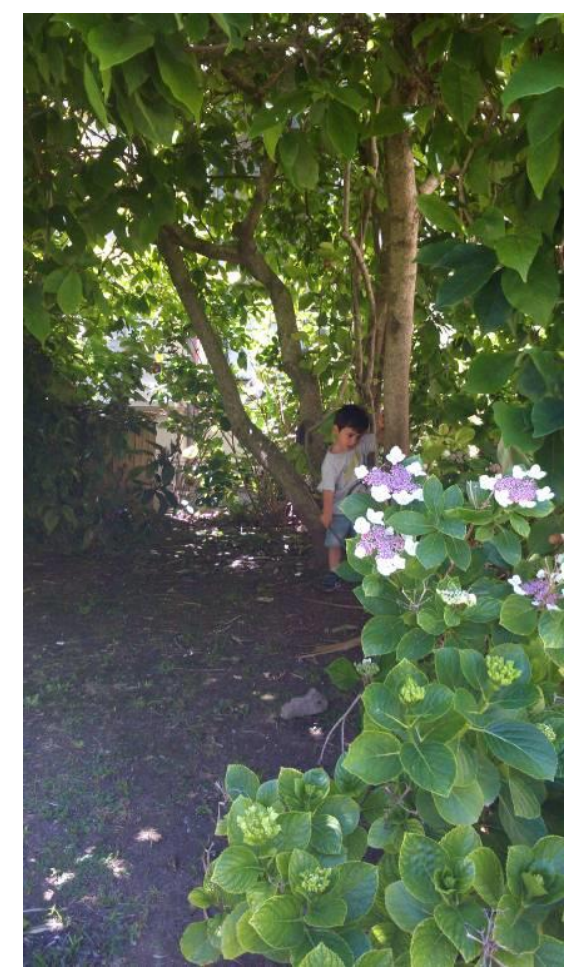

Figura 45: Se puede observar una Magnolia liliflora siendo utilizada como refugio y para trepar.

A su vez, existen especies que no generan refugio salvo que condiciones externas lo conformen (ver Figura 46).

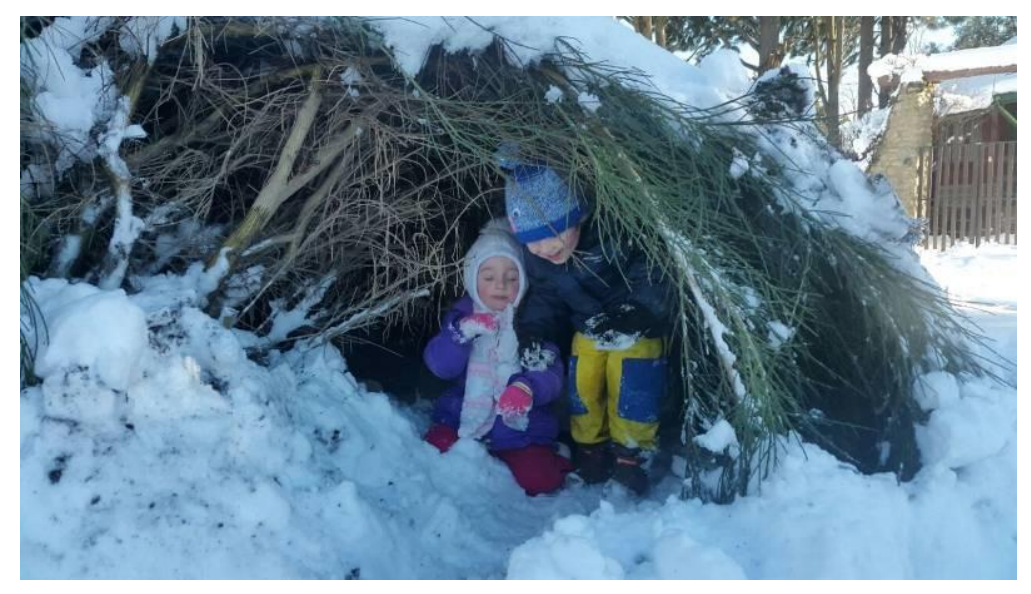

Figura 46: Este conjunto de Retamas se convirtieron en un refugio natural luego de nevadas. El peso de la nieve arqueó su arquitectura y formó la concavidad de acceso. Bariloche, Argentina. Año 2017

Como se mencionó anteriormente, este grupo de especies pueden conformar ámbitos que abonen a la idea de autonomía como vehículo hacia las infancias recreadas. El refugio también puede ser pensado como casa, como posible hogar temporal, donde niñxs puedan jugar a la creación de un 
hábitat propio. Este lugar, al igual que el laberinto, permite a Ixs niñxs dialogar, constituir complicidades, tener intimidad. Aquí, el secreto se enhebra como la posibilidad de Ixs niñxs de hacer y decir algo propio, entre ellxs, ajeno a los adultos, que cree lazos y formas únicas para cada niñez, es la posibilidad de habilitar la disrupción con el mundo superior controlador.

En términos de diversidad de experiencias, el refugio nos permite, al igual que el bosque, acceder a espacios de mayor penumbra, mayor humedad, nuevos olores. A su vez, la fauna de insectos existentes en este ambiente es particular por lo que se descubre un nuevo panorama de naturaleza. En este tipo de ámbitos, también el viento y la temperatura son distintos. Finalmente, la estreches de los espacios ubica a Ixs niñxs en la necesidad de descubrir nuevos movimientos y pensar si les gusta o no ese tipo de lugares donde hay un acercamiento a la sensación de claustro.

\section{Frutos y semillas}

Se registró un total de 137 especies, de las cuales 38 se correspondieron con frutos comestibles. Las especies registradas en esta categoría no poseen fruto o semillas comestibles pero tampoco tóxicas. Esta categoría tienen la función de establecer un grupo de especies que poseen una producción de frutos y/o semillas que pueden ser recolectadas para su uso en el juego. La cosecha puede realizarse de manera directa por Ixs niños, del suelo o se pueden proveer en sectores destinados a tal fin (ver Figura 47 y 48).

Este tipo de especies no comprometen su sobrevida ni la vida útil de la plantas por la cosecha de semillas o frutos. La colecta de semillas también permite a los asistentes conservar parte de la experiencia vivida y reproducirla en sus hogares. La semilla como fuente de vida, como el germen de un futuro movimiento de millones de células que se reproducen y que producen su propio alimento como iniciadores de la cadena trófica es una experiencia que no puede ser negada en las infancias. Poder plantar en su casa aquellas semillas que recogió del parque puede ser un factor vincular entre niñxs y espacio público y privado, lo colectivo con lo individual, entre naturaleza y ciudad. 
Un ejemplo típico de frutos lúdicos es el Brachychiton populneum Braquiquito, que posee un fruto folículo o polifolículo que al liberar las semillas forma dos estructuras similares a pequeños barcos. Respecto a la cosecha de semillas viables, la especie Caesalpinia gilliesii "Barba de chivo" permite cosechar de sus legumbres dehiscentes semillas viables para su posterior plantación.

En este sentido, pensar especies que puedan aportar a la diversidad de experiencias desde la cosecha, agrupamiento y plantación de frutos y semillas permite pensar las plantas como una fuente de elementos lúdicos. Esta categoría se relaciona con la siguiente referida a semillas volubles, donde una particularidad del fruto y la semilla nos permite pensarlas como voladoras.
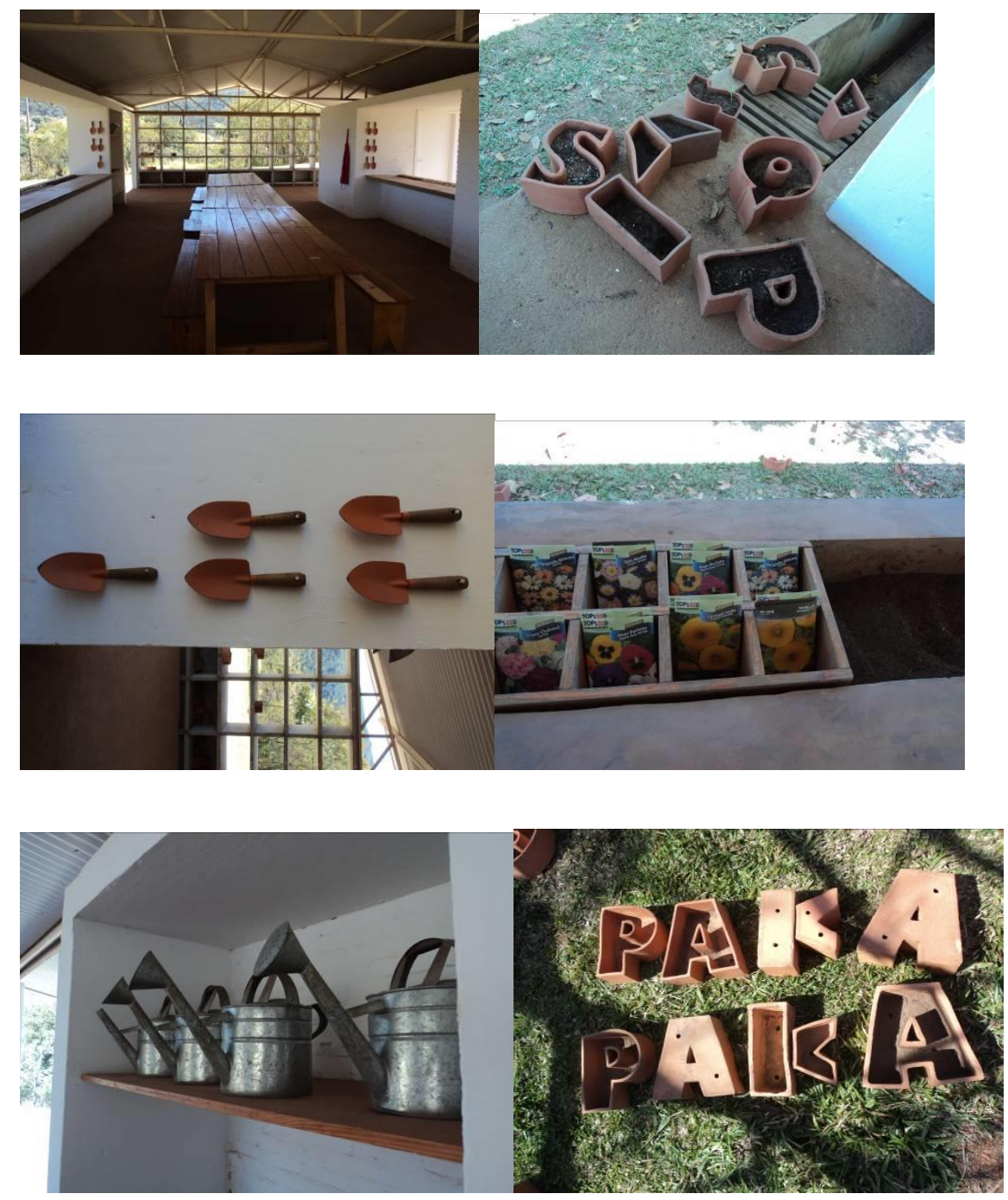

Figura 47: Esta instalación propone la formación de palabras a partir de macetas que se siembran con semillas de plantas. A origem da obra de arte. Marilá Dardot. INHOTIM, Belo Horizonte, Brasil. Año 2002. 


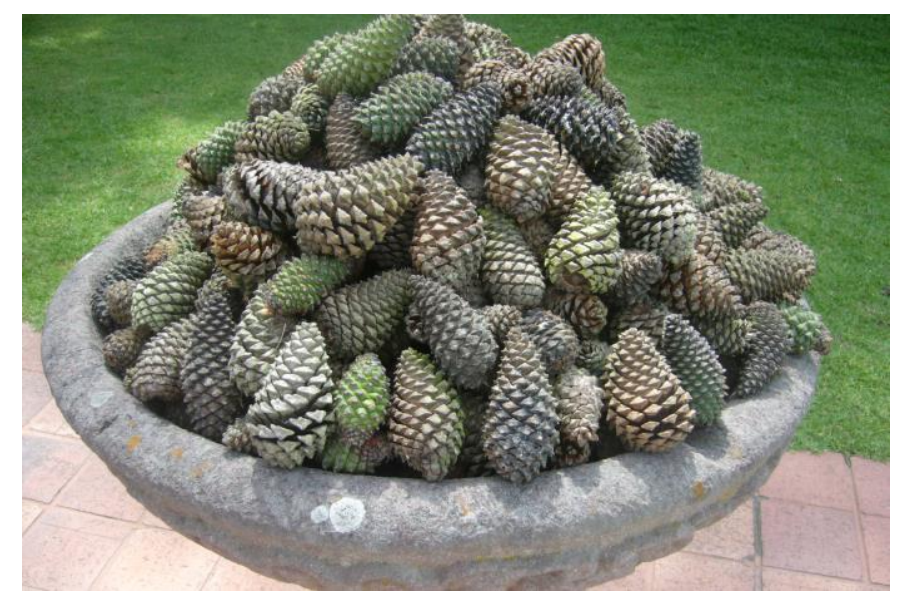

Figura 48: Piñas de Pinus sp. dispuestas en cuenco. Museo de Guayasamin. Quito, Ecuador. Año 2013.

\section{Especies con semillas volubles}

En este grupo se registraron un total de 25 especies que poseen semillas o frutos que se distribuyen por medio del viento, por lo que tienen la capacidad de "volar". Los frutos tipo sámara, disámara, trisámara, cipsela, pequeños aquenios, etc. Estos frutos son los que denominamos helicópteros, plumerillo, plumero.

La especie típica de esta categoría son los "Helicópteros" del Fraxinus pennsylvanica Fresno en referencia a su semilla. Esta especie produce, en los ejemplares femeninos, una abundante fructificación de sámaras que al caer giran en forma de hélice. Es común observar niños colectando estas semillas y lanzándolas al aire para verlas caer. Lo mismo sucede con el plumerillo del Taraxacum officinale Diente de León, que Ixs niñxs colectan para soplar y hacer volar sus semillas.

Si asociamos los grupos de frutos y semillas a un discurso educativo, podremos aprender sobre la reproducción de las plantas: la formación de la flor, fruto y semilla y su posterior diseminación. Es posible empezar a comprender el funcionamiento de los ecosistemas y sus cadenas tróficas. Una forma de aportar a comprender la vida en las ciudades y su importancia. A partir de aquí podemos llevar una partecita del parque a nuestras casas para hacer germinar las semillas y tener nuestra propia planta. También, puede existir un muestrario de diferentes tipos de semillas, de manera tal de poder observar la variabilidad existente y las distintas estrategias que se da la naturaleza para 
prosperar. Estas situaciones son las que aportan al conocerse de la niñez y que les permite poseer mayores grados de autonomía. La capacidad de poder elegir qué hacer con una semilla, cuál es más agradable, qué especie queremos reproducir, o simplemente descartarla por falta de interés, es un camino a transitar y profundizar hacia infancias más autónomas, más libres. Este tipo de experiencias, también brindan la posibilidad de establecer un puente compartido con los adultos, donde se pueda producir el diálogo a partir de una vivencia mutua. En este sentido, reafirmamos que entendemos la autonomía como una nueva forma de relación con el mundo adulto, que no lo niega pero que sí le establece un nuevo marco.

\section{Especies monumentales}

En este grupo se registraron especies arbóreas de segunda y primera magnitud y sumaron un total de 11. Se registraron dos tipos de monumentalidad, especies que por su altura constituyen un hito y especies que lo hacen por el tamaño de copa. En el primer grupo se encontró Platanus $x$ acerifolia Plátano y en el segundo Cinnamomum glanduliferum Falso alcanforero o Ceiba insignis Palo borracho (ver Figura 49, 50 y 51).

Las especies monumentales las asociamos a la diversidad de experiencias. En este caso, poder estar junto a un elemento gigante e inabarcable sitúa al individuo en un lugar de insignificancia y le permite comprender la relatividad de las cosas: sentirse por un rato como una hormiga. La monumentalidad atrae, porque en parte escapa a la razón humana la existencia de elementos vivos de tal magnitud. Los "árboles lobo" de la selva son los elementos vivos más grandes del planeta, la humanidad no conoció seres vivos más grandes que ellos. Tener la posibilidad de estar junto a uno de estos ejemplares, tocarlos, mirarlos de cerca y de lejos, imaginar cómo circula el agua y la savia en su interior, pensar en algún día treparlos o simplemente sentirse protegidos bajo su copa, son algunas de las vivencias de las que no podemos privar a las infancias. 


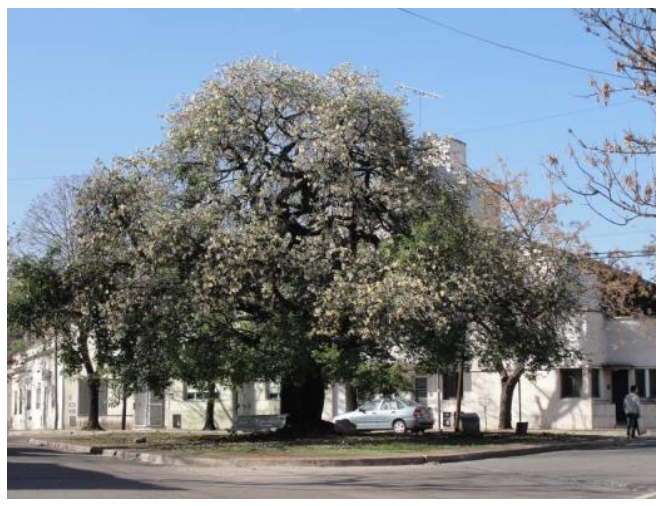

Figura 49: Ceiba insignis Palo Borracho. Ejemplo de especie registrada en la categoría Monumentalidad. Ciudad de La Plata plazoleta calle 18 y 61. Año 2015.

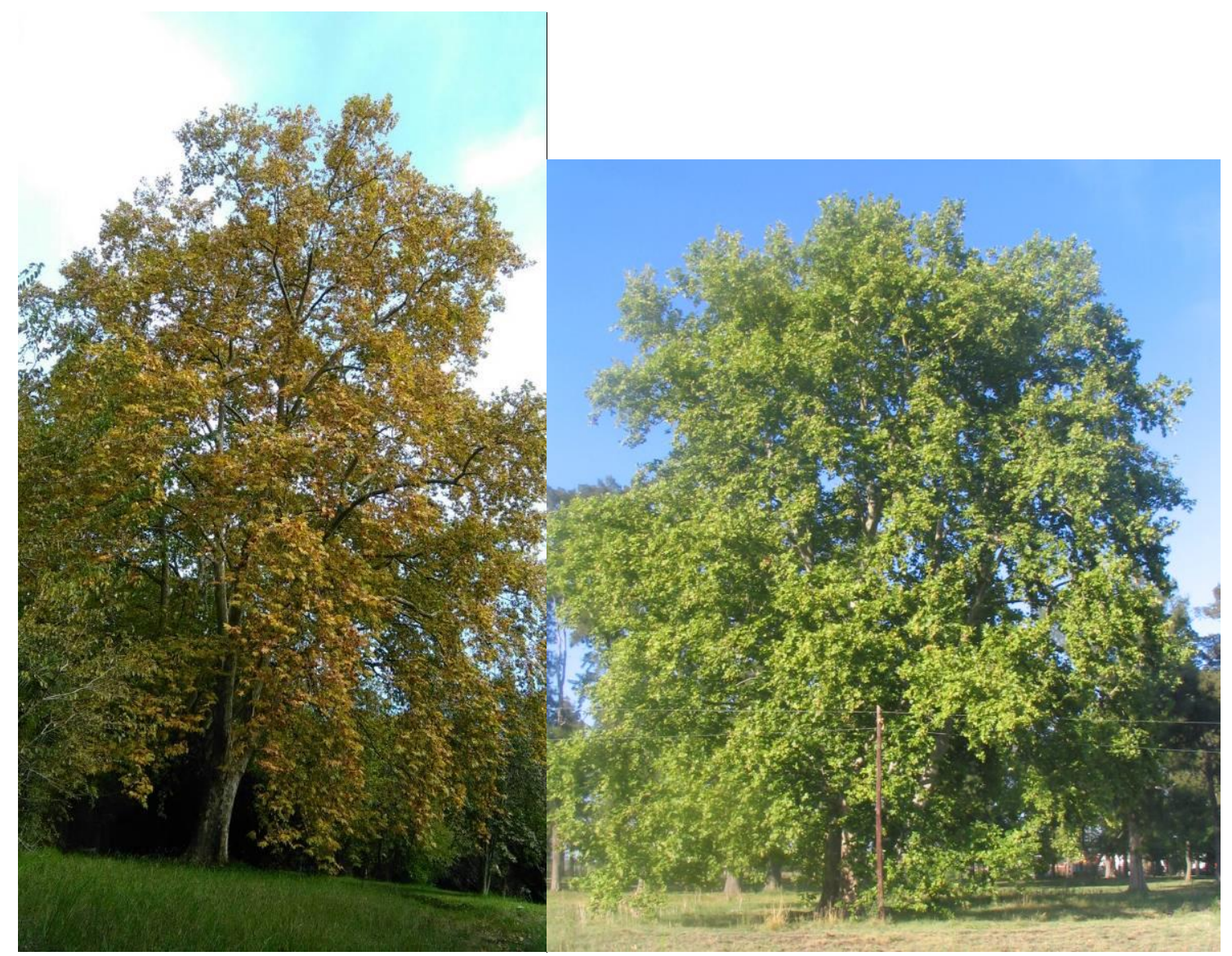

Figura 50: Platanus x acerifolia Plátano. Ejemplo de especie registrada en la categoría Monumentalidad. Parque Provincial Pereyra Iraola, Buenos Aires. Año 2009. 


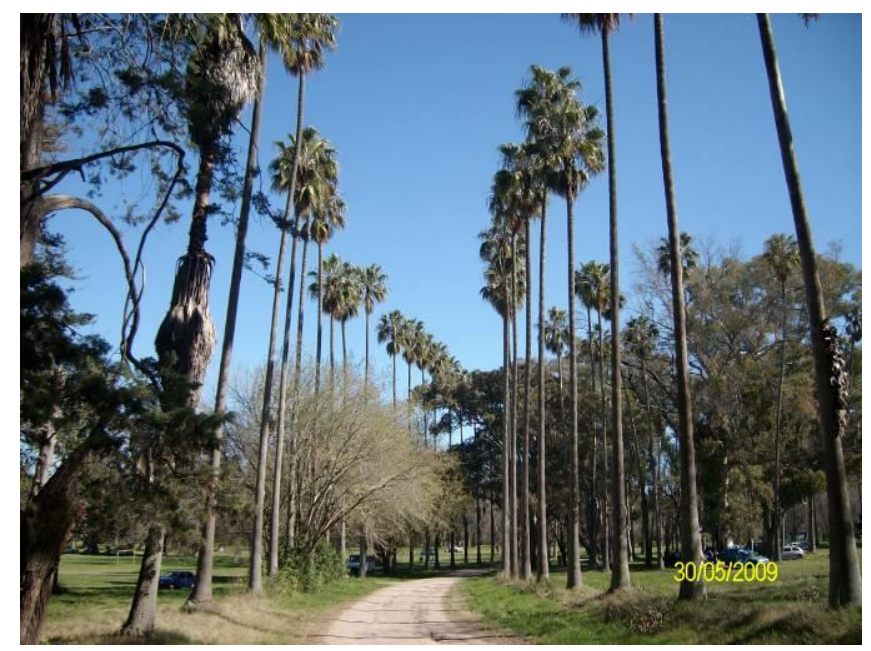

Figura 51: Washingtonia robusta Washintonia. Ejemplo de especie registrada en la categoría Monumentalidad. Parque Provincial Pereyra Iraola, Buenos Aires. Año 2009.

\section{Especies para sombra}

En esta categoría se registraron un total de 73 especies arbóreas de 1ra, 2da y 3ra magnitud. Todas caducifolias, porque lo que se buscó fue tener un grupo de especies que puedan brindar sombra en primavera-verano y sol en otoño-invierno, de manera tal de aumentar la confortabilidad térmica de los ámbitos. Se registraron un total de 12 especies de sombra plena o frescas. En este grupo se encontró la Catalpa bignoniodes Catalpa y el Fraxinus pennsylvanica Fresno americano.

Luego se encontraron 37 especies que brindan sombras medias. En este sentido, Senna spectabilis Acacia carnaval o Rhus typhina Rus fueron algunos de los exponentes (ver Figura 52).

Finalmente, se identificaron 24 especies que brindan sombras laxas o calientes. Erythrina cristagalli Ceibo y Salix humboldtiana Sauce criollo formaron parte de este conjunto.

La existencia de sombra en la niñez y en los adultos en el espacio público es una premisa básica para la confortabilidad de los ámbitos. En días calurosos de primavera-verano, los ámbitos a sol pleno encuentran limitado su uso de manera drástica, no sólo porque las temperaturas a pleno sol son agobiantes, sino porque los pavimentos y los juegos para niñxs adquieren temperaturas extremas 
difíciles de soportar. Este aumento de temperaturas se prolonga durante el día evitando su uso incluso en horas de la tarde-noche (ver Figura 53).

A su vez, la presencia de ámbitos frescos permite evitar en primavera-verano el golpe de calor y quemaduras por excesiva exposición al sol, así como también, la existencia de sombras confortables, permite aumentar la vida útil de los materiales existentes a resguardo del sol.

La calidad de esa sombra está dada por el tipo de cobertura utilizada, de esta manera podemos tener sombras laxas muy similares a estar a sol pleno, o sombras densas y frescas con una reducción considerable de la temperatura del aire. La distribución de los diferentes tipos de sombras y sol, conforma una diversidad básica de ámbitos que admite a los amantes del sol así como también a los amantes de la sombra fresca, con todos sus gradientes intermedios. Esta diversidad de ámbitos deben brindarse como posibilidad a Ixs niñxs recreados como manera de poder experimentar y por lo tanto elegir qué les confiere más placer.

La existencia de sombra en los ámbitos de juegos para niñxs se constituye en una clave fundamental que habilita o niega las experiencias que se puedan desarrollar en el mismo. Es posible pensar que el cuidado de la niñez tiene que ver con aspectos tan básicos como estos. La posibilidad de que niñxs y adultos no sufran insolación, quemaduras, golpes de calor o deshidratación por exposiciones prolongadas al sol en verano, son temas a tener en cuenta que pueden ser solucionados simplemente pensando ámbitos de juego con árboles para sombra. Las plantas desarrolladas en este grupo brindan algunas ideas para ello. De esta manera, los juegos con sombra se pueden pensar como lugares más seguros para la niñez, más protegidos. Esta protección, es la que permite que circulen las experiencias entre niñxs de manera más autónoma porque ya no es necesario que estén los adultos persiguiendo a los niños con el gorro, el protector solar, o hidratándolos cada 15 minutos. A su vez, la existencia de sombra admite el uso del espacio durante largos períodos del día, situación impensada al mediodía o tarde en pleno verano. 
Se podría pensar que la existencia de sombras planificadas es la antesala básica para poder pensar un ámbito de juego. Poder brindar una confortabilidad térmica mínima de los espacios es lo que nos permite desarrollar la gama de experiencias planteadas anteriormente y que éstas puedan ocurrir de manera autónoma, ya sea mediante dispositivos educativos o de forma libre.

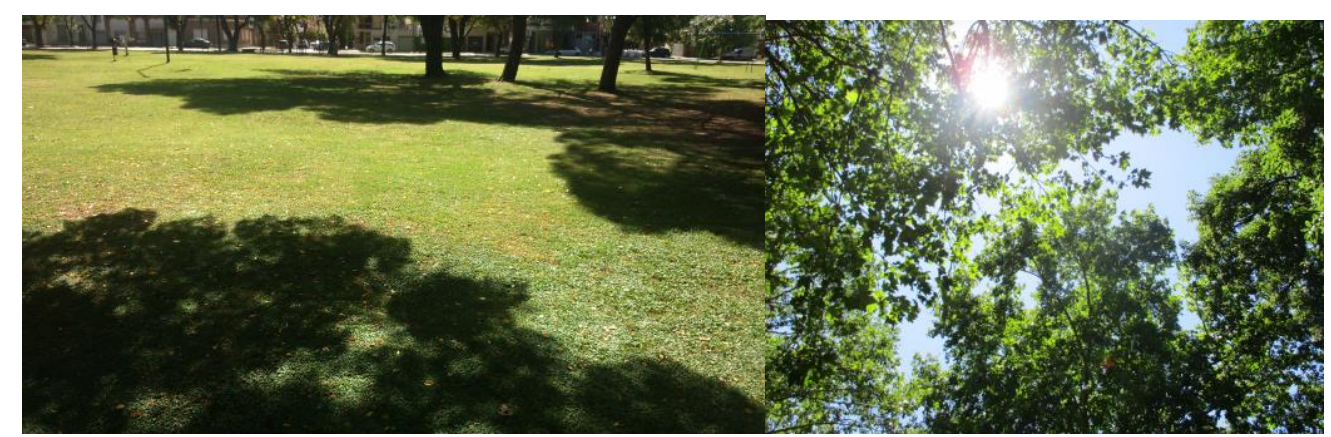

Figura 52: Ámbito de juegos libre para niñxs con sombra media. Parque Juan Vucetich. Ciudad de La Plata. Año 2015.

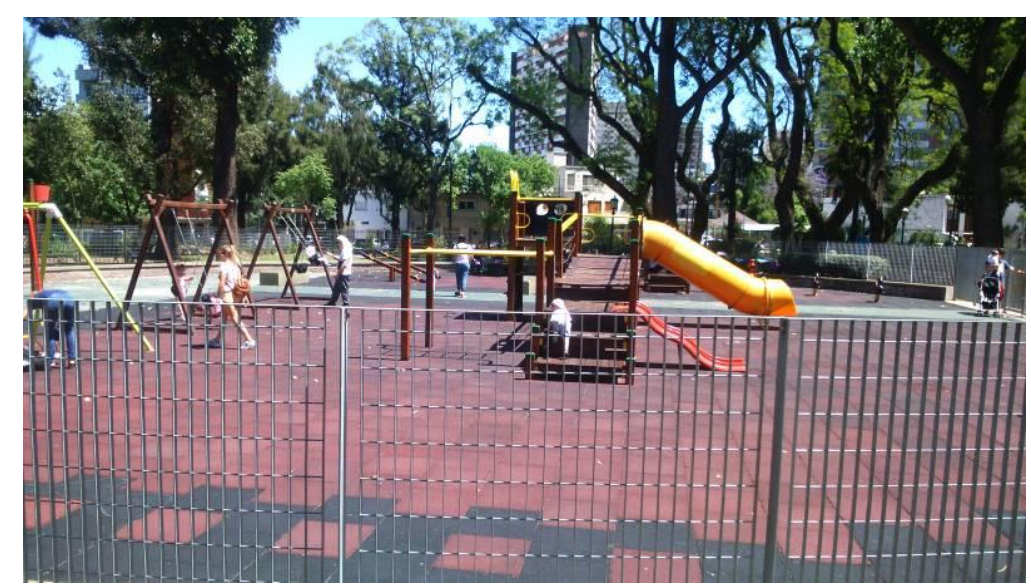

Figura 53: Ámbito pautado de juegos para niñxs. Con cerco perimetral y ausencia de espacios de sombra para permanecer. Plaza Los Olmos, Ciudad Autónoma de Buenos Aires. Año 2016.

\section{Coloración otoñal}

Se registraron un total de 43 especies arbóreas y arbustivas que muestran o marcan el otoño a partir de la coloración de su follaje. La coloración se refirió a follajes que tornan a amarillos, marrones, anaranjados, púrpuras o atropurúreas durante la estación otoñal (ver Figura 56). Una especie difundida ampliamente que se encuentra en este grupo es el Liquidambar styraciflua Liquidambar (ver Figura 54) 
que tiene coloraciones otoñales que van desde el amarillo al atropurpúrea pasando por los naranjas y púrpuras.

En este grupo se encontró el Diospyrus kaki Caqui (ver Figura 55), que adquiere coloraciones otoñales anaranjadas y rojo durante el otoño.

Como se mencionó anteriormente, no todas las especies caducas nos hacen pensar en el otoño. Una manera de remarcar esta estación del año es mediante la utilización de plantas que adquieran un follaje con una coloración específica y lo retengan cierto tiempo en la copa. El otoño nos brinda la posibilidad de conocer una serie de colores inexistentes en las otras estaciones del año. Las cuatro estaciones bien diferenciadas es una característica típica de nuestras latitudes que nos permiten vivir cambios anuales en las estructuras de los paisajes.

El clima y las estaciones del año producen marcas en las personas relacionadas a nuestro hogar y nuestra tierra que difícilmente sean olvidadas. El aroma de las hojas caídas, las láminas foliares en los pisos, la lluvia de hojas, los últimos días soleados cálidos, son el camino hacia el invierno, donde vivimos más el interior que el exterior.

Poder estar en ámbitos donde el otoño aparezca ante nuestras sensibilidades aporta a la diversidad de experiencias que se desarrolló anteriormente. Esto no significa que debemos tener otoño en todos los ámbitos. De esta manera, se diseñarán espacios con mayor proporción de especies perennes que brindarán un verde más estable todo el año y ámbitos con mayor proporción de especies caducas otoñales que acentuarán el cambio de estación. Este pasaje es el que nos permite vivir y elegir los lugares que más nos conmueven. La existencia de un gradiente de especies caducas y perennes multiplica los tipos de ámbitos y por lo tanto la diversidad de experiencias que ocurren en los mismos. 


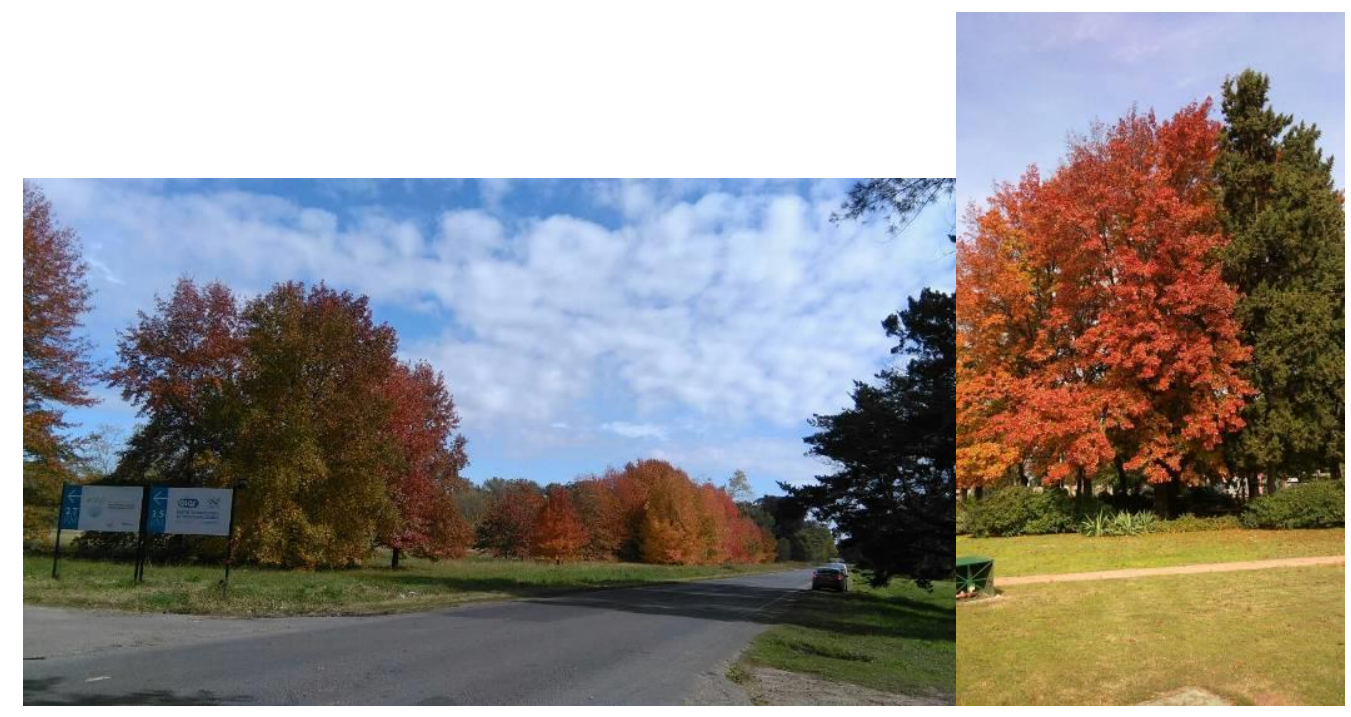

Figura 54: Agrupamiento de Liquidambar styraciflua Liquidambar. Esta especie posee coloraciones amarillas, anaranjadas y púrpuras según el ejemplar arbóreo. Parque Provincial Pereyra Iraola, Buenos Aires. Año 2013.

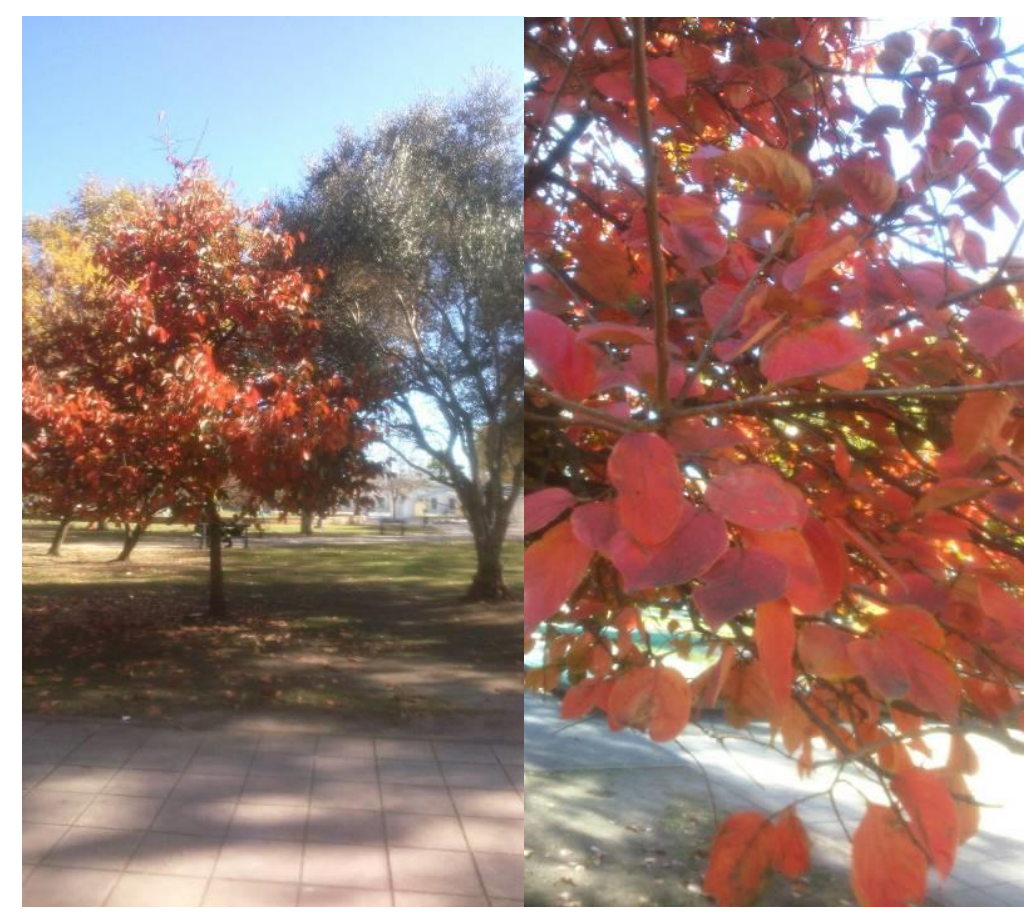

Figura 55: Ejemplar aislado de Diospyrus kaki Caqui. Coloración anaranjada y roja durante el otoño. Plaza Islas Malvinas, ciudad de La Plata. Año 2014. 


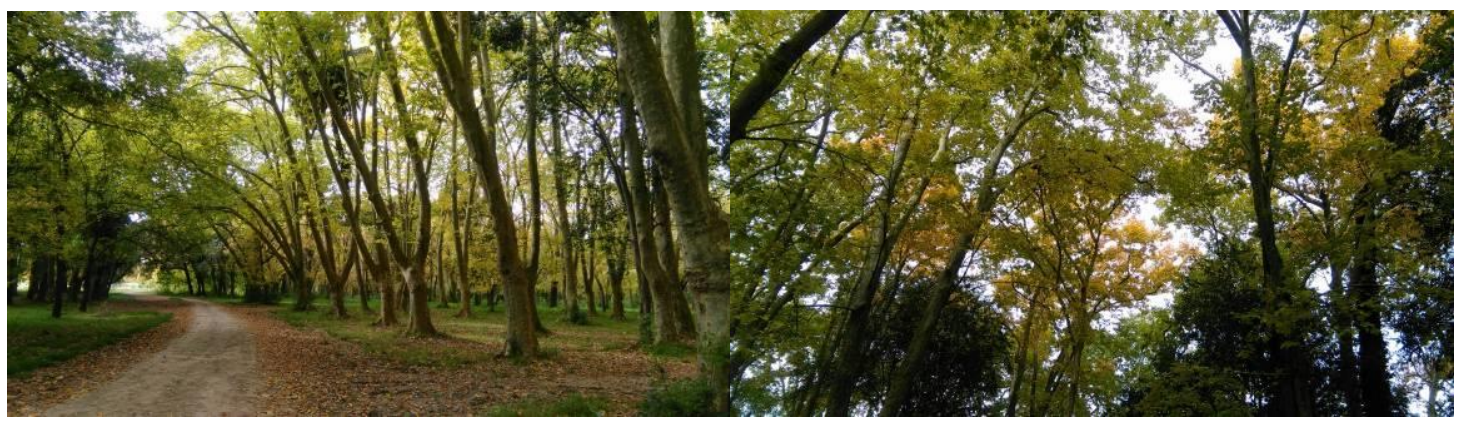

Figura 56: Alineación de Platanus acerifolia Plátano. Esta especie posee coloraciones amarillas y marrones que permanecen en el árbol por un tiempo prolongado. La caída de hojas es prolongada. Parque Provincial Pereyra Iraola, Buenos Aires. Año 2014.

\section{Colchón de hojas}

Esta categoría tuvo 18 especies que tuvieron la capacidad de conformar un colchón de hojas en la superficie del suelo. Para que esto suceda deben ser especies que no tengan textura fina (ya que las hojas se incorporan fácilmente al suelo), que la caída de hojas se dé en un momento determinado y no tenga larga duración, que las hojas conserven su estructura seca por largos períodos, que el follaje sea abundante (por ejemplo densidades de follaje laxas difícilmente conformen colchón de hojas).

Una especie típica de esta categoría es el Fraxinus pennsylvanica Fresno americano. Es una especie dioica por lo que existen ejemplares masculinos y ejemplares femeninos. Especialmente los ejemplares masculinos conforman una copa más compacta, con mayor densidad de hojas y una caída de hojas en menor tiempo. Su follaje torna a coloración amarilla en otoño y cuando caen las hojas conforma una capa de hojas secas marrones en el suelo de gran densidad (ver Figura 57).

Otra especie registrada en este grupo fue el Liriodendron tulipifera Tulipanero que conforma un colchón de hojas marrón-dorado. El Platanus acerifolia Plátano, conforma una capa de hojas marrones de textura gruesa que le da gran espesor al colchón.

La superficie de hojas secas conforma un manto que admite multiplicidad de experiencias, desde la recolección de hojas, la conformación de un ámbito cuidado para jugar en el suelo con vueltas 
carnero o actividades de destreza, se constituyen en elementos para patear, arrojar, realizar lluvia de hojas, triturado de las mismas, conformación de montañas por barrido, etc.

A su vez, este manto de hojas, permite en los parques fertilizar la superficie de suelo y la capa cespitosa. Lentamente se incorpora al suelo mediante triturado por el corte de pasto regular de mantenimiento de un parque.

Por último, los mantos de hojas secas conforman ámbitos efímeros en el espacio público. Es interesante porque existen sólo en un momento del año, el otoño. La caída de las hojas dibuja un espacio que inevitablemente crea un ámbito, es decir un lugar en el que ocurren espontáneamente actividades. La planificación de situaciones como estas aporta a la diversidad de experiencias para la niñez en el espacio público puesto que las vivencias pueden ser múltiples, desde deportivas a contemplativas, moverse o estar, correr o leer. Lo interesante aquí es cómo a partir de un suceso fenológico podemos generar ámbitos de juego no pautados, que guían sucesos donde la imaginación, la invención, y lo que se puede construir con los otros, transforma lo real (un manto de hojas) en una dimensión imaginaria simbólica para la creación. 


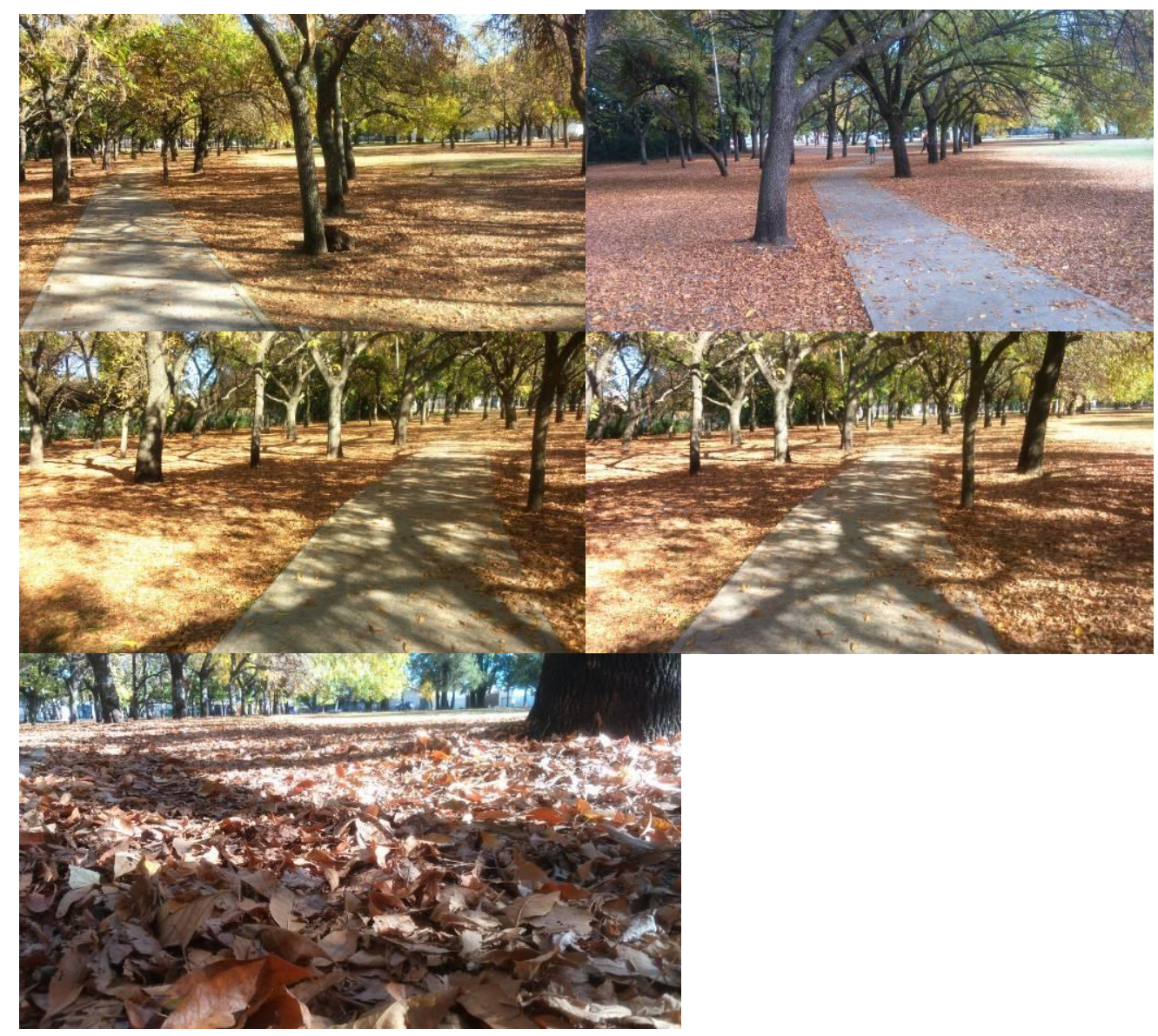

Figura 57: Macizo de Fraxinus pennsylvanica Fresno americano. El manto de hojas secas marrones durante el otoño conforma un ámbito no pautado de juego. Parque Juan Vucetich, Ciudad de La Plata.

\section{Especies que forman bosque}

En este grupo se encontraron 66 especies que tuvieron la capacidad de conformar el ámbito de bosque. Este ámbito tiene la particularidad de tener una elevada densidad de ejemplares arbóreos que permiten crear un microclima de oscuridad, alta humedad relativa y continuidad de copas. Estas especies pueden formar macizos arbóreos en competencia unos con otros (ver Figura 58 y 59).

En este grupo se encontraron especies caducas y perennes. Las segundas con la conformación de ámbitos más oscuros. Como ejemplo del primer caso se encontró Salix vitellina Vitelina injertado a 2 metros que puede formar en alta densidad bosques luminosos por su follaje poco denso. Como ejemplo de caduca de follaje de mayor densidad se encontró Koelreuteria paniculata Jabonero de la India que conforma en primavera-verano ámbitos de bosque más oscuros. En el segundo caso, las 
especies perennes, se ubicó Ligustrum lucidum Ligustro que plantados de manera muy densa pueden conformar ámbitos de bosque muy oscuros y de alta humedad relativa del aire.

El bosque ha tenido varias implicancias en la historia de la humanidad. Pierre Donadieu (2006) desarrolla en "La sociedad Paisajista" lo que denomina "El deseo de Bosque". Allí, analiza cómo el bosque fue considerado en la antigüedad lugar de las divinidades, relacionado a lo sagrado y cómo luego con el cristianismo y el feudalismo se transformó en los cotos de caza del rey en los lugares de abastecimiento de madera para los campesinos. El bosque adquirió también, la significancia de lo desconocido, del lugar del terror y del destierro. P. Donadieu expresa que “... el bosque representa el lugar donde uno puede perderse físicamente, pero también metafóricamente, es la pérdida del buen camino y de la verdad" (p.68). Como contraposición, aparece la idea del bosque como lugar terrorífico de la muerte, de lo desconocido y lo peligros. En estos dos contrapuntos, P. Donadieu establece un puente entre el bosque de las divinidades y el que da refugio, y la sociedad actual urbana, que vuelve a encontrar en el bosque la pureza del aire y la libertad de actuar que no tiene en las metrópolis: "el bosque tranquiliza, la ciudad da miedo". Sin embargo, plantea que el bosque preparado así para el ocio, continúa secretamente causando miedo, con un leve temor.

Esta situación se reproduce en las infancias, donde los cuentos del siglo XX simbolizaron en el bosque una serie de peligros, ligados a lo desconocido, la inmensidad. En el bosque estaba el lobo, allí uno se perdía para no volver, allí se mandaba a matar, allí se desterraba. Todo lo trágico sucedía simbólicamente en el bosque, como lugar donde lo desconocido se asociaba al peligro y no al descubrir, el explorar. En contraposición, el bosque se resignificó como el lugar donde se puede jugar al aire libre, donde encontramos pájaros, donde se vive y se vacaciona, donde se hace música (ver Figura 60). Actualmente, se produce esta dualidad donde el deseo del aire puro y naturaleza simbolizado en el bosque se conjuga con un miedo secretamente constituido.

Todas las dimensiones que se viven en un bosque no pueden ser negadas a las infancias. Es necesario pensar estos ámbitos como potenciadores de la diversidad de experiencias. En este sentido, 
el bosque funciona como un gran refugio, donde el secreto, la intimidad, el diálogo entre pares tiene lugar. Aquí podemos conocer y enfrentar o eludir los miedos, así aparecen los desafíos, donde nos podemos perder para encontrar una salida, donde podemos soñar. En este sentido, pareciera un horizonte posible la conformación de bosques lúdicos en el espacio público.

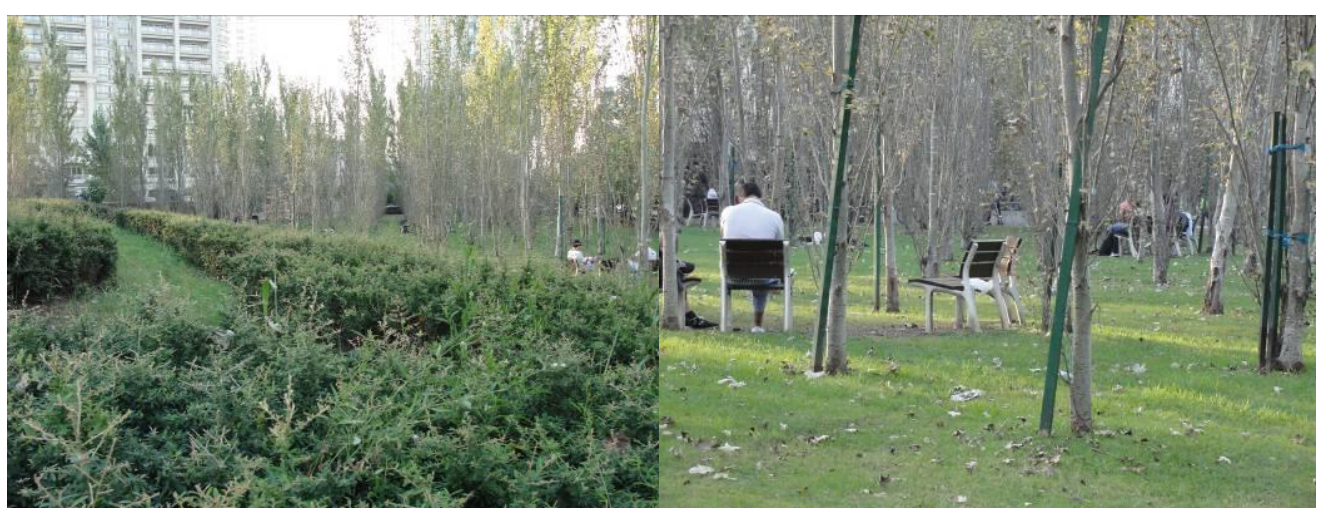

Figura 58: Macizo de Populus alba var. bolleana. Álamo plateado piramidal o Álamo boleana. Este macizo de árboles conforma un bosque urbano que tiene equipamiento para sentarse conformarse como un ámbito fresco de estar. Parque Micaela Bastidas, Ciudad Autónoma de Buenos Aires. Año 2014.

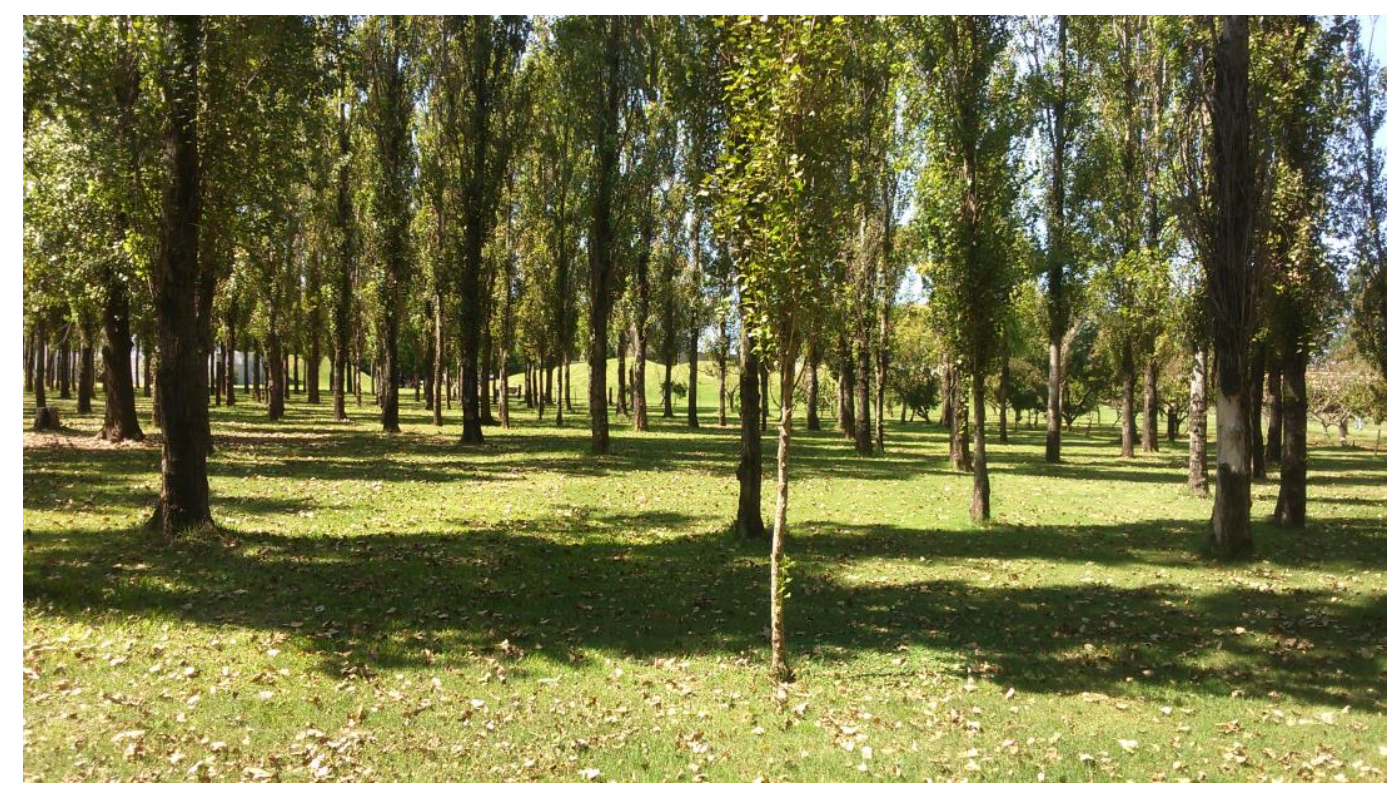

Figura 59: Macizo de Populus nigra var itálica. Álamo piramidal. Granja de la Infancia en el Tríptico de la Infancia. Ciudad de Rosario. Santa Fe. Año 2015. 


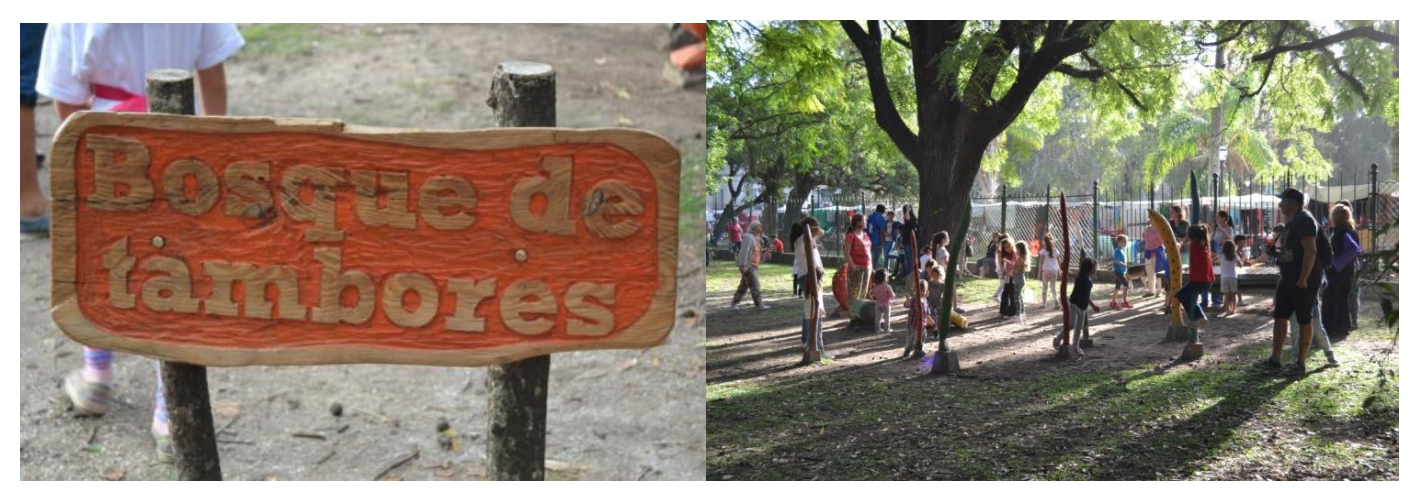

Figura 60: Bosque de tambores. En un macizo de árboles se juega con la metáfora del bosque para la creación de un ámbito para la música. Parque Saavedra. Ciudad de La Plata. Año 2018.

\section{Especies de diferentes texturas}

Tradicionalmente, en paisaje, asociamos las texturas al peso visual de las especies según disposición, densidad y tamaño del follaje así como también a la arquitectura de la planta. Sin embargo, desde una mirada de las infancias, estos atributos formales del diseño se complementan con la mirada de la textura desde lo percibido con el tacto.

En este sentido, en la vegetación existen texturas al tacto suaves, ásperas, pinchudas, secas, húmedas, fina, gruesa, irregulares, regulares. Un grupo de plantas que brindan un esquema de texturas amplio y de escala abordable por niños son las crasas y suculentas (ver Figura 61).

Si trabajamos las especies crasas y suculentas en pequeños espacios donde puedan ser no sólo vistas, sino también tocadas, se puede tener un contacto más claro con los pares binarios de texturas planteadas.

Esta experiencia se llevó a cabo de manera exitosa en el botánico de la ciudad de Curitiba, Brasil donde se estableció un muestrario de especies vegetales disponibles a la altura de los niños. En este caso existía un discurso pautado y una guía a los grupos de niños. Sin embargo, esta experiencia no necesariamente tiene que ser guiada y puede estar disponible para libre exploración del niñx que lo desee. No buscamos normatizar las experiencia ni igualarlas, sino brindar posibilidades para que estén accesibles a todxs. 
Lo mismo sucede en el Jardín Botánico de la ciudad de Quito donde plantean a las texturas de las plantas como una adaptación de la naturaleza para protegerse, defenderse, "atacar", atraer o repeler. Así, las superficies lisas repelen el agua para que no crezcan hongos y musgos en su superficie, un pelaje aterciopelado es un abrigo contra el frío y el viento así como también una barrera contra insectos, tallos y hojas espinosas como una gran armadura, hojas recias como cuero son difíciles de atacar por insectos y un "arma" casi imperceptible pero muy potente como los pelos urticantes de la Urtica urens Ortiga. También allí se trabaja la relación entre las especies comestibles y la textura de las mismas ligadas al gusto. Por ejemplo, la textura suave del fruto de la Persea americana Palta o la textura astringente del fruto de Malus domestica Manzano.
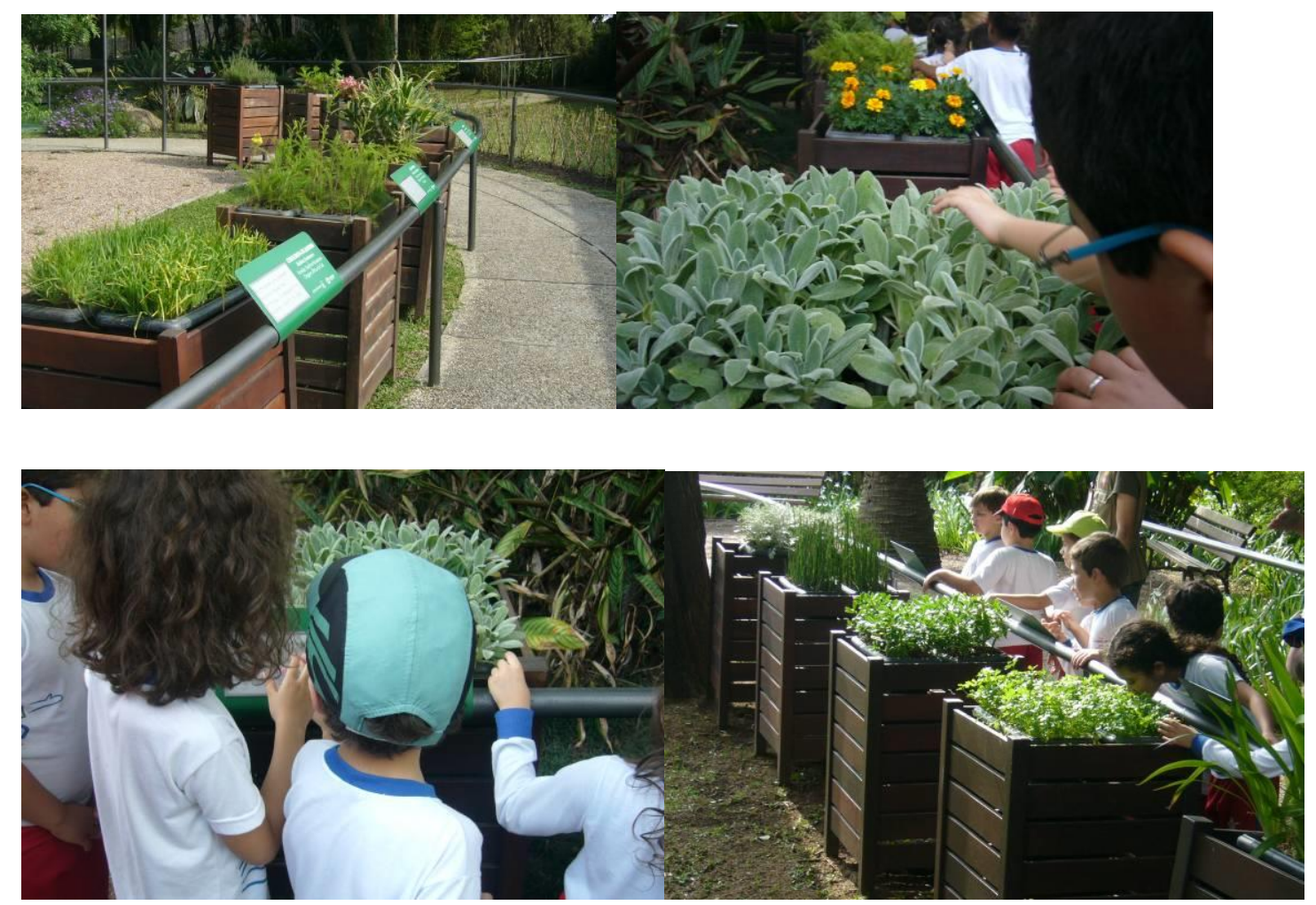

Figura 61: Niñxs tocando diferentes texturas de plantas. Jardín Botánico de Curitiba, Brasil. Año 2012

Una familia de especies que nombramos como posibles a trabajar en base a texturas son las crasas y suculentas. Las siguientes especies pueden funcionar como referencia de posibles texturas.

Kalanchoe tomentosa y Kalanchoe bracteata. Textura suave

Haworthia attenuata y Huernia sp.. Textura pinchuda (sin llegar a lastimar). 
Aloe ciliaris. Textura y forma irregular.

Echeveria glauca. Textura y forma regular.

Haworthia cymbiformis. Textura húmeda.

Kalanchoe blossfeldiana. Textura media.

Crassula pellucida y C. lycopodiodes. Textura fina.

\section{Especies de árboles longevos}

Se registraron 8 especies capaces de tener una longevidad comprobada mayor a 150 años. Existen ejemplares notables de Ficus elastica Gomero y de Magnolia grandiflora Magnolia en la Ciudad de Buenos Aires (ver Figura 62).

Estas especies tienen la capacidad de conformarse en testigos de la experiencia vital de muchas generaciones y en el hilo de continuidad sincrónica entre las infancias. Esta posibilidad de plantar árboles que sean disfrutados y cuidados por múltiples generaciones de niñxs constituye una visión histórica de las infancias que las entrelaza a la historia de infancias pasadas y las proyecta en un futuro común y compartido.

En este sentido, los árboles notables contienen de una u otra manera niñxs a todo lo largo de su vida. Cada generación deja una marca en su vida, en su leño, que puede ser percibido metafóricamente hoy y mañana. En algunos casos, estas marcas no son metafóricas sino que se convierten en reales al quedar impresas en los anillos del árbol. Este signo en los anillos de crecimiento se puede observar mediante una datación dendrocronológica del ejemplar a partir de la extracción de una muestra de barreno. En este barreno, se ubican las diferentes generaciones de niñxs y los hechos históricos que la marcaron en concordancia con el anillo de crecimiento del árbol en el barreno. La edad histórica de los árboles notables introduce la variable del tiempo más allá de lo que dura nuestras vidas y nos permite trabajar con la niñez aspectos relacionados a la identidad histórica. Este trabajo tiene por fin rescatar la tradición en clave de futuro, no como un discurso que mira al pasado, sino principalmente como comprensión de lo que somos para poder proyectarnos en un ser deseado propio, en nuevas identidades. Esto se constituye en una visión sincrónica de las infancias. 
A su vez, la sincronía en las infancias se cruza con la visión diacrónica para la vegetación. Esta visión diacrónica, como se describió anteriormente, nos permite preveer las trayectorias de los ecosistemas existentes. Los árboles longevos se establecen como estructurantes de una cobertura que cambia en el tiempo mientras ellos permanecen. Estas especies permiten pensar la resposición de especies con distintas velocidades de crecimiento, sin comprometer la estabilidad del sistema. La presencia de ejemplares notables nos otorga mayor resiliencia sistémica ante cambios inesperados. Por su importancia estructural es necesario establecer cuidados fitosanitarios especiales, de manera tal de no perder, conservar y potenciar los años acumulados en cada una de las plantas.

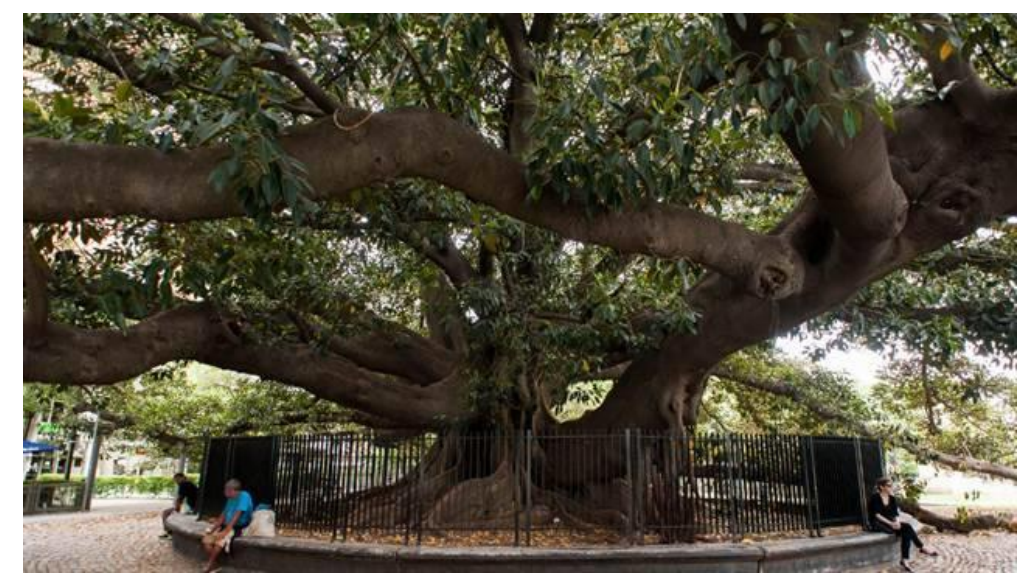

Figura 62: Ficus elastica Gomero. Si bien se desconoce su edad exacta se calcula una vida mayor a 150 años, con un estado fitosanitario muy bueno y con posibilidad de tener sobrevida. Ciudad de Buenos Aires, Recoleta. 


\subsection{SÍNTESIS DE RESULTADOS}

A modo de síntesis, los principales resultados fueron que existieron entre 1 y 3 ámbitos de juegos en cada una de las plazas relevadas, con distribución territorial regular. Estos ámbitos se conformaron en su gran mayoría sin delimitación física perimetral. Cuando existió delimitación física fue de alambre o reja de las calesitas con uso comercial. La gran mayoría de los ámbitos tuvo suelos de tipo conchilla con altísimos porcentajes de erosión que limitaron seriamente la funcionalidad del sector. Respecto a los dispositivos de juegos, se observó que fueron los mismos en todas las plazas, con esquemas más completos o más acotados pero en todos hubo hamacas, sube y baja, tobogán, pasamanos y calesita. El estado general de los mismos fue bueno aunque con un porcentaje significativo de dispositivos disfuncionales y riesgosos.

Respecto a la vegetación de los ámbitos de juegos relevados, se observó que predominaron los árboles de primera y segunda magnitud, con sólo 12 especies que representaron casi la totalidad de la estructura vegetal existente, siendo Fraxinus pennsylvanica Fresno americano el más frecuente. Su ubicación fue perimetral al sector de juegos y su edad fue madura y sobre madura en su gran mayoría. El $60 \%$ fue caduca y el resto persistente o semipersistente, reproduciendo el patrón típico de la tradición paisajista del siglo XIX. Se observó un nivel bajisimo de reposiciones arbóreas. Finalmente, en su gran mayoría los árboles se encontraron podados completamente hasta los $3 \mathrm{~m}$ de altura despejando las visuales desde y hacia el sector de juegos. Se observó un alto riesgo por mal estado fitosanitario de los árboles (25\%).

En lo referido a las especies arbustivas, se relevó una degradación total del estrato, sólo 8 especies representaron casi a la totalidad, siendo el más frecuente el Nerium oleander Laurel de jardín. Los arbustos se ubicaron de manera perimetral bajo los doseles arbóreos y fueron casi en su totalidad perennes y de cuarta y quinta magnitud. El estrato arbustivo se encontró en estado adulto y maduro con un bajísimo nivel de reposiciones. Finalmente, el estado fitosanitario de los mismos fue 
pésimo, con exceso de poda (en altura y despeje de las bases para permitir visuales) y se observó ausencia de tratamientos específicos que afectaron seriamente su crecimiento y sobrevida.

Por el contrario, en viveros comerciales se encontró una amplia diversidad arbórea, arbustiva y herbácea plausible de ser utilizada en ámbitos de juegos para niñxs. Se excluyeron de este grupo las especies peligrosas por riesgo de caída así como también las excesivamente tóxicas. En este sentido, se observó que la especie arbustiva más frecuente en el espacio público tiene un alto nivel de toxicidad (Nerium oleander Laurel de jardín) por lo que fue excluida de las especies de vivero. Se observó que la mayor diversidad de encontró en especies herbáceas, arbustivas, enredaderas y en menor medida en arbóreas. Las especies arbóreas más frecuentes fueron las de tercera magnitud. Respecto al hábito vegetativo se repitió el patrón de $60 \%$ caducas. La textura media fue la más frecuente y la textura gruesa la menos. Predominaron las siluetas esferoidales y elipsoidales.

Para culminar, se descubrieron 16 atributos tipológicos terciarios nuevos en función de las infancias. Se catalogaron las especies precautorias, las trepables, las flores podables, el color, las comestibles, las laberínticas, las especies para refugio, con frutos y semillas cosechables, con semillas volubles, las especies monumentales, los tipos de sombra, las de coloración otoñal, las que forman colchón de hojas, las que conforman bosque, las que son para el tacto y finalmente los árboles longevos. En todas las categoría existió un grupo de especies mínimo plausible de ser usadas, con posibilidad de aumentar el número de especies si se aumenta la investigación sobre las especies en mercado y las especies a viverizar. En todos los casos, el grupo de especies relevado superó al existente actualmente en los ámbitos de juegos de las plazas. 


\section{CAPÍTULO 4}

\subsection{DISCUSIÓN}

En el presente trabajo de investigación se desarrollaron tres ejes principales en la recreación de infancias, una referida a la autonomía, otra a la sincronía y diacronía, y finalmente una relacionada a la diversidad de experiencias como dimensión del conocer. Estas categorías pudieron establecer puentes con la vegetación a fin de poder conformar una infraestructura verde recreativa capaz de dialogar con las nuevas infancias.

En este sentido, retomaremos los tres ejes de análisis planteados en las hipótesis y desarrollados parcialmente en las conclusiones.

\subsubsection{Heteronomía y la autonomía en las infancias paisajísticas.}

La sociedad de control, a partir de la profundización de dispositivos que modelan la heteronomía, fue algo muy presente en los ámbitos de juego. Esta situación tuvo tres vertientes principales: la existencia de un proyecto para las infancias normativizante, la presencia de un discurso de la seguridad ligado a la vigilancia y la existencia de peligros reales para el desarrollo del juego autónomo.

El primer caso, se evidenció en el diagnóstico de los ámbitos de juegos en las plazas. Los resultados demostraron una distribución territorial homogénea de los mismos así como también una homogeneidad en cuanto a los juegos, formas y delimitaciones. De esta manera, los dispositivos se reprodujeron con más o menos hamacas, sube y baja, calesitas, etc. dando cuenta quizá de una mayor frecuencia de uso en ciertas plazas, pero no de un programa de necesidades que cobije a las infancias. Esta mayor frecuencia de usos no se correspondió con propuestas diferentes que puedan contenerlas. La existencia de altos porcentajes de erosión de las superficies así como también dispositivos lúdicos que no logran el objetivo por el que fueron colocados debido a roturas, afectaron seriamente el juego en los ámbitos. Estos problemas se debieron en parte a una falta de cuidado y 
mantenimiento. Pero lo más importante y lo que nos interesa destacar, es que la disfuncionalidad en los ámbitos de juego en la ciudad de La Plata, se produjo debido a la existencia de un proyecto normativizante de infancia que no se corresponde con las nuevas necesidades y miradas sobre las mismas.

En la ciudad de La Plata, perdura una concepción de infancia homogénea, que presupone que todxs Ixs niñxs juegan de una manera determinada en todo el territorio y que tienen las mismas necesidades. La existencia sólo de dispositivos lúdicos activos da cuenta de ello. La batería básica de juegos se compuso de tobogán, hamacas, sube y baja. A los que se adicionó calesita, trepadores, volantes. Esta estructura presupone un tipo de infancia solamente activa que dicta que Ixs niñxs tienen que correr, trepar, hamacarse, saltar y no contempla espacios para otras experiencias temporales y sensibilidades. De esta manera, Ixs niñxs no tienen la posibilidad de encontrarse en lugares de quietud así como tampoco tener una mayor interacción con la naturaleza. No se habilita espacios para el juego libre donde existan elementos que permitan la creación. Ni espacios para leer o simplemente para jugar con algún dispositivo electrónico, individual o colectivo. Finalmente, la inexistencia de lugares que habiliten el diálogo entre las infancias así como también la posibilidad de realizar otro tipo de juegos reafirma lo desarrollado anteriormente.

A su vez, la vegetación encontrada en el trabajo de campo en los ámbitos de juegos, se correspondió principalmente con árboles y en menor medida con arbustos. La idea de homogeneidad también se observó allí con una bajísima cantidad de especies que estructuran los ambientes y un estrato arbustivo muy pobre en cuanto a diversidad, cantidad y estado fitosanitario. Esta estructura vegetal se correspondió básicamente con diseños pre-existentes de la plaza, al cual se le adicionaron dispositivos lúdicos. En ningún caso existió proyecto paisajístico particularizado para el ámbito de juego, así como tampoco proyectos diferenciados por tipo de plaza o barrio. La vegetación, en el mejor de los casos funcionó como acompañante. 
En el segundo planteo, referido a un discurso de la seguridad ligado a la vigilancia en las infancias en el espacio público, pudimos observar que en todos los casos los ámbitos de juegos tuvieron una conformación espacial donde la centralidad estuvo puesta en la mirada del adulto sobre el juego. Esto se manifestó en la disposición del equipamiento y la vegetación, las visuales plenas dentro y hacia el ámbito, y la poda excesiva de las plantas con el consiguiente deterioro paisajístico del espacio. En este sentido, un factor importante en la organización del lugar fue la mirada del adulto, en clave controladora, y no las necesidades de Ixs niñxs. Una mirada desde las necesidades podría contemplar, entre otras, el juego imaginativo, libre, permitir el diálogo en espacios de reposo, habilitar el secreto entre pares, incluir otras sensibilidades, incorporar nuevos materiales para la experimentación, permitir explorar y descubrir.

En el tercer punto, la presencia de peligros reales para el desarrollo del juego autónomo, nos interesa poner en discusión la concepción de seguridad que prima hoy en el espacio público. Pareciera que existe un discurso donde la seguridad-inseguridad está ligado a la presencia-ausencia de robos, hurtos, asaltos, etc. A partir de ello, se disponen una serie de elementos de prevención que buscarían evitarlos. En este sentido, existe un esfuerzo enorme por parte del Estado para la colocación de cámaras de filmación e iluminación excesiva de manera tal de brindar ámbitos más seguros. Esto se manifestó también en las plazas relevadas, donde la necesidad de visuales plenas arrasó con el estrato arbustivo, fomentando podas excesivas para permitir la visión panorámica desde el exterior de las plazas hacia el interior y viceversa. Deberíamos preguntarnos sobre los resultados de esta política pero este es un debate que excede la presente tesis. Sí nos interesa remarcar que estos esfuerzos dejaron de lado la idea de seguridad en términos de cuidado de la integridad física en el espacio público. Nos referimos a integridad física de las personas a que puedan desarrollar las actividades, en nuestro caso del juego, sin estar expuestos a riesgos previsibles. En este sentido, se constató una infinidad de peligros evitables en los ámbitos de juegos para niñxs. Se relevaron cables expuestos de electricidad, árboles enfermos y muertos en pie sobre espacios de permanencia y estar (ver Figura 63), 
dispositivos lúdicos oxidados y destrozados, luminarias con riesgo de caída, entre otros. A estos se sumó la inexistencia de solados que amortigüen caídas así como también ausencia de delimitación perimetral y presencia de arbustos altamente tóxicos. Éstas, fueron algunas de las situaciones que revelaron el bajísimo cuidado en los ámbitos para el desarrollo del juego. Pensamos como cuidado a la reducción de riesgos evitables y previsibles para que Ixs niñxs y adultos puedan jugar sin exponerse a lastimaduras graves. Creemos que el concepto de seguridad también debería ser pensado como cuidado según lo desarrollado anteriormente. Por ello, nos parece necesario pensar ámbitos donde el juego se desarrolle de manera cuidada, atendida, sin dejar de desconocer que existen también otros problemas a resolver en el espacio público. En este sentido, Santillán (2017) expresa que el cuidado es un hecho tejido en una urdimbre social, y por qué no, política. En este sentido, una política del cuidado hacia la niñez generada desde el Estado, debería incluir el espacio público. Cuando hablamos de cuidar, pensamos en una actividad central del bienestar humano, nadie puede sobrevivir sin ser cuidado. Sin embargo, la intensidad de atención cambia a lo largo de la vida, es la niñez y la vejez los momentos donde toma valores preponderantes. Cuando hablamos de cuidar, pensamos en escuchar, contener, ofrecer refugio, preocuparse por el otro, brindarle herramientas (Faur, 2017). Por el contrario, pareciera que lo desarrollado por el Estado en el espacio público es una política de vigilancia y control, bajo dispositivos que recuerdan al panóptico de Foucault (1975) pero que se adaptan a nuevas concepciones de vigilancia, como las desarrolladas por Bauman (2013) bajo el concepto de vigilancia líquida en un esquema post-panóptico. Ya no es el vigilante que controla sino que dicha acción está dada por patrones de consumo, de circulación de datos, dispositivos móviles, entre otros, donde somos nosotros mismos los que constituimos una vigilancia compartida y controladora que se adapta rápidamente a nuevas innovaciones y cambios. No es interés de esta tesis profundizar en el debate sobre la vigilancia, pero sí dar cuenta de la ausencia de una política de cuidado en el espacio público. Esta ausencia es la que posibilita o no la creación de nuevas miradas sobre la niñez, como la recreación de infancias. 
Esta falta de cuidado, tal cual la planteamos en el trabajo de investigación, atenta seriamente la autonomía en las infancias y refuerza la mirada del adulto sobre Ixs niñxs, una mirada sobreportectora que actúa de manera represiva. Tal cual están planteados los ámbitos de juego hoy en la ciudad de La Plata, sería irresponsable por parte del adulto a cargo no estar sobre Ixs niñxs marcando qué hacer y qué no hacer ya que existen riesgos reales para la niñez. La sociedad controladora se manifiesta de dos maneras, desde el Estado con la existencia de una política de la vigilancia y no del cuidado, y desde los adultos acompañantes que tienen que estar cuidando a Ixs niñxs del propio ámbito al cual Ixs llevan a jugar.

Recientemente, una serie televisiva puso en debate de manera artística y masiva este tema a partir del desarrollo de una ficción. La serie Black Mirror (Brooker, 2017) en su episodio Arkangel supone la posibilidad de insertar en una niña un chip que permita a la madre hacer tres cosas: saber la ubicación real de la niña, ver lo que sus ojos miran y pixelarle el peligro o situaciones de estrés a su hija. La madre decide hasta alrededor de los 8-10 años de edad pixelarle el peligro, hasta que en cierto momento decide eliminar de sus ojos dicho filtro. Así, la niña descubre la sangre, el sexo, los perros que ladran, las peleas. Esta situación determinó una seria de comportamientos a la niña y la madre que no excluyeron el peligro, ni la posibilidad de perderse de la niña. En la serie se plantea que la seguridad de la niña no tiene que ver con la posibilidad de que su madre pueda saber dónde está o pueda ver a través de sus ojos, de hecho la única vez que la niña se perdió fue encontrada por los vecinos. Se refuerza la idea de que es la urdimbre y los tejidos sociales los que cuidan junto con las familias y las instituciones. En este sentido, la serie liga el discurso de la sobreprotección y la seguridad al miedo y la inseguridad del adulto. Este debate se encuentra abierto y es el que nos interesa poner en diálogo aquí respecto a la conformación de los ámbitos de juegos para niñxs.

Retomando lo expuesto anteriormente, pareciera que para poder habilitar otro tipo de mirada sobre la niñez que permita mayores grados de autonomía es necesario brindar una serie de condiciones estructurales mínimas del espacio que lo permitan. En este sentido, la reducción de 
riesgos para la niñez sería un primer camino. La delimitación perimetral de los ámbitos de juego permitiría contenerlos y a su vez separarlos de lo que sucede fuera. Esta idea no se debería confundir con el encierro: es posible delimitar espacios sin la utilización de rejas que dan cuenta más de una sociedad de control que de una de liberación. El manejo fitosanitario preventivo de la vegetación es algo que debe incorporarse: ningún árbol ni ningún arbusto debe representar un riesgo, por caída de ramas o ingesta de frutos u hojas, para la niñez. El equipamiento utilizado (bancos, luminarias, cestos, dispositivos lúdicos) deberían encontrarse en perfecto estado, quizá con un mayor nivel de mantenimiento que el resto de la ciudad puesto que existe una concentración de usos de un grupo social que desconoce cómo cuidarse de ciertos riesgos. Es interesante el uso de solados que absorban impactos para evitar lesiones graves por caídas de altura. Estas serian algunas de las condiciones mínimas para poder comenzar a hablar de mayores grados de autonomía para la niñez que nos permita pensarnos en una nueva sociedad.

Finalmente, en la región la existencia de importantes viveros comerciales productores de plantas. Al analizar la oferta de especies vegetales se pudo concluir que es extremadamente superior a la existente en los espacios públicos. Se relevó una amplia gama de especies plausibles de ser utilizadas en ámbitos de juegos para niñxs, que tendrían la capacidad de complejizarlo y de establecer las condiciones para albergar infancias más autónomas. La existencia de especies vegetales de múltiples estratos permiten otorgar complejidad estructural a los ámbitos. Así como también la eliminación de especies peligrosas por riesgo de caída y por toxicidad permite aportar a un marco de seguridad en el juego para que se desarrollen de manera más autónoma. 

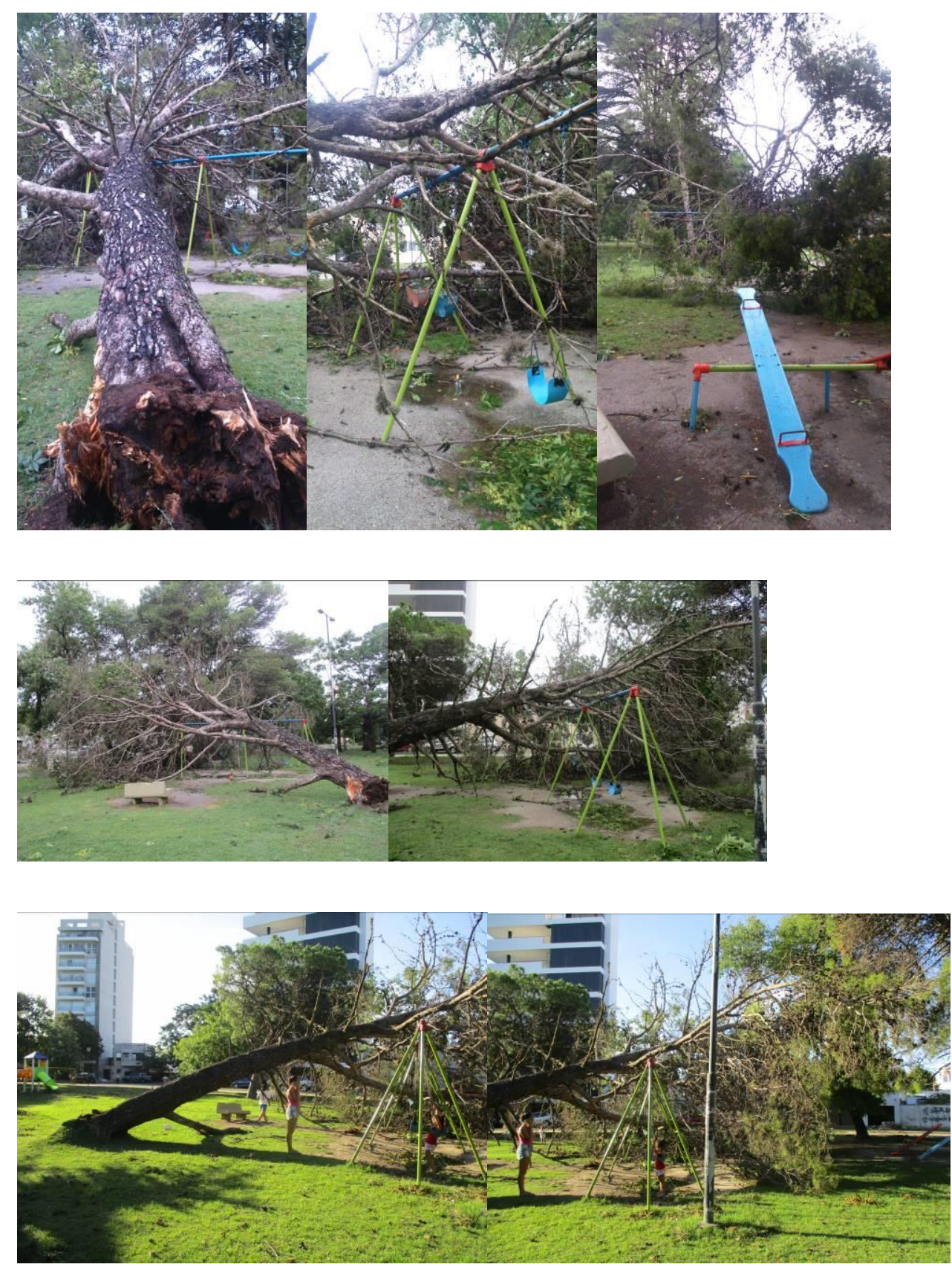

Figura 63: Imagen 1, 2 y 3. Temporal 5 de Febrero de 2017, ejemplar de Pinus halepensis caido sobre hamacas Parque Juan Vucetich, La Plata, 18:50 hs. Imagen 4 y 5, mismo ejemplar 6 de Febrero 2017 10:40 hs sin ningún tipo de intervención. Imagen 6 y 7, mismo ejemplar 7 de Febrero 2017 18:50 hs sin ningún tipo de intervención ni cerco preventivo. Se puede observar la continuidad del juego sin advertir del peligro existente. 


\subsubsection{Sincronía y Diacronía en la vegetación con las infancias}

Como vimos anteriormente la sincronía y diacronía en las infancias se refiere a la línea de tiempo y sus puntos o saltos disruptivos, lo que continúa y lo que cambia o se discontinúa en términos filosóficos (Arendt, 2003; Larrosa y Perez Lara, 1997). Por otro lado, desde la perspectiva de la vegetación, la sincronía se ligó a pensarla en función de los usos simultáneos en un territorio dado y la diacronía a los cambios de dicha vegetación en el tiempo.

Como observamos en los ámbitos para las infancias relevados, los usos en todo el territorio fueron los mismos. Se plantearon los mismos dispositivos distribuidos de manera homogénea. La existencia de similares usos en todo el territorio fue de la mano de un manejo de la vegetación en el mismo sentido. En todos los ámbitos los tratamientos fueron: iguales podas, parecida distribución de árboles y arbustos, especies y riesgos similares. Sin embargo, ¿este tipo de tratamientos es de tipo sincrónico? La respuesta es no, un tratamiento de tipo sincrónico de la vegetación da cuenta principalmente del uso que se lleva a cabo bajo o entre la misma. Como se describió anteriormente, la vegetación llegó al punto de constituir un riesgo para las infancias, por lo que no existió planificación de la misma en función de los usos.

En términos diacrónicos, ecología del no-equilibrio, se observó la existencia de una estructura arbórea madura y sobremadura, con riesgos serios de estabilidad y con ausencia de renuevos que permitan establecer un reemplazo. La estructura arbórea sobre madura y madura determina que en un período corto (en términos forestales) se puede deteriorar seriamente la estructura actual de coberturas de parques y plazas. Este proceso se encuentra acelerado por la presencia de suelos erosionados, compactados por la mayor frecuencia de usos y muy pobres en fertilidad. Finalmente, los árboles adultos relevados no mostraron un estado fitosanitario óptimo y se evidenciaron procesos irreversibles de muerte de individuos, de ramas principales, podredumbres y caries en la base que hacen necesario un programa de extracción preventiva de ejemplares ante pérdida de estabilidad 
estructural. Entonces, la situación demuestra que no sólo es una estructura arbórea madura y sobre madura, sino que se encuentra en claro retroceso.

A su vez, se evidenció la inexistencia de un programa de reemplazo de árboles ya que existen muy pocos renovales que puedan dar cuenta de ello. En el mismo sentido, no se observaron de manera significativa árboles adultos jóvenes que evidencien plantaciones pasadas 0 estrategias de reemplazo anteriores.

Como resultado, la existencia de una estructura arbórea coetánea, al igual que lo planteado por Benassi (2013), demuestra la ausencia de una visión diacrónica sobre la vegetación. La tendencia deberían ser estructuras discetáneas (pluri etáreas) que den cuenta de una estrategia de reemplazo constante de las estructuras vegetales existentes.

Ahora bien, ¿cómo se conjugan vegetación e infancias en términos sincrónicos y diacrónicos? Si para las infancias recreadas la sincronía es la continuidad, y la discontinuidad como parte de ella, el hilo conductor histórico entre pasado, presente y futuro, la vegetación podría realizar un aporte. Los tiempos forestales de muchas especies vegetales arbóreas permiten traspasar generaciones humanas y constituirse en verdaderos hitos culturales. Estas especies son las que se relevaron en la categoría de árboles longevos, con una vida de varias generaciones comprobada en las ciudades. Estos árboles históricos son y serán testigos de varias infancias, que pueden compartir algo entre sí. Quizá, una clave sincrónica sea la de constituir, en proyectos para las infancias, árboles longevos, así como rescatar los heredados de nuestros abuelos o bisabuelos. La posibilidad de plantar árboles que sean disfrutados y cuidados por múltiples generaciones de niñxs constituye una visión histórica de las infancias que las entrelaza a momentos pasados y desde el presente las entrelaza en futuros comunes y compartidos. En este sentido, Jelin (2001), marca a la memoria como: "un proceso subjetivo, anclado en experiencias y en marcas simbólicas y materiales" (p.27) y la reconoce como objeto de disputas. Lo que implica un rol activo productor de sentido de esa memoria por parte de los participantes, de manera tal de producir sentido al pasado. Si bien este es un tema complejo de abordar, tal cual lo 
menciona Jelin (2001), pensamos a las infancias como productoras de resignificaciones de la memoria. Pensar en ámbitos donde sea posible que tenga lugar, como debate público, la memoria desde y para la niñez nos parece interesante como aporte inclusivo a la discusión colectiva sobre lo público.

El rescate de los árboles notables heredados nos permite pensarlos como contenedores de infancias a todo lo largo de su vida. Cada generación dejó una marca en su vida, en su madera, que puede ser percibido. En algunos casos, estas marcas pueden quedar impresas en los anillos de crecimiento del árbol. Como se describió anteriormente, este signo en los anillos se puede observar mediante una datación dendrocronológica del ejemplar a partir de la extracción de una muestra de barreno. La datación histórica de los árboles notables introduce la variable del tiempo más allá de lo que dura nuestras vidas y nos permite trabajar con la niñez aspectos relacionados a la identidad histórica. El tiempo que vivimos es lineal y acumulativo, pero también circular. El árbol marca el tiempo de manera circular y acumulativa y los humanos lo medimos de manera transversal al tronco, al revés de como el ejemplar lo contiene. Este cruce entre lo circular y lo lineal nos permite pensar, a partir de un dispositivo lúdico con rodajas de árboles, que hay otras maneras de pensar el tiempo, en forma de anillos. El anillo como metáfora del tiempo circular nos permite pensar maneras de diseñar los ámbitos de juego que habiliten una mirada sincrónica y diacrónica de las infancias comprometiendo otra mirada del mundo.

Este trabajo tiene por fin rescatar la tradición en clave de futuro, no como un discurso que mira al pasado, sino principalmente como comprensión de lo que somos para poder proyectarnos en un ser deseado propio, en nuevas identidades. Esto se constituye en una visión sincrónica de las infancias.

Según lo descripto anteriormente, la visión diacrónica de la vegetación y la mirada sincrónica de las infancias introducen la variable del tiempo como clave del diseño. En un caso, desde una conformación ecosistémica del espacio y en el otro desde una mirada cultural de dicha conformación. La recreación de las infancias es esa mirada cultural desde la niñez que conforma el paisaje, un paisaje que cambia constantemente pero que no nace con nosotros, que tiene un pasado, presente y 
futuros comunes. Los árboles longevos podrían ser esa manifestación cultural, que conforma paisaje, y que constituyen un nuevo observar de la vegetación, ya no como elemento aislado, sino como fundante de un paisaje compartido, heredado, cambiante, cuidado, proyectivo y creativo. Aparece un lugar para las infancias en el tiempo de los ecosistemas, en forma de anillo, que lo vuelven paisaje, paisajes recreados.

En lo referido a la diacronía en las infancias hablamos de los saltos, cambios generacionales, 0 característicos de cada tipo de infancias en cada momento dado. Estos cambios determinan nuevas actividades en el territorio, algunas que desaparecen, otras que se potencian y algunas que no estaban contemplados. Se podría pensar que en cada salto diacrónico detectamos un nuevo programa territorial de usos para las infancias o incluso que a partir de detectar un nuevas formas de jugar podamos conceptualizar cambios diacrónicos en las infancias. Denominamos programa de usos a todas las actividades que se desarrollan en un espacio determinado. Un ejemplo de nuevo uso a partir de una necesidad emergente desde y para las juventudes fue la creación de los parques de skate, anteriormente inexistentes y que hoy forman parte del programa territorial de juegos. Volviendo a la mirada diacrónica, en cualquiera de los dos casos, ya sea por que se detectó un juego emergente o porque se dispuso una nueva actividad, las asociaciones vegetales tienen que re-adaptarse en una mirada sincrónica de usos (en términos de vegetación). La diacronía para las infancias y la sincronía para la vegetación tienen un puente en común y es en estos momentos de re-diseño o adaptación de los ámbitos de juego a nuevos usos o nuevos programas de usos para las infancias. En este sentido, la idea sería que advertido un cambio en las infancias, un salto diacrónico, se pueda dar cuenta de un re-diseño de las estructuras vegetales para que puedan albergarlos. Seguramente esta remodelación, estará ligada a las estructuras herbáceas y arbustivas y en menor medida a las arbóreas, ya que son las que permiten un rápido cambio del ámbito de juego por su acelerado crecimiento. Es necesario recordar que las estructuras de plantas relevadas, no sólo son deficientes para albergar las necesidades actuales en términos de infancias sino que tampoco brindan el máximo potencial de 
servicios ambientales, con una sobrevida cada vez menor y en constante degradación hacia la muerte de ejemplares valiosos. Según lo trabajado en esta tesis, pareciera que el salto diacrónico en las infancias está dado y que es necesario re adaptar los ámbitos de juegos establecidos, donde la vegetación pueda tener otro rol que aporte en volver a crear infancias.

Por último, si pensamos que el territorio es limitado, no hay otra manera de brindar diversidad de usos para un sector determinado de la población que constituir ámbitos diferentes y complementarios en todo el territorio como una unidad de planificación. Lo que se conforma en un sector de la ciudad no se encuentra en otro y así sucesivamente. Esto nos da la posibilidad de anclar a la particularidad de cada barrio el ámbito de juego sin perder de vista la ciudad como unidad. Pareciera que la planificación del territorio y el diseño del proyecto particularizado son la clave para permitir una mayor diversidad de ámbitos capaces de albergar infancias diversas.

\subsubsection{Sobre la diversidad de experiencias con las plantas}

La diversidad de experiencias fue abordada desde dos perspectivas en esta tesis. Por un lado la dimensión del conocimiento como una clave que abre nuevos mundos. En este sentido, que exista un discurso educativo que ponga a disposición el saber sobre diferentes temáticas en los ámbitos de juegos para niñxs es una forma del conocer-se. Y por otro lado, la posibilidad de establecer nuevos vínculos y relaciones con la naturaleza, desde la experiencia personal individual y/o colectiva, a partir de la conformación de ámbitos con una mayor complejidad de especies y estratos vegetales.

Como se desarrolló en capítulos anteriores es posible establecer dispositivos educativos formales en el espacio público que integren a la vegetación. En este sentido, a partir de las plantas y los ecosistemas podemos trabajar las temáticas que tengan que ver con el ambiente, con la comprensión de las cadenas tróficas y la vida. También con las estrategias de supervivencia de las plantas y de la especie humana a partir de la producción de alimentos, comprender el origen de lo que comemos nos permite estrechar lazos entre la producción y el consumo en las ciudades. Poder trabajar estas ideas en el marco de la soberanía alimentaria nos permite explorar perspectivas de solidaridad y respeto en un camino emancipatorio. También se desarrollaron dispositivos donde aprendemos sobre los peligros a los que tenemos que cuidarnos en la naturaleza: aguijones, espinas, sustancias tóxicas. En este sentido, se trabajó no eliminar el peligro sino asociarlo a un dispositivos educativos que nos permita conocer el universo de las plantas. Finalmente, y ligado a este último 
punto, conocer las plantas medicinales y el origen de los medicamentos es una oportunidad que no se puede desaprovechar. Poner a disposición de Ixs niñxs estos dilemas, conocimientos y preguntas sobre las que se debate el mundo abre nuevas puertas, no sólo desde lo individual o colectivo de esxs niñxs que se encuentra allí, sino como una parte importante de la sociedad que crea y constituye una nueva ética que interpela al mundo adulto. Estos dispositivos nos permiten también pensarnos a nosotros, los adultos, los grandes, los que sabemos, qué estamos haciendo y qué pretenden las nuevas generaciones, imaginar cómo es ese mundo nuevo que desconocemos y cuáles son las preguntas que lo guían, a escucharlxs. Es una oportunidad para abrirnos a los cambios que traen Ixs niñxs, a nuevas ideas radicales que alteren definitivamente nuestro existir. Esa es la intención: no trasmitir conocimiento, sino ponerlo a disposición y dialogar, ponerlo a circular para atrapar esas preguntas que ya no nos hacemos o no tenemos la capacidad de responder o ni siquiera de formular. Un estar atentos para no reprimir, sino abrir y volver a abrir estas nuevas formas.

También, según lo desarrollado en el trabajo de investigación, la diversidad de experiencias consiste en poder habilitar la mayor cantidad posible de usos a partir de potenciar la vegetación como elemento de diseño. Se puede observar en la Figura 64, dos situaciones contrastantes: en las imágenes superiores los dispositivos lúdicos de vanguardia dispuestos para el juego de niñxs. En las inferiores, una asociación vegetal con complejidad de estratos. Ambos casos se encuentran contiguos en el mismo parque público, uno de acceso irrestricto para toda la sociedad y el otro de acceso facultativo. En el primero, se repite el mismo esquema de batería de juegos (sólo que esta vez de madera), con piso que amortigua caídas y reja perimetral, sin ningún elemento vegetal en su interior ni en su perímetro cercano. En el segundo caso, se nos invita a un "Jardín didáctico de especies nativas", al entrar desconocemos lo que podemos descubrir (la sorpresa), vemos árboles, palmeras, lianas, arbustos, herbáceas, senderos, refugios, pájaros, lombrices, tierra, hojas, y así podríamos seguir enumerando tantas situaciones como personas ingresen a ese ámbito. También hay reja perimetral, pero en este caso en clave de cuidado, se encuentra enmascarada por enredaderas. Sin embargo, no se puede acceder de manera irrestricta por parte del público. 

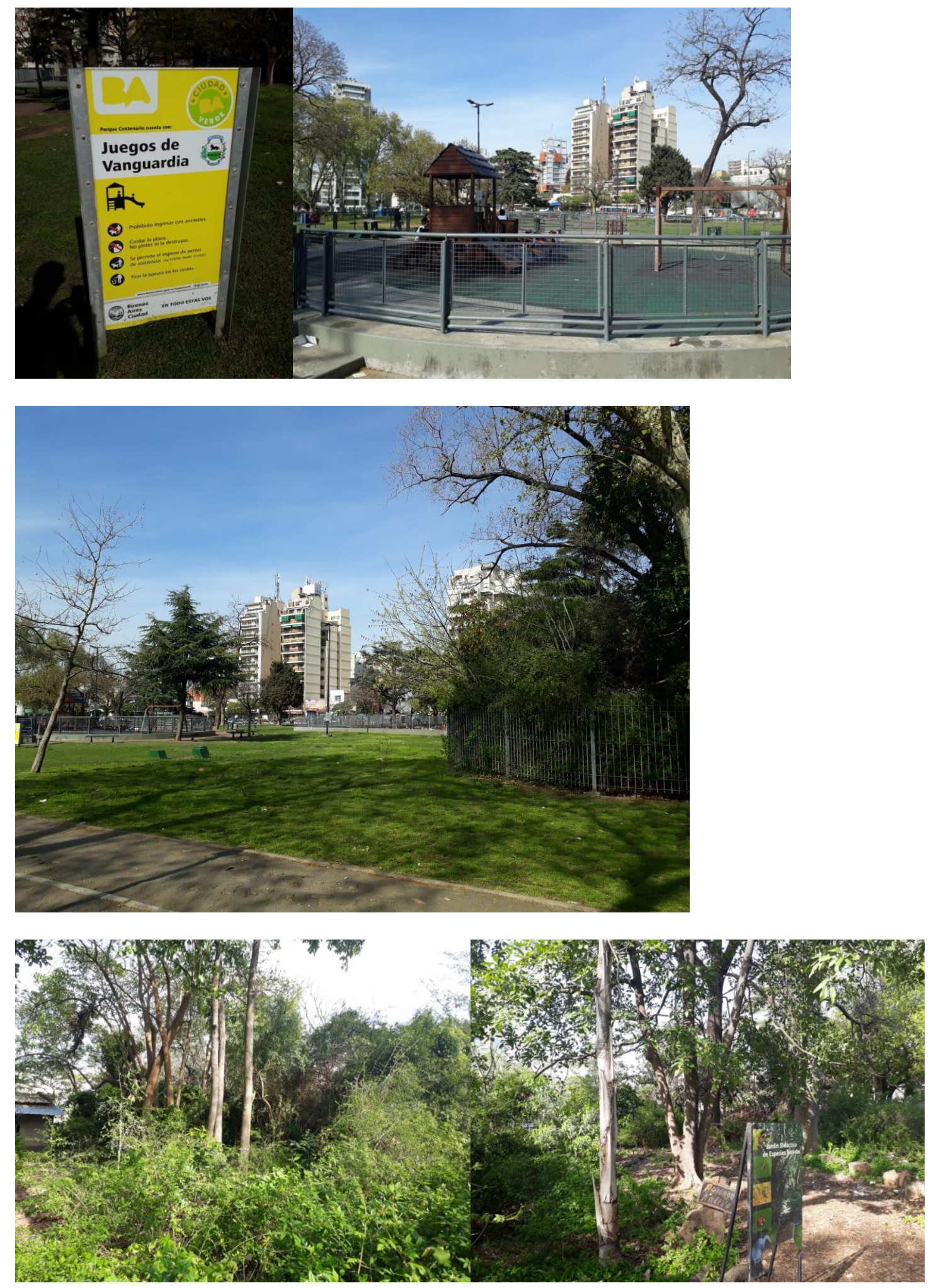

Figura 64: Imágenes superiores: Juegos de vanguardia de acceso irrestricto y ausencia de vegetación. Imágen medio: izquierda juegos de vanguardia, derecha Jardín didáctico. Imágenes inferiores: Jardín Didáctico de Especies Nativas, de acceso facultativo y con complejidad de estratos. Parque Centenario, Ciudad Autónoma de Buenos Aires. Año 2018. 
Es este contrapunto el que queremos poner en debate: ¿tenemos que resignarnos a vivir la experiencia del lado superior? ¿o es posible pensarnos desde ambientes que habiliten múltiples experiencias para un ser humano complejo con acceso libre para toda la sociedad?

Cuanto mayores son las posibilidades que ponemos a disposición de Ixs niñxs, aumentan las posibilidades de elección y por lo tanto de creación propia. La recreación de infancias tiene que ver con esto, con la conformación de espacios para que el juego se desarrolle de otra forma, de manera más autónoma y también más diversa.

En este sentido, fueron los atributos terciarios los que permitieron pensar a la vegetación en función de la niñez de manera tal de poder conformar una Infraestructura Verde Recreativa para recrear infancias. Así, las especies que pueden ser trepadas funcionaron como elemento de diseño ya que posibilitó no sólo la vivencia del desafío físico del evento, sino que también permitió generar un espacio íntimo entre niñxs donde pueden ocurrir infinidad de cosas que ellxs deseen: secretear, dialogar, discutir, gritar, llorar, bromear y reir, o simplemente estar de otra manera. Nos interesó pensar la generación de estas situaciones ya que la diversidad de experiencias la ligamos a la posibilidad de ganar mayores grados de autonomía. En esta estrategia la vegetación fue un aliado central. Las especies para refugio, las laberínticas, la poda de flores, la cosecha de frutos, el juego con semillas volubles, el colchón de hojas, las especies que forman bosque y las diferentes texturas tuvieron un análisis de la experiencia en relación a la generación de ámbitos o situaciones donde la autonomía tenga lugar en vínculo estrecho con la presencia de adultos que no dimitan de su posición de responsabilidad y autoridad.

Es en este punto donde creemos que se debe generar un camino de complejidad estructural de las masas vegetales con un claro sentido político: una Infraestructura Verde Recreativa que brinde mayor diversidad de experiencias. Infancias en camino a la emancipación son capaces de crear y transformar, para ello la vegetación puede ser un aliado. En este sentido, el respeto por la vida como ética de la convivencia es, tal vez, una de las claves para la recreación de infancias. 


\subsubsection{Paisajes para la recreación}

La pregunta que nos hacemos entonces es: ¿Qué son los paisajes para la recreación?. Y difícilmente podamos responderla porque los paisajes para recrear infancias no los conocemos aún, porque anhelamos que sean Ixs niñxs Ixs que nos muestren el camino.

Sin embargo, esto no nos deslinda de la responsabilidad de pensar cómo habilitar ámbitos donde se puedan poner en juego deseos, preferencias, gustos, sentimientos, relaciones, un otrx, de manera tal de que se pueda construir un paisaje compartido, anhelado.

Algunas de las claves que se ponen en juego en la tesis tienen que ver con cuatro puntos: la necesidad de tener en cuenta el tiempo desde una mirada sincrónica y diacrónica, alejarnos de ámbitos normados y controladores para construir espacios de libertad y de cuidado, abrir a la imaginación a partir del juego libre y autónomo con la naturaleza, y finalmente pensar los lugares desde la diversidad de experiencias como llave para pensar desde las infancias.

Creemos que es posible planificar la vegetación en los ámbitos de juegos para niñxs como una Infraestructura Verde Recreativa, que dé cuenta de una complejidad de estratos vegetales capaces de albergar infancias para la recreación. Si entendemos que es un derecho poder pensar un paisaje compartido, aquí, es donde podemos brindar un aporte hacia la emancipación.

Los paisajes recreados posiblemente no los conoceremos nunca, porque son esxs niñxs los que cambian, Ixs que se reconstituyen, y con ellxs los nuevos paisajes. Porque es esa mirada cultural de Ixs niñxs la que nos tiene que marcar el camino. Esta tesis quiere empezar a jugar con ellxs, porque no somos nosotros los que tenemos que hablar sino que llegó el momento de escuchar. Allí estaremos, acompañando esa mirada pensante, cultural y compleja que instituye paisajes para volver a crearse. 


\subsection{BIBLIOGRAFÍA}

ÁBALOS, I. (2010) Naturaleza y Artificio El ideal pintoresco en la arquitectura y el paisajismo contemporáneos.(1ra edición). Barcelona: Gustavo Gili.

ANDRÉ, E. (1879) L'art des jardins. Traité Général de la composition des parcs et jardins. (1 ra edición) París: G. MASSON.

ARENDT, H. (2003). La condición humana. (1ra edición). Buenos Aires: Paidós.

AUGÉ, M. (1995). Los "no-lugares" Espacios del anonimato. Una antropología de la Sobremodernidad. (5ta edición) Barcelona: Gedisa. 2000

BAUMAN, Z. y LYON, D. (2013) Vigilancia líquida. (1ra edición). Buenos Aires: Paidós.

BELLI, E. (2010). Paisajismo, Imagen y Expresión. Teoría, diseño e ingeniería. (1ra edición). Ciudad Autónoma de Buenos Aires: del autor.

BENASSI, A. H. (1994) Guía de estudio: Tipología Vegetal. (1ra edición). La Plata: Planeamiento y Diseño del Paisaje. Facultad de Ciencias Agrarias y Forestales - Universidad Nacional de La Plata.

BENASSI, A. H. (2007, Septiembre) Valoración numérica de componentes paisajísticos en espacios verdes urbanos consolidados. Conferencia presentada en el $V$ Congreso Iberoamericano de Parques y Jardines Públicos (PARJAP), San Miguel de Tucumán, Argentina.

BENASSI, A. H. (2013) Ciudad Botánica. Fundamentos ecológicos en el diseño paisajista. Tesis doctoral. La Plata: Facultad de Ciencias Agrarias y Forestales-Universidad Nacional de La Plata.

BENASSI, A. H. (2015) Ciudad Botánica. Oasis del desierto urbano. (1ra edición). Buenos Aires: Honorable Cámara de Diputados de la Nación.

BORJA, J. y MUXÍ, Z. (2000) El espacio público: ciudad y ciudadanía. (1ra edición) Barcelona, España: Electa.

BROOKER, CH. (Productor creador) (2017). Black Mirror (Serie de Televisión). Gran Bretaña: Zeppotron.

BROTTO, C. (2012). Nuevos Parques Infantiles. Planificación y Diseños Actuales. (1ra edición). Barcelona: LINKSBOOKS.

BUSTELO, E. (2007). El recreo de la infancia: argumentos para otro comienzo.(1ra edición) Buenos Aires: Siglo Veintiuno Editores.

BUSTELO, E. (2012a , abril). El regreso de la infancia. Conferencia presentada en las I Jornadas Patagónicas de Primera Infancia. San Carlos de Bariloche. Disponible: 
http://primerainfanciapatagonia.blogspot.com.ar/p/afiche.html

BUSTELO, E. (2012 , octubre) Teoría de la Infancia: Una propuesta para un enfoque Latinoamericano. Conferencia presentada en el V Congreso Mundial por los Derechos de la Infancia y la Adolescencia. San Juan. Disponible en:

https://www.youtube.com/watch?v=|E2UYBZUDsU

CALMELS, D. (2013). Fugas. El fin del cuerpo en los comienzos del milenio. (1ra edición). Buenos Aires: Biblos.

CARLI, S. (Ed) (2009). La cuestión de la infancia: entre la escuela, la calle y el shopping. (1ra edición). Buenos Aires: Paidós.

CARLI, S. (2011). La memoria de la infancia. Estudios sobre historia, cultura y sociedad. (1ra edición) Buenos Aires: Paidós.

CARRIÓN, F. (2007) Espacio Público: punto de partida para la alteridad. En Olga Segovia (Ed.). Espacios públicos y construcción social. Hacía un ejercicio de ciudadanía (pp.79-97). Santiago de Chile: Ediciones SUR.

COREA, C. y LEWKOWICZ, I. (1999). ¿Se acabó la infancia?. Ensayo sobre la destitución de la niñez. (1ra edición). Buenos Aires: Lumen.

CORNER, J. (2014). The Landscape Imagination. Collected Essays of James Corner 1990-2010. (1 ra edición). Nueva York: Princeton Architectural Press.

DE SOUSA SANTOS, B. (2010). Refundación del Estado en América Latina. Perspectivas desde una epistemología del Sur. Lima: Instituto Internacional de Derecho y Sociedad y Programa Democracia y Transformación Global.

DEL TREDICI, P. (2014) The Flora of the Future. En: REED, C; LISTER, N. M. (2014). Projective Ecologies. (Pp: 238-257). Nueva York: Actar Publishers.

DIXON HUNT, J. D. (2000). Greater perfections: The practice of Garden Theory. (1ra edición) Philadelphia, Pennsylvania: University of Pennsylvania Press.

DOMíNGUEZ, C. (2013) Valoración del patrimonio cultural: plazas platenses. Tesis doctoral. La Plata: Facultad de Arquitectura y Urbanismo - Universidad Nacional de La Plata.

DONADIEU, P. (2006) La sociedad paisajista. (1ra edición). La Plata, Argentina: EDULP.

DOWHAL, A. (2016). Arboricultura Urbana: gestión y manejo del arbolado público. (1ra edición) Ituzaingó, Buenos Aires: Maipue.

FAUR, E. (2017). ¿Cuidar o educar? Hacia una pedagogía del cuidado. En P. Redondo y E. Antelo (Ed). (2017), Encrucijadas entre cuidar y educar: debates y experiencias. (pp 87-117). Buenos Aires: Homo Sapiens Ediciones. 
FOUCAULT, M. (1975). Vigilar y castigar. Nacimiento de la prisión. Buenos Aires: Siglo Veintiuno Editores. 2002.

GARCÍA CANCLINI, N. (1993) El consumo cultural y su estudio en México: una propuesta teórica. En: García Canclini, Néstor (Ed.): El consumo cultural en México. (pp. 15-42) .México: Consejo Nacional para la Cultura y las Artes.

GOLDSTEIN, M. B. (2017). Políticas públicas y niñez. Tensiones entre el derecho y la construcción de la ciudadanía infantil, Análisis comparativo de los Consejos de Niños/as de los municipios de Morón y de la Ciudad Autónoma de Buenos Aires. Tesis Maestría. Buenos Aires: Facultad de Ciencias Sociales. Universidad Nacional de Buenos Aires.

HOLLING, C. S. y GOLDBERG, M. A. (1971). Ecology and Planning. En REED, C; LISTER, N. M. (2014). Projective Ecologies. (Pp: 106-125) Nueva York: Actar Publishers.

JELIN, E. (2001) Los trabajos de la memoria. Memorias de la represión. Madrid: Siglo XXI de España editores S.A.

KOHAN, W. (2014). Um exercício que faz escola: notas para pensar a investigação educacional a partir de uma experiência de formação no Rio de Janeiro. En F. Fernandes Ribeiro, M. J. Vargas Netto y W. O. Kohan (Ed), Encontrar escola: o ato educativo e a experiência da pesquisa em educação (pp. 14-21). Río de Janeiro: Lamparina-FAPERJ.

KOHAN, W.; KENNEDY, D. (2015). La escuela y el futuro de la Scholé: un diálogo preiliminar. Revista Espacios en Blanco - Serie indagaciones (25), 213-226.

KONGJIAN, Y. (2017, abril). Deep Forms: Nature Based Solutions. Conferencia presentada en el congreso: Green Infraestructure. Natural based solutions for sustainable and resilient cities. COST FP1204 GreenInUrbs. Orvieto, Italia.

LARROSA, J. y PÉREZ DE LARA, N. (ed) (1997). Imágenes del otro. Barcelona: Virus.

LINNEO, C. (1762-63). Species plantarum.

LIVINGSTON, J. (Productora, Directora) (1991). Paris is Burning (cinta audiovisual). Estados Unidos, Miramax films.

MORENO, J. (2003). Ser humano. La inconsistencia, los vínculos, la crianza. (1ra edición). Buenos Aires: Libros del Zorzal.

MORENO, J. (2014). La infancia y sus bordes. (1ra edición). Buenos Aires: Paidós.

NARODOWSKI, M. (1994). Infancia y poder: la conformación de la pedagogía moderna. Buenos Aires: AIQUE.

OPEL, R. (2016). Profesor Adjunto Cátedra de Planeamiento y Diseño del Paisaje. Facultad de Ciencias Agrarias y Forestales. Universidad Nacional de La Plata (UNLP). Arquitecto. Especialista en Planeamiento Paisajista y Ambiente-UNLP. 
RANCIÈRE, J. (2003). El maestro ignorante: cinco lecciones sobre la emancipación intelectual. (1ra edición). Buenos Aires: del Zorzal.

RAUSKY, M. E.; SANTOS,J.A; PEIRÓ, M.L.; CREGO, M.L. (2016). Trabajo infantil, adolescente y juvenil: Dimensión, características y perfiles de los trabajadores callejeros en la ciudad de La Plata, Buenos Aires, Argentina. Papeles de población, 22 (89), 9-41.

REDONDO, P. (2016) La escuela con los pies en el aire: Hacer escuela, entre la desigualdad y la emancipación. Tesis doctoral. La Plata: Facultad de Humanidades y Ciencias de la Educación, Universidad Nacional de La Plata..

REED, C y LISTER N. (2014). Projective Ecologies. (1 ra edición). Nueva York: Actar publishers.

SANTILLÁN, L. (2017). ¿Quiénes educan a los chicos? Una mirada desde la antropología sobre el cuidado, la enseñanza y la educación. En P. Redondo y E. Antelo (Ed). (2017), Encrucijadas entre cuidar y educar: debates y experiencias. (pp 17-37). Buenos Aires, Argentina: Homo Sapiens Ediciones.

RIVERA, J. (Productor) y DOCTER, P.; DEL CARMEN R. (Directores) (2015). Inside Out (Cinta cinematográfica). Estados Unidos de Norteamérica: Pixar Animations Studios y Walt Disney Pictures.

TONUCCI, F. (1996). La ciudad de los niños: un modo nuevo de pensar la ciudad. (1ra edición) Buenos Aires: Losada.

ZAFFARONI, E. R. (2013) La Pachamama y el Humano. (1ra edición). Buenos Aires: Ediciones Madres de Plaza de Mayo-Ediciones Colihue.

VERMEREN, P., CORNU, L. y BENVENUTO A. (2003). La actualidad de El maestro ignorante. Entrevista a Jacques Rancière. Cuadernos de pedagogía, 11, 43-57.

\section{LEGISLACIÓN}

\section{Convención sobre los Derechos del niño. Año 1989.}

Ley 26.061. Ley de protección integral de los derechos de niños, niñas y adolescentes. Boletín oficial de la República Argentina, 21 de Octubre de 2005.

Decreto/Ley 8912/77. Ley de Ordenamiento Territorial y Uso del suelo. Boletín oficial de la Provincia de Buenos Aires, Argentina. Año 1977.

Ordenanza 10.703. Código de Ordenamiento Territorial y Uso del suelo en el Partido de La Plata (COU). Partido de La Plata. Año 2010. Buenos Aires. Argentina.

Manual de Seguridad en Patios de Juegos. Año 2001. Ciudad Autónoma de Buenos Aires. Argentina. Normativa del Instituto Argentino de Racionalización de Materiales (IRAM) N:3655 Juegos Infantiles de Instalación Permanente al Aire Libre. Licencia a Roussy, Luciano Marcos. Universidad Nacional de La Plata. Licencia Orden JOR2RNPNL2UPOGXNTQVF del 13/02/2017. Argentina. 
Normativa Europea del Comité Europeo de Normalización:

UNE 1176:2008 Equipamiento de las Áreas de Juegos y Superficies

UNE 1177:2008 Revestimientos de las superficies de las áreas de juego absorbedores de impactos.

Determinación de altura caída crítica

UNE 147103:2001: Planificación y gestión de las áreas y parques de juego al aire libre. 


\section{EPÍLOGO: Barro tal vez (Luis Alberto Spinetta, 1965) \\ El barro como composición metafórica compleja de nuestro ser.}

Esta tesis supone un sustento para la vida vegetal que no fue explorado como tal en el espacio público: la tierra, el suelo, el barro. La base de toda estructura vegetal es el suelo, la tierra. Múltiples culturas han ofrecido tributo a ella como productora de alimentos, de vida.

En nuestra Latinoamérica es la Pachamama, la madre tierra, a la que le brindamos culto todos los años para tener buenas cosechas. Es allí donde enterramos nuestros muertos y de donde sacamos nuestros alimentos, allí pedimos nuestros deseos pero también ofrendamos nuestras riquezas. Esta tradición ancestral, se plasmó en el siglo XXI en el los derechos de cuarta generación de las constituciones de Ecuador y Bolivia, donde son el ambiente, la naturaleza y la tierra sujetos de derecho por los que vela el Estado moderno.

La tradición ancestral de nuestros pueblos originarios se fusionó a la fuerza con las tradiciones europeas, en una nueva identidad que llamamos latina, latinoamericana. Esta identidad rescata los conocimientos y la relación del humano con la naturaleza de nuestras culturas ancestrales para poder pensarnos en la actualidad.

Trabajar con las infancias la tierra, el suelo, la madre tierra, la Pachamamama es una tarea que nos constituye y abre nuevas ideas sobre cómo relacionarnos con la naturaleza, con el ambiente. En este sentido, el arte nos puede dar una mano. Recientemente, en una instalación artística se compusieron esculturas en base a la tierra (ver Figura 64) donde se invertía el pan de tierra de un rectángulo y se recomponía en superficie disponible a la altura de Ixs niñxs. Se podía acceder al hueco para percibir la tierra, el olor a humedad de la misma. $Y$ finalmente, se utilizaba como material (barro) para esculpir formas.

Son los caminos que toman a la tierra en sus manos para jugar los que forjan un nuevo destino compartido latinoamericano.

Sueños densos, de cuevas y recorridos subterráneos.

Encuentros extraños, auténticos.

Somos sólo yo energías limpias.

Ahora, La fragilidad de lo espontáneo

Y la continuidad del deseo.

Que este polvo, tierra volátil, Recorra el espacio distante, Se humedezca y llegue hasta vos. 

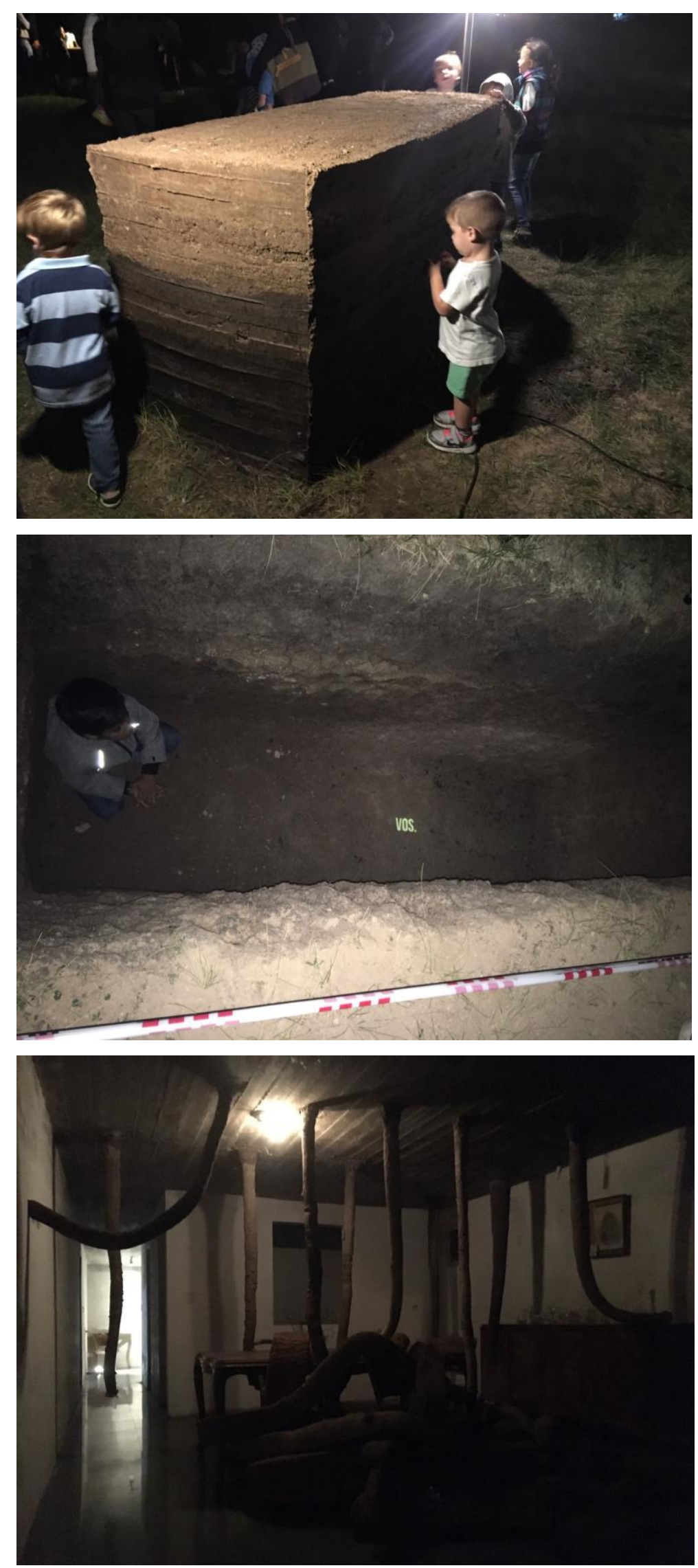

Figura 65: Muestra: "Dar vuelta una montaña". Artistas: Juan Pablo Rosset, Facundo Cardoso, Fran Carranza. Los Campitos, La Plata. Año 2018. 